\title{
Algoritmos para Predição \\ da \\ Estrutura Secundária \\ do \\ RNA
}

Luiz Carlos da Silva Rozante

\author{
DISSERTAÇÃO APRESENTADA \\ AO \\ INSTITUTO DE MATEMÁTICA E ESTATÍSTICA \\ DA \\ UNIVERSIDADE DE SÃO PAULO \\ PARA \\ OBTENÇÃO DO GRAU DE MESTRE \\ EM \\ CIÊNCIA DA COMPUTAÇÃO
}

Área de Concentração: Ciência da Computação

Orientador: Prof. Dr. José Augusto Ramos Soares

- Durante o desenvolvimento deste trabalho, o autor recebeu apoio financeiro do CNPq -

- São Paulo, dezembro de 2001 - 


\title{
Algoritmos para Predição \\ da \\ Estrutura Secundária \\ do \\ RNA
}

\author{
Este exemplar corresponde à redação \\ final da dissertação devidamente corrigida \\ e defendida por Luiz Carlos da Silva Rozante \\ e aprovada pela comissão julgadora.
}

São Paulo, 23 de janeiro de 2002.

Banca examinadora:

- Prof. Dr. José Augusto Ramos Soares (orientador) (IME-USP)

- Prof. Dr. José Coelho de Pina (IME-USP)

- Prof. Dr. João Meidanis (IC-UNICAMP) 
Dedico este trabalho à minha mãe e ao meu pai (in memorian). 


\section{Agradecimentos}

Bem... como cheguei até aqui, acho que vou quebrar o protocolo e ser um pouco informal e abusar das reticências. Para começar, gostaria de mencionar três pessoas que, sem as quais, tenho absoluta certeza, esta dissertação não teria saído, mesmo.

Em primeiro lugar é imprescindivel comentar e agradecer a participação do Zé Augusto nesta história. Penso que cumpriu com perfeição seu papel: sempre disponivel e aberto; foi firme e pontual, quando necessário. Muitas vezes foi necessário... Foi também flexível e compreensivo quando precisei, e olha... eu precisei...

As outras duas pessoas diretamente responsáveis pelo logro deste texto são, os grandes amigos de longa data e boas lutas, o Marco e a Eliany. Sem a insistência deles em vir para São Paulo e a acolhida, com certeza meu destino seria outro. Talvez hoje estivesse criando peixes e abelhas... ou... frustado e impotente num governo sem identidade...

Por aqui fiz novos e importantes amigos. Dentre estes, não posso deixar de expressar minha gratidão pela força que o Claus sempre me deu, em especial assim que cheguei em São Paulo. Sem sua ajuda teria sido muito mais difícil.

Outro novo e importante amigo é o pequeno grande Said. Esse é um sujeito batuta. Sempre atencioso e prestativo, me ajudou muito nas disciplinas que fizemos juntos, nas correções e em tantas outras tarefas que nem consigo enumerar.

Ao pessoal do "Cruspão" pelos momentos de bom convívio e amizade. Em especial ao Hebert e ao Leandro pela acolhida e camaradagem.

Ao Fábio, outro grande e velho amigo, que desde a qualificação forneceu grande ajuda nas correções, nas dicas de exposição, de apresentação e outras tantas que nem me lembro.

À Débora. A esta confesso que não sei como agradecer. Busquei diligentemente palavras que pudessem expressar minha gratidão. Foi em vão. O que dizer? Optei por lembrar que todo homem tem dentro de si um sertão... No meu sertão ela é o entardecer nas veredas...

Aos componentes da banca do exame de qualificação, pelas dicas e sugestões. Em especial ao Prof. Sergio Matioli (do Instituto de Biociências) e à Prof. Nami Kobayashi (do Instituto de Matemática e Estatística) pela ajuda.

A outros tantos que de alguma maneira contribuíram, como o Emmanuel, o Elói, o Jair, o Ricardinho, o Marquinho, o Alexandre, o Uirá e o Dino.

Ao CNPq pelo apoio financeiro proporcionado durante o desenvolvimento desta dissertação e à COSEAS, pelo apoio "logístico" importantíssimo. Gostaria de agradecer também o pessoal da secretaria da CPG, em especial o Pinho, pela atenção e competência. 


\begin{abstract}
Similarly to the proteins, the RNA molecules assume a three-dimensional conformation (structure) that has an important role in determining their function. These molecules can influence the processes of transcription, translation and replication. Further, they can develop catalytic activities or be a structural or a regulator element.

The experimental methods for deducing RNA structures are costly. The RNA secondary structure gives information about the function of the molecule and serves as an important step in determining its tertiary structure. So, it is important develop fast and accurate computer methods on prediction of secondary structure from primary structure.

The two most significant strategies for solving the problem are based on thermodynamic stability criteria (of minimum free-energy) and in the search of the common foldings among homologous molecules. In the first case, the most important algorithms are based on techniques of dynamic programming. In the second, the most important algorithms known are based on models of covariance and perform on a set of aligned sequences.

Being situated on genomics and biocomputing areas, this work presents the models proposed for the problem and describes formally the several existing techniques and methods involved in the solution of this problem. We also developed efficient implementations of the most expressive algorithms based on free energy minimization. We selected these algorithms based on two criteria: computational complexity (of time and space) and representativeness of the thermodynamic model.
\end{abstract}

\title{
Resumo
}

De forma similar à que ocorre com as proteínas, as moléculas de RNA assumem uma conformação espacial (estrutura) que desempenha um importante papel na definição de sua função. Além de influenciar os processos de transcrição, tradução e replicação, as moléculas de RNA podem desenvolver atividades catalíticas. Podem ainda desempenhar papel regulador ou estrutural.

Os métodos laboratoriais para determinação da estrutura do RNA são onerosos. A estrutura secundária do RNA, além de fornecer informações acerca da função da molécula, serve também como importante etapa na definição de sua estrutura terciária. Daí a importância em se desenvolver métodos computacionais, rápidos e precisos, de predição da estrutura secundária a partir da estrutura primária.

As duas mais importantes estratégias de resolução do problema estão baseadas em critérios de estabilidade termodinâmica (de energia livre mínima) e na identificação dos dobramentos comuns entre moléculas homólogas. No primeiro caso, os algoritmos mais importantes são baseados em técnicas de programação dinâmica. No segundo, os mais importantes algoritmos conhecidos são baseados em modelos de covariância e operam sobre um conjunto de seqüências homólogas alinhadas.

Situado no contexto da genômica estrutural e da bioinformática, o trabalho apresenta os modelos propostos para o problema, além de descrever formalmente as várias técnicas e métodos envolvidos na sua resolução. Desenvolvemos também implementações eficientes dos algoritmos mais expressivos baseados em cálculo de energia livre mínima, tanto do ponto de vista da complexidade computacional (de tempo e espaço), como da representatividade do modelo termodinâmico. 


\section{Sumário}

Agradecimentos . . . . . . . . . . . . . . . . . . i

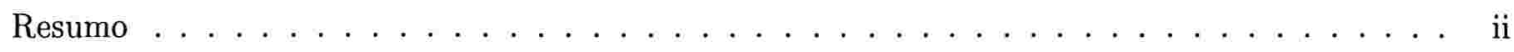

1 Introdução 1

1.1 o Contexto do Trabalho . . . . . . . . . . . . . . . . 1

1.2 Uma Visão dos Métodos para o Problema . . . . . . . . . . . . . . . . . . . 3

1.3 Organização da Dissertação $\ldots \ldots \ldots \ldots \ldots \ldots \ldots \ldots \ldots$

1.3.1 Implementação . . . . . . . . . . . . . . . . . . 5

2 Predição de Estruturas Secundárias do RNA $\quad 7$

2.1 Aspectos Biológicos . . . . . . . . . . . . . . . . 7

2.2 Representação e Conceituação Matemática . . . . . . . . . . . . . . . 11

3 Usando Cálculo de Energia Livre Mínima $\quad 21$

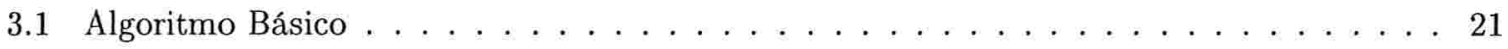

3.2 Incorporação de Laços . . . . . . . . . . . . . . . . . . . . . 25

3.2 .1 Fase traceback . . . . . . . . . . . . . . . . . . 30

3.2 .2 Parâmetros de Energia $\ldots \ldots \ldots \ldots \ldots$

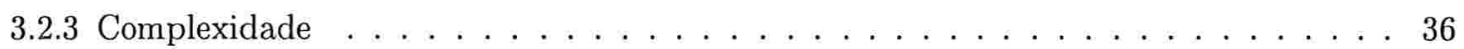

3.3 Melhoria da Eficiência em Laços Internos $\ldots \ldots \ldots \ldots$

3.3 .1 Algoritmo de Waterman e Smith . . . . . . . . . . . . . . . . 38

3.3 .2 Algoritmo de Lyngsø e Zuker . . . . . . . . . . . . . . . . . . . . . . 41

3.4 Geração de Soluções Sub-ótimas . . . . . . . . . . . . . . . . . 46

3.4 .1 Algoritmo de Zuker . . . . . . . . . . . . . . . . . . . 46

3.4 .2 Algoritmo de Wuchty . . . . . . . . . . . . . . . . . . . . 49 
4 Melhoria da Eficiência para Classes Especiais de Funções

4.1 Melhoria da Eficiência para Funções Lineares . . . . . . . . . . . . . . . . . . . . 53

4.2 Melhoria da Eficiência para Funções Côncavas e Convexas . . . . . . . . . . . . . 55

4.2 .1 Algoritmo de Eppstein . . . . . . . . . . . . . . . . . . . 55

4.2 .2 Algoritmo de Larmore e Schieber . . . . . . . . . . . . . . . . . . . 61

5 Usando Análise Comparativa entre Homólogos 65

5.1 Análise de Covariância . . . . . . . . . . . . . . . . . . 67

5.2 Método de Han e Kim $\ldots \ldots \ldots \ldots \ldots \ldots \ldots \ldots$

5.3 Método de Lück . . . . . . . . . . . . . . . . . . . . . . . . 74

5.3.1 Função Partição e Probabilidade de Pares . . . . . . . . . . . . . . . . . . 75

5.4 Métodos Híbridos . . . . . . . . . . . . . . . . . . . . . . . . . . . 79

5.4 .1 Método de Juan e Wilson . . . . . . . . . . . . . . . . . . . . . 79

6 Conclusão $\quad 83$

$\begin{array}{lr}\text { A Implementação } & 87\end{array}$

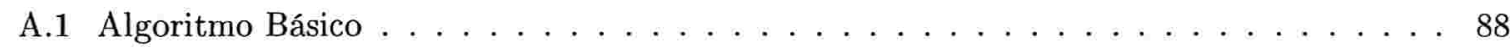

A.2 Incorporação de Laços $\ldots \ldots \ldots \ldots$. . . . . . . . . . . . . . . . 88

A.2.1 Cálculo do Laço de Menor Energia . . . . . . . . . . . . . . . . . . . 89

A.2.2 Cálculo da Energia de um Laço Arco . . . . . . . . . . . . . . . . . . . 91

A.2.3 Cálculo da Energia de um Empilhamento de Pares de Bases Adjacentes . . . . . . . 93

A.2.4 Cálculo da Energia de um Laço Barriga em $i \ldots \ldots$. . . . . . . . . . . . . . 93

A.2.5 Cálculo da Energia de um Laço Barriga em $j \ldots \ldots \ldots \ldots \ldots \ldots$. . . . . . . 94

A.2.6 Cálculo da Energia de um Laço Interno . . . . . . . . . . . . . . . . . . 95

A.2.7 Cálculo da Energia de um Multilaço . . . . . . . . . . . . . . . . . 98

A.2.8 Algoritmo traceback em $E \ldots \ldots \ldots \ldots$

A.2.9 Algoritmo traceback em $L \ldots \ldots \ldots \ldots$. . . . . . . . . . . 99

A.2.10 Algoritmo traceback em $G \ldots \ldots \ldots \ldots$. . . . . . . . . . . 99

A.3 Otimização de Waterman e Smith para Laços Internos $\left(O\left(n^{3}\right)\right) \ldots \ldots \ldots \ldots \ldots \ldots$

A.4 Otimização de Lyngsø e Zuker para Laços Internos $\left(O\left(n^{3}\right)\right) \ldots \ldots \ldots \ldots \ldots$

A.5 Funções Comuns . . . . . . . . . . . . . . . . . . . . . . . . . 101 
A.6 Funções de Inicialização e Leitura . . . . . . . . . . . . . . . . . . . . . . . . . . . . 104

A.7 Funções Auxiliares . . . . . . . . . . . . . . . . . . . . . . . . . . . . 124

A.8 Definições, Declarações e Arquivos de Inclusão ～. . . . . . . . . . . . . . . . 128

A.9 Programa Principal . . . . . . . . . . . . . . . . . . . . . . . . 132

$\begin{array}{lr}\text { B Tabelas } & 137\end{array}$

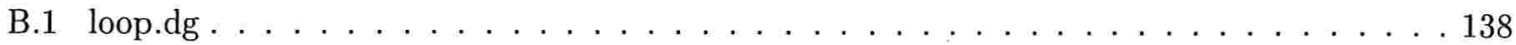

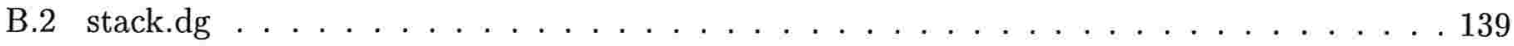

B.3 tstackh.dg . . . . . . . . . . . . . . . . . . . . . . . . . 140

B.4 tstacki.dg . . . . . . . . . . . . . . . . . . . . . . . 141

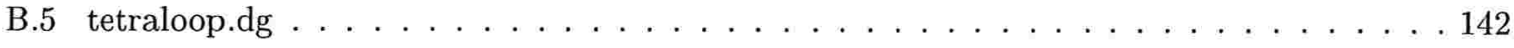

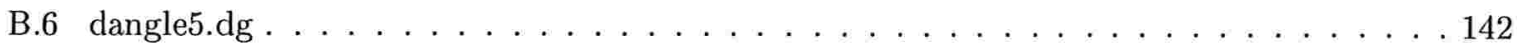

B.7 dangle3.dg . . . . . . . . . . . . . . . . . . . . . . 142

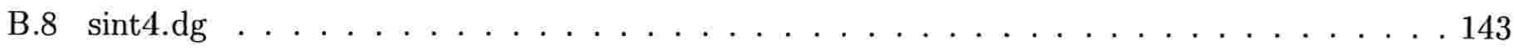

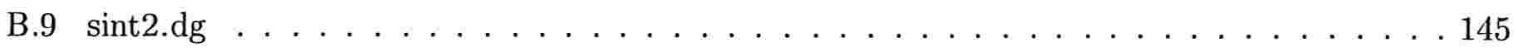

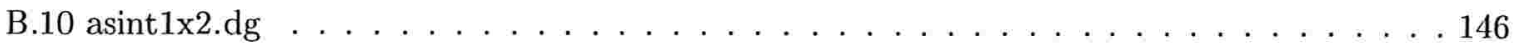

B.11 miscloop.dg . . . . . . . . . . . . . . . . . . . . . . . . 147

$\begin{array}{lr}\text { Referências Bibliográficas } & 147\end{array}$

Îndice Remissivo de Definições e Conceitos $\quad 153$

Îndice Remissivo para o Código 156 


\section{Lista de Figuras}

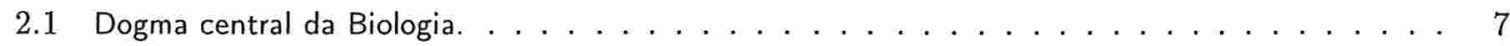

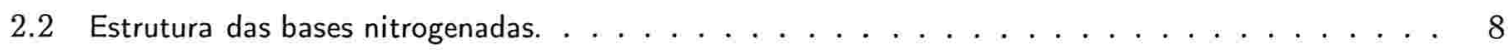

2.3 Exemplo de Estrutura Secundária do RNA na sua representação Normal . . . . . . . . . . . 11

2.4 Representação de Nussinov de uma estrutura secundária . . . . . . . . . . . . . . . . 12

2.5 Representação dotplot de estruturas secundárias . . . . . . . . . . . . . . . . . . . 13

2.6 Representações Vienna e Normal de uma estrutura secundária simples. . . . . . . . . . . . 13

2.7 Representações Nussinov e Normal de um pseudo-nó $\ldots \ldots \ldots \ldots \ldots \ldots$

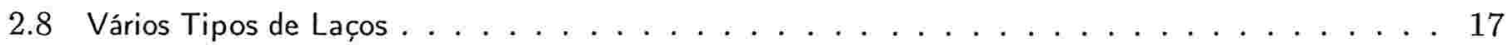

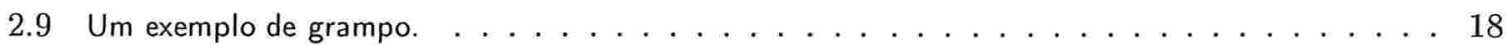

3.1 Ordem de preenchimento das entradas da matriz de programação dinâmica $E \ldots \ldots \ldots$. . . . . 24

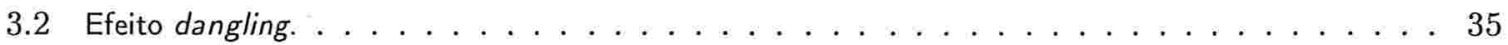

3.3 Entradas consideradas no cálculo da energia associada aos laços. . . . . . . . . . . . . 39

3.4 Algoritmo para cálculo de laço interno conforme Waterman e Smith $\left(O\left(n^{3}\right)\right) \ldots \ldots \ldots$. . . . 39

3.5 Algoritmo para cálculo de laços internos conforme Lyngsø e Zuker $\left(O\left(n^{3}\right)\right) \ldots \ldots \ldots \ldots$

3.6 Preenchimento das entradas da matriz $L I$ no algoritmo de Lyngsø e Zuker . . . . . . . . . 45

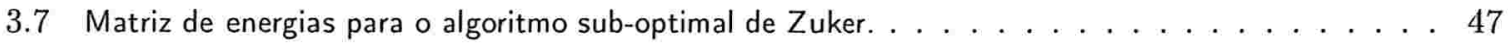

4.1 Algoritmo para computação de domínios em uma diagonal. . . . . . . . . . . 57

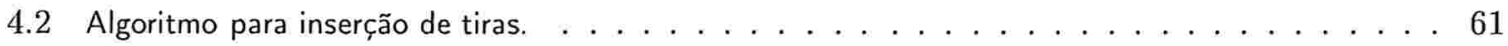

5.1 A matriz de covariância $M C$ para um conjunto de 3 seqüências homólogas $\ldots \ldots \ldots \ldots \ldots 71$

5.2 Notação para uma diagonal na matriz $M C \ldots \ldots \ldots \ldots \ldots \ldots \ldots$

5.3 Passo (2) da heurística de $\operatorname{Han}$ e Kim. . . . . . . . . . . . . . . . . . . . 72

5.4 Matriz de probabilidade de homólogos no Método de Lück . . . . . . . . . . . . . . . . . 74 


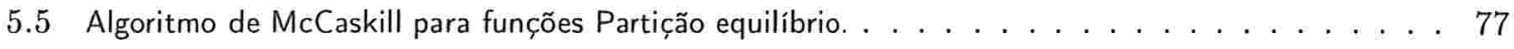




\section{Capítulo 1}

\section{Introdução}

\subsection{O Contexto do Trabalho}

A Biologia Computacional é uma área de pesquisa relativamente nova e que presenciou um extraordinário avanço recentemente, inclusive no Brasil. Este avanço é corroborado por anúncios de grandes conquistas realizadas neste campo dentro e fora do Brasil. O seqüenciamento do genoma humano e da bactéria Xylella fastidiosa no Brasil (através do Projeto Genoma financiado pela FAPESP) talvez correspondam aos fatos mais representativos deste "boom".

Estes fatos foram amplamente veiculados na grande mídia nacional e internacional, contribuindo para popularização deste novo ramo da ciência. Na esteira deste processo, vimos no Brasil o anúncio de outros grandes projetos relacionados, como o Genoma Câncer (FAPESP/Instituto Ludwig), o Projeto Genoma Estrutural (FAPESP/CNPq-LNLS), o RioGene (FAPERJ/CNPq), a Rede Nacional de Seqüenciamento do Genoma da Chromobacterium Violaceum(CNPq) e o CAGE (Cooperation for Analysis of Gene Expression/FAPESP/USP), entre outros.

A Biologia Computacional é uma área de pesquisa que se preocupa em resolver problemas da biologia modeláveis matemática e/ou computacionalmente. A Biologia Molecular é uma das subáreas da biologia mais férteis ao desenvolvimento da Biologia Computacional, haja vista o tipo de problema que ela aborda. Entre os inúmeros tipos problemas com os quais a Biologia Computacional interage podemos citar, por exemplo, o Seqüenciamento de Genomas, a Predição Gênica, a Predição de Estruturas Moleculares, a Reconstituição de Filogenias, etc.

$\mathrm{Na}$ classe de problemas que vem sendo chamada Predição de Estruturas Moleculares, o objetivo básico é a determinação da estrutura das moléculas (conformação espacial). Isto porque, em última instância, quem determina a função de uma molécula é sua estrutura.

Dentre as várias moléculas sobre as quais se tem interesse em conhecer a estrutura, sem dúvida a mais importante são as proteínas. Isto porque as proteínas são responsáveis por todos os processos metabólicos dos organismos vivos, e, como já dissemos, a função de cada uma delas está intimamente relacionada à sua estrutura. 
As proteínas são macromoléculas, formadas por moléculas menores, chamadas aminoácidos. Existem vinte aminoácidos diferentes, e a seqüência dos aminoácidos determina cada tipo de proteína. Essa seqüência é codificada a partir do DNA, passando pelo RNA, de tal modo que cada aminoácido é codificado por um grupo de três nucleotídeos, denominado códon. Isso faz com que o DNA seja visto como um molde para a síntese de proteína.

O problema do dobramento (folding) de proteínas figura entre os mais importantes da biologia molecular, e, por conseguinte, da biologia computacional. Há aproximadamente 30 anos, esforços vêm sendo empreendidos na sua resolução; porém, sem a obtenção de resultados definitivos. A IBM chegou a anunciar recentemente a construção de uma máquina especializada neste problema.

Outro fato que ilustra a importância deste problema, foi o anúncio e a instituição do Projeto Genoma Estrutural, formado por uma rede de 15 laboratórios com a participação do Laboratório Nacional de Luz Sincrotron (LNLS-CNPq), que está formando um Centro de Biologia Estrutural. Este projeto é financiado pela FAPESP e tem como objetivo básico desvendar a estrutura tridimensional de proteínas.

Da mesma forma como ocorre com as proteínas, as moléculas de RNA apresentam uma conformação espacial que desempenha um importante papel no seu funcionamento e, por conseguinte, em alguns processos bioquímicos que se desenvolvem no fenômeno da vida. Esta configuração tridimensional que a molécula de RNA assume tem relevante importância em uma ampla variedade de funções biológicas tais como transcrição, tradução e replicação [FH88, Pol88].

A molécula de RNA é considerada aqui como uma fita única que define uma seqüência composta por nucleotídeos - Adenina (A), Citosina (C), Guanina (G) e Uracil (U) - que se ligam entre si por complementaridade ( $\mathrm{G}$ é complementar a $\mathrm{C}$ e A é complementar a $\mathrm{U}$ ), provocando assim uma dobradura na molécula. A forma como se manifesta localmente esta dobradura define a chamada estrutura secundária da molécula, o que corresponde, grosso modo, à sua configuração bidimensional.

Os métodos laboratoriais atualmente utilizados para a determinação de estruturas (cristalografia e ressonância nuclear magnética) são muito dispendiosos, além do que, para alguns tipos de moléculas, produzem resultados não completamente satisfatórios. Portanto, torna-se essencial a formulação de métodos computacionais rápidos e precisos para predição de estruturas secundárias de moléculas de RNA. Um aspecto importante que deve ser considerado com relação a esta tarefa, é o fato de que a seqüência de nucleotídeos determina a maneira como a molécula se dobrará. Daí a razão pela qual se tenta predizer a estrutura secundária a partir da análise da sua seqüência.

Neste trabalho nos propomos a estudar um problema que se enquadra na classe de problemas que chamamos de Predição de Estruturas Moleculares e é denominado Predição de Estrutura Secundária do RNA.

Estabelecemos como objetivo básico do trabalho estudar e conhecer, em abrangência e profundidade, o referido problema. Por conta disto, descrevemos os aspectos biológicos e a conceituação matemática concernente. Além da caracterização detalhada do problema, nos propusemos também a descrever os diversos modelos e métodos utilizados na sua resolução. Por fim, nos propusemos ainda a desenvolver um código que possibilitasse o entendimento, preciso e detalhado, de alguns destes métodos 
e modelos.

\subsection{Uma Visão dos Métodos para o Problema}

Existe uma razoável variedade de métodos computacionais que foram desenvolvidos para resolver o problema de predição de estrutura secundária do RNA. Sem sombra de dúvida, as duas principais estratégias utilizadas para resolver o problema são ou baseadas no cálculo de energia livre mínima ou na análise comparativa entre moléculas homólogas. É possível agrupar alguns dos vários algoritmos e métodos que tentam resolver o problema sob a ótica de uma destas duas estratégias.

No primeiro caso, ou seja, sob a ótica da estratégia baseada no cálculo de energia livre mínima, os algoritmos são baseados em técnicas de programação dinâmica. Estes algoritmos têm como entrada uma seqüência - que representa a molécula - e fornecem como saída uma representação da estrutura mais estável, segundo um dado modelo termodinâmico, ou, em outras palavras, fornecem uma representação da estrutura de energia livre mínima. São atribuídas energias aos pares de bases e a elementos formadores estruturais denomidados laços. A Figura 2.8 ilustra vários destes laços. Ainda baseados nesta estratégia, existem algoritmos que fornecem soluções sub-ótimas para o problema; ou seja, fornecem como saída um conjunto de estruturas, cujas energias se aproximam da energia associada à estrutura mais estável termodinamicamente. Os algoritmos representam a estrutura secundária como um conjunto de pares de bases para os quais se prevê a formação de ligações por pontes de hidrogênio.

No segundo caso, isto é, sob a ótica da estratégia baseada na análise comparativa entre moléculas homólogas, os mais importantes algoritmos conhecidos são baseadas em modelos de covariância. Estes algoritmos geralmente têm como entrada um conjunto de seqüências homólogas — isto é, que possuem um ancestral comum - alinhadas e fornecem como saída a estrutura secundária comum a este conjunto de homólogos. A partir do alinhamento entre os homólogos, busca-se identificar relações de interdependência entre os seus pares de colunas e, deste modo, inferir a estrutura comum ao conjunto de homólogos. Para isto, geralmente se faz uso de técnicas de análise de covariância. Estes algoritmos exploram um princípio da biologia molecular que diz que, na história evolutiva, a estrutura tende a se manter mais conservada do que a seqüência correspondente.

Os biólogos apreciam uma característica presente neste tipo de método: a insensibilidade a pequenas variações na seqüência de nucleotídeos. Contrariamente ao que ocorre com os algoritmos baseados em cálculo de energia livre mínima, que podem inferir estruturas muito diferentes a partir de diferentes seqüências que variam em poucas bases entre si [ZJT91], aqui não se detecta estas variações - no sentido de que uma estrutura totalmente diferente não é encontrada. Isto, segundo os biólogos, está mais de acordo com o que se observa na realidade biológica.

Existem também métodos híbridos, que incorporam características das duas estratégias citadas acima. O propósito básico dos métodos híbridos é a utilização de propriedades de ambas as estratégias a fim de se obter resultados melhores.

Existem ainda aqueles algoritmos e métodos que não se enquadram perfeitamente em nenhuma das 
classes anteriores. Por exemplo, gramáticas estocásticas independente de contexto parecem representar um bom instrumento para modelagem e tratamento de problemas relacionados ao RNA, incluindo a predição de estrutura.

Os primeiros a tratarem do problema de dobramento de RNA com base em gramáticas estocásticas livre de contexto foram Eddy e Durbin [ED94] e Sakakibara et al [SBH ${ }^{+94]}$ em trabalhos independentes, mas praticamente simultâneos, cujas idéias gerais são basicamente as mesmas. Lefebvre [Lef95, Lef96] também desenvolveu algoritmos similares. Gramáticas estocásticas livres de contexto foram utilizadas para construir uma versão do algoritmo básico descrito na Seção 3.1 [DEKM98]. Elas também foram utilizadas para modelar o problema de predição de estrutura de RNA incluindo alguns tipos de pseudonós [RE00]. Pseudo-nós são elementos estruturais não previstos na estratégia baseada em energia livre mínima. A Figura 2.7 ilustra esta idéia.

Algoritmos genéticos também foram utilizados na predição de estrutura secundária do RNA [SW96, BGP95]. Há também formulações baseadas no método Monte Carlo [ABBP98, GBP95], que incluem os pseudo-nós.

Bouthinon e Soldano [BS99] desenvolveram um método para predição de estrutura secundária baseado na representação da estrutura como um conjunto de relações estruturais entre suas hélices. A partir de um conjunto de seqüências, ele utiliza parâmetros termodinâmicos para selecionar a melhor estrutura para um dada seqüência, que chama de padrão estrutural. Depois repete o processo para as demais sequiências a fim de encontrar padrões estruturais repetidos, a partir dos quais, extrai a estrutura secundária comum.

\subsection{Organização da Dissertação}

No Capítulo 2 fazemos uma descrição detalhada do problema tema da dissertação, que é a predição de estrutura secundária do RNA. Na Seção 2.1 caracterizamos o problema do ponto vista biológico, enquanto na Seção 2.2 fazemos a conceituação matemática do problema e demais definições afins, além de apresentarmos diversos tipos de representação de estrutura secundária.

No Capítulo 3 fazemos a descrição de vários algoritmos para predição de estrutura secundária sob a estratégia baseada no cálculo de energia livre mínima. Na Seção 3.1 descrevemos um algoritmo básico e sua complexidade, bem como fazemos a apresentação de parte do código correspondente. Na Seção 3.2 descrevemos detalhamente o algoritmo geral que incorpora a presença dos laços e suas complexidades (Seção 3.2.3), também com apresentação de código.

Nas Seções 3.3.1 e 3.3.2 descrevemos algoritmos que representam avanços na melhoria de tempo do algoritmo geral, mais uma vez com apresentação de código. Na Seção 3.4 apresentamos variações do algoritmo geral que fornecem soluções sub-ótimas para o problema.

No Capítulo 4 apresentamos algoritmos rápidos para classes especiais mais restritivas de funções associadas ao cálculo de energia dos laços.

No Capítulo 5, nas Seções 5.2 e 5.3, descrevemos alguns algoritmos construídos sob a estratégia que 
tem como base a análise comparativa entre seqüências (RNA's) homólogas. Na Seção 5.4.1 descrevemos um método híbrido, que carrega características da minimização de energia e análise comparativa entre homólogos.

No Capítulo 6 tecemos as considerações finais e conclusões.

Grande parte do código desenvolvido está descrito no Apêndice A. No Apêndice B estão cópias de partes dos arquivos que usamos na implementação e que armazenam os parâmetros de energia que adotamos em nossa implementação. Estes "pedaços" de arquivos (tabelas) têm como finalidade ilustrar ao leitor a organização adotada para estes dados (parâmetros). Se o leitor desejar, pode encontrar cópias completas dos referidos arquivos em http://www.ime.usp.br/dcc/posgrad/teses/rozante/.

\subsubsection{Implementação}

Feito a indicação do que cada capítulo contém, é conveniente agora que façamos algumas considerações acerca de como o texto está estruturado, em especial no que diz respeito à implementação, a fim de que possamos garantir maior clareza ao leitor.

Grande parte do código desenvolvido, como já disssemos, está descrito no Apêndice A. Porém, o texto foi construído sob a filosofia Literate Programming (ambiente CWEB [KL93]), de modo que inserimos, de forma "diluída", código $\mathrm{C}$ ao longo do texto principal. Ou seja, à medida que os conceitos e métodos são apresentados, incluímos, no ponto da apresentação, o código correspondente ao conceito ou método. Esta inserção direta de código é feita em alguns pontos do texto. Em outros, fazemos apenas referência a um bloco de código presente no Apêndice A. Esta distinção foi adotada segundo a importância do código e também a fim de garantir maior fluidez ao texto como um todo; isto é, evitamos tornar o texto excessivamente "poluído" de código.

Para que o leitor entenda como o texto está estruturado neste esquema, basta conhecer o conceito de bloco - que é análogo ao conceito de macro na linguagem $\mathrm{C}$ - e a notação que o envolve. Quando quisermos definir um bloco usaremos a sintaxe

$$
\begin{gathered}
\langle\text { Nome do bloco id }\rangle \equiv \\
\text { código } \mathrm{C}
\end{gathered}
$$

Os blocos de código no Apêndice A ou dispersos ao longo do texto possuem um identificador inteiro, aqui representado por $i d$. As definições de bloco estão ordenadas pelo seu identificador. Quando quisermos fazer referência a um bloco simplesmente repetiremos seu nome e identificador entre os delimitadores "(" e ")".

Para ilustrar, citamos os grandes blocos que definem uma primeira categorização do código que produzimos, como segue:

2 〈Definições, Declarações e Arquivos de Inclusão 95〉

〈Programa Principal 97)

〈Algoritmo Básico 36〉 
〈Incorporação de Laços 37

〈Funções comuns 53〉

〈Funções de Inicialização e Finalização 58

〈Funções Auxiliares 87〉

Aqui chamamos de módulo cada um destes blocos já que estes representam a forma geral como o código está dividido, além de serem bastantes extensos. Grande parte deste código está no Apêndice A, seguindo a divisão sugerida acima. Dessa forma este Apêndice pode ser considerado aquele que concentra a maior parte da implementação. No entanto, há também trechos de programa - em geral as funções mais expressivas e importantes - que são inseridos ao longo dos demais capítulos, conforme a conveniência de mostrar o código no local onde o conceito ou algoritmo é apresentado.

No bloco 〈Algoritmo Básico 36 , descrito no Apêndice A, estão apenas as chamadas a outros blocos ( $($ Cálculo matriz de energia (pares de bases independentes) 7〉 e (Identificação de pares do dobramento (Algoritmo traceback) 8)), os quais, por sua vez, estão descritos na Seção 3.1 e correspondem à implementação de uma versão simplificada de um dos algoritmos baseados em cálculo de energia livre mínima.

No bloco 〈Incorporação de Laços 37 , também descrito no Apêndice A, há descrições e chamadas de outros blocos. Elas correspondem à implementação do algoritmo geral, baseado no cálculo de energia livre mínima, que contabilizada a energia relativa aos laços e versões melhoradas destes. Parte deste código está no Apêndice A e parte está na Seção 3.2.

Os demais blocos mencionados na relação acima contêm código necessário, mas que não representam a essência dos algoritmos, como por exemplo, funções comuns, inicializações, etc.

$\mathrm{O}$ código $\mathrm{C}$ gerado, os arquivos de dados e demais arquivos necessários à execução dos programas, bem como arquivos no formato dvi/ps contendo a dissertação, estão disponíveis e podem ser acessados no endereço http : //www.ime.usp.br/dcc/posgrad/teses/rozante/. 


\section{Capítulo 2}

\section{Predição de Estruturas Secundárias do RNA}

\subsection{Aspectos Biológicos}

Uma molécula de RNA consiste em uma cadeia de nucleotídeos conectados por ligações covalentes. Cada nucleotídeo contém um grupo fosfato, um açúcar (ribose) e uma base. Essa molécula de RNA é um polímero e é formado pela ligação de grupos fosfato. Somente as bases diferem e elas são quatro: Adenina $(A)$, Citosina $(C)$, Guanina $(G)$ e Uracil $(U)$, cujas estruturas moleculares estão ilustradas na Figura 2.2.

Quando comparado ao DNA, o RNA apresenta basicamente duas diferenças no que diz respeito à sua composição: a) o açúcar do DNA é a desoxirribose enquanto que o do RNA é a ribose; b) no RNA a base pirimídica Uracil substitui a Timina presente no DNA.

Com relação à forma das moléculas, enquanto o DNA possui uma estrutura regular de dupla hélice - formada pelo pareamento das bases $A$ com $U$ e de $C$ com $G$-, o RNA consiste em uma fita única na qual não observamos a equivalência entre as quantidades de $A \operatorname{com} U$ e de $C$ com $G$. Deste modo, não seria possível encontrar, para cada base da molécula, uma outra correspondente com a qual esta poderia formar um par.

Em 1956, Francis Crick esquematizou uma hipótese de trabalho hoje conhecida como dogma central da Biologia Molecular, segundo a qual, o DNA atua como molde para a síntese de RNA, cujas moléculas

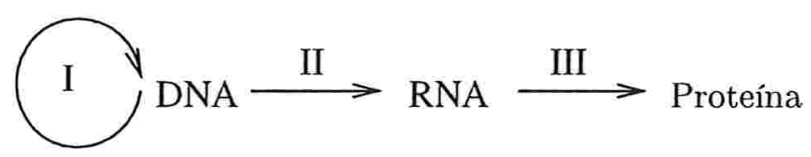

Figura 2.1: Dogma central da Biologia. 
<smiles>Nc1ncnc2[nH]cnc12</smiles><smiles></smiles>

Guanina<smiles>[2H]c1cc(N)nc(=O)[nH]1</smiles>

Citosina<smiles>O=C1C=CC(=O)NC1</smiles>

Uracil

Figura 2.2: Estrutura das bases nitrogenadas.

migram para o citoplasma onde determinam o arranjo dos aminoácidos nas proteínas. Este esquema é resumido e ilustrado na Figura 2.1, onde os passos I, II e III significam:

I. Replicação, através da qual a informação é perpetuada;

II. Transcrição, onde uma molécula de RNA de fita simples é gerada. Esta molécula é idêntica em seqüência de bases a uma das fitas do DNA;

III. Tradução, onde a seqüência de bases do RNA é convertida na seqüência de aminoácidos da proteína.

Existem vários tipos de RNAs. Os mais importantes são RNA ribossômico (rRNA), RNA transportador (tRNA) e RNA mensageiro (mRNA).

O RNA ribossômico é encontrado em toda célula viva, além de ser fundamental ao ribossomo (local onde se processa a fase de tradução na síntese protéica), pois faz parte da composição estrutural deste; é também encontrado em organelas como as mitocôndrias e os cloroplastos.

Mais da metade da massa dos ribossomos corresponde a moléculas de rRNA. As subunidades dos ribossomos, assim como as moléculas de rRNA, são designadas pelo seu coeficiente de sedimentação, 
expresso em unidades Svedberg (S). Svedberg é a medida da razão de sedimentação de partículas em suspensão, centrifugadas em gradiente de sacarose sob condições padronizadas.

O RNA transportador (ou RNA de transferência) é um agente que desempenha papel fundamental na montagem das cadeias peptídicas - que ocorre no ribossomo - , pois serve como "chave" associando um aminoácido a uma trinca de nucleotídeos codificadas no RNA mensageiro.

Os tRNAs estão envolvidos em uma variedade de processos. Para desempenhar certas funções é necessário que todos os tipos de tRNAs possuam algumas características em comum mas, por outro lado, eles possuem pequenas diferenças que permitem a distinção entre os diferentes tipos de moléculas. As bases das moléculas precursoras dos tRNAs sofrem várias modificações, desde simples metilações até a reestruturação do anel purínico. Tais modificações aumentam a versatilidade dos tRNAs, o que é importante para as várias funções que desempenham. Um exemplo clássico destas modificações é a alteração em sua capacidade de emparelhamento com o mRNA: a modificação ocorre em bases da trinca (anticódon) por meio das quais o tRNA se emparelha com mRNA durante a síntese proteíca, ou nas vizinhanças dela.

O RNA mensageiro, além de carregar a informação na síntese de proteínas, desempenha outras funções. Por exemplo, sua estrutura secundária pode ser usada para explicar em parte o controle da tradução [Mac90, SD90] e o controle da replicação [ZT99] em RNAs virais de fita única. Há diferenças importantes nos detalhes da síntese e da estrutura dos RNAs de procariontes e eucariontes. Nas células procariontes o mRNA é transcrito e traduzido no único compartimento celular e os dois processos ocorrem acopladamente. Nos eucariontes, a síntese e maturação dos mRNA ocorrem exclusivamente no núcleo: apenas quando o mRNA está maduro é que ele é exportado para o citoplasma e traduzido.

Há diferenças significativas na tradução dos mRNAs de procariontes e de eucariontes. Estas diferenças ocorrem em virtude das suas características estruturais e estabilidade. A diferença estrutural é que o mRNA de procariontes freqüentemente é usado para construir ("codificar") várias proteínas, enquanto que em eucariontes o mRNA invariavelmente é usado para construir ("codificar") apenas uma cadeia polipeptídica. A diferença funcional é que o mRNA de procariontes geralmente é instável e é, por esta razão, traduzido durante um intervalo de tempo bastante pequeno - tipicamente poucos minutos. Em contrapartida, o mRNA dos eucariontes, por ser mais estável, pode levar várias horas ou dias para ser traduzido em proteínas.

Os rRNAs e mais alguns pequenos RNAs nucleares são conhecidos como RNAs estruturais (sRNA). Muito já se conhece sobre os sRNAs, mas alguns aspectos ainda são desconhecidos e é possível que estes sRNAs desempenhem um papel importante em funções regulatórias das células [ZT99]. Há muita expectativa em torno de descobertas que esclareçam mais a respeito do papel destes RNAs. Outro dado importante é que o RNA não é apenas um elemento passivo - estrutural ou regulador -, visto que ele pode também desenvolver atividade catalítica, atuando como um componente de um complexo RNA-proteína, cuja função é ativar o trabalho do tRNA.

Sob condições naturais, uma cadeia de RNA dobra-se sobre si mesma, através da formação de pontes de hidrogênio entre bases complementares ( $A$ com $U$ e $C$ com $G$ ) e entre bases wobble ( $U$ com $G$ ). As bases complementares formam pares de bases estáveis através da criação de pontes de hidrogênio 
entre elas, que são ditos pares de bases de Watson-Crick. Além disso, é possível considerar também (e geralmente o é) o par G-U, cuja ligação é mais fraca e que é denominado par de base oscilante ou instável (em inglês wobble). Os pares de bases de Watson-Crick, juntamente com os oscilantes, são denominados pares de bases canônicos.

A estrutura secundária de uma molécula de RNA é o conjunto de pares de bases canônicos - ou simplificadamente pares de bases - que ocorrem na "dobradura" natural da molécula. A conformação tridimensional, ou estrutura terciária, amplia esta "dobradura" incorporando as interações entre os elementos da estrutura secundária. Estes elementos são determinados por suas regiões de dupla hélices (regiões pareadas, tal como no DNA), que são formadas por seqüências de bases canônicas que se ligam entre si através de pontes de hidrogênio. Ambas estão intrinsecamente relacionadas e suas configurações assumem implicações importantes na atividade bioquímica da célula.

O que os biólogos querem é conhecer a estrutura da molécula o suficiente para entender sua função. Isto significa que o que eles geralmente desejam é interpretá-la (a molécula) em termos de seu dobramento tridimensional. Para tal não é necessário conhecer as coordenadas de cada um de seus átomos, mas sim conhecer parte em termos de sua resolução atômica, outra parte em termos dos pares de bases formados e o resto apenas como uma aproximação.

Isto decorre do fato de que, tendo em vista os aspectos funcionais de um RNA, podem existir regiões irrelevantes. Algumas seqüências podem dobrar em estruturas que são rígidas e compactas; outras podem ser flexíveis para maximizar a interação com algum ligante particular.

Um indício que sugere a importância de uma estrutura é o grau de sua conservação, inclusive se esta conservação é observada para seqüências não idênticas. Em outras palavras, se, por exemplo, uma região formada por pares de bases define um dobramento local, onde este dobramento local é conservado em muitas espécies, assume-se que esta região é importante na definição da função da molécula.

As energias envolvidas na formação da estrutura secundária são maiores do que aquelas envolvidas nas interações terciárias, de modo que elementos estruturais secundários podem ser estáveis o suficiente para existirem à revelia das interações terciárias que os envolvam. Desta forma, as contribuições energéticas dos elementos estruturais secundários e terciários podem ser separadas e é possível então, a partir daí, tratar a energia das interações terciárias como uma perturbação na estabilidade energética da estrutura secundária.

Esta característica permite estabelecer uma relação hierárquica no caminho que leva ao dobramento do RNA: a estrutura primária determina a estrutura secundária que, por sua vez, determina a estrutura terciária, cuja formação apenas altera levemente a estrutura secundária. O dobramento do RNA pode então ser entendido como o fluxo de informação que nos leva da estrutura primária à terciária.

Ademais, é conhecido que a função do RNA só pode ser entendida em termos de sua estrutura secundária e/ou terciária. Para o entendimento da sua atividade catalítica, por exemplo, conhecer a estrutura secundária não basta. Contudo, ainda assim poucas estruturas terciárias foram determinadas até hoje por cristalografia (um método laboratorial) [ZT99]. É razoável considerar a modelagem da estrutura secundária como um primeiro passo na modelagem da estrutura terciária. 


\section{Bacillus subtilis RNase P RNA}
M - multi-loop
I - interior loop
B - bulge loop
H - hairpin loop
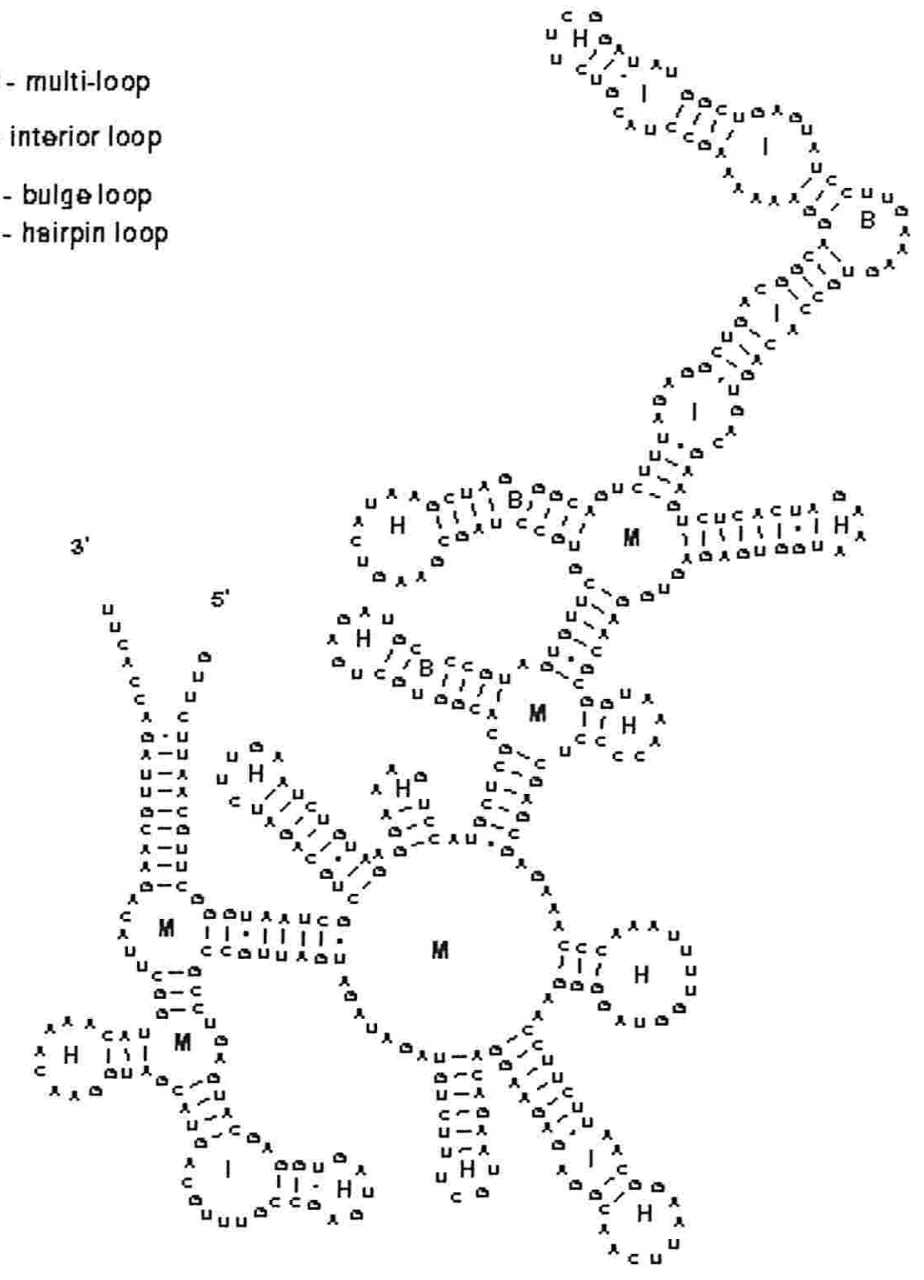

Figura 2.3: Exemplo de Estrutura Secundária do RNA na sua representação Normal. Obtida no endereço <http://www.ibc.wustl.edu/ zuker/Bio-5495/RNAfold-html>.

\subsection{Representação e Conceituação Matemática}

A estrutura secundária da molécula de RNA pode ser representada de diversas formas. A forma de representação mais comum e mais aceita na comunidade de biólogos (conhecida por representação normal) é aquela na qual a cadeia de RNA é representada por uma linha curvada de tal forma que a série de pontos eqüidistantes (representando os nucleotídeos) são dispostos de maneira que é possível visualizar as pontes de hidrogênio formadas pelos pares canônicos. A Figura 2.3 ilustra esta representação que foi proposta por Fresco e Doty [FAD60] em 1960.

Uma segunda representação, mais abstrata, proposta por Nussinov et al. [NPGK78], distribui as bases eqüidistantemente umas das outras ao longo de uma circunferência. As ligações covalentes são representadas pelo arco da circunferência e as pontes de hidrogênio por linhas ligando os pares canônicos. A Figura 2.4 ilustra esta representação. 


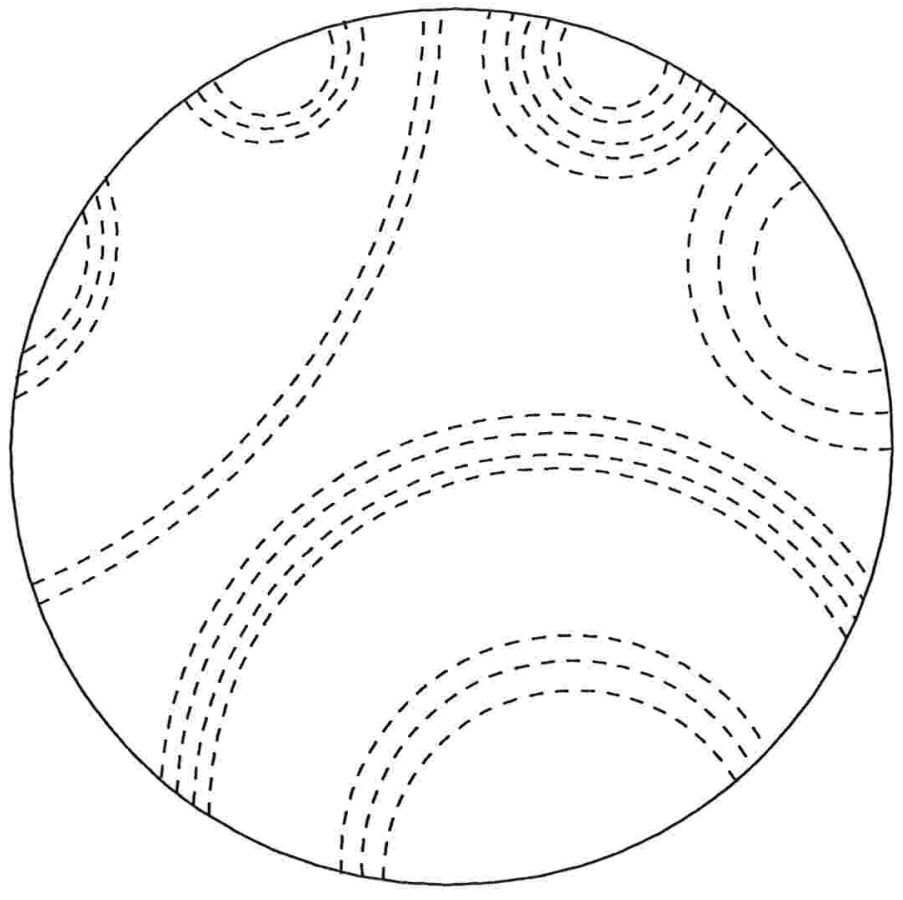

Figura 2.4: Representação de Nussinov de uma estrutura secundária: as linhas pontilhadas indicam as pontes de hidrogênio e a continua as ligações covalentes.

Uma outra forma de representação, conhecida por dot plot, atribui status às células em uma matriz triangular, de modo a indicar a existência ou não de pontes de hidrogênio entre o nucleotídeo $i$ e nucleotídeo $j$ (tomando $i$ para representar as linhas da matriz e $j$ as colunas, por exemplo). Esta representação é muito utilizada para fazer análises comparativas entre estruturas, pois permite a sobreposição de várias estruturas em uma única matriz dot plot. A ilustração desta representação é feita na Figura 2.5.

Há ainda uma quarta forma de representação, denominada representação Vienna, na qual a molécula é representada por uma seqüência de caracteres ' ', '(' e ')'. As posições da seqüência ocupadas por '.' indicam nucleotídeos entre os quais não há formação de pontes de hidrogênio na estrutura. As posições ocupadas por '(' e ')' indicam nucleotídeos entre os quais há formação de pontes de hidrogênio, onde para cada '(' existe um ')' correspondente indicando que estes dois nucleotídeos ligam-se entre entre si através da formação de pontes de hidrogênio. A Figura 2.6 ilustra esta representação. Em nossas implementações utilizamos a representação Vienna para expressar as saídas (estruturas) produzidas.

Uma molécula de RNA é representada como uma seqüência de $n$ caracteres $R=r_{1}, r_{2}, \ldots, r_{n}$, onde $r_{i} \in\{A, U, C, G\}$ representa o $i$-ésimo nucleotídeo. Uma estrutura secundária da molécula - cuja noção topológica está ilustrada na Figura 2.3 - é um conjunto $S$ de pares de inteiros tal que cada par $(i, j) \in S$, com $1 \leq i<j \leq n$, satisfaz as seguintes restrições:

Restrição $1 r_{i}$ e $r_{j}$ é um par de bases canônico; 


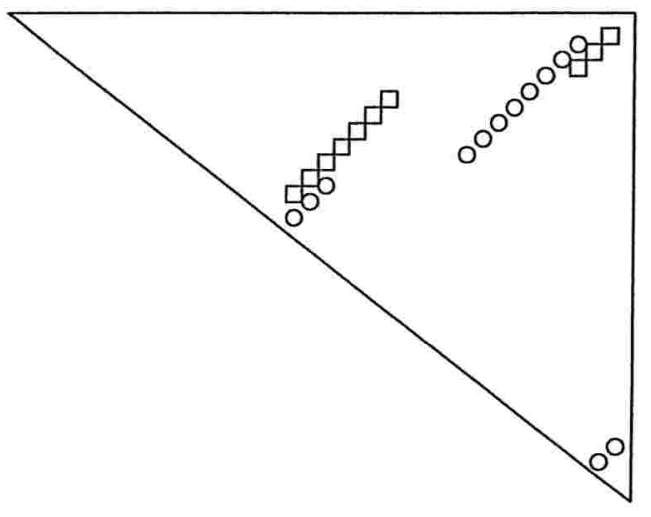

Figura 2.5: Representação dotplot de duas ( $\diamond$ e o) estruturas secundárias.

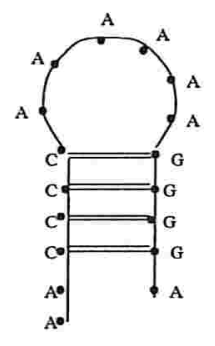

AACCCCAAAAAGGGGA

. $((((\ldots \ldots))))$.

Figura 2.6: Representações Vienna e Normal de uma estrutura secundária simples.

Restrição $2 j-i>t$, onde tipicamente $t=4$ ou $t=3$;

Restrição 3 se $i \leq i^{\prime}$ e $\left(i^{\prime}, j^{\prime}\right) \in S$, então somente um dos casos ocorre:

Caso $1 i=i^{\prime}$ e $j=j^{\prime}$;

Caso $2 i<j<i^{\prime}<j^{\prime}$;

Caso $3 i<i^{\prime}<j^{\prime}<j$.

Se $(i, j) \in S$ dizemos que $r_{i}$ e $r_{j}$ são bases pareadas. A Restrição 2 modela um fato da realidade biológica, observado experimentalmente, que consiste na impossibilidade de uma molécula dobrar-se sobre si mesma - em alguma parte - de forma pontiaguda.

Os Casos 2 e 3 excluem uma configuração natural chamada pseudo-nó (do inglês pseudoknot). Dizemos que ocorre um pseudo-nó quando existem pares $\left(r_{i}, r_{j}\right),\left(r_{i^{\prime}}, r_{j^{\prime}}\right) \in S$ com $i<i^{\prime}<j<j^{\prime}$. A Figura 2.7 mostra como são visualizados os pseudo-nós na representação de Nussinov (a) e Normal (b). Sua exclusão simplifica o problema, pois, fora os pseudo-nós, $S$ - na representação de Nussinov - não contém cruzamento das linhas que indicam as pontes de hidrogênio.

Geralmente, os pseudo-nós são considerados pertencentes à estrutura terciária (conformação tridimensional da molécula). No entanto, alguns pesquisadores o consideram como parte da estrutura 


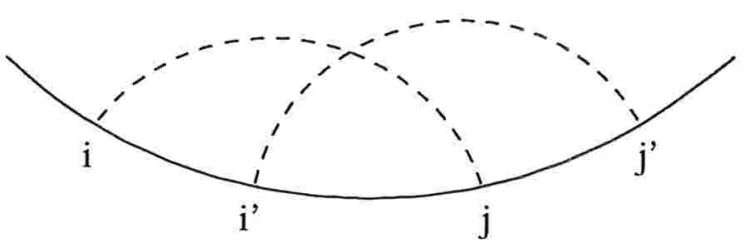

(a)

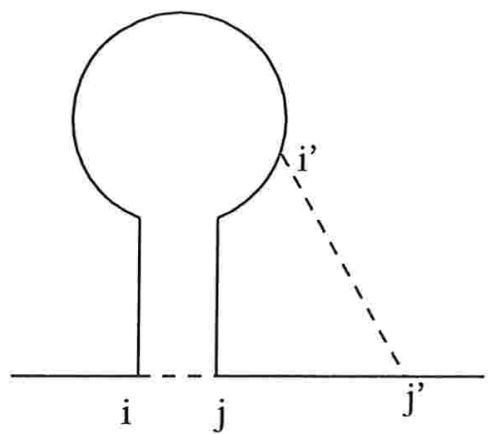

(b)

Figura 2.7: Representações Nussinov (a) e Normal (b) de um pseudo-nó: as linhas tracejadas indicam as pontes de hidrogênio e as contínuas as ligações covalentes.

secundária, de modo que tentam propor soluções para a predição de estrutura secundária que os incorpore. Isto exige uma redefinição do conceito de estrutura secundária em relação ao que adotamos acima.

Uma justificativa para a exclusão dos pseudo-nós nos cálculos do dobramento do RNA é que eles não ocorrem com muita freqüência nos tipos de estrutura mais comuns. Entretanto, esta afirmação não é amplamente aceita. Neste trabalho, a motivação que nos leva a não tratá-los é que sua exclusão simplifica enormente os modelos e algoritmos para o problema. Alguns tipos de pseudo-nós foram tratados no algoritmo de Rivas e Eddy [RE99], cujas complexidades de tempo e espaço são, respectivamente, $O\left(n^{6}\right)$ e $O\left(n^{4}\right)$ para uma molécula com $n$ bases. Entretanto, Lyngsø e Pedersen [LP00] mostraram recentemente que o problema geral é NP-difícil.

Pseudo-nós são funcionalmente importantes para muitos RNAs [DPD92]. Por exemplo, pseudo-nós são conservados em RNAs ribossômicos e nas P RNAses. Estruturas com pseudo-nós propostas há algum tempo [PRB92] foram recentemente confirmadas [ $\left.\mathrm{KGW}^{+} 98\right]$ para vários RNAs virais de plantas.

Vários métodos para predição de estrutura de RNA, que incluem os pseudo-nós, caracterizados como heurísticas, foram propostos. Exemplos destes incluem o método quasi-Monte Carlo [ABBP98] e algoritmos genéticos ([GBP95], [BGP95]). Por serem heurísticas, estes métodos não garantem que a estrutura ótima é encontrada para um dado modelo termodinâmico.

Um método baseado no algoritmo de emparelhamento máximo ( [Edm65], [Gab76]), que foi primeiramente introduzido por Cary e Stormo [CS95] e retomado por Tabaska et al [TCGS98], também trata os pseudo-nós com complexidade de tempo e espaço de $O\left(n^{3}\right)$ e $O\left(n^{2}\right)$, respectivamente. No entanto, este método é apropriado para predizer o dobramento de seqüências para as quais se dispõe de um alinhamento múltiplo entre elas; de modo que este método, portanto, não representa um avanço no caso de dispormos apenas de uma seqüência única como entrada.

Gramáticas estocásticas livre de contexto também foram utilizadas para modelar o problema de predição de estrutura de RNA incluindo pseudo-nós ( [RE00]). Neste trabalho, Rivas e Eddy descrevem 
uma gramática transformacional que corresponde ao algoritmo descrito por eles mesmos em [RE99].

O problema da predição da estrutura secundária do RNA pode ser tratado através de duas estratégias. A primeira, e mais difundida, é baseada no cálculo da estrutura secundária que requer energia (ou energia livre) mínima, ou seja, aquela mais estável termodinamicamente. Para este propósito, vale observar que os organismos vivos não são exceções às Leis Físicas que governam as trocas energéticas. O seu crescimento e manutenção requer energia, que deve ser "paga" de alguma maneira. Os organismos vivos absorvem do ambiente as formas de energia que lhe são úteis, nas condições especiais de temperatura e pressão em que vivem. Eles então retornam ao ambiente uma quantidade equivalente de alguma outra energia, menos útil, do ponto de vista do organismo. O tipo de energia útil que a célula requer é a energia livre, que pode ser definida como o tipo de energia que pode realizar trabalho a temperatura e pressão constantes. O tipo de energia menos útil que as células retornam ao seu ambiente consiste principalmente em calor, que é aleatoriamente dissipado aos arredores.

A energia necessária para dissociar, por exemplo, uma ligação covalente do tipo C-C é de 83 $\mathrm{kcal} / \mathrm{mol}$. A energia de um fóton verde é de $57 \mathrm{kcal} / \mathrm{mol}$, o ATP tem um conteúdo utilizável de energia de $12 \mathrm{kcal} / \mathrm{mol}$ e a energia média de cada grau de liberdade de vibração em uma molécula é muito menor, de cerca de 0,6 kcal/mol. Portanto, o esqueleto covalente das biomoléculas é estável na ausência de enzimas e de entrada de luz. Por outro lado, as ligações não covalentes (as pontes de hidrogênio, por exemplo) em sistemas biológicos têm tipicamente uma energia de apenas poucas quilocalorias por mol, de modo que a energia térmica é suficiente para rompê-las [NC00].

Uma segunda forma conhecida de tratar o problema computa dobramentos comuns para uma família de RNAs homólogos alinhados. Duas ou mais seqüências de RNAs são ditas homólogas se derivam de uma mesma seqüência; ou seja, se têm - do ponto de vista da história evolutiva - um ancestral comum do qual descendem.

Tentando resolver o problema sob a ótica da primeira estratégia, poderíamos ser levados a conceber um algoritmo trivial que enumerasse todas as possíveis candidatas a estruturas e depois simplesmente escolhesse, entre aquelas que podem ser estruturas secundárias, aquela que correspondesse à de menor energia. No entanto, o número possível de candidatas a estruturas é de pelo menos $2^{n}$, para seqüências de $n$ nucleotídeos, como veremos no Teorema 2.2.3, o que, evidentemente, torna tal algoritmo inviável para seqüências de tamanho razoável. Hofacker et al [HSS98] desenvolveram uma contagem mais precisa do número de possíveis estruturas secundárias para uma dada seqüência.

Para provarmos a afirmação acima é necessária a incorporação de algumas definições, que serão também utilizadas nos próximos capítulos. Seja $(i, j) \in S$ e sejam $i^{\prime}, v$ e $j^{\prime}$ posições tais que $i<i^{\prime}<$ $v<j^{\prime}<j$. Então dizemos que:

1. $v$ é acessivel a $(i, j)$ se $\left(i^{\prime}, j^{\prime}\right) \notin S$ para todo $i^{\prime}$ e $j^{\prime}$;

2. $\left(i^{\prime}, j^{\prime}\right)$ é acessivel a $(i, j)$ se $\left(i^{\prime}, j^{\prime}\right) \in S$ e $i^{\prime}$ e $j^{\prime}$ são acessíveis a $(i, j)$;

3. o conjunto formado pelas bases dos pares de bases acessíveis a $(i, j)$ e pelas bases não pareadas - também acessíveis a $(i, j)$ - é o laço fechado por $(i, j)$, ou simplesmente laço.

4. o laço formado por $k$ pares de bases (o par de fechamento $(i, j)$ juntamente com $(k-1)$ pares de 
bases acessíveis a $(i, j)$ ) e por $k^{\prime}$ bases não pareadas é chamado $k$-laço (ou $k$-ciclo) de tamanho $k^{\prime}$ fechado por $(i, j)$.

5. uma base não pareada não pertencente a nenhum laço é uma base externa; um par de bases pareadas não pertencente a nenhum laço é denominado par externo. A coleção formada pelas bases externas e pares externos é denominado laço externo.

A idéia de laço externo equivale à noção de inclusão de bases imaginárias 0-ésima e $(n+1)$-ésima as quais formam um par imaginário $(0, n+1)$. Então o laço externo da estrutura secundária é o laço fechado pelo par $(0, n+1)$.

Lema 2.2.1 Cada base não pareada em uma estrutura secundária é acessivel a exatamente um laço ou é uma base externa. Cada par de bases pareadas em uma estrutura secundária é acessivel a exatamente um laço ou é um laço externo.

Prova: Suponhamos uma base $r$ que é acessível aos pares $(i, j)$ e $\left(i^{\prime}, j^{\prime}\right)$. Pela definição de acessibilidade, temos que $i<r<j$ e $i^{\prime}<r<j^{\prime}$ e que não pode ocorrer que $i<i^{\prime}<r<j^{\prime}<j$ nem que $i^{\prime}<i<r<j<j^{\prime}$. Portanto, ou $i^{\prime}<i<r<j^{\prime}<j$ ou $i<i^{\prime}<r<j<j^{\prime}$; mas ambas situações contradizem o princípio de não existência de pseudo-nós. Para provarmos a segunda parte do lema supomos que o par $(r, t)$ é acessível aos pares $(i, j)$ e $\left(i^{\prime}, j^{\prime}\right)$ e usamos a mesma argumentação.

De posse destes conceitos é possível, então, definir os vários tipos de laços (Figura 2.8):

1. o 1-laço é denominado arco;

2. se $\left(i^{\prime}, j^{\prime}\right)$ é acessível a $(i, j)$, então o 2-laço fechado por $(i, j)$ pode ser:

(a) uma hélice, se $i^{\prime}-i=1$ e $j-j^{\prime}=1$;

(b) uma barriga em $i$, se $i^{\prime}-i>1$ e $j-j^{\prime}=1$;

(c) uma barriga em $j$, se $j-j^{\prime}>1$ e $i^{\prime}-i=1$;

(d) um laço interno, se $i^{\prime}-i>1$ e $j-j^{\prime}>1$.

3. se $k>2$, então o $k$-laço é denominado multi-laço.

Um grampo é uma estrutura secundária com exatamente um laço arco. A Figura 2.9 ilustra um grampo.

Seja $H(n)$ o número de possíveis estruturas secundárias com exatamente um laço arco (grampo) para sequências de RNA com $n \geq t+2$ bases, onde $t$ é um inteiro da definição de estrutura secundária (Restrição 2). Nessas condições, temos o seguinte.

Lema 2.2 .2

$$
H(n)=2^{n-(t+1)}-1 .
$$




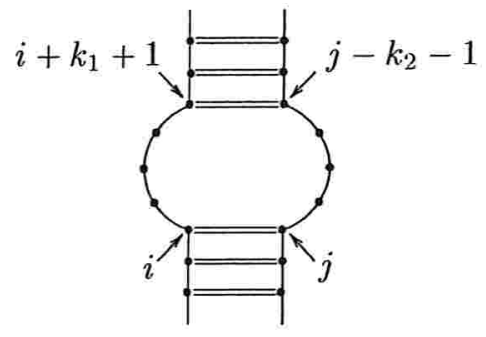

A: Laço Interno

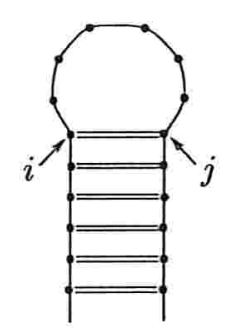

C: Laço Arco

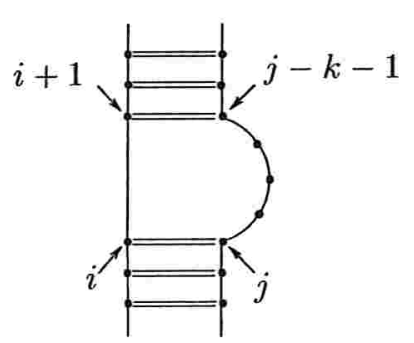

E: Laço Barriga em $j$

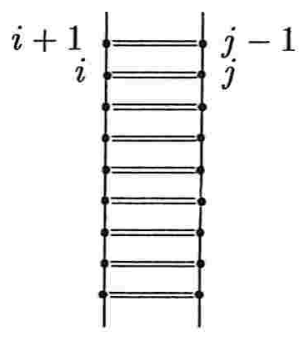

B: Laço Hélice (ou Empilhamento)

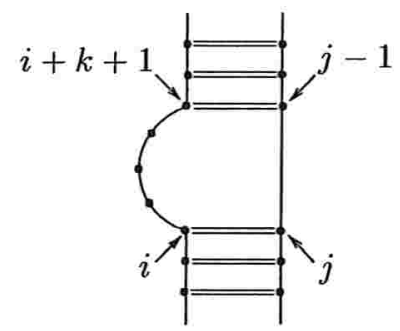

D: Laço Barriga em $i$

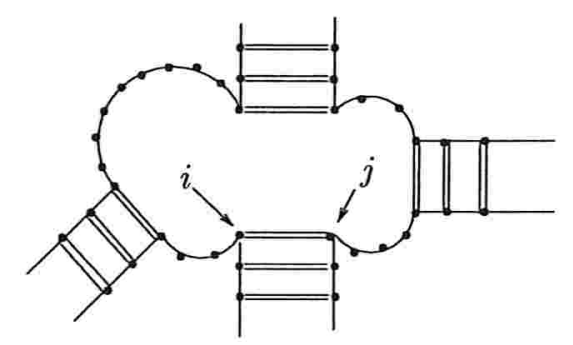

F: Multi-laço (4-laço)

Figura 2.8: Vários Tipos de Laços. As linhas simples representam as ligações covalentes e as duplas as pontes de hidrogênio. Obtida de [SM97]. 


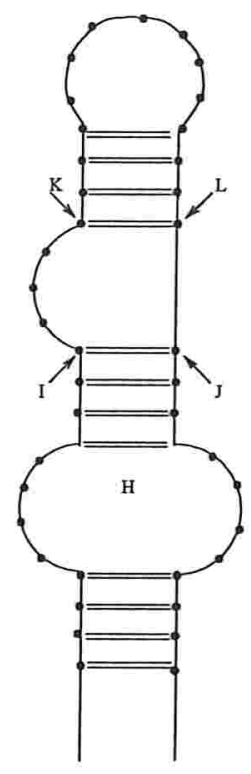

Figura 2.9: Um exemplo de grampo.

Prova: Seja $L(n)$ o número de estruturas secundárias distintas com no máximo um laço arco para uma sequência de tamanho $n$. Claramente temos que $L(0)=L(1)=L(t)=L(t+1)=1$. Consideremos a sequência $[1, n+1]$. Ou a base de posição $n+1$ é não pareada ou está pareada com alguma base de posição $i, 1 \leq i \leq n-t$. Note que a base $n+1$ não pode estar pareada com bases posicionadas no intervalo $[n-t+1, n]$, pela Restrição 2. Com a base $n+1$ não pareada, existem $L(n)$ estruturas. Com a base $n+1$ pareada, a subsequência $[1, i-1]$ não pode ter bases pareadas, pois existe no máximo um laço arco. Então, existem $L(n-(i+1)+1)=L(n-i)$ estruturas secundárias com um laço arco para cada $i$ variando no intervalo $1 \leq i \leq n-t$. Deste modo, temos que

$$
\begin{aligned}
L(n+1) & =L(n)+L(n-1)+\cdots+L(t+2)+L(t+1)+L(t) \\
& =2 L(n), n \geq t+1 .
\end{aligned}
$$

Logo,

$$
L(n)=\left\{\begin{array}{l}
1, \quad \text { se } n<t+2 \\
2^{n-(t+1)}, \quad \text { se } n \geq t+2 .
\end{array}\right.
$$

Como todas as estruturas contidas no conjunto de estruturas com no máximo um laço arco (cuja cardinalidade é $L(n))$ são grampos, exceto aquela que não contém bases pareadas, então

$$
H(n)=L(n)-1=2^{n-(t+1)}-1, n \geq t+2 .
$$

Seja $T(n)$ o número de possíveis estruturas secundárias para seqüências de RNA com $n$ bases. Como $H(n) \leq T(n)$, fica fácil mostrar um limitante inferior para $T(n)$ usando o Lema 2.2.2, conforme vemos no Teorema abaixo. 


\section{Teorema 2.2.3}

$$
T(n)=\Omega\left(2^{n}\right)
$$

Prova: Imediato, pois $H(n) \leq T(n)$ e $H(n)=\Omega\left(2^{n}\right)$, pelo Lema 2.2.2. Portanto $T(n)=\Omega\left(2^{n}\right)$.

Note que esse número é, em geral, maior do que o número máximo de possíveis estruturas secundárias para uma seqüência fixa de RNA. O motivo disso é que, no segundo caso, a seqüência é fixa e exclui os pares não canônicos na estrutura secundária. Com isso, um algoritmo ingênuo que lista todos os possivieis candidatos à estrutura secundária e analisa cada uma deles não seria prático. 


\section{Capítulo 3}

\section{Usando Cálculo de Energia Livre Mínima}

Dizemos que uma molécula de RNA é dobrada quando há formação de uma estrutura secundária para esta molécula. Em outras palavras, dizemos que uma molécula de RNA dobra em uma estrutura secundária.

A estratégia mais difundida para se predizer a estrutura secundária de uma molécula de RNA é baseada no cálculo da estrutura secundária de energia livre mínima. Tal estratégia utiliza-se da idéia de se atribuir uma energia a cada um de seus pares de bases, ou a seus elementos formadores estruturais, como laços internos, barrigas, arcos, hélices e multilaços [ZS84].

Os algoritmos baseados nesta estratégia têm como entrada uma seqüência de bases, representando a molécula a ser dobrada e oferecem como saída um conjunto de pares representando a estrutura secundária de energia livre mínima.

\subsection{Algoritmo Básico}

Uma simplificação do problema supõe que as energias de cada um dos pares de bases são independentes entre si, de maneira que a energia total da estrutura $S$ pode ser escrita como

$$
\operatorname{Energia}(S)=\sum_{(i, j) \in S} \alpha\left(r_{i}, r_{j}\right), \text { onde } \alpha\left(r_{i}, r_{j}\right)<0
$$

Ou seja, pressupõe-se existir uma função $\alpha$ tal que $\alpha\left(r_{i}, r_{j}\right)$ é definida como a energia de ligação do par de bases $\left(r_{i}, r_{j}\right)$.

Valores razoáveis de $\alpha$, a $37^{\circ} \mathrm{C}$, são -3 e $-2 \mathrm{kcal} / \mathrm{mol}$ para pares de bases $(C, G)$ e $(A, U)$, respectivamente. Caso seja considerado o par $(G, U), \alpha=-1 \mathrm{kcal} / \mathrm{mol}$ (também a $37^{\circ} \mathrm{C}$ ), é também um valor razoável [ZS84]. O valor da função $\alpha$ altera-se na medida em que as temperaturas também se alteram, pois o ruído térmico exerce influência sobre a estabilidade dessas moléculas, visto que o 
calor pode romper as pontes de hidrogênio. A temperatura de $37^{\circ} \mathrm{C}$ é considerada padrão, embora em muitos casos deseje-se predizer estruturas secundárias sob outras condições de temperatura.

Esta idéia permite-nos modelar o problema como segue. Seja a seqüência $R=r_{1}, r_{2}, \ldots, r_{n}$ para a qual desejamos encontrar uma estrutura secundária $S$ de energia livre mínima. Definimos

$$
E(R)=\min _{S}\{\text { Energia }(S)\}
$$

onde $S$ varia em todas as estruturas secundárias de R.

Tomando a subseqüência $R_{i, j}=r_{i}, r_{i+1}, \ldots, r_{j}, 1 \leq i<j \leq n$, para a qual desejamos encontrar a estrutura secundária $S_{i, j}$ correspondente de energia livre mínima, há quatro possibilidades a serem tratadas:

1. se $r_{i}$ não é base pareada em nenhuma estrutura de energia mínima, então $E\left(R_{i, j}\right)=E\left(R_{i+1, j}\right)$;

2. se $r_{j}$ não é base pareada em nenhuma estrutura de energia mínima, então $E\left(R_{i, j}\right)=E\left(R_{i, j-1}\right)$;

3. se em alguma estrutura de energia mínima, $r_{i}$ e $r_{j}$ são bases pareadas, mas não entre si, então $E\left(R_{i, j}\right)=\min _{k}\left\{E\left(R_{i, k}\right)+E\left(R_{k+1, j}\right)\right\}$, para $i+t<k<j-t ;$

4. se $r_{j}$ é pareada com $r_{i}$ em alguma estrutura de energia mínima, então $E\left(R_{i, j}\right)=E\left(R_{i+1, j-1}\right)+$ $\alpha\left(r_{i}, r_{j}\right)$.

Vale observar que o Item 3 acima é válido devido ao fato de que assumimos que em $S$ não existem pseudo-nós. É bom lembrarmos também que $t$ modela o fato biológico, observado na natureza, que consiste na impossibilidade de uma molécula dobrar-se sobre si mesma - em alguma parte — de forma pontiaguda. Tipicamente temos $t=3$ ou $t=4$.

De modo mais formal, reescrevemos então as situações (modelo) acima como

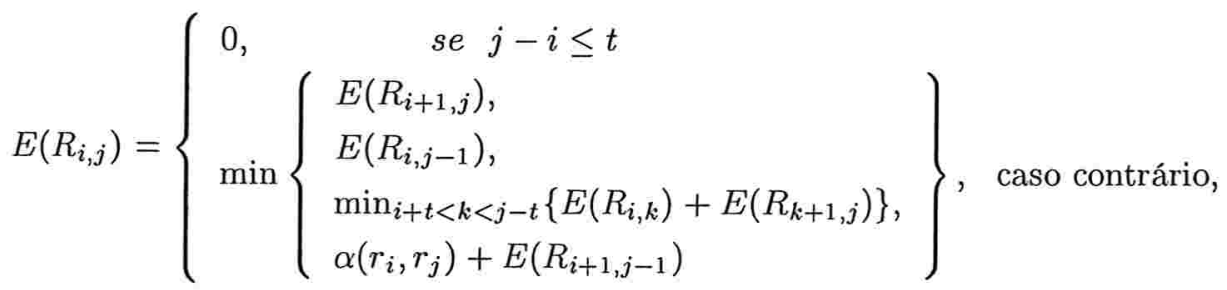

o que pode pode ser simplificado para a forma

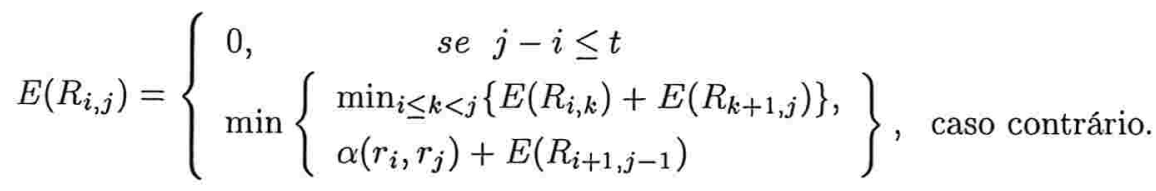

A Expressão 3.3 é resolvida por programação dinâmica. Resolvemos esta recorrência através de um algoritmo iterativo o qual preenche uma matriz de energias $E$, onde cada célula $E[i][j]$ armazena $E\left(R_{i, j}\right), 1 \leq i<j \leq n$. Atribuímos $E[i][j] \leftarrow 0$ para valores iniciais $j-i \leq t$. A ordem com que as entradas da matriz $E$ são preenchidas está indicada na Figura 3.1. Somente a parte triangular superior da matriz $E$ necessita ser preenchida, representada pelos pares $(i, j)$ tal que $i \leq j$. 
A função nomeada calc_matriz_energia(), descrita abaixo, corresponde à implementação deste algoritmo. Esta função tem como entrada uma string (que representa a molécula) e fornece como saída a matriz $E$ preenchida.

$7\langle$ Cálculo matriz de energia (pares de bases independentes) 7$\rangle \equiv$

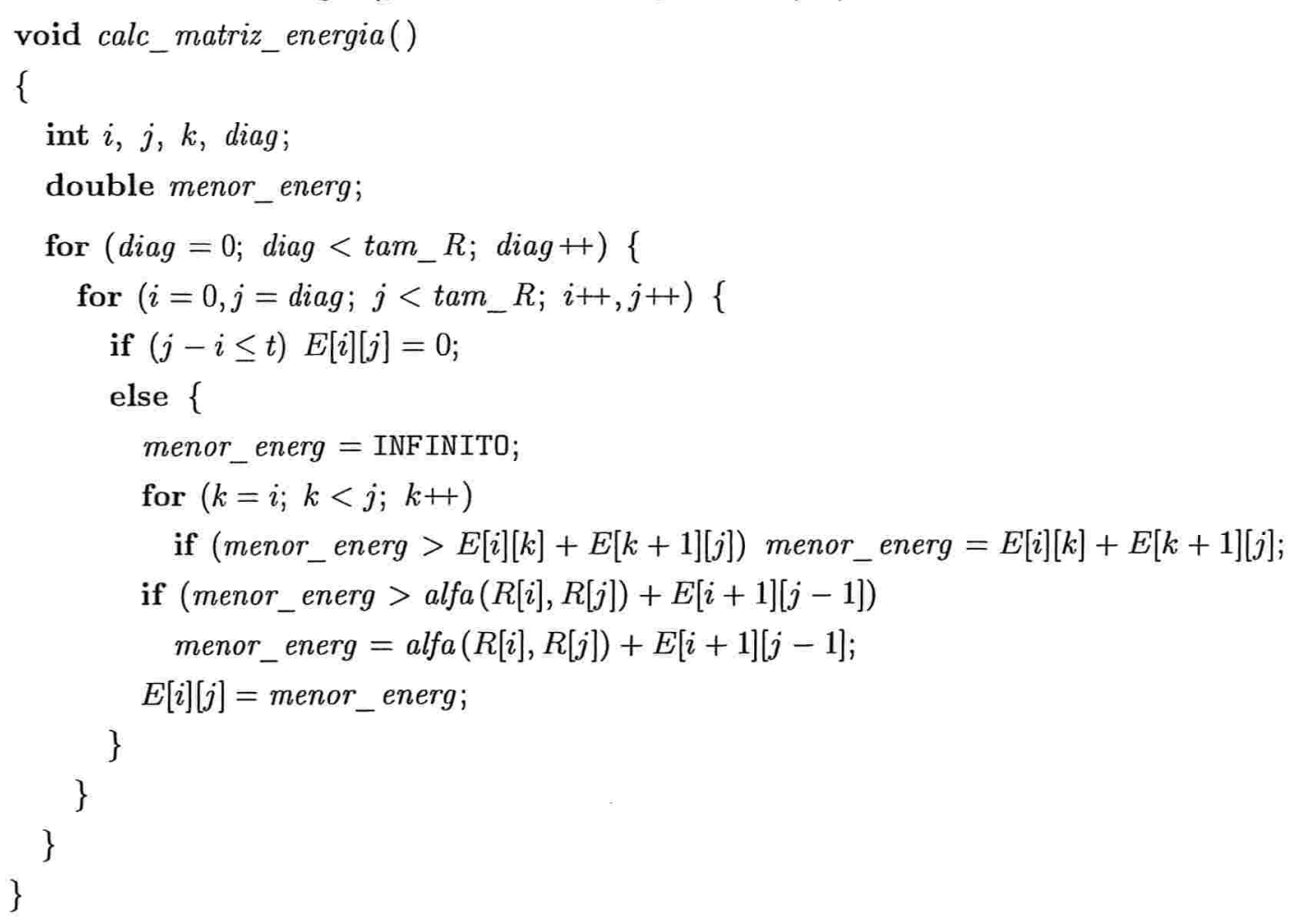

Este código é citado no bloco 3 .

Este código é usado no bloco 36.

Este algoritmo é de complexidade $O\left(n^{3}\right)$, pois na recorrência acima temos que no preenchimento de cada entrada $E[i][j]$ necessitamos computar $j-i$ somas de entradas da matriz. Desta forma, o número de operações para computar $E$ é proporcional a

$$
\sum_{i<j}(j-i)=\sum_{i=1}^{n-1} \sum_{j=i+1}^{n}(j-i)=O\left(n^{3}\right) .
$$

Uma vez calculado $E[1][n]$, a computação (identificação) do dobramento de energia mínima $S_{1, n}$ é feita através do algoritmo recursivo, cujo código, em nossa implementação, corresponde à função identifica_pares(), como segue. Ela recebe a matriz $E$ preenchida e dois inteiros, os quais, na sua primeira chamada, correspondem à primeira e à última posições da seqüência e devolve o conjunto de pares do dobramento.

8 〈Identificação de pares do dobramento (Algoritmo traceback) 8) $\equiv$ void identifica_pares(int $i$, int $j$ ) 


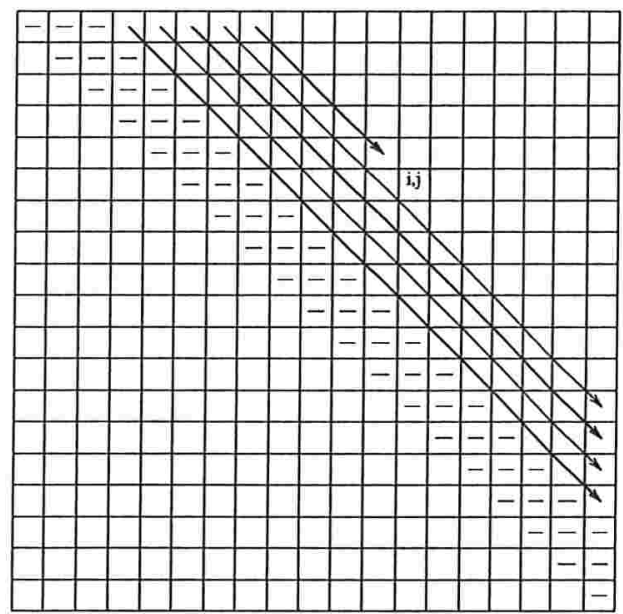

Figura 3.1: Ordem de preenchimento das entradas da matriz de programação dinâmica $E$.

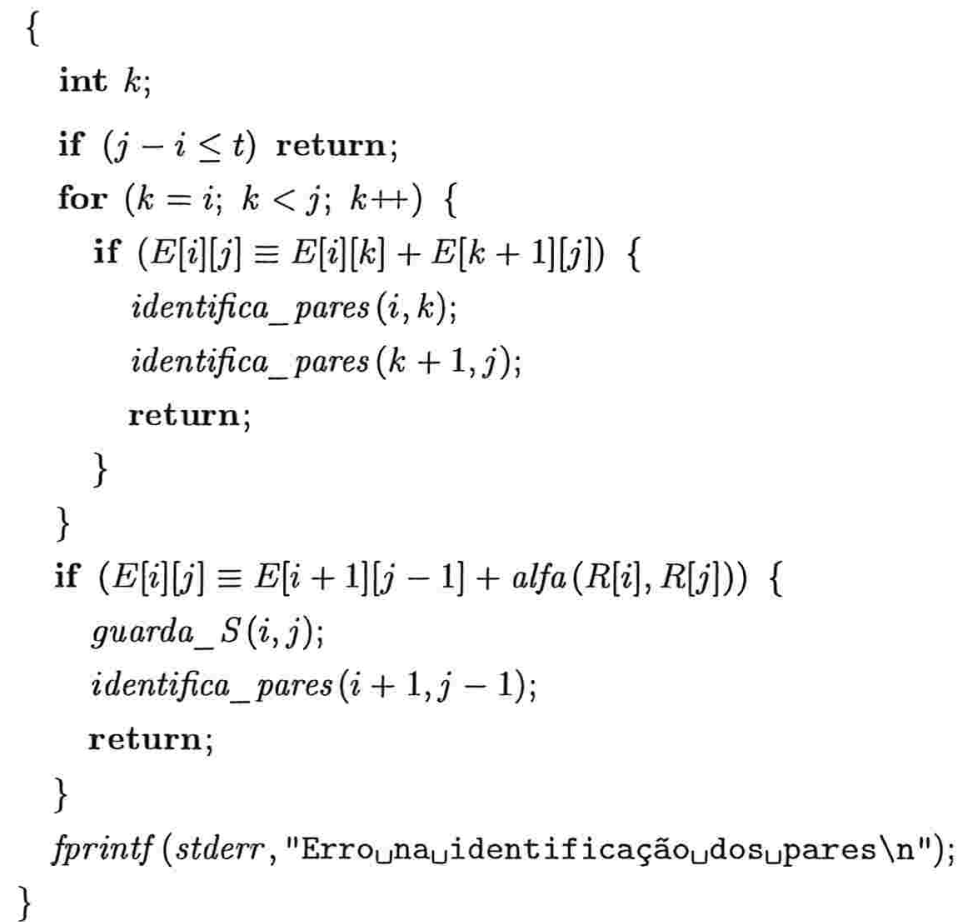

Este código é citado no bloco 3 .

Este código é usado no bloco 36 . 


\subsection{Incorporação de Laços}

Infelizmente, a abordagem acima é insuficiente para capturar e representar algumas situações que concretamente ocorrem na definição das estruturas secundárias, pois não leva em consideração a influência que a energia de um par de bases exerce sobre outro, notadamente os pares adjacentes; tampouco contabiliza as energias associadas a estruturas denominadas laços, definidas anteriormente. A Figura 2.8 ilustra vários tipos de laços.

A formulação que segue está baseada nos trabalhos de Zuker et al [ZS84], Sankoff [San85], Waterman e Smith [WS86] e Zuker e Turner [ZT99], cuja idéia básica foi primeiro apresentada (de forma independente) por Waterman e Smith [WS78] e Nussinov et al [NPGK78] e leva a um algoritmo de complexidade $O\left(n^{4}\right)$. A notação aqui utilizada para esta formulação é uma adaptação das apresentadas em [ZS84], [WS86], [San85] e [ZT99].

O Lema 2.2.1 nos diz que uma estrutura secundária $S$ induz uma decomposição de $R$ em uma coleção de laços disjuntos $L a c ̧ o_{1}, L a c ̧ o_{2}, \ldots, L a c ̧ o_{m}$, onde $m>0$, se e somente se, $S \neq \emptyset$. Energias são atribuídas aos $k$-laços e a energia da estrutura $S$ passa a ser escrita como

$$
\operatorname{Energia}(S)=\sum_{i=1}^{m} \varepsilon\left(\operatorname{Laço}_{i}\right) \text {, }
$$

onde $\varepsilon$ é uma função que fornece a energia de um $k$-laço $L a c ̧ o_{i}$.

Para atribuir energias aos seis tipos de laços, são definidas as seguintes funções (melhor caracterizadas adiante):

- $\varepsilon h(i, j)$ é a energia do laço arco fechado pelo par $(i, j)$;

- $\varepsilon i(i, j)$ é a energia mínima de um laço interno fechado por $(i, j)$;

- $\varepsilon b i(i, j)$ é a energia mínima de um laço barriga em $i$ fechado por $(i, j)$;

- $\varepsilon b j(i, j)$ é a energia mínima de um laço barriga em $j$ fechado por $(i, j)$;

- $\varepsilon s(i, j)$ é a energia de empilhamento de dois pares de bases adjacentes $(i, j)$ e $(i+1, j-1)$;

- $E m(i, j)$ é a energia mínima de um $k$-laço de tamanho $k^{\prime}$, com $k>2$ (multi-laço), fechado por $(i, j)$.

Novamente usamos a estratégia de programação dinâmica para resolver o problema. Segue a nova formulação. Seja a seqüência $R=r_{1}, r_{2}, \ldots, r_{n}$ para a qual desejamos encontrar a estrutura secundária $S_{1, n}$ de energia livre mínima. Consideremos a subseqüência $R_{i, j}=r_{i}, r_{i+1}, \ldots, r_{j}, 1 \leq i<j \leq n$, para a qual desejamos encontrar a estrutura secundária $S_{i, j}$ de energia livre mínima. Como na modelagem anterior, há quatro possibilidades a serem tratadas, diferenciando-se apenas na situação 4:

1. se $r_{i}$ não é base pareada em nenhuma estrutura de energia mínima, então $E\left(R_{i, j}\right)=E\left(R_{i+1, j}\right)$;

2. se $r_{j}$ não é base pareada em nenhuma estrutura de energia mínima, então $E\left(R_{i, j}\right)=E\left(R_{i, j-1}\right)$; 
3. se $r_{i}$ e $r_{j}$ são bases pareadas, mas não entre si, ou se não são pareadas, então $E\left(R_{i, j}\right)=$ $\min _{k}\left\{E\left(R_{i, k}\right)+E\left(R_{k+1, j}\right)\right\}$, para $i<k<j$;

4. se $(i, j) \in S$, então $E\left(R_{i, j}\right)=L\left(R_{i, j}\right)$, onde $L\left(R_{i, j}\right)$ corresponde à energia de uma das estruturas - a de menor energia - ilustradas na Figura 2.8.

Podemos então reescrever a descrição acima de modo similar à Expressão 3.2 :

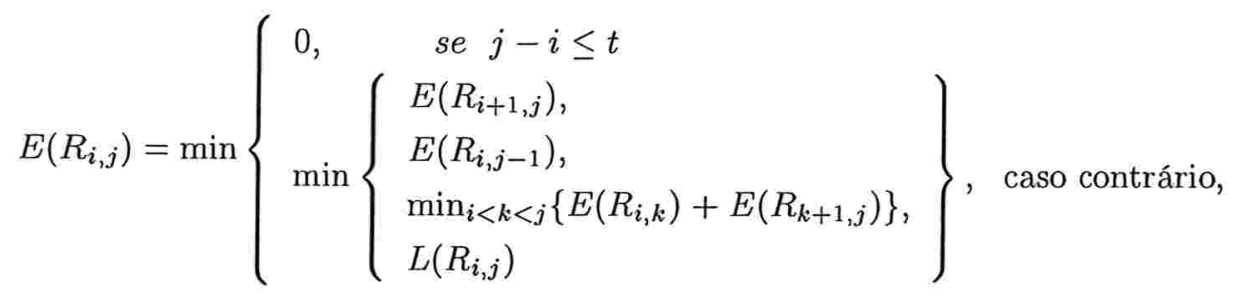

que pode ser simplificada para

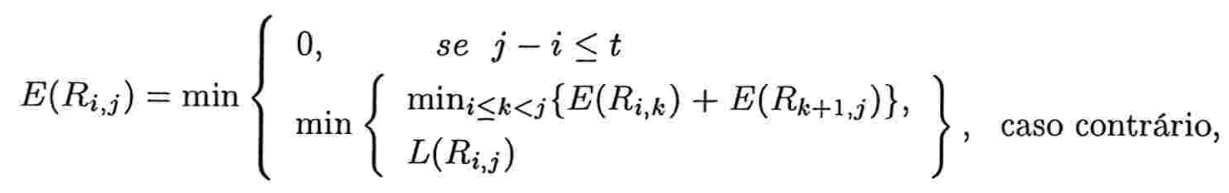

onde

$$
L\left(R_{i, j}\right)=\min \left\{\begin{array}{l}
\varepsilon h(i, j) \\
\varepsilon i(i, j) \\
\varepsilon b i(i, j) \\
\varepsilon b j(i, j) \\
\varepsilon s(i, j) \\
\varepsilon m(i, j)
\end{array}\right.
$$

A resolução da Expressão 3.6 é feita de forma similar ao feito em relação à Expressão 3.3; ou seja, tomando-a como uma relação de recorrência de programação dinâmica. Resolvemos esta recorrência através de um algoritmo iterativo o qual preenche matrizes de energias $E, L$ e $G$. A matriz $G$ entra no cálculo da energia $\varepsilon m(i, j)$ associada ao multilaço e seu uso é melhor descrito na Expressão 3.8 . A ordem com que as entradas destas matrizes são preenchidas é a mesma indicada na Figura 3.1. Somente a parte triangular superior de cada uma delas necessita ser preenchida, representada pelos pares $(i, j)$ tal que $i \leq j$.

Cada célula $E[i][j]$ armazena $E\left(R_{i, j}\right)$, isto é, a energia do dobramento de energia mínima sobre todos os dobramentos, para a subseqüência $R_{i, j}=r_{i}, r_{i+1}, \ldots, r_{j}$, independente se $i$ e $j$ formam ou não pares. Atribuímos $E[i][j] \leftarrow 0$ para valores iniciais $j-i \leq t$.

Cada célula $L[i][j]$ armazena $L\left(R_{i, j}\right)$; ou seja, a energia do dobramento de energia mínima, para a subseqüência $R_{i, j}=r_{i}, r_{i+1}, \ldots, r_{j}$, onde $i$ e $j$ formam um par de bases, isto é, onde $i$ e $j$ fecham um laço. Se $i$ e $j$ não paream então $L[i][j] \leftarrow \infty$. Atribuímos $L[i][j] \leftarrow \infty$ para valores iniciais $j-i \leq t$. A função que implementa a Expressão 3.7 está descrita em 〈Cálculo do laço de menor energia 40$\rangle$ no Apêndice A.2.1. 
Como veremos na Seção 3.2.3, para que consigamos atingir um algoritmo de complexidade de tempo $O\left(n^{4}\right)$, é necessário supor que a função de desestabilização para multi-laços seja linear. A matriz $G$ armazena energias que serão utilizadas para implementar esta suposição. Atribuímos $G[i][j] \leftarrow \infty$ para valores iniciais $j-i \leq t$.

Nomeada como calc_matriz_energia_dep_laços() e descrita em (Cálculo da matriz de energia (dependente de laços) 10 , a função que implementa a Expressão 3.6 tem como entrada uma string (que representa a molécula) e um inteiro que sinaliza se o cálculo da energia correspondente ao laço interno deve ser calculada de forma convencional ou otimizada. Fornece como saída as matrizes $E, L$ e $G$ preenchidas.

Durante sua execução ela opera sobre o vetor civil que auxilia na definição da contribuição energética relativa ao efeito dangling, que é melhor descrito na Seção 3.2.2. Além disto, ela opera também sobre uma matriz auxiliar, denominada rastro, que armazena - para cada par $(i, j)$ - informações relativas à situação energética do par; ou seja, se o par pareia ou não e, se sim, de que forma - isto é, que tipo de laço ele fecha. Estas informações serão utilizadas posteriormente pelos algoritmos traceback que identificarão o conjunto de pares do dobramento com base no "rastro" impresso em rastro.

$10\langle$ Cálculo da matriz de energia (dependente de laços) 10$\rangle \equiv$

〈matrizes que guardam parâmetros de energia 38)

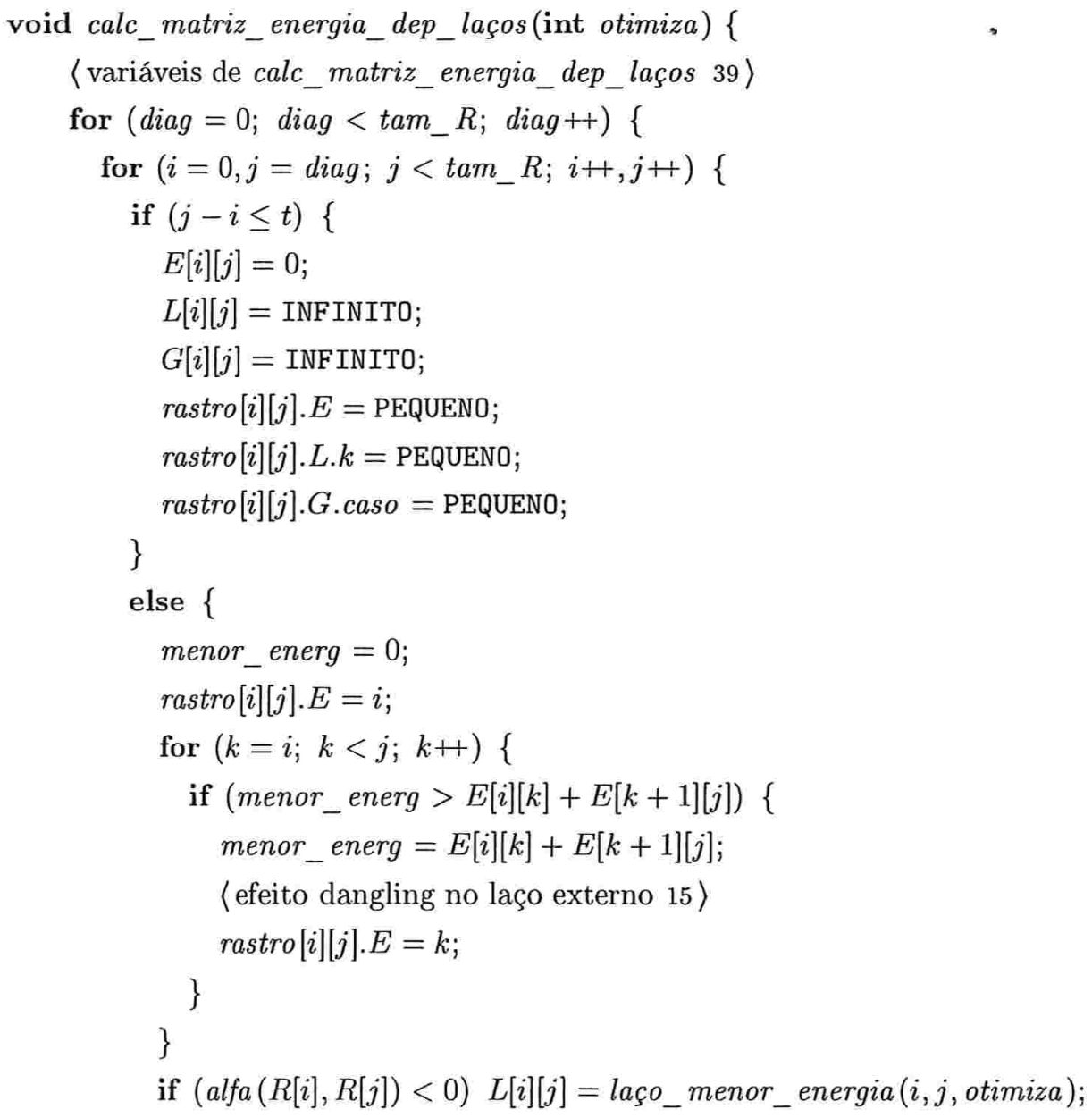




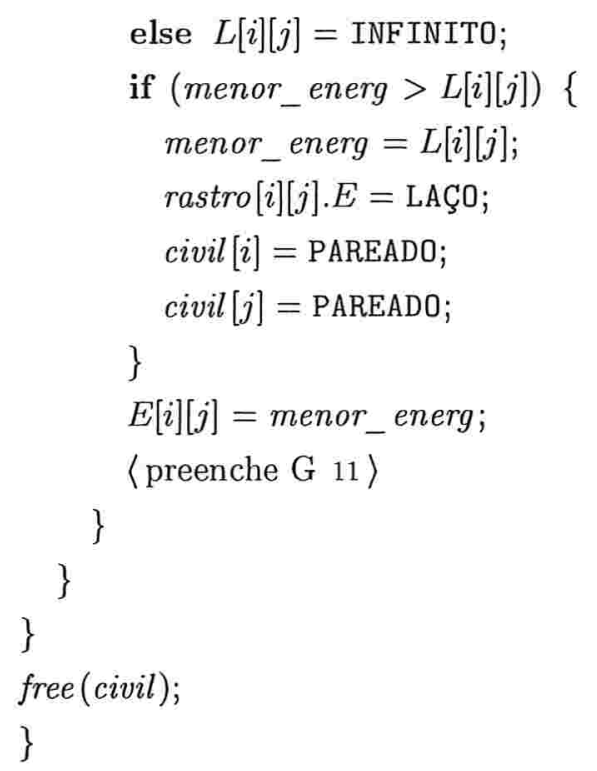

Este código é citado nos blocos 10, 11, 15 e 40.

Este código é usado no bloco 37 .

A estrutura secundária com energia total mínima é aquela com a menor energia dentre aquelas indicadas pelas quatro possibilidades representadas na Expressão 3.5, onde $L\left(R_{i, j}\right)$ é determinada pela adoção de funções obtidas experimentalmente, que são melhor descritas na Seção 3.2 .2 , a saber:

1. $\zeta(k)$ é definida como a energia de desestabilização de laço arco de tamanho $k$;

2. $\eta$ é definida como a energia de empilhamento de pares de bases adjacentes;

3. $\beta(k)$ é definida como a energia livre de desestabilização de uma barriga de tamanho $k$;

4. $\gamma(k)$ é definida como a energia livre de desestabilização de um laço interno de tamanho $k$.

De posse destas funções e das matrizes $L$ e $G$, podemos então caracterizar os cálculos associados a $L\left(R_{i, j}\right)$ para cada uma das configurações ilustradas na Figura 2.8, cuja opção correspondente pode ser vista na Expressão 3.7. Assim sendo,

- se $L_{i, j}$ é um laço arco, então

$$
L[i][j] \leftarrow L\left(R_{i, j}\right)=\varepsilon h(i, j)=\zeta(j-i-1) .
$$

O código que implementa esta expressão está em 〈Cálculo da energia de um laço arco 41 〉 no Apêndice A.2.2.

- se $L_{i, j}$ é uma região empilhada (ou hélice), então

$$
L[i][j] \leftarrow L\left(R_{i, j}\right)=\varepsilon s(i, j)=\eta+L[i+1][j-1] .
$$

O código que implementa esta expressão está em 〈Cálculo da energia de um empilhamento de pares de bases adjacente 42$\rangle$ no Apêndice A.2.3. 
- se $L_{i, j}$ é uma barriga em $i$, então

$$
L[i][j] \leftarrow L\left(R_{i, j}\right)=\varepsilon b i(i, j)=\min _{k \geq 1}\{\beta(k)+L[i+k+1][j-1]\} .
$$

O código que implementa esta expressão está em 〈Cálculo da energia de um laço barriga em i 43$)$ no Apêndice A.2.4.

- se $L_{i, j}$ é uma barriga em $j$, então

$$
L[i][j] \leftarrow L\left(R_{i, j}\right)=\varepsilon b j(i, j)=\min _{k \geq 1}\{\beta(k)+L[i+1][j-k-1]\} .
$$

O código que implementa esta expressão está em 〈Cálculo da energia de um laço barriga em j 44) no Apêndice A.2.5.

- se $L_{i, j}$ é um laço interno, então

$$
L[i][j] \leftarrow L\left(R_{i, j}\right)=\varepsilon i(i, j)=\min _{k_{1}, k_{2} \geq 1}\left\{\gamma\left(k_{1}+k_{2}\right)+L\left[i+1+k_{1}\right]\left[j-1-k_{2}\right]\right\} .
$$

O código que implementa esta expressão está em 〈Cálculo da energia de um laço interno 45 ) no Apêndice A.2.6.

- se $L_{i, j}$ é um multilaço, então

$$
L[i][j] \leftarrow L\left(R_{i, j}\right)=\varepsilon m(i, j)=\min _{i<k<j-1}\{G[i+1][k]+G[k+1][j-1]+a\} .
$$

O código que implementa esta expressão está em 〈Cálculo da energia de um multilaço 47 〉 no Apêndice A.2.7, onde

$$
G[i][j]=\min \left\{\begin{array}{l}
L[i][j]+b \\
\min _{i<h<j} \min \left\{\begin{array}{l}
G[i][h]+(j-h) \times c \\
G[i][h]+G[h+1][j] \\
(h-i+1) \times c+G[h+1][j],
\end{array}\right.
\end{array}\right.
$$

sendo que $a, b$ e $c$ são constantes onde $a$ representa a contribuição do par de fechamento $(i, j)$ do multi-laço, $b$ a contribuição de cada par acessível a $(i, j)$ e $c$ a contribuição de cada base não pareada acessível a $(i, j)$.

Com relação à matriz $G$, é importante lembrarmos que ela é utilizada para implementarmos a suposição de que a função de desestabilização para multilaços é linear no número de bases não pareadas acessíveis e no número de pares de bases acessíveis ao multilaço em questão. Em outras palavras, supondo $k^{\prime}$ o número de bases não pareadas acessíveis ao multilaço e $k$ o número de pares de bases acessiveis ao multilaço, temos que

$$
\varepsilon m(i, j)=a+(k-1) \times b+k^{\prime} \times c .
$$

Na Seção 3.2.3 é desenvolvida uma argumentação atravês da qual mostramos porque é adotada a referida suposição de linearidade. O trecho de código através do qual preenchemos a matriz $G$, conforme a Expressão 3.8, é invocado em 〈Cálculo da matriz de energia (dependente de laços) 10), nesta seção, e é descrito a seguir. 
$11\langle$ preenche G 11$\rangle \equiv$

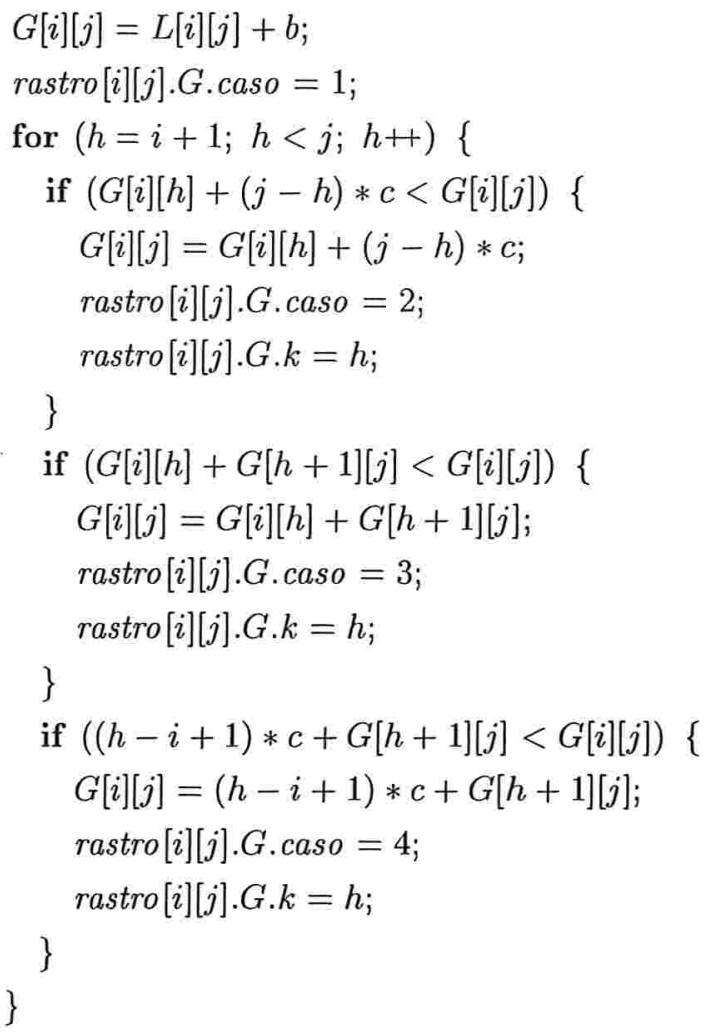

Este código é usado no bloco 10.

\subsubsection{Fase traceback}

A computação (identificação) do dobramento de energia mínima $S_{1, n}$ é feita através de algoritmos recursivos mostrados nos blocos abaixo. Estes algoritmos fazem uso de uma matriz auxiliar - denominada rastro - que armazena, para cada par $(i, j)$, informações acerca de como o algoritmo de programação dinâmica preencheu as matrizes $E, L$ e $G$. A idéia geral desta fase é fazer o "caminho de volta" nesta matriz de modo a "reconstituir" o caminho seguido no preenchimento das matrizes de energia.

A função traceback_E() recebe como entrada dois inteiros que correspondem, na sua primeira chamada, à primeira e à última bases da seqüência. A partir desta primeira chamada, o bloco 〈 traceback em L 13) é invocado, se há fechamento de um laço.

$12\langle$ traceback em E 12$\rangle \equiv$ void traceback_E(int $i$, int $j)$

\{

if $($ rastro $[i][j] . E \equiv$ PEQUENO) $\quad / * \mathrm{j}-\mathrm{i}<=\mathrm{t} * /$

return;

if (rastro $[i][j] . E \equiv \mathrm{LAÇO})\{\quad / *$ i e j fecham um laço $* /$ traceback_L(i,j); 


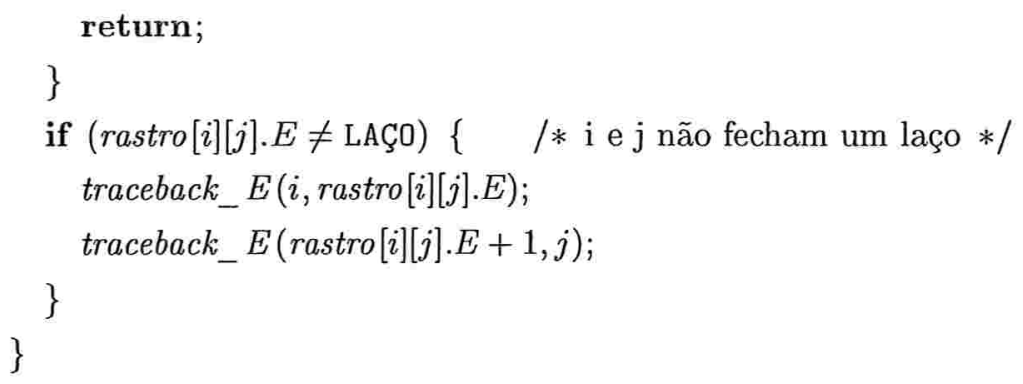

Este código é usado no bloco 37 .

Na função traceback_L() o algoritmo correspondente ao bloco 〈traceback em G 14〉 é invocado, se o laço formado é um multilaço.

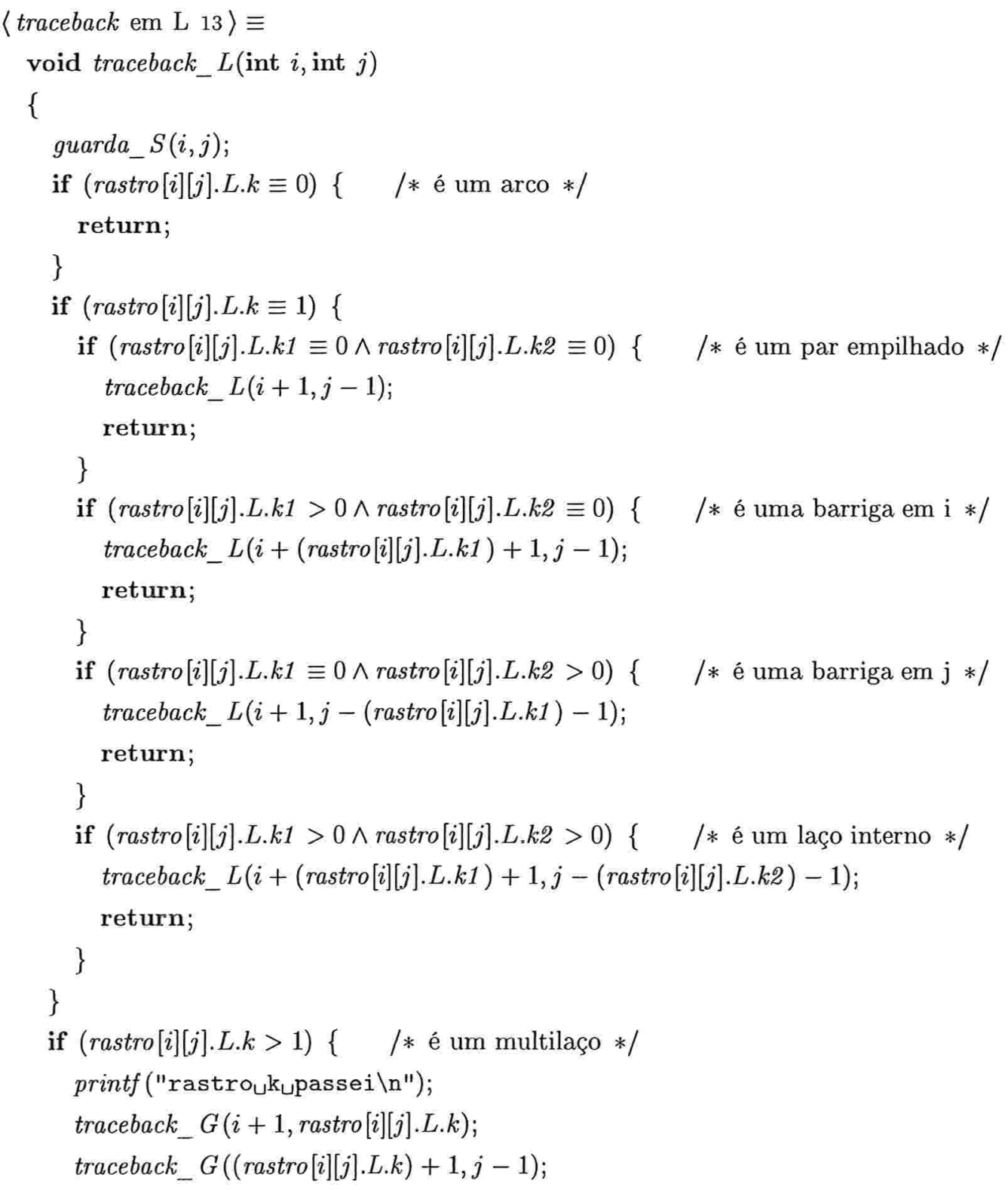




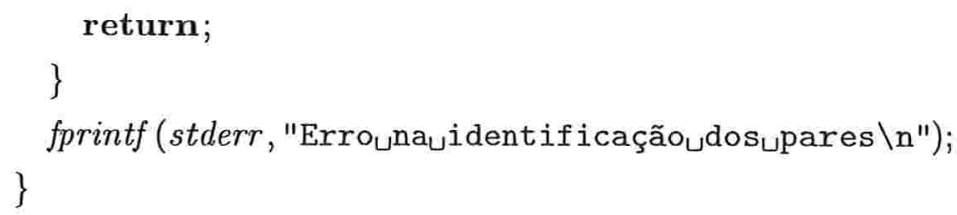

Finalmente, a função que verifica o multilaço é como segue.

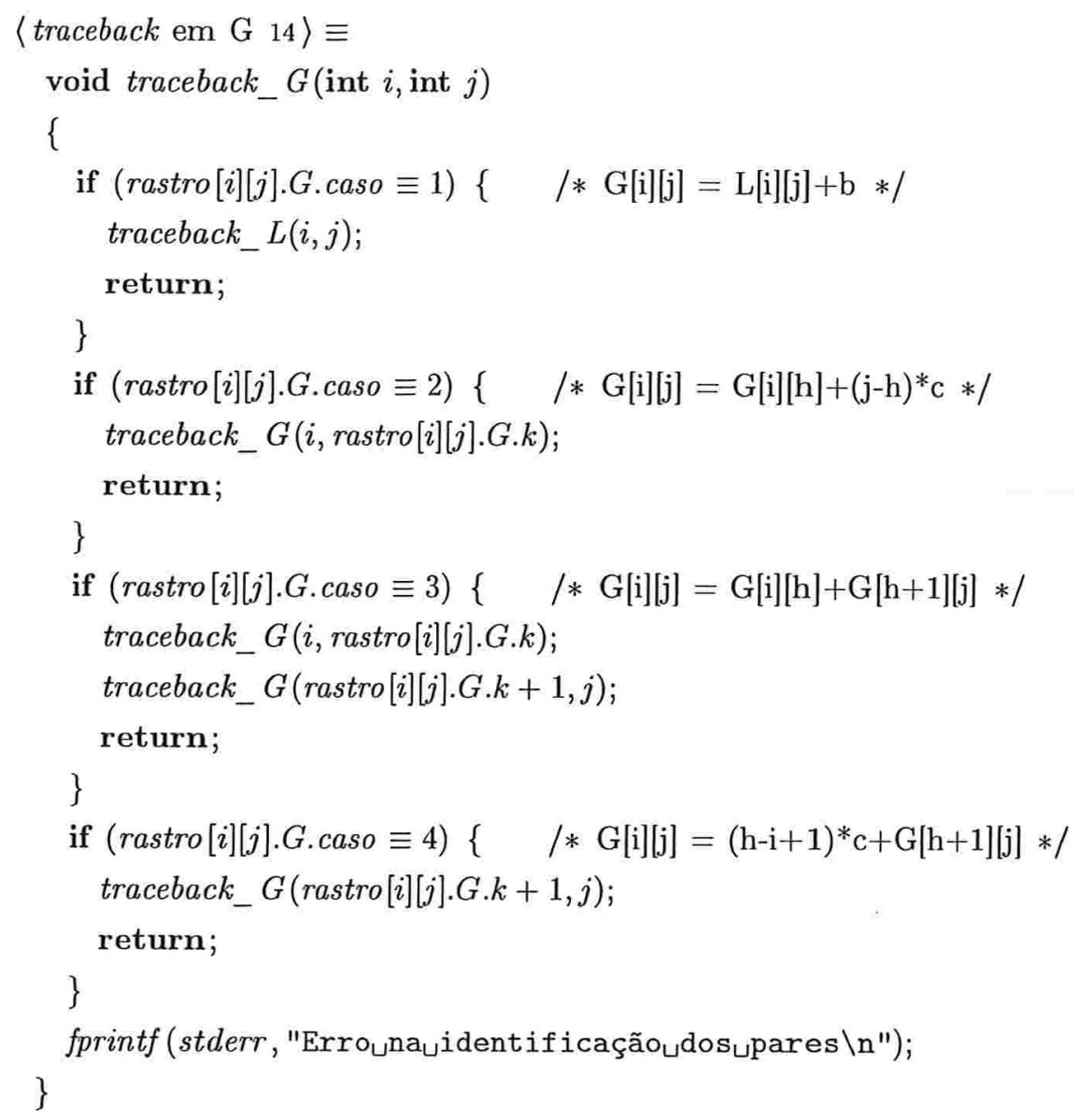

\subsubsection{Parâmetros de Energia}

Vamos agora então melhor caracterizar as funções experimentais que fornecem as energias associadas aos vários tipos de laços. Nas descrições que seguem referenciamos alguns nomes de arquivos que estão parcialmente reproduzidos no Apêndice B. Estes "pedaços" de arquivos (tabelas) têm como finalidade 
ilustrar ao leitor a organização adotada para estes dados (parâmetros). Se o leitor desejar, pode encontrar cópias completas dos referidos arquivos em http : //www.ime.usp.br/dcc/posgrad/teses/rozante/.

Para o laço de tamanho $k$ a função $\zeta$ é assim definida: $\zeta(k)=E h 1+E h 2+E h 3+E h 4$. O trecho de código onde esta definição é implementada está em 〈Cálculo da energia de um laço arco 41) no Apêndice A.2.2. Os parâmetros $E h 1, E h 2, E h 3$ e $E h 4$ são assim descritos:

- Eh1: contribuição energética puramente entrópica, que depende do tamanho do laço. O cálculo desta energia livre mínima está baseado na expressão $1.75 \times R \times T \times \ln (k)$, que vem da teoria dos polímeros [ZT99], onde onde $\mathrm{R}$ é a constante universal dos gases, $\mathrm{T}$ é a temperatura absoluta e $k$ é o número de bases não pareadas acessíveis ao arco. Para $t \leq k \leq 30$, usamos medidas e interpolações de medidas experimentais previamente calculadas e armazenadas no arquivo loop.dg. Para tamanhos maiores do que 30 um termo extra $1.75 \times R \times T \times \ln (k / 30)$ é adicionado. Os valores de $E h 1$ são lidos no bloco 〈Leitura de loop.dg 71 〉.

- Eh2: contribuição energética dos pares terminais não pareados mismatched. Existe uma interação energética entre o par de fechamento do laço (pode ser um arco ou um laço interno) e o par não pareado adjacente, denominado par terminal não pareado (do inglês terminal mismatched pairs). Esta energia é denominada energia livre não pareada terminal ou energia de empilhamento terminal para laços arco ou laços interno. Os valores de Eh2 são lidos no bloco 〈Leitura de tstackh.dg 73〉.

- Eh3: bônus energético de triloops (para arcos de tamanho 3) ou tetraloops (para arcos de tamanho 4). Este bônus deve-se ao fato de que é observado experimentalmente que para arcos pequenos valem regras de atribuição energéticas específicas. Os valores relativos aos tetraloops são lidos no bloco 〈Leitura de tetraloop.dg 77 〉. Os valores relativos aos triloops foram atribuídos diretamente em 〈Cálculo da energia de um laço arco 41 ).

- Eh4: bônus ou penalidades energéticas para casos especiais, por exemplo se $i$ e $j$ fecham um arco chamado "GGG" ou se o arco é um laço chamado "poli-C" - arco onde todas as bases não pareadas são citosinas ("C"). Os valores relativos a estes casos foram atribuídos diretamente em 〈Cálculo da energia de um laço arco 41 〉.

No Apêndice B estão alguns valores destes parâmetros adotados em nossa implementação. As tabelas loop.dg, tstackh.dg e tetraloop.dg contêm valores para $E h 1, E h 2$ e $E h 3$, respectivamente. Uma descrição sucinta destes arquivos também pode ser vista no Apêndice A.6.

A definição da função $\eta$ leva em consideração apenas o tipo de par que fecha o laço (hélice) e o tipo de par que é empilhado: pares de fechamento C-G e A-U proporcionam contribuições energéticas mais significativas do que o par de fechamento G-U, por exemplo. Confira em stack.dg no Apêndice B alguns dos valores deste parâmetro que foram adotados em nossa implementação. Veja também no Apêndice A.6 uma descrição sucinta deste arquivo, assim como a função de leitura correspondente. Em 〈Cálculo da energia de um empilhamento de pares de bases adjacente 42〉 no Apêndice A.2.3 está descrito o código referente à implementação de $\eta$. 
A definição da função $\beta$ leva em consideração basicamente a contribuição energética entrópica, ou seja, que depende do tamanho do laço. Da mesma forma como no cálculo de $\zeta$, para barrigas de tamanho até 30 usamos a expressão $1.75 \times R \times T \times \ln (k)$. Quando a barriga tem tamanho 1 , uma energia de empilhamento $\eta$ é adicionada à definição de $\beta$. Para tamanhos maiores do que 30 um termo extra $1.75 \times R \times T \times \ln (k / 30)$ é adicionado, onde $\mathrm{R}$ é a constante universal dos gases, $\mathrm{T}$ é a temperatura absoluta e $k$ é tamanho do laço. Confira em loop.dg no Apêndice B alguns dos valores deste parâmetro que foram adotados em nossa implementação. Veja também no Apêndice A.6 uma descrição sucinta deste arquivo, assim como as funções de leitura correspondente. Nos blocos 〈Cálculo da energia de um laço barriga em i 43〉 e 〈Cálculo da energia de um laço barriga em j 44〉, nos Apêndices A.2.4 e A.2.5, respectivamente, estão descritos os códigos que implementam a definição de $\beta$.

No laço interno de tamanho $k$ a função $\gamma$ é assim definida: $\gamma(k)=E i 1+E i 2+E i 3+E i 4$. O trecho de código onde esta definição é implementada está em 〈Cálculo da energia de um laço interno 45〉 no Apêndice A.2.6. Os parâmetros Ei1, Ei2, Ei3 e Ei4 são assim descritos:

- Ei1: exatamente igual ao cálculo da contribuição energética que depende do tamanho do laço quando se calcula $\zeta$, ou seja, Ei1 é calculado da mesma forma que Eh1.

- Ei2: contribuição energética do par terminal não pareado mismatched adjacente ao par de fechamento do laço.

- Ei3: contribuição energética do par terminal não pareado mismatched adjacente ao par acessível ao par fechamento do laço.

- Ei4: é uma penalidade atribuída a um laço interior caso ele seja assimétrico. Dado um laço interior $L a c ̧ o_{i}$, fechado por $(i, j)$ com $\left(i^{\prime}, j^{\prime}\right)$ acessível a $L a c ̧ o_{i}$. Dizemos que Laço $_{i}$ é assimétrico quando

$$
\left|\left(i^{\prime}-i\right)-\left(j-j^{\prime}\right)\right|>0
$$

Quando um laço interior é simétrico ele recebe penalidade 0.

Papanicolaou et al [PGN84] propuseram uma função para a assimetria, também adotada no algoritmo de Lyngsø e de Waterman descrito adiante, que é da forma

$$
\operatorname{assimetria}\left(k_{1}, k_{2}\right)=\min \{K, n \times f(m)\}
$$

onde $n=\left|k_{1}-k_{2}\right|$ e $m=\min \left\{k_{1}, k_{2}, c\right\}$. As constantes $K, c$ e a função $f$ são assim definidas: $c=5, K=6, f(1)=0.7 ; f(2)=0.6 ; f(3)=0.4 ; f(4)=0.2$ e $f(5)=0.1$. Peritz et al [PKST91] redefiniram a constante $c$ como sendo $c=1$. Em nossa implementação utilizamos a versão de Peritz para $c$.

Os valores para Ei2 e Ei3 são lidos em (Leitura de tstacki.dg 74). Confira em tstacki.dg, no Apêndice B, alguns dos valores deste parâmetro que foram adotados em nossa implementação. Uma descrição sucinta deste arquivo pode ser vista no Apêndice A.6.

Em termos práticos, esta definição de $\gamma$ só vale para laços internos maiores do que 4 ou de assimetria maior do que 1 . Isto porque existem regras especiais para laços internos do tipo $1 \times 1,1 \times 2$ e $2 \times 2$. 


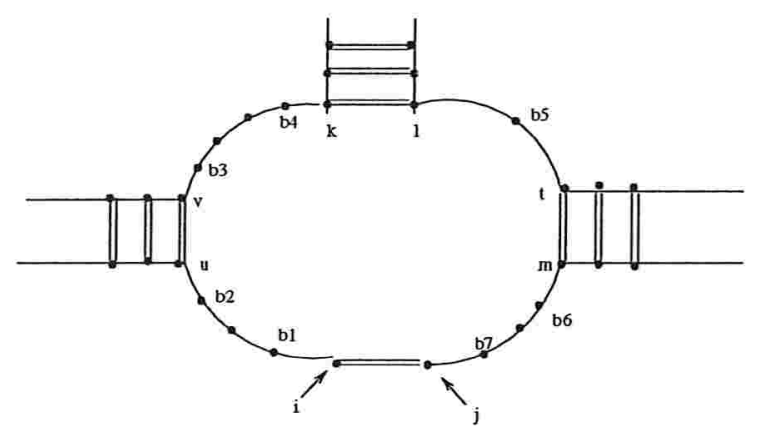

Figura 3.2: Efeito dangling.

Alguns dos valores, obtidos experimentalmente, que expressam estas especificidades podem ser vistos em sint2.dg, asint1×2.dg e sint4.dg no Apêndice B. As funções que fazem a leitura dos arquivos que contêm estes valores estão, bem como uma descrição sucinta de cada um deles, no Apêndice A.6, que são invocadas em 〈Cálculo da energia de um laço interno 45 〉.

Além das contribuições energéticas descritas acima, consideramos também o efeito energético relativo a bases não pareadas, pertencentes ao laço externo e/ou aos multilaços, que são adjacentes aos pares acessiveis destes laços. Por exemplo, na Figura 3.2 as bases $b 1, b 2, b 3, b 4, b 5, b 6$ e $b 7$ proporcionam um bônus energético por serem adjacentes aos pares $(i, j),(u, v),(k, l)$ e $(t, m)$, supondo que $(i, j)$ fecha um multilaço ou o laço externo.

Este efeito é denominado efeito oscilatório (do inglês dangling) e seu valor energético depende do par ao qual a base não pareadada é adjacente, da base que "oscila" (A, C, G ou U) e da extremidade da molécula à qual esta base mais se aproxima, isto é, 5 ' ou 3'. Por exemplo, supondo que as bases $b 2$ e $b 3$ da Figura 3.2 sejam as mesmas, elas podem proporcionar contribuições energéticas diferentes, embora sejam adjacentes ao mesmo par de bases. No caso da base $b 5$ sua contribuição é contada apenas para uma vizinhança, no caso aquela de menor energia - geralmente a mais próxima à extremidade 3'.

O código que corresponde à implementação desta contribuição energética em multilaços, está presente em 〈Cálculo da energia de um multilaço 47 . Por sua vez, a mesma contribuição energética no laço externo é expresso pelo bloco abaixo. Este bloco é invocado em 〈Cálculo da matriz de energia (dependente de laços) 10$\rangle$. As tabelas que mostram alguns dos valores obtidos experimentalmente para o efeito dangling são lidos nos arquivos dangle3.dg e dangle5.dg e podem ser vistos nas Seções B.6 e B.7. Descrições destes arquivos e funções de leitura correspondente podem ser vistas no Apêndice A.6.

$15\langle$ efeito dangling no laço externo 15$\rangle \equiv$

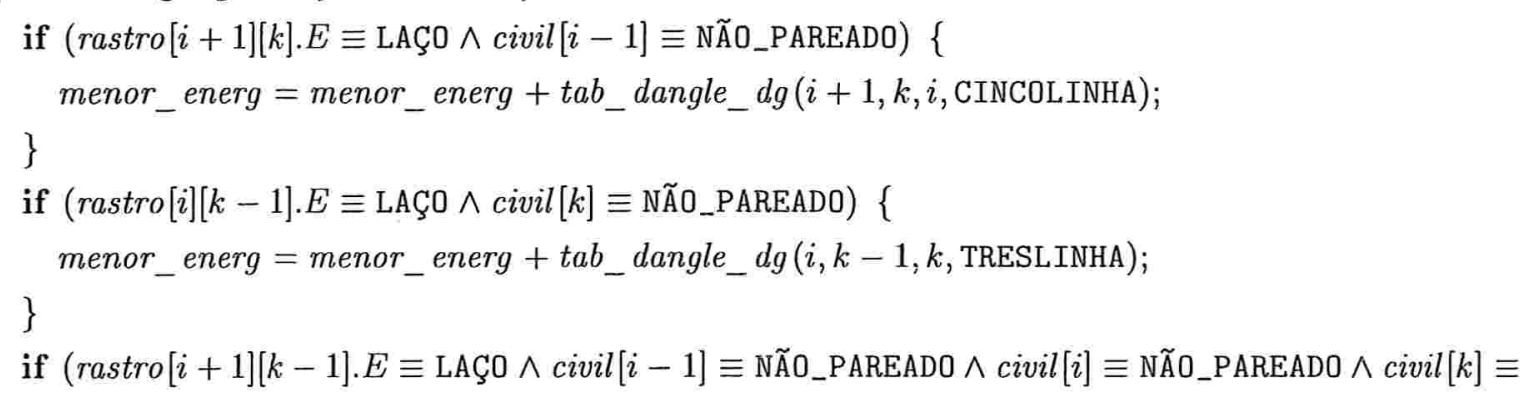




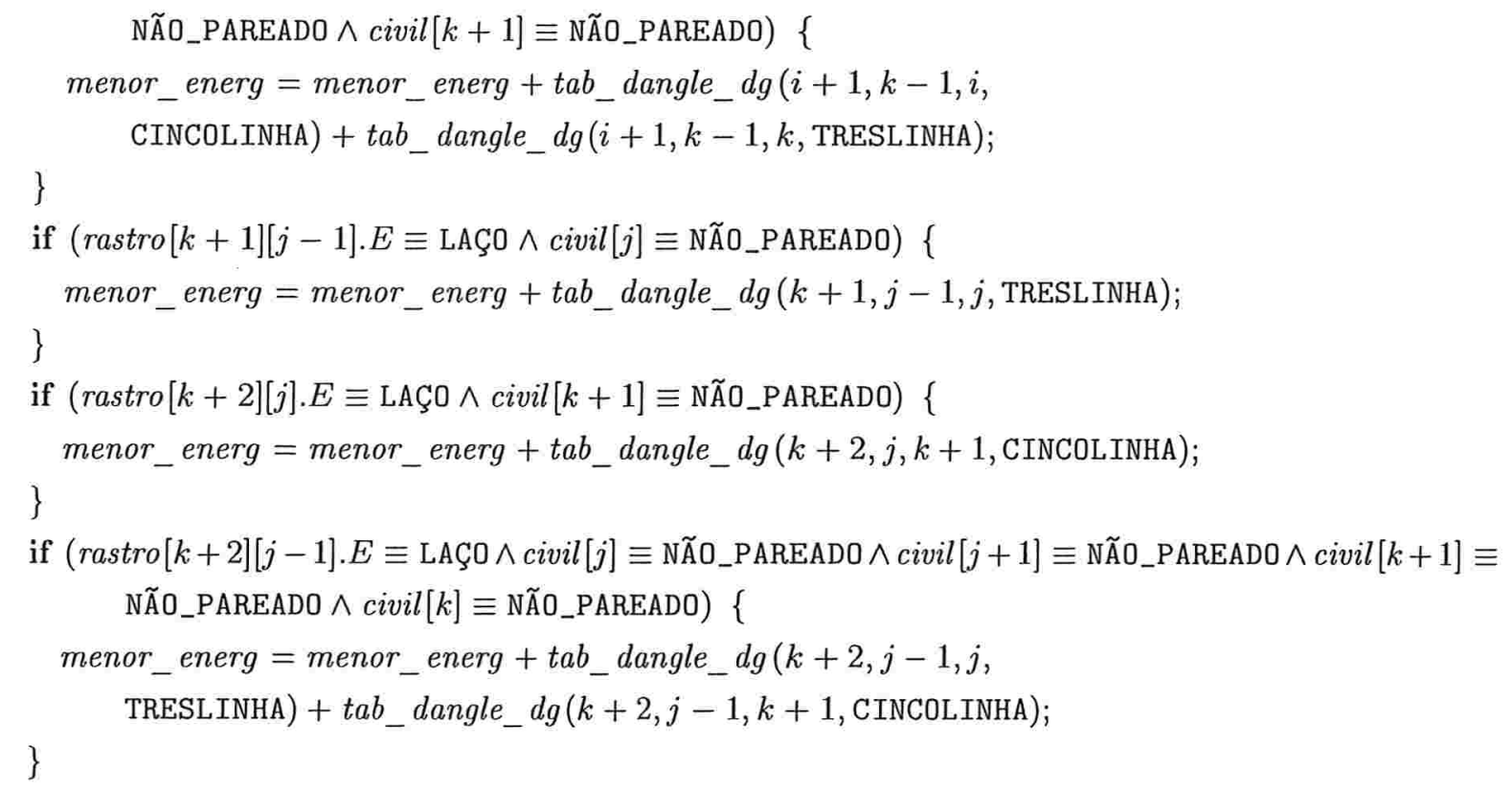

Este código é usado no bloco 10.

É interessante observar que os parâmetros de energia variam levemente, dependendo da fonte adotada. Outro fato que vale observar, relacionado aos parâmetros de energia, é a freqüente incorporação de novos casos especiais que surgem à medida em que avança o conhecimento sobre as propriedades físico-químicas dos ácidos nucléicos. Estes novos casos são freqüentemente detectáveis em pequenos laços. Nos pacotes de sofwtares aos quais tivemos acesso (Viena e mfold), observamos estas diferenças.

\subsubsection{Complexidade}

Para estimar a complexidade de tempo do algoritmo de programação dinâmica descrito implicitamente acima é interessante que olhemos para o cálculo de energia de cada um dos possíveis laços separadamente, cujo número de operações é proporcional a:

- laços grampo e regiões empilhadas:

$$
\sum_{1 \leqslant i \leqslant j \leqslant n} 1=O\left(n^{2}\right)
$$

- laços barriga em $i$ e barriga em $j$ :

$$
\sum_{1 \leqslant i \leqslant j \leqslant n}(j-i)=\sum_{i=1}^{n} \sum_{j=i}^{n}(j-i)=\sum_{i=1}^{n}=O\left(n^{3}\right)
$$

- laços interiores:

$$
\sum_{1 \leqslant i \leqslant j \leqslant n}\left(\sum_{i \leqslant i^{\prime} \leqslant j^{\prime} \leqslant j} 1\right) \leqslant \sum_{1 \leqslant i \leqslant j \leqslant n} C \cdot(j-i)^{2}=O\left(n^{4}\right)
$$


- multi-laços:

Devido ao cálculo de $\varepsilon m(i, j)$ o algoritmo deveria calcular todos os possíveis $k$-laços; ou seja, o algoritmo deveria examinar todas as $2 k$-tuplas da forma

$$
i<i_{1}^{\prime}<j_{1}^{\prime}<\cdots<i_{k-1}^{\prime}<j_{k-1}^{\prime}<j
$$

Como temos $O\left(n^{2}\right)$ pares $(i, j)$ tal que $i<j$ a considerar, então isto requer tempo $O\left(n^{2 k}\right)$. Visto que $k$ cresce linearmente com $n$, então o algoritmo consome tempo exponencial, o que o torna impraticável. Gotoh [Got82] mostrou que é possível reduzir a complexidade de tempo em alinhamento de seqüências através da adoção de funções de penalização afins (lineares). A mesma idéia pode ser usada para melhorar o tempo de multi-laços. A suposição que se faz é que a função de energia para um multilaço $\varepsilon m$ é linear no número de bases não pareadas $k^{\prime}$ e no número de pares de bases acessíveis $k$ ao laço. Especificamente:

$$
\varepsilon m(i, j)=a+(k-1) \times b+k^{\prime} \times c,
$$

onde $a, b$ e $c$ são constantes não negativas que fornecem a contribuição do par $(i, j)$, dos $(k-1)$ pares de bases acessiveis a $(i, j)$ e das $k^{\prime}$ bases não pareadas acessiveis a $(i, j)$, respectivamente. Esta suposição de linearidade é implementada através de uma matriz auxiliar $G$ (veja Expressão 3.8) e leva a um algoritmo que consome tempo $O\left(n^{3}\right)$. 


\subsection{Melhoria da Eficiência em Laços Internos}

Como vimos anteriormente, os laços internos são as estruturas que dominam assintoticamente no algoritmo geral apresentado na seção anterior. A partir deste fato, esforços foram empreendidos a fim de melhorar a complexidade do algoritmo como um todo por meio da melhoria da complexidade dos laços internos. Os algoritmos descritos abaixo representam importantes resultados obtidos neste sentido.

Uma forma mais direta e simples de se obter melhoria de desempenho no cálculo de laços internos é através da limitação do tamanho do laço; ou seja, é necessário assumirmos que apenas laços internos "pequenos" ocorrem - por exemplo 30, como sugerido por Hofacker et al [HFS+94].

A partir desta suposição podemos então reescrever a expressão associada ao cálculo da energia do laço interno como

$$
\min _{\substack{k_{1}, k_{2} \geq 1 \\ k_{1}+k_{2} \leq \text { máximo }}}\left\{\gamma\left(k_{1}+k_{2}\right)+L\left[i+1+k_{1}, j-1-k_{2}\right]\right\},
$$

onde máximo corresponde ao maior tamanho permitido para o laço interno.

Esta abordagem leva a um algoritmo que consome tempo $O(n)$ no cálculo do laço interno, de modo que o algoritmo geral passa a consumir tempo $O\left(n^{3}\right)$. No entanto, infelizmente a suposição acima não é realista, pois observa-se a existência de laços internos grandes e estáveis, especialmente quando o dobramento é realizado a temperaturas mais elevadas [LZP99].

\subsubsection{Algoritmo de Waterman e Smith}

Assumindo que a estabilidade de um laço interno depende apenas do seu tamanho, Waterman e Smith [WS86] mostraram como reduzir o tempo de computação do algoritmo geral para $O\left(n^{3}\right)$.

Lembremos que o cálculo da energia livre mínima associada a um laço interno é dado por

$$
\varepsilon i(i, j)=\min _{k_{1}, k_{2} \geq 1}\left\{\gamma\left(k_{1}+k_{2}\right)+L\left[i+1+k_{1}\right]\left[j-1-k_{2}\right]\right\} .
$$

Nesta expressão observamos que o parâmetro da função $\gamma$ obedece, para um dado par $(i, j)$, a restrição $j-i-2-t \geq k_{1}+k_{2} \geq 2$, onde $t$, lembremos, tipicamente $t=3$ ou $t=4$.

Para calcular a energia livre mínima do laço interno fechado pelo par $(i, j)$, os possíveis candidatos são as posições $\left(i^{\prime}, j^{\prime}\right)$ pertencentes a $P(i, j)$ tal que

$$
P(i, j)=\left\{\left(i^{\prime}, j^{\prime}\right) \mid j^{\prime}-i^{\prime}-1 \geq t, i^{\prime} \geq i+2, j-2 \geq j^{\prime}\right\} .
$$

A região da matriz de programação dinâmica que corresponde ao conjunto destes candidatos, está representada pelas entradas preenchidas com círculos na ilustração da Figura 3.3.

O tamanho do laço interno é dado por

$$
c=(j-i-1)-\left(j^{\prime}-i^{\prime}+1\right)=(j-i)-\left(j^{\prime}-i^{\prime}\right)-2 .
$$




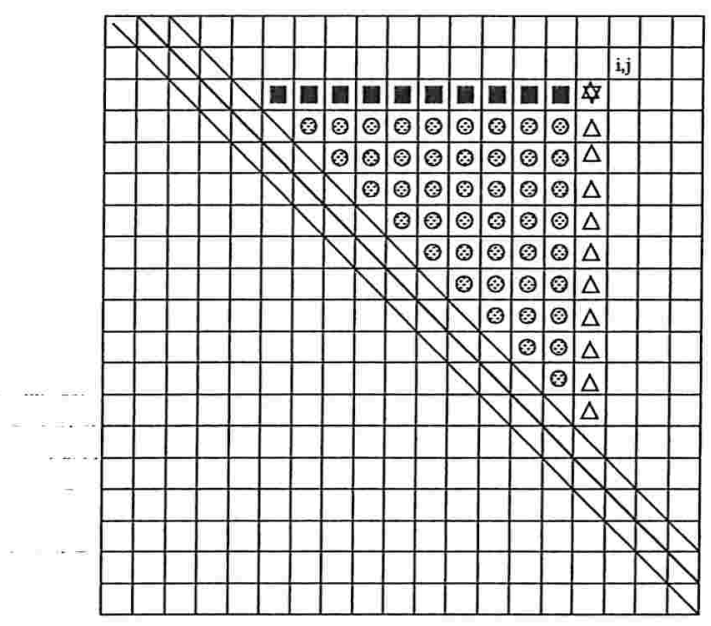

Figura 3.3: Entradas consideradas no cálculo da energia associada aos laços: interno = círculos, barriga em $j=$ quadrados, barriga em $i=$ triângulos e hélice $=$ estrela.

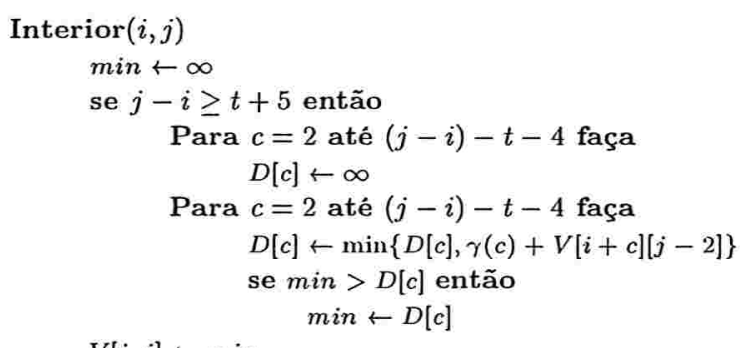

$V[i, j] \leftarrow \min$

Figura 3.4: Algoritmo para cálculo de laço interno conforme Waterman e Smith $\left(O\left(n^{3}\right)\right)$.

Esta equação implica, que ao longo das posições onde a expressão $j^{\prime}-i^{\prime}$ é constante, a função $\gamma(c)$, se supormos que $\gamma$ depende apenas do tamanho, também é constante. Isto quer dizer que em uma mesma diagonal o valor de $\gamma(c)$ se mantém constante, pois ao longo desta o valor $k_{1}+k_{2}$ é o mesmo. Podemos então realizar os cálculos de modo a explorar esta propriedade.

A idéia de como se realizar isto é armazenando, para cada par $(i, j)$, os valores

$$
D[c]=\min _{\left(i^{\prime}, j^{\prime}\right) \in P(i, j)}\left\{\gamma(c)+L\left(R_{i^{\prime}, j^{\prime}}\right) \mid c=(j-i)-\left(j^{\prime}-i^{\prime}\right)-2\right\}
$$

onde $2 \leq c \leq j-i-4-t$. Em outras palavras, armazenamos para cada par $(i, j)$ o valor mínimo da expressão

$$
\gamma\left(k_{1}+k_{2}\right)+L\left[i+1+k_{1}\right]\left[j-1-k_{2}\right]
$$

para toda diagonal considerada no cálculo de $L\left(R_{i, j}\right)$. Isto é feito armazenando o mínimo para toda coluna $c=k_{1}+k_{2}, 2 \leq c \leq(j-i)-t-4$. 
Daí podemos então calcular a energia livre associada ao laço interno por

$$
\min _{2 \leq c \leq(j-i)-t-4}\{\gamma(c)+D[c]\}
$$

Se mantivermos a mesma ordem de varredura das entradas da matriz de programação dinâmica indicada na Figura 3.1, podemos então apresentar o pseudo-código para este algoritmo como descrito na Figura 3.4.

A função nomeada como calc_energ_inter_cubico() implementa este algoritmo. Esta função recebe dois inteiros nas variáveis $i$ e $j$, os quais representam o par de fechamento do laço interno. Recebe também dois endereços ( $k 1 l i$ e $k 2 l i)$ de posições de memória nas quais serão gravados os valores de $k_{1}$ e $k_{2}$ que fornecem o valor mínimo para $\varepsilon i(i, j)$. Retorna, então, à função chamadora (laco_menor_energia()) descrita no bloco 〈Cálculo do laço de menor energia 40 〉 o valor da contribuição energética do laço interno fechado por $i$ e $j$ através da variável minimo.

$19\langle$ Cálculo, conforme Waterman e Smith, da energia de um laço interno 19$\rangle \equiv$

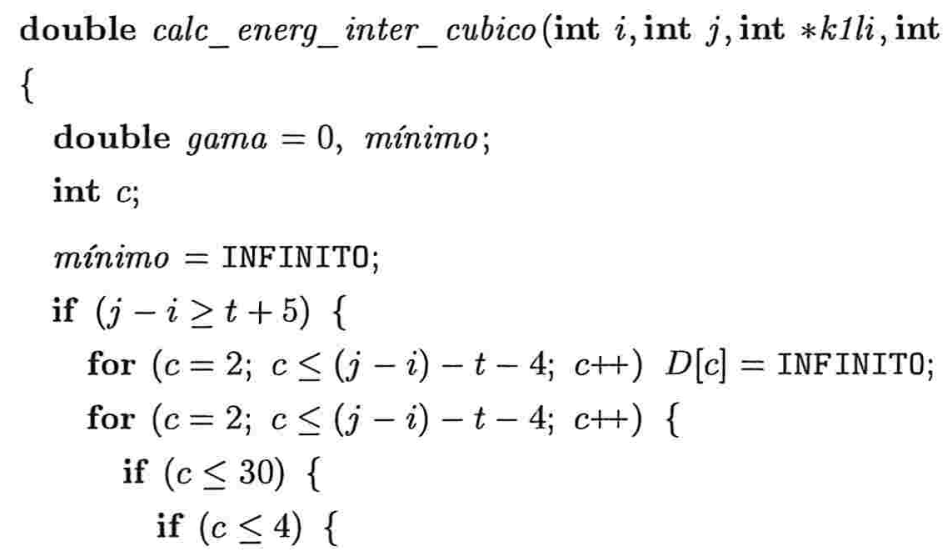

〈Casos especiais no cálculo do laço interno em Waterman e Smith 51)

\}

else \{

gama $=l o o p \_d g[c-1][0] ;$

\}

\}

else \{

$g a m a=1.75 * \operatorname{ERRE} * T * \log ((c-1) / 30)+l_{0 o p} d g[29][0] ;$

\}

if $(D[c]>g a m a+L[i+c][j-2])$

$D[c]=g a m a+L[i+c][j-2]$

if (minimo $>D[c])\{$

minimo $=D[c]$;

$* k 1 l i=c / 2$;

$* k 2 l i=c-* k 1 l i ;$

\}

\} 


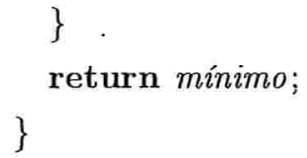

Este código é citado no bloco 51.

Este código é usado no bloco 37.

\subsubsection{Algoritmo de Lyngs $\emptyset$ e Zuker}

Como vimos na seção anterior, Waterman e Smith [WS86] apresentaram um algoritmo que calcula a energia associada aos laços internos em tempo $O(n)$, reduzindo, assim, o tempo do algoritmo geral para $O\left(n^{3}\right)$. Como vimos, eles assumem que esta energia depende apenas do tamanho do laço. No entanto, como descrevemos na Seção 3.2.2 o cálculo da energia associada ao laço interno fechado por $(i, j)$ e $\left(i^{\prime}, j^{\prime}\right)$ é determinado por quatro fatores:

- contribuição entrópica, que depende do tamanho do laço e que nesta seção denotaremos por $\operatorname{tamanho}(l)$, onde $l=i^{\prime}-i-1+j-j^{\prime}-1$;

- contribuição referente ao par terminal não pareado adjacente a $(i, j)$, denotada aqui por empilha $(i, j)$;

- contribuição referente ao par terminal não pareado adjacente a $\left(i^{\prime}, j^{\prime}\right)$, denotada aqui por empilha $\left(i^{\prime}, j^{\prime}\right)$;

- penalidade associada a assimetria do laço, que denotaremos aqui por assimetria $\left(i^{\prime}-i-1, j-\right.$ $\left.j^{\prime}-1\right)$.

Nesta seção descreveremos um algoritmo proposto por Lyngsø et al [LZP99] que executa o algoritmo geral em tempo $O\left(n^{3}\right)$ - otimizando o cálculo de laços internos para $O(n)$ - mas com a vantagem de incorporar todos os fatores acima.

A fim de simplificar a descrição, adotaremos uma matriz denotada por $L I$ para armazenar as energias associadas aos laços internos. Desta forma, a energia do laço interno fechado por $(i, j)$ e $\left(i^{\prime}, j^{\prime}\right)$ pode ser escrita como

$$
L I[i][j]=\min _{\substack{i<i^{\prime}<j^{\prime}<j \\ i^{\prime}-i+j-j^{\prime}-2 \geq 2}}\left\{L\left[i^{\prime}\right]\left[j^{\prime}\right]+e L\left(i, j, i^{\prime}, j^{\prime}\right)\right\}
$$

onde

$$
e L\left(i, j, i^{\prime}, j^{\prime}\right)=\left\{\begin{array}{l}
\operatorname{tamanho}\left(i^{\prime}-i+j-j^{\prime}-2\right)+ \\
\operatorname{empilha}(i, j)+ \\
\text { empilha }\left(i^{\prime}, j^{\prime}\right)+ \\
\text { assimetria }\left(i^{\prime}-i-1, j-j^{\prime}-1\right) .
\end{array}\right.
$$

Papanicolaou et al [PGN84] propuseram uma função para a assimetria, que adotamos na implementação tanto do algoritmo de Lyngsø e Zuker como na do algoritmo de Waterman e Smith, que é da forma

$$
\operatorname{assimetria}(n 1, n 2)=\min \{K, n \times f(m)\},
$$


onde $n=|n 1-n 2|$ e $m=\min \{n 1, n 2, c\}$. As constantes $K, c$ e a função $f$ são assim definidas: $c=5$, $K=6, f(1)=0.7 ; f(2)=0.6 ; f(3)=0.4 ; f(4)=0.2$ e $f(5)=0.1$. Peritz et al [PKST91] redefiniram a constante $c$ como sendo $c=1$. Em nossa implementação utilizamos a versão de Peritz para $c$. $O$ código desta função pode ser visto no bloco 〈Calcula penalidade de assimetria segundo Ninio 54 〉.

Lyngsø et al [LZP99] observaram que a função assimetria() pode ser dividida em dois termos:

$$
\operatorname{assimetria}(n 1, n 2)=\text { desbalanço }(n 1, n 2)+\operatorname{tamanho}^{\prime}(n 1+n 2),
$$

onde desbalanço $(n 1, n 2)=|n 1-n 2|$ e tamanho'() representa a influência que o tamanho do laço (indicado pelo valor $n 1+n 2$ ) exerce sobre a função assimetria().

Se definirmos $g(n 1+n 2)=\operatorname{tamanho}(n 1+1+n 2+1)-\operatorname{tamanho}^{\prime}(n 1+n 2)$ e observarmos que desbalanço $(n 1+1, n 2+1)=$ desbalanço $(n 1, n 2)$, então

$$
\begin{aligned}
\operatorname{assimetria}(n 1+1, n 2+1) & =\text { desbalanço }(n 1+1, n 2+1)+\operatorname{tamanho}(n 1+1+n 2+1) \\
& =\text { desbalanço }(n 1, n 2)+\operatorname{tamanho}^{\prime}(n 1+1+n 2+1) \\
& =\text { desbalanço }(n 1, n 2)+\operatorname{tamanho}(n 1+n 2)+g(n 1, n 2) \\
& =\operatorname{assimetria}(n 1, n 2)+g(n 1+n 2) .
\end{aligned}
$$

Esta dependência do tamanho da função assimetria(), representada por tamanho'(), pode ser movida para a função tamanho(). Em outras palavras, a variação na função assimetria() quando variamos os valores da função tamanho'() e mantemos constante o valor de desbalanço() depende apenas do tamanho do laço. Esta dependência do tamanho da função de assimetria pode ser transferida para a função tamanho(), que ajuda a compor o cálculo geral da energia do laço interno (indicada no primeiro ítem da Expressão 3.12).

A partir disto é possível então fazer a observação chave de que se fixamos o desbalanço(), a penalidade assimetria() não se altera com o tamanho, isto é,

$$
\text { assimetria }(n 1+1, n 2+1)=\text { assimetria }(n 1, n 2) \text {. }
$$

Definimos a matriz $L I^{\prime}[i][j][l]$ como sendo a energia mínima de uma laço interno fechado por $(i, j)$ de tamanho $l$.

Lema 3.3.1 Se a equação 3.13 mantém-se, então para $l \geq 2$

$$
L I^{\prime}[i][j][l]=\left\{\begin{array}{l}
L I^{\prime}[i+1][j-1][l-2]+\operatorname{tamanho}(l)-\operatorname{tamanho}(l-2)+ \\
\operatorname{empilha}(i, j)-\operatorname{empilha}(i+1, j-1)
\end{array}\right.
$$

Prova: Por definição

$$
L I^{\prime}[i][j][l]=\min _{\substack{i<i^{\prime}<j^{\prime}<j \\ i^{\prime}-i+j-j^{\prime}-2=l}}\left\{L\left[i^{\prime}\right]\left[j^{\prime}\right]+e L\left(i, j, i^{\prime}, j^{\prime}\right)\right\}
$$


Daí

$$
\begin{aligned}
L I^{\prime}[i][j][l]=\min _{\substack{i<i^{\prime}<j^{\prime}<j \\
i^{\prime}-i+j-j^{\prime}-2=l}}\left\{\begin{array}{l}
L\left[i^{\prime}\right]\left[j^{\prime}\right]+\operatorname{tamanho}(l)+ \\
\operatorname{assimetria}\left(i^{\prime}-i-1, j-j^{\prime}-1\right)+ \\
\text { empilha }(i, j)+\operatorname{empilha}\left(i^{\prime}, j^{\prime}\right)
\end{array}\right. \\
=\min _{\substack{i<i^{\prime}<j^{\prime}<j \\
i^{\prime}-i+j-j^{\prime}-2=l}}\left\{\begin{array}{l}
L\left[i^{\prime}\right]\left[j^{\prime}\right]+\operatorname{tamanho}(l)+ \\
\operatorname{assimetria}\left(i^{\prime}-i-2, j-j^{\prime}-2\right)+ \\
\operatorname{empilha}(i, j)+\text { empilha }\left(i^{\prime}, j^{\prime}\right)
\end{array}\right. \\
=\min _{\substack{i<i^{\prime}<j^{\prime}<j \\
i^{\prime}-i+j-j^{\prime}-2=l}}\left\{\begin{array}{l}
L\left[i^{\prime}\right]\left[j^{\prime}\right]+\operatorname{tamanho}(l-2)+ \\
\operatorname{assimetria}\left(i^{\prime}-i-2, j-j^{\prime}-2\right)+ \\
\operatorname{empilha}(i+1, j-1)+\text { empilha }\left(i^{\prime}, j^{\prime}\right)+ \\
\operatorname{tamanho}(l)-\operatorname{tamanho}(l-2)+ \\
\text { empilha }(i, j)-\operatorname{empilha}(i+1, j-1)
\end{array}\right.
\end{aligned}
$$

para todo $i^{\prime}<j^{\prime}$ com $i^{\prime}>i+1, j^{\prime}<j-1$ e $i^{\prime}-(i+1)+(j-1)-j^{\prime}-2=l-2$. As três primeiras linhas da chave acima equivalem, segundo a definição, a $L I^{\prime}[i+1][j-1][l-2]$, de modo que

$$
L I^{\prime}[i][j][l]=\min _{\substack{i<i^{\prime}<j^{\prime}<j \\
i^{\prime}-i+j-j^{\prime}-2=l}}\left\{\begin{array}{l}
L I^{\prime}[i+1][j-1][l-2]+ \\
\operatorname{tamanho}(l)-\operatorname{tamanho}(l-2)+ \\
\operatorname{empilha}(i, j)-\operatorname{empilha}(i+1, j-1) .
\end{array}\right.
$$

Como o lado direito desta igualdade não depende de $i^{\prime}$ ou $j^{\prime}$, então

$$
L I^{\prime}[i][j][l]=\left\{\begin{array}{l}
L I^{\prime}[i+1][j-1][l-2]+\operatorname{tamanho}(l)-\operatorname{tamanho}(l-2)+ \\
\operatorname{empilha}(i, j)-\operatorname{empilha}(i+1, j-1) .
\end{array}\right.
$$

A Expressão 3.14 fornece a recursão necessária para computar cada entrada de $L I^{\prime}$ em tempo constante. Observemos que $L I^{\prime}$ contém $O\left(n^{3}\right)$ entradas e que $L I$ pode ser calculado a partir de $L I^{\prime}$ como

$$
L I[i][j] \leftarrow \min _{l}\left\{L I^{\prime}[i][j][l]\right\},
$$

onde cada uma das $O\left(n^{2}\right)$ entradas de $L I$ são computadas em tempo $O(n)$.

Infelizmente, a matriz $L I^{\prime}$ requer espaço $O\left(n^{3}\right)$, o que praticamente inviabiliza o método. Entretanto, podemos observar que precisamos de $L I^{\prime}[i][j][l]$ apenas em dois momentos:

- quando queremos determinar se ele é um candidato a $L I[i][j]$;

- no cálculo do valor de $L I^{\prime}[i-1][j+1][l+2]$.

Isto é utilizado no algoritmo representado pela Figura 3.5 para evitar a manutenção da matriz $L I^{\prime}$.

A função nomeada como calc_energ_inter_cubico2() implementa o algoritmo da Figura 3.5. Esta função recebe dois inteiros nas variáveis $i$ e $j$, que correspondem à entrada corrente da matriz $L$, 
segundo a ordem de varredura adotada e ilustrada na Figura 3.1. Ela então preenche $L I[u][v]$, onde $i-(n-j) \leq u \leq i-1, j+2 \leq v \leq n$ e $u+v=j+i$. A coleção destas entradas está ilustrada na Figura 3.6. Nesta função também é atribuído à $L[i][j]$ o valor de energia presente em $L I[i][j]$. Esta atribuição é direta porque a entrada de $L I$ para a iteração $(i, j)$ já foi calculada em iterações anteriores.

$20\langle$ Cálculo, conforme Lyngsø e Zuker, de energia de um laço interno 20 〉三

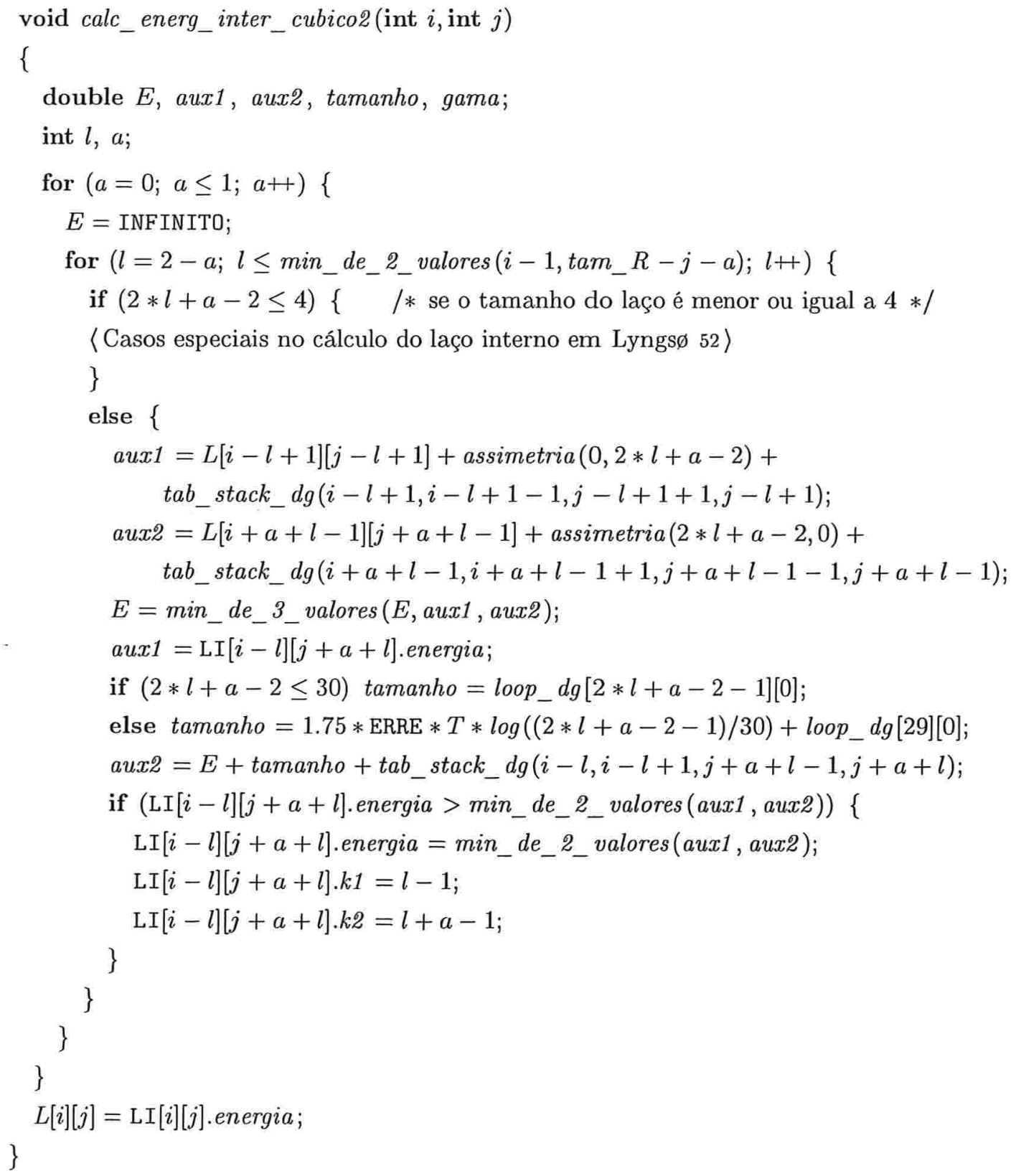

Este código é usado no bloco 37. 


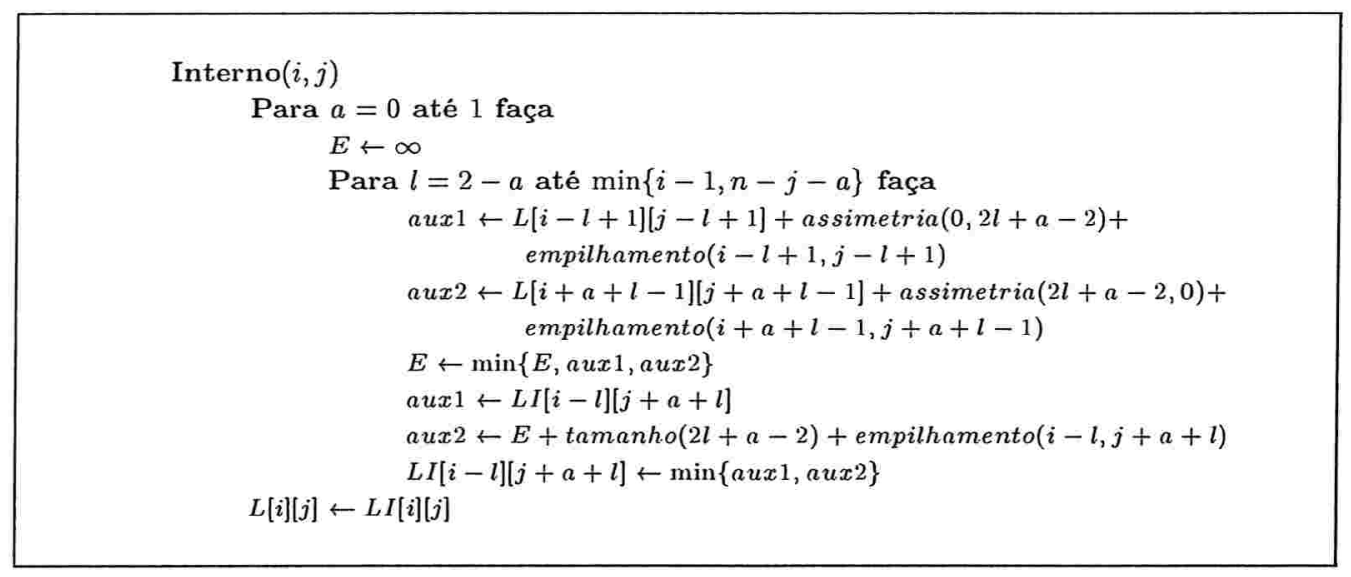

Figura 3.5: Algoritmo para cálculo de laços internos conforme Lyngsø e Zuker $\left(O\left(n^{3}\right)\right)$.

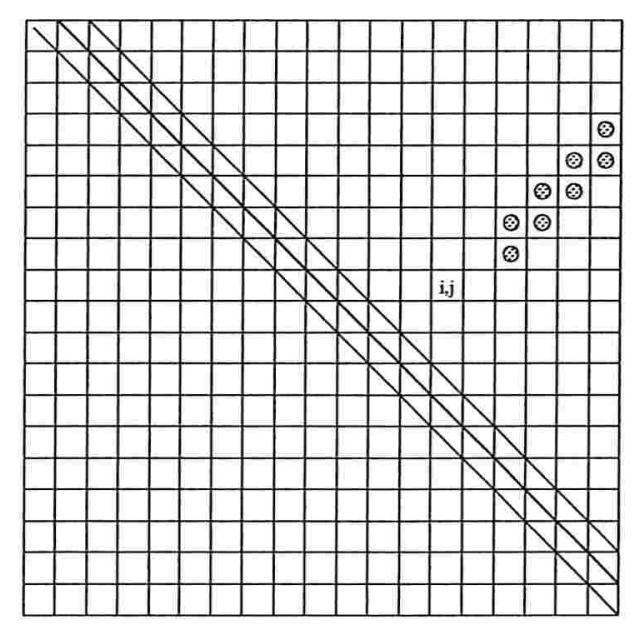

Figura 3.6: Os círculos representam as entradas da matriz LI que são preenchidas no algoritmo de Lyngsø e Zuker para um dado par $(i, j)$. 


\subsection{Geração de Soluções Sub-ótimas}

Uma consideração importante que deve ser feita com relação às modelagens acima e aos respectivos algoritmos, é que elas nos fornecem uma única solução, que pode não ser necessariamente a estrutura verdadeira. É desejável, então, que se tenha um conjunto de soluções, onde algumas delas representem valores sub-ótimos, no que se refere à energia livre. Zuker [Zuk89] descreve um algoritmo que oferece soluções sub-ótimas baseado num truque, parecido com o forward-backward da programação dinâmica, que é geralmente usado na obtenção de soluções sub-ótimas no problema de alinhamento de seqüências [VA90, Zuk91].

Em 1998, Chen et al [CLSM98] desenvolveram duas implementações paralelas para o algoritmo de Zuker [Zuk89]. A primeira implementação é para um supercomputador CRAY Y-MP com memória compartilhada, que corresponde a uma arquitetura SMP MIMD e com oito processadores vetoriais. A segunda implementação é para um sistema de processamento maciçamente paralelo MasPar MP-2 de memória distribuída (que corresponde a uma arquitetura SIMD) com 16.384 processadores.

Em 1999, Wuchty et al [WFHS99] apresentaram um algoritmo que gera todas as estruturas secundárias sub-ótimas dentro de um intervalo energético definido pela energia livre mínima da estrutura ótima e um limite superior arbitrário.

Num trabalho que apresenta alguma relação com a sub-optimalidade em estruturas secundárias de RNA, Nakaya et al [NYY96] propuseram um método através do qual constrói-se uma classificação para um conjunto de estruturas sub-ótimas. Para isto eles definiram uma métrica baseada em médias aritméticas que serve de critério para a classificação.

Uma maneira de se gerar estruturas secundárias alternativas é através da repetição, por inteiro, do processo de dobramento com ligeiras alterações nos parâmetros de energia. Este é, evidentemente, um caminho excessivamente oneroso para se obter dobramentos alternativos.

\subsubsection{Algoritmo de Zuker}

O primeiro passo em direção a um algoritmo que forneça múltiplos dobramentos vem com a tentativa de estender o algoritmo a fim de que ele dobre RNAs circulares, como por exemplo de vírus. Em um RNA circular a escolha da origem é arbitrária.

Uma característica importante a ser observada em um RNA circular $R=r_{1}, r_{2}, \ldots, r_{n}$ é que um par de bases $(i, j)$ divide a estrutura secundária em duas partes: uma da base $r_{i}$ à base $r_{j}$ e outra da base $r_{j}$ à $r_{i}$. Cada uma destas partes define um fragmento denominado fragmento incluso e fragmento excluso, respectivamente. Em sendo assim, existe um dobramento, relativo ao fragmento incluso, que vai da base $r_{i}$ à base $r_{j}$ e um outro dobramento, relativo ao fragmento excluso, que vai da base $r_{j}$ à $r_{i}$. Em uma molécula linear não observamos esta simetria, pois o fragmento excluso é quebrado em dois segmentos lineares: um que vai da base $r_{1}$ à $r_{i}$ e outro que vai da base $r_{j}$ à $r_{n}$.

Uma outra observação a ser feita, quando consideramos moléculas circulares, é que a suposição de aditividade característica dos algoritmos recursivos implica que a energia total de um dobramento é a 


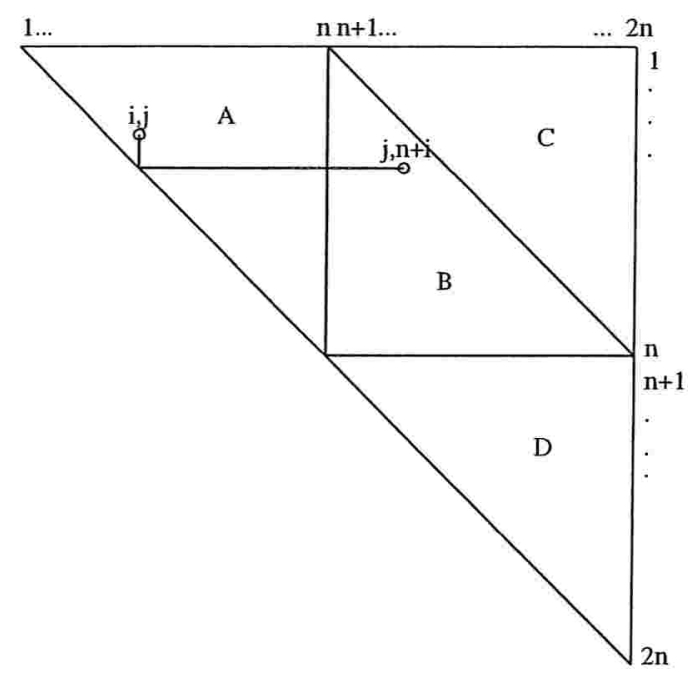

Figura 3.7: Matriz de energias para o algoritmo sub-optimal de Zuker.

soma das energias de dois dobramentos.

Steger et al $\left[\mathrm{SHF}^{+} 84\right]$ observaram que, em moléculas circulares, $L[i][j]+L[j][i]$ é a energia livre mínima de uma estrutura contendo o par de bases $(i, j)$ e que o valor mínimo de $L[i][j]+L[j][i]$, sobre todos os possíveis pares de bases, é a energia do dobramento de energia mínima - aqui denotada por $E_{\text {min }}$ - para um RNA circular. Em outras palavras,

$$
E_{\min }=\min _{1 \leq i<j \leq n}\{L[i][j]+L[j][i]\}
$$

As observações acima nos fornecem os elementos necessários à formulação de um algoritmo que fornece soluções alternativas sub-ótimas para moléculas circulares. A inspiração deste algoritmo é que, ao invés de simplesmente identificar um par de bases $(i, j)$ que fornece $E_{\min }$ computando o dobramento ótimo, tenta-se identificar todos os pares de bases para os quais $L[i][j]+L[j][i]$ está "próximo" de $E_{\text {min }}$.

Seja $P$ um número entre 0 e 100. Dizemos que um par de bases $(i, j)$ é $P$-otimal se $L[i][j]+L[j][i] \geq$ $(1-100 / P) \times E_{\min }$. Ou seja, um par de bases $P$-otimal está contido em pelo menos uma estrutura com $P$ por cento da energia livre mínima. Uma estrutura com $P$ por cento da energia da estrutura de energia livre mínima é dita ser $P$-otimal. $\mathrm{O}$ conjunto de todos os pares $P$-otimais é a união de todas as estruturas $P$-otimais.

A idéia básica desta proposta é duplicar - no sentido de concatenar uma cópia - a sequêencia de nucleotídeos fazendo $r_{i+n}=r_{i}$ para $1 \leq i \leq n$. Deste modo, para qualquer par de bases $(i, j)$ pertencente a alguma estrutura, com $1 \leq i \leq n$, a energia mínima das estruturas contendo este par de base é $L[i][j]+L[j][i+n]$ (note que $r_{i+n}=r_{i}$ ).

Então, para $1 \leq i \leq n, i<j \leq n+i-1$, computamos $E\left(R_{i, j}\right)$ e $L\left(R_{i, j}\right)$ da mesma forma como feito nas expressões 3.6 e 3.7 , respectivamente. Deste modo, baseados nos valores de $L[i][j]+L[j][i+n]$ podemos obter a energia da estrutura ótima através da expressão

$$
E_{\min }=\min _{1 \leq i<j \leq n}\{L[i][j]+L[j][i+n]\}
$$


bem como a energia de qualquer estrutura $P$-otimal.

Executamos os algoritmos descritos nas seções anteriores sobre a seqüência $R=r_{1}, r_{2}, \ldots, r_{2 n}$, onde $r_{i+n}=r_{i}$ para $1 \leq i \leq n$. Isto define uma matriz de energias quatro vezes maior do que a matriz original, como ilustra a Figura 3.7 .

As entradas desta matriz representadas pela região $C$ (na Figura 3.7) não são utilizadas, isto é, o algoritmo não opera sobre as posições $(i, j)$ da matriz onde $j-i \geq n$. A região definida pelas posições $(i, j)$ tal que $1 \leq i<j \leq n$ corresponde à matriz de programação dinâmica original e é chamada região inclusa, numa referência aos fragmentos inclusos; isto sugere que $L[i][j]$, nesta região, contém a energia do melhor dobramento no fragmento incluso pelo par de bases $(i, j)$. Na Figura 3.7 esta região é representada pela letra $A$. A região definida pelas posições $(i, j)$ tal que $n+1 \leq i<j \leq 2 n$ (representada pela letra $D$ ) é uma cópia idêntica à região $A$. A região definida pelas posições $(i, j)$ tal que $i \leq n$, onde $j>n$ e $j-i<n$ - representada pela letra $B$ - é chamada região exclusa, numa referência aos fragmentos exclusos; isto sugere que $L[i][j]$, nesta região, contém a energia do melhor dobramento no fragmento excluso pelo par de bases $(i, j)$.

Existe uma correspondência um para um entre $A$ e $B$. Este mapeamento é dado por $(i, j) \mapsto$ $(j, i+n)$; o mapeamento reverso é $(i, j) \mapsto(j-n, i)$. Se $(i, j) \in A$, então $(j, i+n) \in B$ e $L[j][i+n]$ é a energia do melhor dobramento do fragmento excluso pelo par de base $(i, j)$.

O algoritmo é exato quando a entrada é uma molécula circular. No entanto, ele exige que operemos correções quando a molécula de entrada é linear. Ou seja, alguns casos especiais devem ser observados. Quando um laço contém bases nas posições $n$ e $n+1$ ele deve ser tratado como um laço externo ao invés de arco, barriga, interior ou multilaço; isto porque estas posições contêm a quebra representada pelo fim da molécula linear. Outra situação que deve ser tratada como caso especial é aquela na qual temos um multi-laço ótimo, fechado por $(i, j)$, com $1 \leq i<n+1 \leq j \leq 2 n$ e $k=n$. Neste caso o par $(i, j)$ deve ser tratado como par de base exterior.

Estruturas $P$-otimais podem ser identificadas selecionando-se um par de bases $(i, j)$ e executando um duplo traceback. O primeiro traceback identifica um dobramento ótimo no fragmento incluso, isto é, da base $r_{i}$ à $r_{j}$. O segundo identifica um dobramento ótimo no fragmento excluso, isto é, da base $r_{j}$ à $r_{i+n}$. Estes dois dobramentos são, então, combinados em um terceiro que corresponde ao dobramento da seqüência de entrada.

A escolha destes pares pode se dar de duas formas: interativamente, através da representação dot plot ou automaticamente.

Na primeira forma, os pares de bases $P$-otimais são plotados de forma a construir uma representação dot plot dos pares $P$-otimais. Esta representação consiste na superposição de todos os possíveis dobramentos $P$-otimais. Os dobramentos $P$-otimais são então computados selecionando-se pares a partir da representação dot plot.

Na segunda forma, todos os possíveis pares são ordenados, ascendentemente, por $L_{E}[i][j]=L[i][j]+$ $L[j][i+n]$. Uma estrutura pode ser identificada usando o primeiro par $L_{E}[i][j]$ desta lista ordenada. Uma segunda estrutura pode então ser identificada a partir do próximo par da lista ordenada e assim 
por diante.

A identificação automática de estruturas pode gerar um grande número de estruturas $P$-otimais. Por esta razão foi definida uma função de distância cujo propósito é medir a diferença topológica entre duas estruturas. A distância entre duas estruturas $S_{1}$ e $S_{2}$ é o menor número inteiro $d$ tal que:

- para todo par de bases $(i, j) \in S_{1}$, existe um par de bases $(h, k) \in S_{2}$ satisfazendo $|i-h| \leq d$ e $|j-k| \leq d$

- para todo par de bases $(n, m) \in S_{2}$, existe um par de bases $(u, v) \in S_{1}$ satisfazendo $|n-u| \leq d$ $\mathrm{e}|m-v| \leq d$.

Esta medida é zero se e somente se as duas estruturas são idênticas. Com relação ao tempo e espaço consumidos na geração de soluções sub-ótimas, não há alteração no grau dos polinômios que representam as complexidades de tempo e espaço obtidas nos métodos anteriores, pois os algoritmos utilizados são basicamente os mesmos. Ou seja, este tempo é $O\left(n^{4}\right)$, caso não adotemos nenhuma otimização no cálculo dos laços internos, ou $O\left(n^{3}\right)$ caso adotemos as melhorias apresentadas por Waterman (Seção 3.3.1) ou Lyngsø (Seção 3.3.2).

No entanto, pelo fato deste algoritmo operar sobre uma matriz de energias quatro vezes maior do que a original e sobre uma seqüência duas vezes maior do que a original, as constantes multiplicativas são modificadas por conta destes fatores, sem, é claro, alterar o seu comportamento assintótico.

\subsubsection{Algoritmo de Wuchty}

A idéias básicas do algoritmo de Wuchty [WFHS99] foram primeiro utilizadas no contexto de soluções sub-ótimas para o problema do caminho mínimo em redes e no problema de alinhamento de seqüências.

Esta solução consiste em algumas modificações no algoritmo, descrito na Seção 3.2, de tal forma que a decomposição do multilaço e a fase de backtraking permitem a identificação e avaliação de estruturas alternativas segundo um critério energético, que definimos adiante. Aqui, a atribuição de energia para um segmento que vai da base $i$ à base $j$, caso estas formem um par, de forma similar à Expressão 3.11, é dada por

$$
L[i][j] \leftarrow L\left(R_{i, j}\right)=\min \left\{\begin{array}{l}
\varepsilon h(i, j) \\
\min _{i<i^{\prime}<j^{\prime}<j}\left\{L\left[i^{\prime}\right]\left[j^{\prime}\right]+e L\left(i, j, i^{\prime}, j^{\prime}\right)\right\} \\
\varepsilon m(i, j) .
\end{array}\right.
$$

Nesta expressão, o primeiro termo corresponde à energia do laços arco. A energia de hélices, de barrigas e dos laços internos são dadas pelo segundo termo. O terceiro termo representa a energia dos multilaços, que é definida como

$$
\varepsilon m(i, j)=\min _{i+1<k<j-m-2}\left\{G^{1}[i+1][k-1]+G^{2}[k][j-1]+d_{i, j, j-1}^{5}+d_{i, j, i+1}^{3}+a\right\},
$$

onde

$$
G^{1}[i][j]=\min \left\{\begin{array}{l}
\min _{i+m+1 \leq k \leq j-m-1}\left\{G^{1}[i][k-1]+G^{2}[k][j]\right\} \\
\min _{i \leq k \leq j-m-1}\left\{G^{2}[k][j]+c \times(k-i)\right\}
\end{array}\right.
$$


e

$$
G^{2}[i][j]=\min _{i+m+1<k<j}\left\{L\left(R_{i, k}\right)+c \times(j-k)+d_{i, k, i-1}^{5}+d_{i, k, k+1}^{3}+b\right\}
$$

Denotamos por $d_{i, j, k}^{5}$ a energia correspondente ao efeito dangling da base não pareada $k$ adjacente ao par $(i, j)$ posicionada mais próxima à extremidade 5' da molécula. De forma análoga, denotamos por $d_{i, j, k}^{3}$ a energia correspondente ao efeito dangling da base não pareada $k$ adjacente ao par $(i, j)$ posicionada mais próxima à extremidade 3' da molécula.

A melhor energia livre no segmento que vai da base 1 à base $j$, independentemente se $j$ está ou não pareada, denotada por $E\left(R_{j}\right)$, é então definida por

$$
E[j] \leftarrow E\left(R_{j}\right)=\min \left\{\begin{array}{l}
E\left(R_{j-1}\right) \\
\min _{i \leq k \leq j-m-1}\left\{E\left(R_{k-1}\right)+L\left(R_{k, j}\right)+d_{k, j, k-1}^{5}+d_{k, j, j+1}^{3}\right\},
\end{array}\right.
$$

de tal modo que a energia da estrutura ótima para a sequência $R=r_{1}, r_{2}, \ldots, r_{n}$ é atribuída a $E\left(R_{n}\right)$.

A descrição da fase de identificação dos pares (traceback) que comporão o dobramento exige algumas definições e nomenclatura, como segue.

Seja uma estrutura parcial $\partial$ a tripla $\partial=\left(\sigma ; \varsigma ; W_{L \partial}\right)$ consistindo de uma pilha $\sigma$ de segmentos de seqüência $\left\{\left[i_{1}, j_{1}\right] \rightarrow\left[k_{2}, l_{2}\right] \cdots\right\}$, um conjunto $\varsigma$ de pares e um inteiro $W_{L \partial}$ que representa a energia livre do laço $L \partial$ que constitui uma dada estrutura parcial $\partial$. Uma estrutura completa é uma estrutura parcial na qual a pilha $\sigma$ está vazia, isto é, $\partial=\left(\emptyset ; \varsigma ; W_{L \partial}\right)$.

Cada segmento de seqüência $\sigma$ contém um rótulo (que pode ser $E, L, G^{1}$ ou $G^{2}$ ) indicando em qual das matrizes de energia $E, L, G^{1}$ e $G^{2}$ está a melhor energia para o segmento. Estes rótulos são também necessários na realização do caminho de volta nas matrizes apropriadas. Estes rótulos são atribuídos de acordo com a forma com que os segmentos são gerados no refinamento (recorrência) de outro segmento maior.

Denotamos a melhor energia possível para o segmento $[i, j]_{W}$ por $W_{i, j}$, onde $W \in\left\{E, L, G^{1}, G^{2}\right\}$. Suponhamos agora que estamos refinando ("recorrendo") uma estrutura parcial $\partial=\left([i, j]_{W} \rightarrow \sigma ; \varsigma ; W_{L \partial}\right)$ segundo as recorrências acima. Dependendo da recorrência usada, isto produzirá subintervalos de $[i, j]_{W}$ cuja energia livre total denotaremos por Energ. Todas as estruturas completas representadas pelos refinamentos de $\partial$ têm uma energia não menor do que $W_{\partial}$, onde

$$
W_{\partial}=\operatorname{Energ}+W_{L \partial}+\sum_{[k, l] \in \sigma} W_{k, l} .
$$

Podemos então adotar (aceitar) o refinamento para o qual

$$
W_{\partial} \leq W_{\min }+\delta
$$

onde $W_{\min }$ é a energia livre mínima da estrutura ótima e $\delta$ é um inteiro positivo representando um limite superior arbitrário definido pelo usuário para a variação energética. Fazendo uma analogia com o algoritmo de Zuker da Seção 3.4.1, podemos entender que $\delta$ define a $P$-otimalidade desejada.

O algoritmo traceback inicia com a estrutura parcial $\partial=\left([1, n]_{W} ; \emptyset ; 0\right)$. 
Vamos agora descrever mais detalhadamente os caminhos que o procedimento de "volta" pode seguir no algoritmo tracebak. Há cinco possíveis casos a serem tratados e para ilustrá-los vamos supor que estamos processando o refinamento da estrutura parcial $\partial=\left([i, j]_{W} \rightarrow \sigma ; \varsigma ; W_{L \partial}\right)$ a qual acaba de ser desempilhada de uma pilha de estruturas parciais $P$. O segmento $[i, j]_{W}$ é então retirado da pilha de segmentos da estrutura parcial e refinado de acordo com a marca $W$ :

Caso $1 W=E$ (backtrack em $E$ ) Aqui temos $i$ e $j$ como bases externas e o refinamento possível segue pela recorrência 3.21. A condição de aceitação é dada pela expressão

$$
E\left(R_{j-1}\right)+W_{L \partial}+\sum_{[k, l] \in \sigma} W_{k, l} \leq W_{\min }+\delta .
$$

Se 3.22 é satisfeita, então empilhamos a nova estrutura parcial $\partial^{\prime}=\left([i, j-1]_{E} \rightarrow \sigma ; \varsigma ; W_{L \partial}\right)$ na pilha $P$ para refinamento futuro. Em seguida varremos todos os possíveis pares $(l, j)$. Se para um particular par $(l, j)$ o critério

$$
E\left(R_{l-1}\right)+L\left(R_{l, j}\right)+d_{l, j, l-1}^{5}+d_{l, j, j+1}^{3}+W_{L \partial}+\sum_{[k, l] \in \sigma} W_{k, l} \leq W_{\min }+\delta
$$

é satisfeito, então empilhamos o refinamento $\partial^{\prime}=\left([l, j]_{L} \rightarrow[i, l-1]_{E} \rightarrow \sigma ; \varsigma ; d_{l, j, l-1}^{5}+d_{l, j, j+1}^{3}+\right.$ $\left.W_{L \partial}\right)$ na pilha $P$.

Caso $2 W=L$ (backtrack em $L$ ) Aqui temos $i$ e $j$ pareados no segmento desempilhado $[i, j]_{L}$. Consideramos três possibilidades para o segmento. Se ele é um arco e

$$
\varepsilon h(i, j)+W_{L \partial}+\sum_{[k, l] \in \sigma} W_{k, l} \leq W_{\min }+\delta
$$

nós obtemos o refinamento $\partial^{\prime}=\left(\sigma ; \varsigma \cup\{(i, j)\} ; W_{L \partial}+\varepsilon h(i, j)\right)$ que é empilhado em $P$. Depois testamos laços tipo hélice, interno e barrigas pela verificação de todos os admissíveis pares $\left(i^{\prime}, j^{\prime}\right)$ checando a condição

$$
L\left(R_{i, j}\right)+e L\left(i, j, i^{\prime}, j^{\prime}\right)+W_{L \partial}+\sum_{[k, l] \in \sigma} W_{k, l} \leq W_{\min }+\delta .
$$

Toda vez que 3.25 é satisfeita, obtemos um refinamento $\partial^{\prime}=\left(\left[i^{\prime}, j^{\prime}\right]_{L} \rightarrow \sigma ; \varsigma \cup\left\{(i, j),\left(i^{\prime}, j^{\prime}\right)\right\} ; W_{L \partial}+\right.$ $\left.e L\left(i, j, i^{\prime}, j^{\prime}\right)\right)$ que é empilhado em $P$. Fazemos a verificação dos multilaços, em correspondência com 3.18. Para isto, variamos $k$ checando a condição

$$
G^{1}[i+1, k]+G^{2}[k+1, j-1]+d_{i, j, i+1}^{5}+d_{i, j, j-1}^{3}+a+W_{L a}+\sum_{[k, l] \in \sigma} W_{k, l} \leq W_{\min }+\delta
$$

e obtendo mais refinamentos $\partial^{\prime}=\left([k+1, j-1]_{G^{2}} \rightarrow[i+1, k]_{G^{1}} \rightarrow \sigma ; \varsigma \cup\{(i, j)\} ; W_{L \partial}+d_{i, j, i+1}^{5}+\right.$ $\left.d_{i, j, j-1}^{3}+a\right)$ que são empilhados em $P$.

Caso $3 W=G^{2}$ (backtrack em $G^{2}$ ) Para fazer o caminho de volta em 3.20 nós testamos a base do segmento mais próxima à extremidade 3' da seqüência verificando se esta base está ou não pareada. Primeiro nós testamos se

$$
G^{2}[i, j-1]+c+W_{L \partial}+\sum_{[k, l] \in \sigma} W_{k, l} \leq W_{\min }+\delta .
$$


Se 3.27 é satisfeita, nós empilhamos $\partial^{\prime}=\left([i, j-1]_{G^{2}} \rightarrow \sigma ; \varsigma ; W_{L \partial}+c\right)$. Quando $\partial^{\prime}$ for novamente desempilhada, este teste na extremidade 3' será novamente realizado. Depois checamos se $i$ e $j$ podem ser um par. Se sim, consideramos a expressão

$$
L\left(R_{i, j}\right)+d_{i, j, i-1}^{5}+d_{i, j, j+1}^{3}+b+W_{L \partial}+\sum_{[k, l] \in \sigma} W_{k, l} \leq W_{m i n}+\delta
$$

a qual, caso satisfeita, leva-nos a empilhar $\partial^{\prime}=\left([i, j]_{L} \rightarrow \sigma ; \varsigma ; W_{L \partial}+d_{i, j, i-1}^{5}+d_{i, j, j+1}^{3}+b\right)$.

Caso $4 W=G^{1}$ (backtrack em $G^{1}$ ) Para fazer o caminho de volta em 3.19 nós inserimos 3.20 em 3.19.

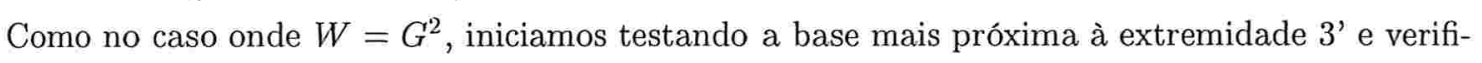
cando se ela pareia ou não. Isto trata parcialmente do termo $G_{2}$ em 3.19. O procedimento aqui segue exatamente como no caso onde $W=G^{2}$, exceto que agora o já testado segmento $[i, j-1]$, para ser empilhado, é agora marcado com $G^{2}$. Para completar a Expressão 3.19 necessitamos apenas variar $k$ considerando os pares $\left(r_{k+1}, r_{j}\right)$, os quais satisfazem

$$
G_{i, k}^{1}+L\left(R_{k+1}, j\right]+d_{k+1, j, k}^{5}+d_{k+1, j, j+1}^{3}+b+W_{L \partial}+\sum_{[k, l] \in \sigma} W_{k, l} \leq W_{\min }+\delta
$$

Os correspondentes refinamentos $\partial^{\prime}=\left([k+1, j]_{L} \rightarrow[i, k]_{G^{1}} \rightarrow \sigma ; \varsigma ; W_{L \partial}+d_{k+1, j, k}^{5}+d_{k+1, j, j+1}^{3}+b\right)$ são então empilhados em $P$. Para cobrir o caso no qual a decomposição do multilaço no segmento $[i, j]_{G^{1}}$ contém exatamente um par de base acessível (interno), variamos $k$ no segundo termo da Expressão 3.19 checando os pares $(k+1, j)$ que satisfazem

$$
\begin{gathered}
L\left(R_{k+1, j}\right)+d_{k+1, j, k}^{5}+d_{k+1, j, j+1}^{3}+b+(k-i-1) \times c+W_{L \partial}+\sum_{[k, l] \in \sigma} W_{k, l} \leq W_{\min }+\delta \\
\text { e empilhando } \partial^{\prime}=\left([k+1, j]_{L} \rightarrow \sigma ; \varsigma ; W_{L \partial}+d_{k+1, j, k}^{5}+d_{k+1, j, j+1}^{3}+b+c \times(k-i+1)\right) .
\end{gathered}
$$

Caso 5 Se $\partial=\left([i, j]_{W} \rightarrow \sigma ; \varsigma ; W_{L \partial}\right)$ não causa refinamento, então empilhamos $\left(\sigma ; \varsigma ; W_{L \partial}\right)$.

O tempo consumido por este algoritmo, na fase de preenchimento das matrizes de energia, não se altera em relação aos algoritmos já estudados. Ou seja, este tempo é $O\left(n^{4}\right)$ caso não adotemos nenhuma otimização no cálculo dos laços internos ou $O\left(n^{3}\right)$ caso adotemos as melhorias apresentadas por Waterman (Seção 3.3.1) ou Lyngsø (Seção 3.3.2).

Com relação à fase de identificação dos pares de bases (traceback), o tempo consumido para computar todas as estruturas com energia entre $W_{\min }$ e $W_{\min }+\delta$ depende do número de estruturas que este intervalo contém, que denotamos por densidade. Portanto, este tempo depende do tamanho do intervalo e da sua densidade. Experimentos que Wuchty [WFHS99] realizou sugerem que para intervalos pequenos (até $5 \%$ de $W_{\min }$ ) o número de estruturas geradas é razoável. Porém, para intervalos maiores o número de estruturas geradas cresce exponencialmente. Se escolhermos $\delta=0$ algoritmo realiza um backtracking convencional. 


\section{Capítulo 4}

\section{Melhoria da Eficiência para Classes Especiais de Funções}

Com o intuito de melhorar o desempenho do algoritmo geral, alguns esforços foram empreendidos a partir de suposições acerca do comportamento das funções de desestabilização dos laços. Neste Capítulo, tratamos de algoritmos que melhoram sensivelmente a complexidade de tempo supondo linearidade, convexidade ou concavidade destas funções. Infelizmente estas suposições não refletem de maneira confiável a realidade biológica; ou seja, estas funções na prática não são lineares, convexas ou côncavas. De qualquer modo, estes algoritmos representam avanços no campo estrito da computação.

\subsection{Melhoria da Eficiência para Funções Lineares}

Caso façamos a suposição de que as funções de desestabilização $g$ sejam lineares no tamanho $k$ do laço, isto é, quando explicitamente fazemos $g(k)=a+b k$, então é possível reduzir o tempo de computação de barrigas e laços interiores para uma constante.

Isto leva a um algoritmo geral de complexidade de tempo $O\left(n^{2}\right)$ [WS86], caso não consideremos os multilaços. Se nos cálculos levarmos em conta os multilaços, então a complexidade de tempo do algoritmo geral é $O\left(n^{3}\right)$. Lembremos que já estamos supondo a linearidade para os multilaços. Lembremos também que, como vimos na Seção 3.2, as expressões associadas ao cálculo de barrigas em $i$, barrigas em $j$ e laços internos são

$$
\begin{aligned}
& \varepsilon b i(i, j)=\min _{k \geq 1}\left\{\beta(k)+L\left(R_{i+k+1, j-1}\right)\right\} \\
& \varepsilon b j(i, j)=\min _{k \geq 1}\left\{\beta(k)+L\left(R_{i+1, j-k-1}\right)\right\}
\end{aligned}
$$

e

$$
\varepsilon i(i, j)=\min _{k_{1}, k_{2} \geq 1}\left\{\gamma\left(k_{1}+k_{2}\right)+L\left(R_{i+1+k_{1}, j-1-k_{2}}\right)\right\}
$$

respectivamente. 
Analisando a expressão acima para $\varepsilon b i(i, j)$, considerando $\beta$ linear e assumindo, por conveniência, que $\beta(k)=a+b(k-1)$, temos que

$$
\begin{aligned}
\varepsilon b i(i, j) & =\min \left\{a+L\left(R_{i+2, j-1}\right), \min _{k \geq 2}\left\{\beta(k)+L\left(R_{i+k+1, j-1}\right)\right\}\right\} \\
& =\min \left\{a+L\left(R_{i+2, j-1}\right), \min _{l \geq 1}\left\{\beta(l+1)+L\left(R_{i+l+2, j-1}\right)\right\}\right\} \\
& =\min \left\{a+L\left(R_{i+2, j-1}\right), \min _{l \geq 1}\left\{\beta(l)+L\left(R_{i+l+2, j-1}\right)\right\}+b\right\} \\
& =\min \left\{a+L\left(R_{i+2, j-1}\right), \varepsilon b i(i+1, j)+b\right\} .
\end{aligned}
$$

Portanto,

$$
\varepsilon b i(i, j)=\min \left\{a+L\left(R_{i+2, j-1}\right), \varepsilon b i(i+1, j)+b\right\} .
$$

Para barriga em $j$, de forma similar ao tratamento acima, obtemos que

$$
\varepsilon b j(i, j)=\min \left\{a+L\left(R_{i+1, j-2}\right), \varepsilon b j(i, j-1)+b\right\} .
$$

No caso de laços internos, a função $\varepsilon i(i, j)$ pode ser reescrita da forma

$$
\varepsilon i(i, j)=\min \left\{\begin{array}{l}
\min _{k_{1}=1, k_{2} \geq 1}\left\{\gamma\left(1+k_{2}\right)+L\left(R_{i+1+1, j-1-k_{2}}\right)\right\}, \\
\min _{k_{1} \geq 1, k_{2}=1}\left\{\gamma\left(k_{1}+1\right)+L\left(R_{\left.i+1+k_{1}, j-1-1\right)}\right\},\right. \\
\min _{k_{1}>1, k_{2}>1}\left\{\gamma\left(k_{1}+k_{2}\right)+L\left(R_{i+1+k_{1}, j-1-k_{2}}\right)\right\} .
\end{array}\right.
$$

Os dois primeiros casos da Expressão 4.3 são equivalentes aos casos barriga em $i$ (Expressão 4.1) e barriga em $j$ (Expressão 4.2), respectivamente.

Assumindo que $\gamma(k)=c+d(k-2)$, temos para o terceiro termo da Expressão 4.3 que

$$
\begin{aligned}
\min _{k_{1}>1, k_{2}>1}\left\{\gamma\left(k_{1}+k_{2}\right)+L\left(R_{i+1+k_{1}, j-1-k_{2}}\right)\right\} & =\min _{l \geq 1, k_{2}>1}\left\{\gamma\left(1+l+k_{2}\right)+L\left(R_{i+2+l, j-1-k_{2}}\right)\right\} \\
& =d+\varepsilon i(i+1, j) .
\end{aligned}
$$

Portanto, se supormos que as funções $\beta$ e $\gamma$ são lineares, como indicado acima, então o tempo de computação do algoritmo geral - se excluírmos os multilaços - consome tempo e espaço $O\left(n^{2}\right)$. 


\subsection{Melhoria da Eficiência para Funções Côncavas e Convexas}

Dizemos que uma função $w(x, y)$ é côncava quando ela satisfaz a desigualdade quadrangular

$$
w(i, j)+w\left(i^{\prime}, j^{\prime}\right) \leq w\left(i^{\prime}, j\right)+w\left(i, j^{\prime}\right)
$$

para todo $i \leq i^{\prime} \leq j \leq j^{\prime}$. De forma similar, dizemos que $w(x, y)$ é convexa quando $-w(x, y)$ é côncava, ou seja:

$$
w(i, j)+w\left(i^{\prime}, j^{\prime}\right) \geq w\left(i^{\prime}, j\right)+w\left(i, j^{\prime}\right)
$$

\subsubsection{Algoritmo de Eppstein}

Buscando melhora no desempenho para soluções do problema, Eppstein, Galil e Giancarlo [EGG88] propuseram um algoritmo com tempo de execução $O\left(n^{2} \log ^{2} n\right)$. Neste algoritmo faz-se a suposição de que não ocorrem multi-laços na estrutura, bem como a função que fornece o custo (contribuição energética) de um laço, denotada por $g(k)$, onde $k$ é o número de bases acessíveis ao laço, é convexa. Assim sendo, a expressão 3.7 (excetuando-se os multi-laços) pode ser reescrita como

$$
V[i, j] \leftarrow E\left(L_{i, j}\right)=\min \{\varepsilon h(i, j), C[i, j]\}
$$

onde

$$
C[i, j]=\min _{i<i^{\prime}<j^{\prime}<j}\left\{V\left[i^{\prime}, j^{\prime}\right]+g\left(\left(i^{\prime}-i\right)+\left(j-j^{\prime}\right)\right)\right\}
$$

Para simplificar a apresentação do algoritmo, a recorrência 4.4 é modificada através da mudança de algumas variáveis. Especificamente, fazemos $E[i, j]=C[n-i-1, j], D[i, j]=V[n-i-1, j] \mathrm{e}$ $w(x, y)=g(y-x)$. Daí a recorrência 4.4 torna-se

$$
E[i, j]=\min _{\substack{0 \leq i^{\prime}<i \\ 0 \leq j^{\prime}<j}}\left\{D\left[i^{\prime}, j^{\prime}\right]+w\left(i^{\prime}+j^{\prime}, i+j\right)\right\}
$$

A restrição $i^{\prime}<j^{\prime}$ presente em 4.4 não está contemplada em 4.5. Isto pode ser tratado com a atribuição $V[i, j] \leftarrow+\infty$ quando $i+j>n+1$ ou reescrevendo a recorrência 4.5 da seguinte forma

$$
E[i, j]=\min _{\substack{i^{\prime}<i \\ j^{\prime}<j \\ i^{\prime}+j^{\prime}>n+1}}\left\{D\left[i^{\prime}, j^{\prime}\right]+w\left(i^{\prime}+j^{\prime}, i+j\right)\right\}
$$

Na recorrência 4.6 , definimos os pontos $\left(i^{\prime}, j^{\prime}\right)$ que podem contribuir para o valor de $E[i, j]$ como sendo candidatos. Dizemos que dois pontos $(i, j)$ e $\left(i^{\prime}, j^{\prime}\right)$ nas matrizes $D$ ou $E$ estão na mesma diagonal quando $i+j=i^{\prime}+j^{\prime}$.

Um retângulo é delimitado através de seu canto superior esquerdo e de seu canto inferior direito, ou seja, um retângulo delimitado por $(i, j)$ e $\left(i^{\prime}, j^{\prime}\right)$ é o conjunto de pontos $(x, y)$ tal que $i \leq x \leq i^{\prime} \mathrm{e}$ $j \leq y \leq j^{\prime}$. Definimos a área de um ponto $(i, j)$ como sendo o retângulo delimitado por $(i+1, j+1) \mathrm{e}$ $(n, n)$. 
Dizemos que um ponto $(k, l)$ está na área de um ponto $(i, j)$ quando $k>i$ e $l>j$, ou seja, quando o ponto $(i, j)$ é um candidato para o valor de $E[k, l]$.

Considerando que a computação de $E[i, j]$ é uma disputa entre candidatos, de tal forma que o vencedor é o ponto $\left(i^{\prime}, j^{\prime}\right)$ tal que o valor de $D\left[i^{\prime}, j^{\prime}\right]+w\left(i^{\prime}+j^{\prime}, i+j\right)$ seja mínimo, a idéia deste algoritmo é eliminar candidatos de uma mesma diagonal, a fim de obter melhor tempo de execução.

Lema 4.2.1 Se $(i, j)$ e $\left(i^{\prime}, j^{\prime}\right)$ estão na mesma diagonal e $D[i, j] \leq D\left[i^{\prime}, j^{\prime}\right]$, então para todo $(k, l)$ na área de $(i, j)$ e na área de $\left(i^{\prime}, j^{\prime}\right)$, simultaneamente, vale que $D[i, j]+w(i+j, k+l) \leq D\left[i^{\prime}, j^{\prime}\right]+w\left(i^{\prime}+\right.$ $\left.j^{\prime}, k+l\right)$. Ou seja, $\left(i^{\prime}, j^{\prime}\right)$ não precisa ser considerado como um candidato para os pontos da área de $(i, j)$.

Prova: Como $(i, j)$ e $\left(i^{\prime}, j^{\prime}\right)$ estão na mesma diagonal, então $i+j=i^{\prime}+j^{\prime}$. Daí $w(i+j, k+l)=$ $w\left(i^{\prime}+j^{\prime}, k+l\right)$. Portanto $D[i, j]+w(i+j, k+l) \leq D\left[i^{\prime}, j^{\prime}\right]+w\left(i^{\prime}+j^{\prime}, k+l\right)$, pois $D[i, j] \leq D\left[i^{\prime}, j^{\prime}\right]$.

Dado um ponto $(i, j)$ em alguma diagonal, definimos como sendo seu limite superior o ponto $\left(i^{\prime}, j^{\prime}\right)$ tal que $i^{\prime}<i$ e $D\left[i^{\prime}, j^{\prime}\right] \leq D[i, j]$ onde $i^{\prime}$ é tão grande quanto possível. Se tal ponto não existe, tomamos o ponto $(n, n)$ como sendo o seu limite superior. Intuitivamente, o limite superior é o ponto mais próximo e acima de $(i, j)$ na diagonal, cujo valor é menor do que aquele em $(i, j)$. De forma similar, definimos como sendo o limite inferior de $(i, j)$ o ponto $\left(i^{\prime \prime}, j^{\prime \prime}\right)$ tal que $i^{\prime \prime}>i$ e $D\left[i^{\prime \prime}, j^{\prime \prime}\right] \leq D[i, j]$ onde $i^{\prime \prime}$ é tão pequeno quanto possível. Da mesma forma, se não existe tal ponto, tomamos $(n, n)$ como sendo seu limite inferior.

Definimos como sendo o dominio de um ponto $(i, j)$ o retângulo delimitado por $(i+1, j+1) \mathrm{e}$ $\left(i^{\prime \prime}, j^{\prime}\right)$, onde $\left(i^{\prime}, j^{\prime}\right)$ é o limite superior de $(i, j)$ e $\left(i^{\prime \prime}, j^{\prime \prime}\right)$ é o limite inferior de $(i, j)$.

Lema 4.2.2 Cada ponto $(i, j)$ de uma dada diagonal necessita ser considerado como candidato apenas para os elementos que compõem o dominio de $(i, j)$.

Prova: Se um ponto $(x, y)$ está abaixo da linha $i^{\prime \prime}$ (ou seja, com $x<i^{\prime \prime}$ ) e está dentro da área de $(i, j)$, então $(x, y)$ também pertence a área de $\left(i^{\prime \prime}, j^{\prime \prime}\right)$. Logo $(i, j)$ nunca vencerá a competição nesta situação, pois se $\left(i^{\prime \prime}, j^{\prime \prime}\right)$ é limite inferior de $(i, j)$ então $D\left[i^{\prime \prime}, j^{\prime \prime}\right]<D[i, j]$ (pelo Lema 4.2.1). De forma similar, se um ponto $(k, l)$ está na área de $(i, j)$ e vem depois da coluna $j^{\prime}$ (ou seja, com $l>j^{\prime}$ ), então $(i, j)$ será vencido por $\left(i^{\prime}, j^{\prime}\right)$ ou por algum outro ponto que é ainda melhor.

Neste trabalho, Eppstein et al [EGG88] mostram que os domínios de todos os pontos de uma diagonal são disjuntos e cobrem o conjunto de todos os pontos abaixo desta diagonal. A partir disto, precisamos agora de um algoritmo que compute os domínios de cada um dos pontos necessários ao cálculo da estrutura de energia mínima.

Este algoritmo executa sobre uma diagonal, ou seja, identifica os domínios dos pontos $(i, j)$, pertencentes à diagonal $i+j$, em ordem crescente de $i$. Para isto mantém uma pilha, denotada por $S$, na qual armazena alguns pontos processados anteriormente. Para cada ponto em $S$, o ponto imediatamente abaixo (em $S$ ) é seu limite superior. Cada ponto já processado, mas não mais pertencente a $S$, já terá seu domínio identificado. Inicialmente a pilha conterá o ponto $(n, n)$. 


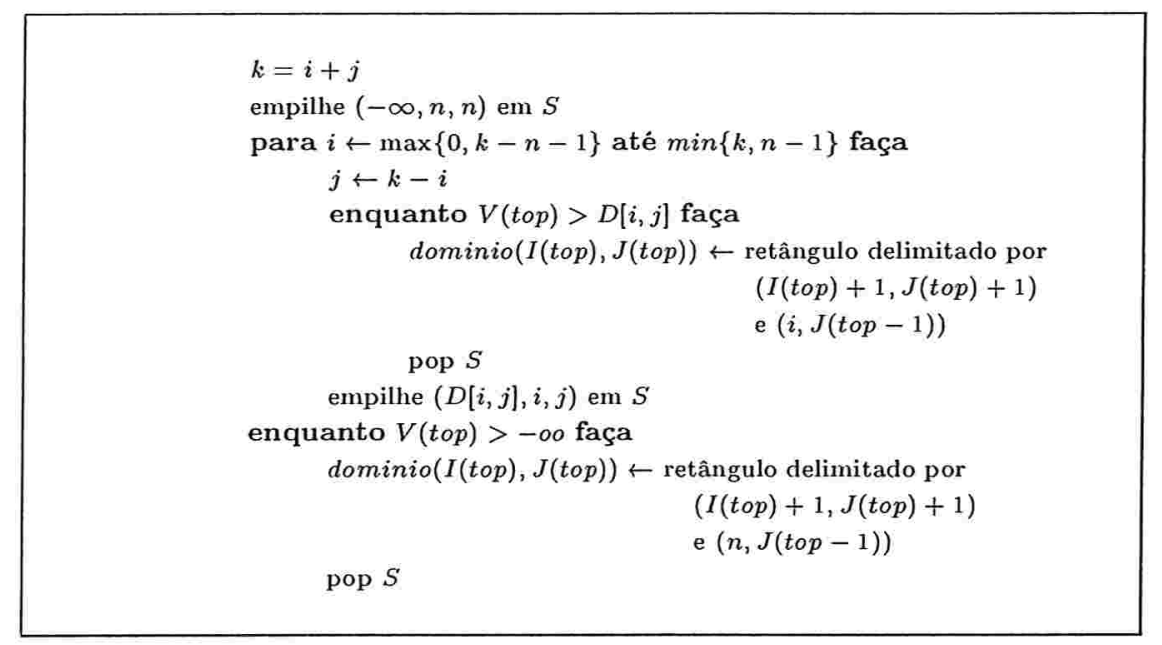

Figura 4.1: Algoritmo para computação de domínios em uma diagonal.

Informalmente o algoritmo funciona da seguinte maneira: para processar o ponto $(i, j)$, olhamos o ponto $\left(i^{\prime}, j^{\prime}\right)$ no topo da pilha $S$; se $\left(i^{\prime}, j^{\prime}\right) \neq(n, n)$ e $D[i, j]<D\left[i^{\prime}, j^{\prime}\right]$,

- então $(i, j)$ é um limite inferior de $\left(i^{\prime}, j^{\prime}\right)$; assim retiramos o ponto $\left(i^{\prime}, j^{\prime}\right)$ da pilha e computamos seu domínio através do seu limite inferior $(i, j)$ e de seu limite superior, que é o ponto na próxima posição da pilha. Repetimos o processo com o ponto agora no topo da pilha.

- senão $(i, j)$ não é um limite inferior para qualquer ponto empilhado, mas $\left(i^{\prime}, j^{\prime}\right)$ pode ser um limite superior de $(i, j)$, de modo que empilhamos $(i, j)$.

- quando todos os pontos tiverem sido processados, os pontos que permanecerem na pilha têm $(n, n)$ como seu limite inferior, de modo que podemos desempilhá-los, um a um, e computar seus domínios como antes.

Uma descrição mais formal deste algoritmo é feita na Figura 4.1. Nela, cada posição $p$ da pilha $S$ consiste de três componentes: $V(p), I(p)$ e $J(p)$. $V(p)$ é o valor de $D$ indexado por $I(p)$ e $J(p)$. A pilha $S$ contém um membro dummy na sua base ao qual se atribui o valor $-\infty$. Denota-se por $k=i+j$ o número da diagonal para a qual o algoritmo está calculando os domínios.

Lema 4.2.3 Os domínios de uma diagonal contendo $m$ pontos pode ser encontrado em tempo $O(m)$.

Prova: No algoritmo descrito na Figura 4.1 cada ponto é empilhado e desempilhado uma única vez. Logo o tempo consumido é linear em $m$.

Este algoritmo mostra como resolver a competição entre candidatos posicionados na mesma diagonal. Precisamos agora incrementá-lo a fim de resolver a competição entre candidatos de diferentes diagonais. Para isto, precisaremos de uma estrutura de dados que mantenha uma partição de uma seqüência de números de 1 a $n$ em intervalos, e, sobre a qual, possamos realizar as seguintes operações em tempo eficiente: 
1. Encontrar qual intervalo contém um dado número.

2. Dado um intervalo na seqüência, encontrar o intervalo subseqüente.

3. Unir dois intervalos em um intervalo maior.

4. Dado um ponto em um intervalo, dividi-lo em dois intervalos menores.

Tal estrutura de dados pode ser implementada a um custo de $O(\log n)$ por operação usando árvores de busca balanceada [Knu73]. Para este fim suponhamos existir procedimentos, como definidos logo abaixo, que implementam, correspondentemente, as quatro operações relacionadas acima, bem como funções que retornam o proprietário (definido logo adiante) de um dado intervalo e vice-versa.

\section{1. $\operatorname{CONTEM}(k)$}

Entrada: um número $k$.

Encontra o intervalo no qual $k$ está inserido.

Saída: um intervalo $X$ que contém $k$.

2. PRÓXIMO $(X)$

Entrada: um intervalo $X$.

Encontra o intervalo subseqüente a $X$ na partição.

Saída: um intervalo $Y$ subseqüente a $X$.

3. $\operatorname{UNIR}(\mathrm{X}, \mathrm{Y})$

Entrada: dois intervalos $\mathrm{X}$ e $\mathrm{Y}$.

Intercala X e Y em um intervalo maior.

Saída: um intervalo $\mathrm{Z}$ resultado da intercalação de $\mathrm{X}$ e $\mathrm{Y}$

4. $\operatorname{DIVIDIR}(k, X)$

Entrada: um número $k$ e um intervalo $X$.

Divide $X$ no ponto $k$.

Saída: dois intervalos $X$ e $Y$, com $Y$ iniciando em $k$.

\section{5. $\operatorname{DONO}(X)$}

Entrada: um intervalo $X$.

Retorna o proprietário de $X$.

Saída: um ponto $(i, j)$.

6. $\operatorname{POSSUIDO}((i, j))$

Entrada: um ponto $(i, j)$.

Retorna o intervalo o qual $(i, j)$ é proprietário.

Saída: um intervalo $X$.

Manteremos tal partição para cada linha e coluna da matriz do problema original. Cada intervalo em cada partição conterá um ponteiro para seu proprietário: um dos pontos $(i, j)$ para os quais já foi 
calculado $E(i, j)$. Qualquer ponto $(i, j)$ poderá possuir um conjunto de intervalos, ou em partições de linhas, ou em partições de colunas, mas não em ambos tipos de partições.

Deveremos observar o seguinte invariante: se o proprietário de um intervalo tipo linha que contém o ponto $(i, j)$ é o ponto $\left(i_{r}, j_{r}\right)$, então $(i, j)$ está na área de $\left(i_{r}, j_{r}\right)$ e a expressão $D\left[i_{r}, j_{r}\right]+w\left(i_{r}+j_{r}, i+\right.$ $j$ ) é aquela de valor mínimo entre todas aquelas que incluem pontos $\left(i^{\prime}, j^{\prime}\right)$ que possuem intervalos de linhas. De forma semelhante, o proprietário $\left(i_{c}, j_{c}\right)$ do intervalo de coluna que contém o ponto $(i, j)$ é o melhor ponto entre todos aqueles que são proprietários de intervalos de colunas; ou seja, a expressão $D\left[i_{c}, j_{c}\right]+w\left(i_{c}+j_{c}, i+j\right)$ é aquela que fornece o valor mínimo dentre todas que consideram os pontos $\left(i^{\prime}, j^{\prime}\right)$ que são proprietários de intervalos de colunas. Quando computarmos $E(i, j)$, esse cálculo considerará os casos para cada ponto $\left(i^{\prime}, j^{\prime}\right)$ tal que $(i, j)$ está na área de $\left(i^{\prime}, j^{\prime}\right)$, onde os pontos $\left(i^{\prime}, j^{\prime}\right)$ ou são proprietários de alguns intervalos ou $\left(i^{\prime}, j^{\prime}\right)$ não podem ser candidatos vencedores para $(i, j)$. Desta forma podemos calcular $E(i, j)$ como:

$$
E(i, j)=\min \left\{\begin{array}{l}
D\left[i_{r}, j_{r}\right]+w\left(i_{r}+j_{r}, i+j\right), \\
D\left[i_{c}, j_{c}\right]+w\left(i_{c}+j_{c}, i+j\right)
\end{array}\right.
$$

o que requer apenas duas consultas a intervalos na estrutura de dados mais um número constante de operações aritméticas para combinar estes dois valores.

De posse da estrutura de dados acima e do algoritmo para identificação de domínios, podemos então enunciar o esquema geral do algoritmo que computa corretamente $E(i, j)$. Este algoritmo executa para cada diagonal $k=i+j, 2 \leq k \leq 2 n$, os seguintes passos:

1. Olhamos os proprietários de cada ponto $(i, j)$ da diagonal nas partições linha e coluna da estrutura de dados e calculamos $E[i, j]$ e $D[i, j]$, isto é,

$$
\begin{gathered}
E(i, j)=\min \left\{\begin{array}{l}
D\left[i_{r}, j_{r}\right]+w\left(i_{r}+j_{r}, i+j\right) \\
D\left[i_{c}, j_{c}\right]+w\left(i_{c}+j_{c}, i+j\right)
\end{array}\right. \\
D(i, j)=\min \left\{\begin{array}{l}
E[i, j]+\alpha\left(r_{i}, r_{j}\right) \\
\varepsilon h(i, j) .
\end{array}\right.
\end{gathered}
$$

2. Identificamos os domínios dos pontos da diagonal (algoritmo da Figura 4.1).

3. Para cada ponto $(i, j)$ dividimos o seu domínio em tiras, ou por linhas ou por colunas - dependendo da direção que fornece o menor número de tiras - e combinamos estas tiras com a partição apropriada de tal modo que o invariante acima seja mantido.

Iremos agora detalhar o passo três (resumido na Figura 4.2) do algoritmo geral, ou seja, como inserir a(s) tira(s) para $(i, j)$ na partição de intervalos tipo linha (ou coluna), uma vez que tenhamos calculado o domínio para $(i, j)$. Neste procedimento fazemos uso da suposição de que $w$ é convexa.

Lema 4.2.4 Se w é convexa e se todos os intervalos na partição de uma linha (ou coluna) são possuídos por pontos posicionadas na diagonal anterior. Então, se $(i, j)$ é melhor do que esses proprietários anteriores para quaisquer pontos na linha (ou coluna) contida no domínio de $(i, j)$, então ele é melhor em um intervalo simples que inicia no menor ponto numerado da linha (ou coluna) no dominio de $(i, j)$. 
Prova: Provaremos este lema apenas para linhas, pois a prova para colunas é a mesma. Seja $\left(i^{\prime \prime}, j^{\prime \prime}\right)$ o primeiro ponto na linha para o qual $(i, j)$ é pior do $\left(i^{\prime}, j^{\prime}\right)$, isto é,

$$
D[i, j]+w\left(i+j, i^{\prime \prime}+j^{\prime \prime}\right) \geq D\left[i^{\prime}, j^{\prime}\right]+w\left(i^{\prime}+j^{\prime}, i^{\prime \prime}+j^{\prime \prime}\right) .
$$

Então, se $k \geq 1$, o ponto $\left(i^{\prime \prime}, j^{\prime \prime}+k\right)$ segue $\left(i^{\prime \prime}, j^{\prime \prime}\right)$ nesta linha e $i^{\prime \prime}+j^{\prime \prime}<i^{\prime \prime}+j^{\prime \prime}+k$. Supomos que $i^{\prime}+j^{\prime}<i+j$. Então pela convexidade de $w$, o inverso da desigualdade quadrangular

$$
w\left(i+j, i^{\prime \prime}+j^{\prime \prime}+k\right)-w\left(i+j, i^{\prime \prime}+j^{\prime \prime}\right) \geq w\left(i^{\prime}+j^{\prime}, i^{\prime \prime}+j^{\prime \prime}+k\right)-w\left(i^{\prime}+j^{\prime}, i^{\prime \prime}+j^{\prime \prime}\right)
$$

mantém-se. Somando as equações 4.8 e 4.9 , obtemos

$$
D[i, j]+w\left(i+j, i^{\prime \prime}+j^{\prime \prime}+k\right) \geq D\left[i^{\prime}, j^{\prime}\right]+w\left(i^{\prime}+j^{\prime}, i^{\prime \prime}+j^{\prime \prime}+k\right)
$$

o que significa que $(i, j)$ continua pior do que $\left(i^{\prime}, j^{\prime}\right)$

Primeiro olhamos para o primeiro ponto $\left(i^{\prime}, j^{\prime}\right)$ da tira e encontramos o intervalo contendo este ponto. Se o proprietário deste intervalo é, no mínimo, tão bom quanto $(i, j)$ naquele ponto, então $(i, j)$ nunca vencerá nesta tira e então a inserção da tira é realizada. Caso contrário, dividimos o intervalo contendo $\left(i^{\prime}, j^{\prime}\right)$ em dois intervalos de modo que o segundo inicie em $\left(i^{\prime}, j^{\prime}\right)$. O primeiro destes intervalos permanecerá com seu proprietário original e o segundo (ou parte deste) poderá eventualmente ser possuído por $(i, j)$.

Por ora, manteremos ambos intervalos com o mesmo proprietário original. Pode ser que, quando finalizarmos, mais do que um intervalo tipo linha tenha o mesmo proprietário. Isto não é um problema.

Encontramos um intervalo no início do qual $(i, j)$ é melhor do que os outros pontos possuindo intervalos na linha $i^{\prime}$. Este intervalo, que denominamos intervalo candidato, é atualmente possuído por algum outro ponto; este proprietário pode ser melhor do que $(i, j)$ na outra ponta do intervalo candidato. Necessitamos também lembrar qual é o intervalo possuído por $(i, j)$; por ora este é o intervalo vazio.

Repetimos os seguintes passos: primeiro encontre o intervalo subseqüente ao intervalo candidato. Se este intervalo inicia dentro do domínio de $(i, j)$ e se $(i, j)$ é melhor do que o proprietário deste novo intervalo no seu primeiro ponto, então $(i, j)$ deve ser melhor do que o proprietário do intervalo candidato para todos os pontos do intervalo candidato (pelo Lema 4.2.4). Daí concluímos que $(i, j)$ é melhor no início do novo intervalo. Neste caso, unimos o intervalo candidato com o intervalo possuído por $(i, j)$ e atribuímos como proprietário do intervalo resultante desta união o ponto $(i, j)$. Fazemos o intervalo seguinte como o novo intervalo candidato e continuamos o loop. Caso contrário, o intervalo no qual $(i, j)$ é melhor está contido dentro do intervalo candidato, de modo que interrompemos o loop.

Neste caso sabemos que o intervalo no qual $(i, j)$ é melhor termina em algum lugar no intervalo candidato. $\mathrm{O}$ intervalo necessita ser dividido em duas partes; a primeira parte será possuída por $(i, j)$ e a segunda parte esquerda mantém seu proprietário original. Encontramos o ponto no qual dividimos o intervalo por busca binária, em cada passo comparando o valor de $D+w$ para $(i, j)$ com aquele do proprietário anterior do intervalo candidato. Os pontos procurados começam no início do intervalo candidato e terminam ou no fim do intervalo ou no fim da tira, seja qual for que venha primeiro. 


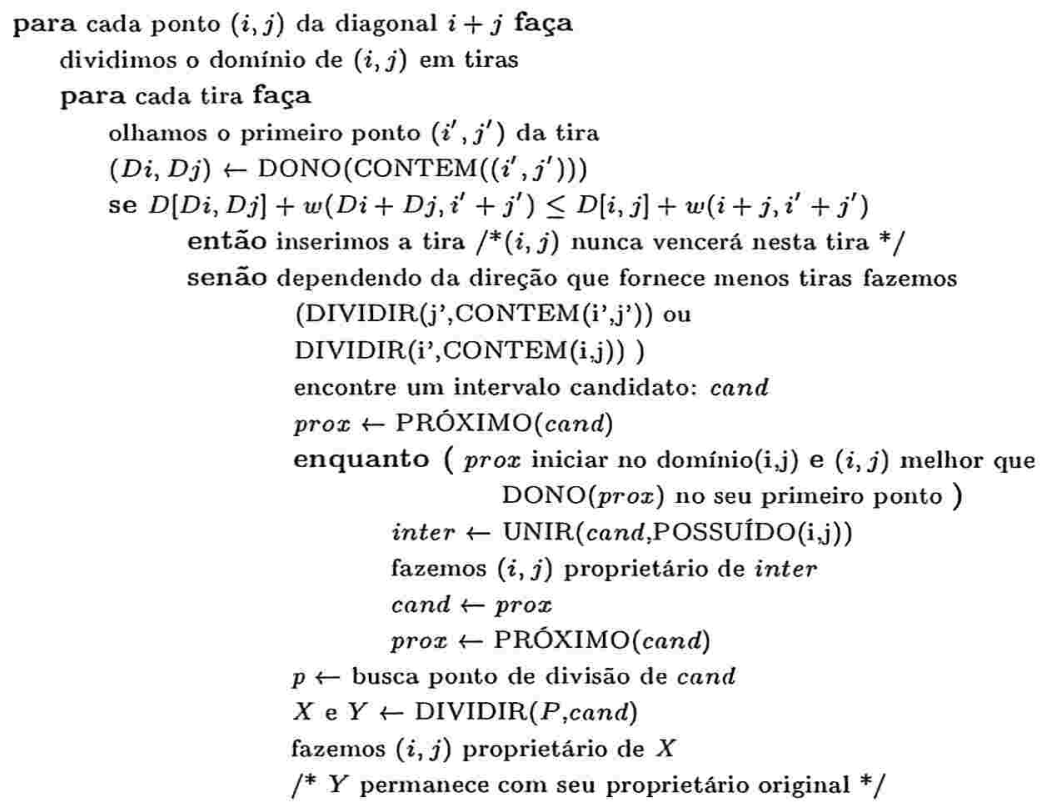

Figura 4.2: Algoritmo para inserção de tiras.

Eppstein et al [EGG88] mostram que o número de tiras de uma diagonal é $O(n \log n)$. Então, a partir deste resultado, eles enunciaram o teorema abaixo.

Teorema 4.2.5 $O$ algoritmo acima calcula os valores de $E(i, j)$ para a recorrência 4.6 com funções de desestabilização convexas em um tempo total expresso por $O\left(n^{2} \log ^{2} n\right)$.

Prova: Para cada diagonal o tempo consumido é:

- No passo (1) gastamos $O(\log n)$ para cada ponto (busca na estrutura dados). Como temos $O(n)$ pontos em cada diagonal, então para cada diagonal consumimos tempo $O(n \log n)$ neste passo.

- No passo (2) consumimos $O(n)$ para cada diagonal (Lema 4.2.3).

- No passo (3) gastamos $O(\log n)$ para cada tira. Como existem $O(n \log n)$ tiras, neste passo o tempo gasto é $O\left(n \log ^{2} n\right)$ para cada diagonal.

Como existem $O(n)$ diagonais, então o tempo total consumido pelo algoritmo é $O\left(n^{2} \log ^{2} n\right)$.

\subsubsection{Algoritmo de Larmore e Schieber}

Larmore e Schieber [LS90] melhoraram o tempo de execução para $O\left(n^{2}\right)$ no caso de funções côncavas. Apresentaram ainda um algoritmo cujo crescimento assintótico é expresso por $O\left(n^{2} \alpha(n)\right)$ no caso de funções convexas, onde $\alpha(n)$ é uma função com crescimento extremamente lento (inversa da função de Ackermann). 
Lembremos que o objetivo em questão é resolver o problema de programação dinâmica bidimensional representado pela recorrência 4.5. Para fazê-lo, o algoritmo de Larmore e Schieber utiliza como módulo um outro algoritmo que resolve um problema de programação dinâmica unidimensional similar representado pela recorrência

$$
E[i]=\min _{\substack{1 \leq i \leq n \\ 0 \leq C_{1} \leq \cdots \leq C_{n}<n}}\left\{D\left[i^{\prime}\right]+w\left(i^{\prime}, i\right) \mid 0 \leq i^{\prime} \leq C_{i}\right\} .
$$

Este algoritmo que resolve o problema de programação dinâmica unidimensional faz uso de duas suposições:

1. Os valores de $D[j]$ para $j=C_{i-1}+1, \cdots, C_{i}$ são facilmente computados a partir dos valores de $E[i-1]$. Por conveniência definimos $C_{0}=0$;

2. A função $w$ é côncava.

Para o caso de $w$ ser convexa Larmore e Schieber utilizam-se de outro algoritmo, desenvolvido por Klawe e Kleitman [KK88], para resolver a recorrência 4.11.

O problema de programação dinâmica unidimensional, mencionado acima, pode ser visto como um problema de busca em matriz. O algoritmo descrito por Larmore e Schieber não resolve este problema (recorrência 4.11) diretamente. Eles tratam-no como um problema de busca em matriz. Para que possamos enunciar este problema equivalente é necessário antes que façamos algumas definições.

Uma matriz $n \times m$ triangular $M$ é dita ser monotônica totalmente côncava se para todo $1 \leq i<i^{\prime} \leq$ $n$ e $0 \leq j<j^{\prime}<m$, a desigualdade $M[i, j]>M\left[i, j^{\prime}\right]$ implica que $M\left[i^{\prime}, j\right]>M\left[i^{\prime}, j^{\prime}\right]$. De forma similar uma matriz $n \times m$ triangular $M$ é dita ser monotônica totalmente convexa se para todo $1 \leq i<i^{\prime} \leq n$ e $0 \leq j<j^{\prime}<m$, a desigualdade $M[i, j]<M\left[i, j^{\prime}\right]$ implica que $M\left[i^{\prime}, j\right]<M\left[i^{\prime}, j^{\prime}\right]$. Para facilitar, assume-se que todos os elementos finitos de $M$ são distintos.

Uma matriz $n \times m$ é dita ser triangular superior generalizada se existem $0 \leq C_{1} \leq C_{2} \leq \cdots \leq$ $C_{n}=m-1$ tal que $M[i, j]=\infty$ para todo $C_{i}<j<m$. Uma matriz triangular superior generalizada é côncava (ou convexa) totalmente monotônica, se a condição de concavidade (ou convexidade) acima mantém-se para qualquer quatro entradas não infinitas de $M$, as quais formam uma sub-matriz retangular.

O problema de programação dinâmica unidimensional representado pela recorrência 4.11 pode ser, então, traduzido em um problema de busca em uma matriz triangular superior generalizada totalmente monotônica. Definimos uma matriz $n \times m$ triangular superior $M$ por

$$
M\left[i, i^{\prime}\right]=D\left[i^{\prime}\right]+w\left(i^{\prime}, i\right), 1 \leq i \leq n, 0 \leq i^{\prime} \leq C_{i}
$$

O resto dos elementos de $M$ são definidos como sendo $\infty$. Então resolver a recorrência 4.11 é equivalente a encontrar o elemento mínimo em cada linha da matriz $M$.

É interessante notarmos que a suposição de que $w$ é côncava traduz a condição de que $M$ é côncava totalmente monotônica. Da mesma forma, supor que $w$ é convexa traduz a condição imposta de que 
$M$ é convexa totalmente monotônica. É interessante observarmos também que a restrição - atribuída aos elementos das colunas $C_{i-1}+1, \ldots, C_{i}$ de $M$ (que não estão definidos como $\infty$ ) - que determina que estes devem estar disponíveis apenas depois do elemento mínimo na linha $i-1$ ter sido calculado, implica que não necessitamos de todas as entradas da matriz $D$ o tempo todo.

Vamos então definir o problema equivalente de busca em matriz. Seja $M$ uma matriz $n \times m$ triangular superior generalizada totalmente monotônica. As linhas de $M$ são indexadas no intervalo $1, \ldots, n$ e as colunas no intervalo $0, \ldots, m-1$. Para cada $1 \leq i \leq n$ existe uma coluna $C_{i-1} \leq C_{i}<m$ tal que $M[i, j]=\infty$, para todo $j>C_{i}$. Queremos então encontrar o elemento mínimo em cada linha de $M$ considerando a seguinte restrição: para $i>1$ o valor de $c_{i}$ e dos elementos das colunas $C_{i-1}+1, \ldots, C_{i}$ de $M$ (que não estão definidos como $\infty$ ) estarão disponíveis apenas depois de calculado o elemento mínimo na linha $i-1$.

Larmore e Schieber conceberam então um algoritmo linear para resolver o problema definido acima. Isto levou à formulação de um algoritmo para resolver o problema de programação dinâmica bidimensional - representado pela recorrência 4.5 - que consome tempo $O\left(n^{2}\right)$, no caso de $w$ ser côncava.

Klawe e Kleitman [KK88] construíram um algoritmo para o problema off-line de busca em uma matriz triangular superior generalizada totalmente monotônica que consome tempo $O(n \alpha(n))$, onde $\alpha$ é a inversa da função de Ackermann. Larmore e Schieber utilizaram este algoritmo para resolver o respectivo problema on-line e, a partir daí, formularam um algoritmo para o problema de programação dinâmica bidimensional (recorrência 4.5) que consome tempo $O\left(n^{2} \alpha(n)\right)$, no caso de $w$ ser convexa. 


\section{Capítulo 5}

\section{Usando Análise Comparativa entre Homólogos}

Uma outra forma de calcular a estrutura secundária de moléculas de RNAs é através da comparação de um dado conjunto de seqüências homólogas, entre as quais supõe-se existir um grau de similaridade que permita que as mesmas sejam alinhadas de modo confiável. Lembremos que duas ou mais seqüências são ditas homólogas se derivam de uma mesma seqüência, ou seja, se têm - do ponto de vista da história evolutiva - um ancestral comum. Esta estratégia está baseada no princípio da biologia molecular que diz que, no processo evolucionário, a estrutura é mais conservada do que a seqüência de nucleotídeos correspondente.

Ou seja, como o que realmente determina a função de uma molécula é sua estrutura, supõe-se que na eventualidade de uma alteração em uma dada base da seqüência que implique na modificação de sua estrutura (devido, por exemplo, a fatores mutacionais), esta vai ser acompanhada de uma outra alteração que neutralize aquela, de modo que a estrutura e função são conservadas. Este tipo de alteração é chamada de alteração compensatória.

Para ilustrar este princípio, suponhamos que - em um dado momento evolucionário - em uma seqüência $A$ a base na posição $i$ é uma adenina e forma uma ponte de hidrogênio com a base na posição $j$ (uma uracila) e que a ligação entre estas duas bases participa da definição da estrutura da molécula como um todo. Agora suponhamos também que - num outro momento da história evolutiva - a seqüência $B$ deriva de $A$ através da alteração da adenina para citosina na posição $i$. Como $B$ deriva de $A$, é razoável pensar que $B$ deva preservar as funções de $A$, a fim de perpetuar um processo qualquer, como a síntese de uma proteína vital, por exemplo. No entanto, a alteração ocorrida na posição $i$ pode alterar a estrutura da molécula e também sua função, pois a citosina na posição $i$ não se ligará com a uracil da posição $j$. Assim, mecanismos evolucionários irão garantir que uma outra alteração ocorra (no caso a mudança de uracil para guanina na posição $j$ ), de modo que a ligação entre $i$ e $j$ seja mantida e a estrutura da molécula preservada.

Os métodos que se utilizam deste princípio geralmente fazem uso de técnicas de análise de cova- 
riância para inferir a estrutura da molécula. Eles também geralmente envolvem, de alguma forma, algoritmos de alinhamento múltiplo, pois ou recebem um alinhamento das seqüências homólogas como entrada ou produzem um alinhamento para estas seqüências. Alguns métodos utilizam programas de alinhamento prontos, como por exemplo o CLUSTAL W [THG94, HS88].

Para melhor analisar os métodos que envolvem o problema de alinhamento múltiplo, é interessante tecer algumas considerações acerca dos algoritmos para o problema. Tendo como critério de pontuação o SP-pontuação ${ }^{1}$, já se provou que o problema geral de alinhamento múltiplo é NP-difícil [WJ94]. Bonizzoni e Vedova [BV01] provaram que, para matrizes de pontuação que representam uma métrica do tipo distância, o problema também é NP-difícil. Um "bom" algoritmo para o problema (usando SP-pontuação) foi proposto por Carrilo e Lipman [CL88]. No entanto, existem heurísticas que são utilizadas na prática, bem como há também algoritmos de aproximação para o problema. Por exemplo, Gusfield [Gus93] descreveu um algoritmo para o problema com fator 2 de aproximação.

Vários métodos foram formulados baseados nestas idéias. Existem também esforços no sentido de incorporar em um único método características oriundas do cálculo de energia livre mínima, bem como da análise comparativa entre homólogos. Há ainda métodos que não se utilizam diretamente das técnicas de análise de covariância, mas exploram o fato de disporem de um conjunto de seqüências homólogas e as propriedades que daí advém.

Han e Kim [HK93] propuseram uma heurística baseada em técnicas de análise de covariância com complexidade $O\left(m n^{2}+n^{3}\right)$, onde $m$ é o número de seqüências homólogas e $n$ o número de bases em cada uma das moléculas alinhadas. Este método é descrito adiante.

Winker et al $\left[\mathrm{WOW}^{+} 90\right]$ também propuseram um algoritmo que se utiliza de técnicas de covariância para determinação de estrutura secundária a partir de um alinhamento de seqüências homólogas.

Lück et al [LSR96] elaboraram um método que combina elementos de análise comparativa com distribuição de probabilidade de estruturas. Eles se utilizam do algoritmo para cálculo da função Partição Equilíbrio e de probabilidade de pares de McCaskill [McC90], descrito na Seção 5.3.1.

Gulko e Haussler [GH96] formularam um método estatístico para determinar se um par de colunas em um alinhamento de RNAs homólogos formam pares nas seqüências do alinhamento. Este método faz uso de uma dada árvore filogenética clássica, que descreve os relacionamentos filogenéticos entre as sequiências do alinhamento.

Chan et al [CZJ90] descreveram um método para identificar o dobramento comum em um conjunto de seqüências homólogas alinhadas, que utiliza tabelas hashing para codificar as hélices encontradas no alinhamento.

Alguns métodos recentes baseados em gramáticas estocásticas independentes de contexto, que utilizam a dependência estatística entre as colunas de um alinhamento de homólogos, também foram propostos para identificar o dobramento comum entre as seqüências: [Lef95], [Lef96] [ED94], [SBH+ 94].

\footnotetext{
${ }^{1}$ Grosso modo, SP-pontuação pode ser entendido como um critério que contabiliza a pontuaçāo para todo os pares do alinhamento. Esta pontuação é expressa em termos de uma função objetivo que pode ser maximizada (similaridade) ou minimizada (distância).
} 
Grate [Gra95] desenvolveu um método para predição de estrutura secundária comum a uma seqüência de RNA's homólogos alinhados que utiliza gramáticas estocásticas livre de contexto. Neste trabalho, Grate também utiliza o índice de informação mútua como medida de covariância em pares de colunas do alinhamento.

\subsection{Análise de Covariância}

Como já dissemos, os métodos que se utilizam do princípio enunciado acima, geralmente, fazem uso de técnicas de análise de covariância para inferir a estrutura da molécula. A fim de melhor descrever este tipo de técnica, suponhamos um alinhamento múltiplo de um conjunto de seqüências homólogas $R^{1}, R^{2}, \ldots, R^{m}$ todas de tamanho $n$, como ilustrado abaixo:

$$
\begin{aligned}
& R^{1}=\begin{array}{lllll}
r_{1}^{1} & r_{2}^{1} & r_{3}^{1} & \cdots & r_{n}^{1}
\end{array} \\
& R^{2}=\begin{array}{lllll}
r_{1}^{2} & r_{2}^{2} & r_{3}^{2} & \cdots & r_{n}^{2}
\end{array} \\
& \begin{array}{llllll}
\vdots & \vdots & \vdots & \vdots & \ddots & \vdots
\end{array} \\
& R^{m}=\begin{array}{lllll}
r_{1}^{m} & r_{2}^{m} & r_{3}^{m} & \cdots & r_{n}^{m}
\end{array}
\end{aligned}
$$

Uma medida quantitativa da interdependência entre pares de colunas, que vem da teoria da informação [CK91, GPH ${ }^{+}$92, DEKM98], é denominada indice de informação mútua.

Para melhor entender esta medida, façamos antes algumas definições e considerações. Uma entropia é uma medida da incerteza de um evento. Dado uma variável aleatória $X$ com probabilidades $P\left(x_{i}\right)$ para o conjunto discreto de $k$ eventos $x_{1}, x_{2}, \cdots, x_{k}$, a entropia de Shannon é definida por

$$
H(X)=-\sum_{i=1}^{k} P\left(x_{i}\right) \log _{2} P\left(x_{i}\right) .
$$

Esta entropia é maximizada quando todos os termos da soma são iguais, isto é, $P\left(x_{i}\right)=1 / k$. Deste modo, temos

$$
H(X)=-\sum_{i=1}^{k} P\left(x_{i}\right) \log _{2} P\left(x_{i}\right)=-\sum_{i=1}^{k} \frac{1}{k} \log _{2} \frac{1}{k}=\log _{2} k .
$$

Se estamos certos do resultado de um evento $x_{i}$, isto é, se temos que $P\left(x_{i}\right)=1$ ou $P\left(x_{i}\right)=0$, então a entropia é zero.

Em teoria da informação, de um modo geral, podemos entender índice de informação I como uma medida da redução da incerteza depois de alguma "mensagem", isto é, a diferença de entropia antes e depois da mensagem:

$$
I(X)=H_{\text {antes }}(X)-H_{\text {depois }}(X) .
$$

Índice de informação pode ser usado para mensurar o grau de conservação de bases em um alinhamento de RNAs. Por exemplo, suponhamos que a expectativa para uma base de RNA é aleatória, ou seja, $P(r)=1 / 4$ e $H_{\text {antes }}=2$, onde $r \in\{A, C, G, U\}$. Suponhamos também que observamos, para uma posição particular, sempre um 'A' ou um 'G' com $P(A)=0.7$ e $P(G)=0.3$. Desta forma, temos 
$H_{\text {depois }}=-0.7 \log _{2} 0.7-0.3 \log _{2} 0.3=0.88$. Portanto, o índice de informação para esta posição é $2-0.88=1.12$. Entretanto, notemos que o índice de informação pode assumir valor negativo se a distribuição observada tem uma entropia maior do que a esperada.

Por conta disto, é então melhor mensurar a diferença entre duas distribuições por meio da entropia relativa. Para duas distribuições $P$ e $Q$, a entropia relativa é definida como

$$
H(P \| Q)=\sum_{i=1}^{k} P\left(x_{i}\right) \ln \frac{P\left(x_{i}\right)}{Q\left(x_{i}\right)} .
$$

Entropia relativa apresenta a propriedade de ser sempre maior ou igual a zero, onde a igualdade é verificada se $P\left(x_{i}\right)=Q\left(x_{i}\right)$.

Prova: Temos que $\ln x \leq x-1$, onde $\ln x=x-1$ apenas se $x=1$. Segue que

$$
\begin{aligned}
-H(P \| Q) & =\sum_{i=1}^{k} P\left(x_{i}\right) \ln \frac{Q\left(x_{i}\right)}{P\left(x_{i}\right)} \\
& \leq \sum_{i=1}^{k} P\left(x_{i}\right)\left(\frac{Q\left(x_{i}\right)}{P\left(x_{i}\right)}-1\right) \\
& =\sum_{i=1}^{k} P\left(x_{i}\right) \frac{Q\left(x_{i}\right)}{P\left(x_{i}\right)}-\sum_{i=1}^{k} P\left(x_{i}\right) \\
& =\sum_{i=1}^{k} P\left(x_{i}\right) \frac{Q\left(x_{i}\right)}{P\left(x_{i}\right)}-1=0,
\end{aligned}
$$

com a igualdade mantendo-se apenas se, para cada $i, Q\left(x_{i}\right)=P\left(x_{i}\right)$.

É útil encarar a entropia relativa $H(P \| Q)$ como a distância entre as distribuições de probabiliade $P$ e $Q$. Entretanto, devemos observar que elas não são simétricas, ou seja, $H(P \| Q) \neq H(Q \| P)$.

Duas variáveis aleatórias $X$ e $Y$ são independentes se $P(X, Y)=P(X) P(Y)$. Nos interessa saber quão independentes elas são. Isto pode ser mensurado por meio da entropia relativa entre as distribuições $P(X, Y)$ e $P(X) P(Y)$. Assim,

$$
M(X, Y)=\sum_{i, j} P\left(x_{i}, y_{j}\right) \log _{2} \frac{P\left(x_{i}, y_{j}\right)}{P\left(x_{i}\right) P\left(y_{j}\right)},
$$

onde $M(X, Y)$ é uma medida da interdependência entre $X$ e $Y$ e os valores possíveis de $X$ e $Y$ são $\left\{x_{i}\right\}$ e $\left\{y_{j}\right\}$.

Em teoria da informação, é frequente se assumir que a distribuição de probabilidade é conhecida. No entanto, em muitas aplicações não se conhece a distribuição verdadeira. Então, as entropias são calculadas através das freqüencias relativas dos eventos ao invés da distribuição de probabilidade. Para uma coluna $i$, seja $f_{i}(r)$ a freqüência relativa com que a base $r$ ocorre na $i$-ésima coluna, onde $r \in\{A, C, G, U\}$. Vamos considerar uma outra coluna $j$ e tomar $f_{i, j}(r, s)$ como sendo a freqüência relativa conjunta de ocorrência dos dois nucleotídeos $r$ e $s$ nas colunas $i$ e $j$. Em outras palavras, seja $f_{i, j}(r, s)$ a frequiência relativa com que ocorre um dos dezesseis possíveis pares de bases nas colunas $i$ e $j$. 
Na hipótese onde quaisquer duas colunas são independentes, devemos esperar que $f_{i, j}(r, s)$ seja aproximadamente igual a $f_{i}(r) f_{j}(s)$. Desta forma, esperamos

$$
\log \frac{f_{i, j}(r, s)}{f_{i}(r) f_{j}(s)} \approx 0 .
$$

Isto leva à definição do indice de informação mútua entre duas diferentes colunas $i$ e $j$, denotado por $M_{i, j}$, como

$$
M_{i, j}=\sum_{r, s \in\{A, C, G, U\}} f_{i, j}(r, s) \log _{2} \frac{f_{i, j}(r, s)}{f_{i}(r) f_{j}(s)} .
$$

Utilizamos o logaritmo na base 2 , de tal modo que o resultado de $M_{i, j}$ - para as quatro letras do alfabeto do RNA - varia entre 0 e 2. Quando $i$ e $j$ covariam perfeitamente, devemos esperar que

$$
f_{i, j}(r, s)=f_{i}(r)=f_{j}(s)
$$

para todos os pares de nucleotídeos. Esta quantidade deve ser 0 quando $r$ e $s$ não formam par.

Desta forma, esperamos que $M_{i, j}$ seja máximo (isto é, $M_{i, j}=2$ ) quando $i$ e $j$ correlacionam perfeitamente e mínimo (isto é, $M_{i, j}=0$ ) quando $i$ e $j$ não estão correlacionados. Ou seja, $M_{i, j}$ é máximo se $i$ e $j$, individualmente, aparecem completamente aleatórios $\left(f_{i}=f_{j}=0.25\right)$ com $i$ e $j$ perfeitamente correlacionados (formando par).

\subsection{Método de Han e Kim}

A solução (heurística) de Han e Kim [HK93] tem como entrada um conjunto de $m$ seqüências homólogas alinhadas $R^{1}, R^{2}, \ldots, R^{m}$ todas de tamanho $n$, onde alguns dos elementos podem ser buracos ( $g a p$ 's) em algumas seqüências, porém não em todas as seqüências para uma mesma posição; isto é, pensando nesta entrada como uma matriz, não temos uma coluna formada apenas de buracos, ou seja, não temos $r_{i}^{1}=r_{i}^{2}=r_{i}^{3}=\cdots=r_{i}^{m}=g a p$, para algum $i$ fixo entre 1 e $n$ :

$$
\begin{aligned}
& \begin{array}{llllll}
R^{1}= & r_{1}^{1} & r_{2}^{1} & r_{3}^{1} & \cdots & r_{n}^{1}
\end{array} \\
& R^{2}=\begin{array}{llllll}
r_{1}^{2} & r_{2}^{2} & r_{3}^{2} & \cdots & r_{n}^{2}
\end{array} \\
& \begin{array}{llllll}
\vdots & \vdots & \vdots & \vdots & \ddots & \vdots
\end{array} \\
& R^{m}=\begin{array}{lllll}
r_{1}^{m} & r_{2}^{m} & r_{3}^{m} & \cdots & r_{n}^{m} .
\end{array}
\end{aligned}
$$

Esta heurística trabalha em dois passos: (1) é realizado um processo denominado análise comparativa filogenética do qual resulta uma matriz chamada matriz de covariância, a partir da qual é possível identificar hélices (ou regiões de pares de bases empilhados); (2) inferência de estruturas analisando as hélices potenciais identificadas na matriz de covariância obtida no passo anterior. O passo (1) pode ser assim descrito:

$$
\begin{gathered}
\text { Para cada coluna } i \text { no alinhamento faça } \\
\text { Para cada coluna } j(>i) \text { no alinhamento faça } \\
\text { determine a relação } M C(i, j)
\end{gathered}
$$


onde a relação $M C(i, j)$ representa o tipo de pareamento entre as bases das colunas $i$ e $j$ para todas as $m$ seqüências do alinhamento. Neste algoritmo é então estabelecida uma rotulação para as entradas de $M C$ que manifestam uma relação com o conceito de índice de informação mútua, descrito acima. Como diferentes seqüências podem ter diferentes tipos de pareamento nas colunas $i$ e $j$, esta rotulação tenta então definir claramente a relação $M C(i, j)$ :

- se a base $r_{i}^{v}$ pareia com a base $r_{j}^{v}$ em todas as $m$ seqüências $(1 \leq v \leq m)$ e não existe variação das bases tanto em $i$ como em $j$, então $M C(i, j)$ é um par invariante exato denotado por '\#';

- se a base $r_{i}^{v}$ pareia com a base $r_{j}^{v}$ em todas as $m$ seqüências e existem alterações compensatórias em $r_{i}^{v}$ e/ou $r_{j}^{v}$, então $M C(i, j)$ é um par variante exato denotado por '*';

- se nas colunas $i$ e $j$ a maioria das seqüências formam um par wobble (G-U), então $M C(i, j)$ é um par wobble, denotado por ' $w$ ';

- se a base $r_{i}^{v}$ pareia com a base $r_{j}^{v}$ em muitas seqüências (mas não em todas) e a freqüência de bases não pareadas não ultrapassa um número específico (determinado pelo usuário), então este é um par inexato, denotado por '十';

- se a freqüência de bases não pareadas entre as colunas $i$ e $j$ ultrapassa um número específico (também determinado pelo usuário), então $M C(i, j)$ é dito ser um não-par, denotado por ''.

Como resultado do passo (1), temos uma matriz $(n \times n)$ para seqüências de tamanho $n$, onde a entrada $(i, j)$ representa a relação $M C(i, j)$. Como a relação $M C(i, j)$ é simétrica, somente a parte correspondente à matriz triangular superior é utilizada. Hélices potenciais são representadas nesta matriz como diagonais formadas por elementos diferentes de não-pares, no caso identificados pelos símbolos '\#', '*', ' $w$ ' e '+'. É interessante observar que o pareamento da base $r_{i}^{v}$ com a base $r_{j}^{v}$ em todas (ou na maioria) das $m$ seqüências do alinhamento, corresponde a uma entrada na matriz de covariância $M C$. A Figura 5.1 ilustra estes conceitos.

Infelizmente, não é possível inferir a estrutura secundária diretamente a partir da matriz de covariância, pois muitas das hélices potenciais identificadas podem ser conflitantes entre si. Em outras palavras, o conjunto de pares representado na matriz de covariância pode não corresponder a uma estrutura secundária; ou seja, este conjunto de pares pode não satisfazer as restrições impostas pela definição de estrutura secundária (definida na Seção 2.2). Os conflitos ocorrem em quatro situações, que podem ser indentificados a partir de $M C$. Para então identificar estas situações a partir de $M C$ vamos adotar uma notação que nos auxilie:

- $R_{i, j}^{v}=r_{1}, r_{2}, \ldots, r_{n}$, onde $i<j$, representa um intervalo de bases na seqüência $R^{v}, 1 \leq v \leq m$, que vai da base $r_{i}^{v}$ à base $r_{j}^{v}$;

- $R_{i, j}^{v} \odot R_{k, l}^{v}$, com $i<j$ e $k<l$, representa o pareamento, na seqüência $R^{v}$, das bases do intervalo $R_{i, j}^{v}$ com as bases do intervalo $R_{k, l}^{v}$, formando nesta seqüência uma hélice (ver Figura 5.2 à esquerda); 


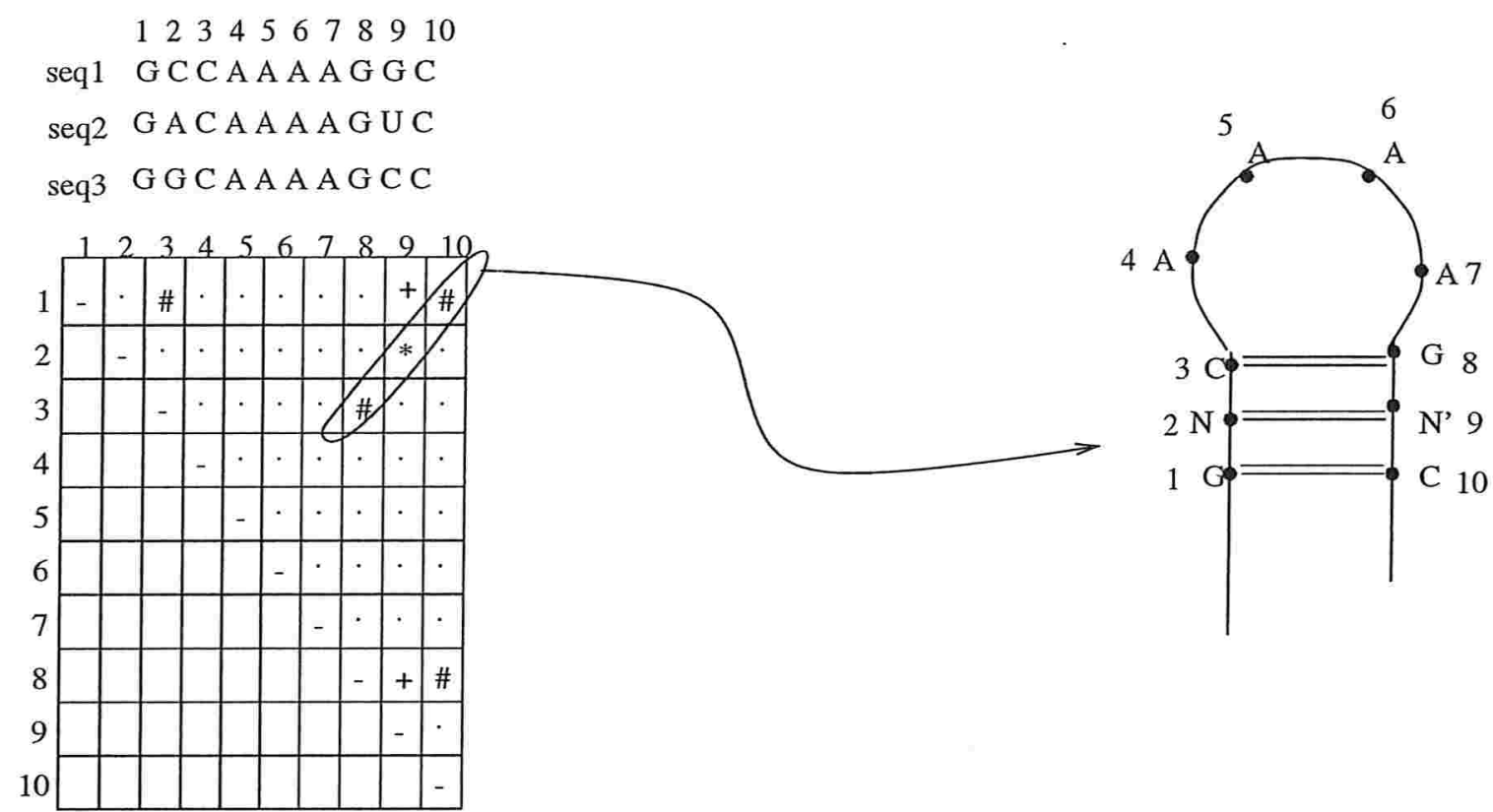

MC

Figura 5.1: A matriz $M C$ para um conjunto de 3 seqüências homólogas (seq1, seq2 e seq3) de tamanho 10 com a diagonal circundada indicando a hélice potencial comum às três seqüências, que está desenhada à direita.

- Se houver pareamentos $R_{i, j}^{v}$ ( $R_{k, l}^{v}$ em todas (ou na maioria) das seqüências que compõem o alinhamento, então observamos uma correspondente diagonal em $M C$ para estes pareamentos. Denotamos este conjunto de pareamentos por $R_{i, j}$ (S) $R_{k, l}$, que é ilustrado à direita na Figura 5.2.
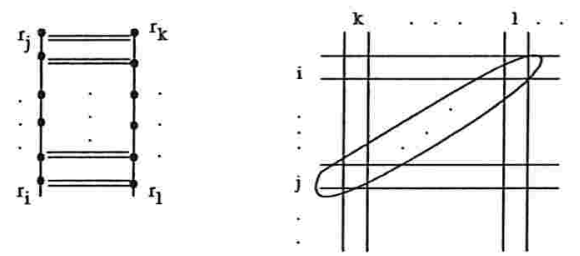

MC

Figura 5.2: Desenho à esquerda: pareamento $R_{i, j}^{v} \odot R_{k, l}^{v}$ em uma determinada seqüência. Desenho à direita: pareamentos $R_{i, j}\left(R_{k, l}\right.$ correspondendo a uma diagonal em $M C$.

As quatro situações de conflito são:

1. Uma base, em uma dada estrutura, pode parear uma única vez. Isto pode ser visto em $M C$ como a situação onde mais do que uma diagonal interceptam uma mesma linha ou coluna de $M C$. Por exemplo, se tivermos em $M C$ as diagonais $R_{1,2}(S) R_{3,4}$ e $R_{1,2}(S) R_{5,6}$ onde $R_{1,2}$ indica a subseqüência onde há sobreposição; 


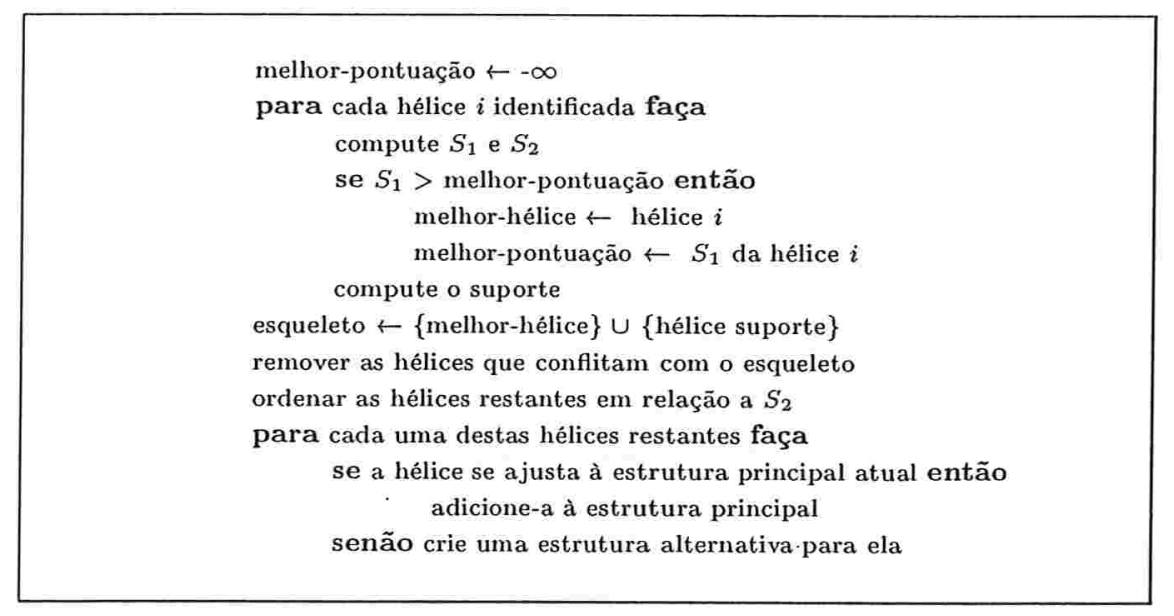

Figura 5.3: Passo (2) da heurística de Han e Kim.

2. Uma outra situação que representa o pareamento de uma mesma base por mais de uma vez, pode ser visto em $M C$ através de pareamentos em linhas e colunas disjuntas, mas a linha limite de um sobrepõe-se à coluna limite de outro ou vice-versa. Por exemplo, quando temos as diagonais $R_{1,2}$ (S) $R_{3,4}$ e $R_{3,4}$ (S) $R_{5,6}$;

3. Quando ocorrem pseudo-nós. Isto em $M C$ corresponde à situação na qual há pareamentos de bases $R_{1,2}(\mathrm{~S}) R_{5,6}$ e $R_{3,4}(\mathrm{~S}) R_{7,8}$ onde $R_{1,2}$ precede $R_{3,4}$ e $R_{3,4}$ precede $R_{5,6}$;

4. Quando surgem resultados contendo arcos com tamanhos menores que 3. Isto em $M C$ pode ser visto se, para $R_{i, j}$ (S) $R_{k, l}$, tem-se que $k-j<t=3$.

Para decidir sobre estes conflitos no passo (2), o método utiliza um procedimento (heurística), descrito na Figura 5.3, que computa, para cada hélice potencial identificada, duas pontuações $S_{1}$ e $S_{2}$, que são calculadas com base nos seguintes parâmetros: tamanho da hélice, número de pares variantes exatos presentes, número de pares wobble presentes, número de pares inexatos presentes e o tamanho de um possível laço arco formado pela hélice.

As pontuações $S_{1}$ e $S_{2}$ são utilizadas para identificar a hélice mais estável (denominada melhorhélice) de toda a estrutura e o seu suporte (uma outra hélice estável que se situa no mesmo eixo da melhor-hélice, se existir), respectivamente. A melhor-hélice juntamente com o seu suporte constituem o esqueleto da estrutura, que é utilizado para eliminar hélices conflitantes com ele.

No cálculo de $S_{1}$ e $S_{2}$, os pesos dos parâmetros acima relacionados variam conforme a necessidade e interpretação do usuário. Abaixo mostramos um exemplo de atribuição de pesos a estes parâmetros:

\footnotetext{
- $S_{1}=1.0 *$ tamanho_da_helice $+1.0 *$ numero_de_pares_variantes_exatos $+(-0.5) * n u m e r o \_d e \_p a r e s \_w o b b l e+$ $(-2.0) *$ numero_de_pares_inexatos $+(-0.05) * \overline{t a m a n h o} \bar{C}_{-}{ }^{2}$ _hairpin

- $S_{2}=1.0 *$ tamanho_da_helice+1.0*numero_de_pares_variantes_exatos $+(-1.0) *$ numero_de_pares_inexatos
}

Este método encontra entre 1 e 5 estruturas (limite imposto pelo usuário). Acredita-se que um número excessivo (mais do que 5) de estruturas geradas não traz grandes contribuições, do ponto de 
vista das informações que elas podem oferecer para o biólogo. Isto porque parte-se do pressuposto de que as seqüências alinhadas têm entre si um grau de similaridade razoável, o que implica num leque de variação pequeno nas estruturas encontradas.

Esta heurística consome tempo e espaço proporcionais a $O\left(m n^{2}+n^{3}\right)$ e $O\left(n^{2}\right)$, respectivamente, pois a matriz de covariância é gerada, no passo (1), em tempo $O\left(m n^{2}\right)$ e espaço $O\left(n^{2}\right)$. O número de hélices potenciais na matriz é $O\left(n^{2}\right)$ e ordená-las consome tempo $O\left(n^{2} \log n\right)$. Cada hélice é examinada uma única vez e comparada com uma outra hélice em $k$ estruturas $(k<5)$. Visto que cada estrutura contém hélices não conflitantes, então o número máximo de hélices em cada estrutura é $O(n)$. Portanto, construir as estruturas toma tempo $O\left(n^{2} \log n+n^{2} k n\right)=O\left(n^{3}\right)$ e espaço $O\left(n^{2}\right)$. 


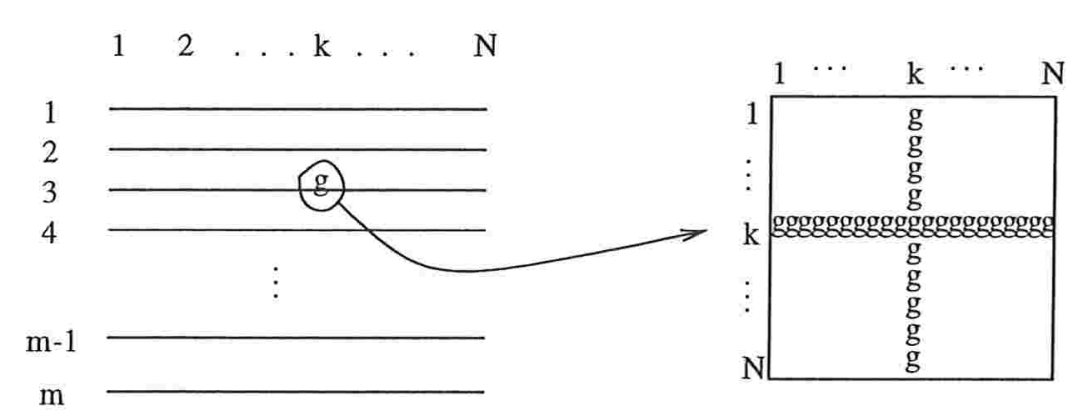

Alinhamento $(\mathrm{g}=\mathrm{gap}) \quad$ Matriz de Probabilidade de Homólogos

Figura 5.4: Alinhamento (à esquerda) e matriz de probabilidade de homólogos da terceira seqüência do alinhamento (à direita).

\subsection{Método de Lück}

Este método proposto por Lück et al [LSR96] calcula a estrutura secundária "ótima" e estruturas secundárias sub-ótimas para cada uma das seqüências de um conjunto de RNAs homólogos. As seqüências são alinhadas para que se possa identificar regiões onde a estrutura é conservada individualmente em cada uma das seqüências. Então, uma estrutura consensual é calculada pela comparação e análise destas regiões onde há conservação das estruturas individuais a cada seqüência.

O método tem como entrada um conjunto $R^{1}, R^{2}, \ldots, R^{m}$ de seqüência homólogas e fornece como saída uma estrutura secundária "ótima" e estruturas secundárias sub-ótimas. Ele pode ser dividido em cinco passos, assim definidos:

Passo 1 Para cada das $m$ seqüências de RNAs homólogas, é calculada - em uma temperatura definida - a distribuição de estrutura contendo a estrutura ótima e as sub-ótimas, conforme o algoritmo descrito na Seção 5.3.1. Conforme veremos na Seção 5.3.1, é gerada, então, para cada uma das $m$ seqüências homólogas, uma matriz de probabilidade de pares de base. Esta matriz estima levando em conta fatores termodinâmicos - as alternativas estruturais para a seqüência dada.

Passo 2 Executa-se um alinhamento múltiplo sobre o conjunto de RNAs homólogos. Depois de executado o alinhamento, as seqüências têm tamanho $N$ maior ou igual ao tamanho original $n$, devido à inserção de gaps.

Passo 3 De acordo com a informação obtida no Passo 2, gaps são introduzidos nas matrizes de probabilidade de pares de cada RNA, em posições onde aparecem gaps no alinhamento correspondente. Por exemplo, se depois do alinhamento a $v$-ésima seqüência passa a conter um gap na posição $k$, então na matriz correspondente à $v$-ésima seqüência são inseridas uma linha (de índice $k$ ) contendo apenas gaps e uma coluna (também de índice $k$ ) contendo também apenas gaps. $\mathrm{O}$ resultado desta operação é um conjunto de matrizes denominadas matrizes de probabilidade de homólogos, que assumem tamanho máximo $N \times N$. A Figura 5.4 ilustra esta operação.

Passo 4 As matrizes de probabilidade de homólogos são somadas a fim de que a probabilidade do 
par de bases $\left(r_{i}, r_{j}\right)$ (denotada por $\left.P_{k}(i, j)\right)$ de cada uma das $m$ seqüências contribua para a probabilidade do par de bases conservado na(s) estrutura(s) predita(s) (denotada por $P^{c}(i, j)$ ), de modo que

$$
P^{c}(i, j)=\frac{\left(\sum_{k=1}^{m} P_{k}(i, j)^{a}\right)^{b}}{m} .
$$

Os expoentes $a$ e $b$ no somatório são adotados para suprimir valores de probabilidade individual, que não são conservados na matriz de probabilidade de homólogos. O resultado é uma outra matriz, denominada matriz de probabilidade de pares de base consensual. No caso onde muitas das estruturas contêm hélices em posições idênticas nas matrizes de probabilidade de homólogos, hélices consensuais proeminentes aparecem na matriz de probabilidade consensual. Entretanto, se uma certa hélice aparece apenas em uma ou em poucas matrizes de probabilidade de homólogos, seu aparecimento na matriz de probabilidade consensual é suprimido.

Passo 5 A partir da matriz de probabilidade consensual, é, então, extraída uma estrutura secundária consensual. Isto é feito através de um algoritmo de programação dinâmica, que maximiza a soma das probabilidades dos pares de bases. Este algoritmo é similar ao proposto por Nussinov et al [NPGK78]. Se a probabilidade de um determinado par de bases é menor do que um limite adotado pelo usuário, por exemplo 0.01 vezes a maior probabilidade encontrada para todos os pares de bases, este par pode ser excluído da estrutura secundária.

Com relação à complexidade, temos que no Passo 1 este método consome tempo $O\left(m n^{3}\right)$, onde $m$ é o número de sequiências homólogas da entrada e $n$ é o tamanho de cada uma delas, pois o cálculo da matriz de probabilidade de pares para cada uma consome $O\left(n^{3}\right)$.

O Passo 3 consome $O(m N)$, onde $N$ é o tamanho das seqüências depois do alinhamento. O Passo 4 consome $O\left(m N^{2}\right)$ e o Passo 5 consome $O\left(N^{3}\right)$. Com relação à complexidade de espaço, o método consome $O\left(m N^{2}\right)$, pois precisa armazenar as $m$ matrizes com gaps produzidas no Passo 3.

\subsubsection{Função Partição e Probabilidade de Pares}

Agora vamos descrever um algoritmo para computar as funções Partição Equilíbrio e, a partir disto, as probabilidades de todos os pares de base. Este algoritmo foi proposto por MacCaskill [McC90] e é dividido basicamente em duas partes, de forma bastante parecida com os algoritmos para cálculo de energia livre mínima da Seção 3.2: usando programação dinâmica, onde uma parte calcula as funções Partição e outra as probabilidades dos pares de bases (fase backtracking).

Para melhor descrever as recursões deste algoritmo e levando em conta esta semelhança, vamos relembrar as definições de funções de energia para laços:

- $\varepsilon h(i, j)$ é a energia do laço arco fechado pelo par $\left(r_{i}, r_{j}\right)$;

- $\varepsilon L\left(i, j, i^{\prime}, j^{\prime}\right)$ é a energia mínima de um laço interno ou de uma barriga fechados por $\left(r_{i}, r_{j}\right)$ ou do empilhamento de dois pares de bases adjacentes $\left(r_{i}, r_{j}\right)$ e $\left(r_{i+1}, r_{j-1}\right)$; 
- $\varepsilon m(i, j)$ é a energia mínima de um k-laço de tamanho $k^{\prime}$, com $k>2$ (multilaço), fechado por $\left(r_{i}, r_{j}\right)$. Aqui também é assumido que a contribuição dos multilaços é representada por uma função linear da forma $\varepsilon m(i, j)=a+(k-1) \times b+k^{\prime} \times c$, onde $k^{\prime}$ o número de bases não pareadas acessiveis ao multilaço e $\mathrm{k}$ o número de pares de bases acessíveis ao multilaço.

Lembremos também que naquela Seção (3.2) dissemos que as energias são atribuídas aos laços e a energia da estrutura $S$ é escrita como

$$
\operatorname{Energia}(S)=\sum_{i=1}^{m} \varepsilon\left(\operatorname{Laço}_{i}\right) \text {. }
$$

Seja $U$ o conjunto de todas as possíveis estruturas secundárias. A aditividade da energia livre induzida pelo Lema 2.2.1 — possibilita definir o valor Partição $Q$ por

$$
Q=\sum_{S \in U} e^{-\frac{\text { Energia(S) }}{R T}} .
$$

Esta é a distribuição de probabilidades de todas as estruturas. Segundo a teoria mecânica estatística [McC90], este número, denominado ponderação de Boltzmann, fornece a densidade de probabilidade para todo dobramento. Ou seja, a probabilidade de qualquer dobramento (estrutura secundária) particular $S$ é dado por

$$
P(S)=\frac{1}{Q} e^{-[\text {Energia }(S) / R T]}
$$

Evidentemente, o cálculo de $Q$ se torna impraticável se utilizarmos um algoritmo ingênuo, pois o número de possíveis candidatos à estrutura secundária cresce exponencialmente com $n$, como vimos no Teorema 2.2.3. Entretanto, $Q$ pode ser calculada em tempo $O\left(n^{4}\right)$ usando um algoritmo de programação dinâmica.

Neste algoritmo, utilizamos as funções Partição $Q B(i, j)$ e $Q(i, j)$ - armazenadas nas matrizes $Q B[i][j]$ e $Q[i][j]$, respectivamente - para as "sub-estruturas" na subseqüência $R_{i, j}=r_{i}, r_{i+1}, \ldots, r_{j}$, $1 \leq i<j \leq n$ para as situações onde há formação de pares de bases e onde pode ou não haver a formação de pares de bases, respectivamente. Elas assumem valores iniciais $Q B[i][i]=0$ e $Q[i][i]=1.0$ e $Q[i+1][i]=1.0$. Variáveis (matrizes) auxiliares $Q M$ e $Q M 1$ são necessárias - como ocorreu na Seção 3.2 - para manipulação de multilaços, com valores iniciais $Q M[i][i]=0, Q M[i+1][i]=0 \mathrm{e}$ $Q M 1[i][i]=0, Q M 1[i+1][i]=0$. A Figura 5.5 descreve este algoritmo.

Para reduzir o tempo de computação deste algoritmo para $O\left(n^{3}\right)$, as estratégias utilizadas são as mesmas adotadas no Capítulo 3. Primeiro, é necessário fazer a suposição de linearidade relativa aos multilaços como visto acima e, segundo, tenta-se melhorar a complexidade do algoritmo como um todo por meio da diminuição do tempo de computação dos laços internos.

É interessante observar que quando MacCaskill elaborou este algoritmo, ele adotou como solução para melhorar o tempo dos laços internos a restrição do tamanho destes laços a um tamanho máximo igual a 30 e introduzindo uma variável auxiliar $Q A$, onde esta assume valores iniciais $Q A[i][i]=0$. Esta restrição melhora o tempo associado ao cálculo dos laços internos de $O\left(n^{2}\right)$ para $O(n)$. O algoritmo que descrevemos através da Figura 5.5 corresponde a esta versão original de MacCaskill [McC90]. 
No entanto, algumas formulações que o sucederam tentaram tratar as funções Partição sem esta restrição. Lyngsø [LZP99], por exemplo, quando propôs o algoritmo descrito na Seção 3.3.2, descreveu também um procedimento para o cálculo das funções Partição, cujo tempo do algoritmo geral é $O\left(n^{3}\right)$.

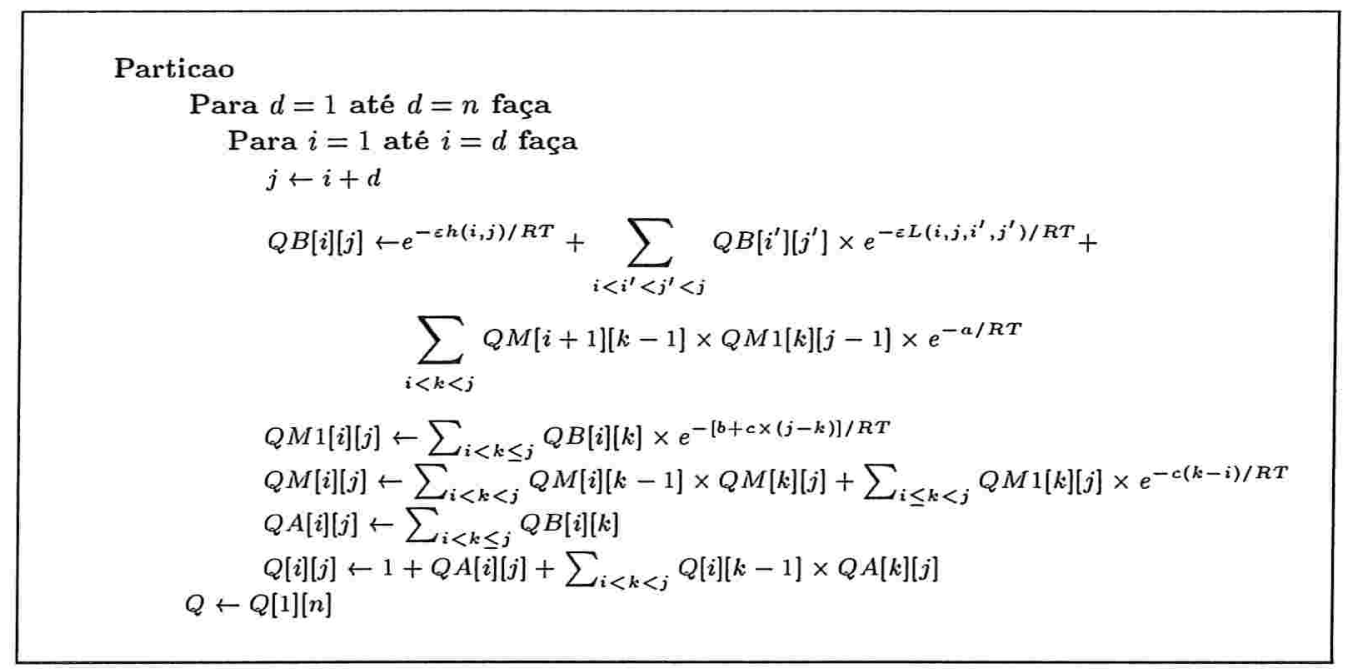

Figura 5.5: Algoritmo de McCaskill para funções Partição equilíbrio.

Feito o cálculo da função Partição, o próximo passo é calcular, através de um algoritmo backtracking, a probabilidade dos pares de base. Seja $P(k, l)$ a probabilidade das posições $k$ e $l$ formarem um par de bases. Em outras palavras, definimos $P(k, l)$ como a probabilidade de que $r_{k}$ se ligue a $r_{l}$ no conjunto equilíbrio das estruturas:

$$
P(k, l)=\sum_{S \ni(k, l)} P(S)
$$

Esta probabilidade pode ser definida como a soma de três contribuições: $P^{c}(k, l), P^{i}(k, l)$ e $P^{m}(k, l)$ e armazenada em uma matriz bidimensional $P$ denominada matriz de probabilidade de pares de base; ou seja,

$$
P[k][l] \leftarrow P(k, l)=P^{c}(k, l)+P^{i}(k, l)+P^{m}(k, l) .
$$

A probabilidade de $(k, l)$ fechar um par externo ou não formar um par de bases é representada por $P^{c}(k, l)$, que é definida como

$$
P^{c}(k, l)=\frac{Q[1][k-1] \times Q B[k][l] \times Q[l+1][n]}{Q[1][n]} .
$$

A probabilidade de $(k, l)$ fechar uma barriga, um laço interno ou um empilhamento de pares (hélice) é dada por $P^{i}(k, l)$, que, por sua vez, é definida como

$$
P^{i}(k, l)=\sum_{\substack{i j \\ i<k<l<j}} P(i, j) \times \frac{Q B[k][l]}{Q B[i][j]} \times e^{\varepsilon L(i, j, k, l) / R T} .
$$

A probabilidade de $(k, l)$ fechar um multilaço é representada por $P^{m}(k, l)$ e a expressão que a define 
é dada por

$$
\begin{aligned}
P^{m}(k, l)= & \sum_{i<k} Q B[k][l] \times e^{-[(a+b) / R T]} \times \\
& \left(P M 1[i][l] Q M[i+1][k-1]+P M[i][l] Q M[i+1][k-1]+P M[i][l] e^{-[(k-i-1) c / R T]}\right) .
\end{aligned}
$$

No cálculo de $P^{m}(k, l)$ novamente se faz uso de variáveis auxiliares ( $P M$ e $\left.P M 1\right)$ para se conseguir executar em tempo $O\left(n^{3}\right)$. Estas variáveis auxiliares são assim definidas:

$$
P M[i][l]=\sum_{i>j} \frac{P(i, j)}{Q B[i][j]} \times Q M[l+1][j-1]
$$

e

$$
P M 1[i][l]=\sum_{j>l} \frac{P(i, j)}{Q B[i][j]} \times e^{-[(j-l-1) c / R T]} .
$$

As expressões acima resumem as recursões que compõem este passo backtracking do algoritmo de MacCaskill [McC90]. 


\subsection{Métodos Híbridos}

Como já sabemos, existem duas estratégias principais para predição de estrutura de RNA: por minimização de energia livre e por dobramento comum entre homólogos (ou também chamada por análise comparativa).

Há propostas de métodos híbridos que incorporam características tanto de uma, quanto de outra estratégia. A idéia básica destes métodos é aproveitar as vantagens de cada uma delas para construir um método que forneça resultados melhores.

Juan e Wilson [JW99] construíram um método que se inspira neste propósito. Eles se utilizam de um algoritmo para cálculo de energia livre mínima como descrito na Seção 3.2.

O método descrito na Seção 5.3 pode também ser classificado como sendo híbrido, pois se utiliza de conceitos de estabilidade termodinâmica - embora na forma de distribuição de probabilidades e de informação presente em seqüências homólogas alinhadas.

\subsubsection{Método de Juan e Wilson}

Para melhor descrever este método, é necessário antes fazermos algumas definições. Suponhamos que existe um alinhamento de $m$ seqüências como ilustrado abaixo:

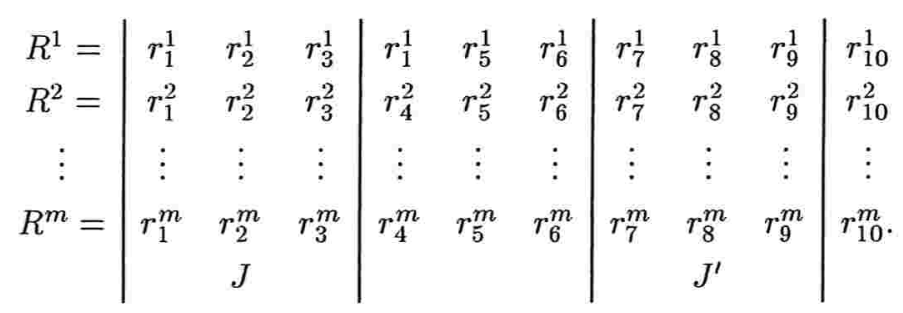

Dado o pareamento $R_{i, j}^{v} \odot R_{k, l}^{v}, 1 \leq v \leq m$, definimos o par $(j, k)$ como sendo o centro do pareamento. Por exemplo, supondo que no alinhamento acima há um pareamento $R_{1,3}^{1} \odot R_{7,9}^{1}$ na seqüência $R^{1}$, o centro deste pareamento seria $(3,7)$.

Dado o pareamento $R_{i, j}^{v} \odot R_{k, l}^{v}, 1 \leq v \leq m$, definimos o par $(i, l)$ como sendo o fim do pareamento. Por exemplo, supondo que no alinhamento acima há um pareamento $R_{1,3}^{1} \odot R_{7,9}^{1}$ na seqüência $R^{1}$, o fim deste pareamento seria $(1,9)$.

Dado um alinhamento de $m$ seqüências, uma janela $J$ deste alinhamento é o intervalo $R_{i, j}$ para todas as $m$ seqüências, como ilustrado na expressão 5.4. Denotamos uma janela que vai da base $r_{i}$ à base $r_{j}$ nas sequiências do alinhamento por $r_{i} \square r_{j}$ e o seu tamanho é indicado por $j-i+1$. No exemplo do alinhamento 5.4 , temos $J$ e $J^{\prime}$ nomeando as janelas $r_{1} \square r_{3}$ e $r_{7} \square r_{9}$, respectivamente.

É interessante notar que, dado um conjunto de pareamentos $R_{i, j}\left(R_{k, l}\right.$, a janela $r_{i} \square r_{j}$ corresponde ao "lado" esquerdo destes pareamentos. Ou seja, $R_{i, j}\left(R_{k, l}\right.$ é equivalente ao pareamento, nas seqüências correspondentes, das bases de $r_{i} \square r_{j}$ com as bases de $r_{k} \square r_{l}$. 
Dado um pareamento $R_{i, j}^{v} \odot R_{k, l}^{v}$, definimos como sendo o alcance deste pareamento a diferença $k-j$. Este conceito está associado ao tamanho (número de bases não pareadas) de um laço arco definido na Seção 2.2 .

Este método tem como entrada um conjunto de $m$ seqüências homólogas alinhadas e fornece como saída um conjunto de pares correspondentes a um dobramento. Ele é organizado em 8 passos, assim definidos:

Passo 1 Um matriz de energias $E$ é calculada para cada uma das sequiências do alinhamento utilizando um algoritmo de programação dinâmica, como aquele descrito na Seção 3.2. Para cada uma destas matrizes, regiões com menor energia (onde há formação de hélices) são identificadas e consideradas como regiões onde há possibilidade de formação de hélices na estrutura final que será predita. Cada uma destas regiões é denominada de pareamento potencial e são representadas por diagonais nas matrizes de energia.

Passo 2 Todos os pareamentos potenciais de todas as matrizes produzidas no Passo anterior são rankeados de tal modo que, aqueles de menor energia, são armazenados em uma lista. O tamanho desta lista, ou seja, o número de pareamentos potenciais classificados é um parâmetro que o usuário determina com base no tamanho das seqüências de entrada, no número de seqüências de entrada e em informações obtidas empiricamente. Os Passos 3, 4 e 5 utilizam cada um destes pareamentos potenciais classificados.

Passo 3 Uma matriz de covariância $M C[j][k]$ é calculada para o alinhamento em posições $j$ e $k$ que correspondem aos centros dos pareamentos potenciais identificados no Passo 2, conforme a fórmula

$$
M C[j][k]=2 \sum_{q=0}^{j a n e l a-1} \sum_{v=2}^{m} \frac{\left(b p_{j, k, v, q} \times \sum_{l=1}^{v-1}\left(b p_{j, k, l, q \times d i f_{j, k, v, l, q}}\right)\right)}{\text { janela } \times m \times(m-1)}
$$

onde:

- $b p_{j, k, v, q}$ indica a existência ou não de um par de bases entre os nucleotídeos nas posições $(j-q)$ e $(k+q)$ na $v$-ésima seqüência. Assumimos $b p_{j, k, v, q}=1$ se houver pareamento e $b p_{j, k, v, q}=0$ caso contrário;

- $d i f_{j, k, v, l, q}$ indica a falta, ou não, de conservação de nucleotídeos nas posições $(j-q)$ e $(k+q)$ nas sequiências $v$ e $l$. Se os nucleotídeos são idênticos em uma ou outra posição, então $d i f_{j, k, v, l, q}=0$; caso contrário, $d i f_{j, k, v, l, q}=1$;

- $q$ representa representa o tamanho das janelas tratadas no alinhamento, que varia de 0 até um tamanho máximo janela (parâmetro fornecido pelo usuário); $m$ representa o número de sequiências do alinhamento.

Passo 4 Uma pontuação energética $P E$ é atribuída a cada pareamento potencial identificado no Passo 2. Aos pareamentos potenciais com fim $(i, j)$, sua pontuação energética $P E_{i, j}$ é dada pela média das energias $E_{i, j}$ de todas as seqüências do alinhamento, isto é,

$$
P E_{i, j}=\left(\sum_{v=1}^{m} E_{i, j}^{v}\right) / m
$$


onde $E_{i, j}^{v}$ corresponde a $E_{i, j}$ da $v$-ésima seqüência do alinhamento. No cálculo de $P E$ há também a utilização de fatores correção que têm por objetivo diminuir o peso dos pareamentos de longo alcance, favorecendo os de curto alcance. Outros critérios podem ser utilizados no cálculo de $P E_{i, j}$, como por exemplo a adoção da menor $E_{i, j}$ entre todas obtidas a partir do alinhamento, isto é,

$$
P E_{i, j}=\min _{1 \leq v \leq m}\left\{E_{i, j}^{v}\right\}
$$

Passo 5 Uma função de custo associada ao alcance dos pareamentos (tamanhos dos laços) é calculada pela expressão

$$
L_{j, k}=\left\{\begin{array}{l}
1, s e(k-j) \leq \text { loop_ótimo } \\
\exp \left(\frac{\text { loop ótimo-(k-j))}}{\text { tam_loop }}\right), s e(k-j)>\text { loop_ótimo },
\end{array}\right.
$$

onde loop_ótimo é o tamanho de laço ótimo. Laços menores ou iguais a loop_ótimo recebem pontuação máxima. O termo tam_loop controla a razão (taxa) pela qual diminui a pontuação dos laços à medida que eles se tornam maiores. Este termo favorece o pareamento local em relação aos pareamentos de longo alcance e corrige o fato de que o custo de entropia de pareamentos de longo alcance são ignorados no cálculo de energia livre descrito no Passo anterior.

Passo 6 As pontuações para laços, energia e covariância de cada região são então combinadas para se obter uma pontuação geral:

$$
P G_{i, j}=w_{M} M C_{i, j}+w_{E} P E_{i, j}+w_{L} L_{i, j}
$$

onde $w_{M}, w_{E}$ e $w_{L}$ são pesos determinados experimentalmente.

Passo 7 Depois de calculada a pontuação geral para todas as hélices potenciais, elas são rankeadas segundo esta pontuação (em uma quantidade limitada por num_candidatas, que também é um parâmetro de usuário) e então consideradas como candidatas a estarem na estrutura. Regiões (hélices) com alta pontuação são adicionadas progressivamente à estrutura, das maiores pontuações para as menores pontuações. A hélice de maior pontuação é inserida automaticamente à estrutura. Depois as hélices de pontuação menor são adicionadas se não se sobrepõem às anteriormente inseridas. Se há sobreposição no fim da hélice que se está tentando adicionar, então este fim é ajustado para diminuir a hélice e eliminar a sobreposição. Se há sobreposição no centro da hélice que se está tentando adicionar, então, da mesma forma, este centro é ajustado para diminuir a hélice e eliminar a sobreposição. Se estas edições das sobreposições reduzirem o tamanho da hélice para menos do que hélice_min (de novo parâmetro de usuário) nucleotídeos, então ela é eliminada e não fará parte da estrutura. Caso contrário, a região pareada (hélice) torna-se então parte da estrutura secundária definida.

Passo 8 Depois de construir o "esqueleto" da estrutura secundária nos Passos anteriores, as regiões imediatamente vizinhas aos centros e fins dos pareamentos já presentes na estrutura são testadas para possível inclusão na estrutura secundária final. Se uma destas regiões apresenta bom potencial de pareamento (avaliado a partir da matriz $M C$ ), por exemplo, com formação de pares em $60 \%$ (mais uma vez parâmetro de usuário) das posições avaliadas e contendo pelo menos hélice_min nucleotídeos, então, esta região passa a fazer parte do dobramento final. 
Com relação à complexidade deste método, temos que no Passo 1 é consumido tempo e espaço da ordem dex $O\left(m n^{3}\right)$, onde $m$ é o número de seqüências homólogas da entrada e $n$ é o tamanho de cada uma delas, pois consome-se $O\left(n^{3}\right)$ para calcular cada uma das matrizes de energia.

$\mathrm{O}$ número de hélices potenciais, por seqüência, é $O\left(n^{2}\right)$. Então o número total de hélices potenciais geradas no Passo 1 é $O\left(m n^{2}\right)$. Logo, ordená-las, no Passo 2, consome tempo $O\left(m n^{2} \log n\right)$.

Calcular cada entrada de $M C$ consome $O\left(m n^{2}\right)$. Como calculamos as entradas de $M C$ para cada uma das $O\left(m n^{2}\right)$ hélices potenciais, então o Passo 3 consome tempo $O\left(m^{2} n^{4}\right)$.

O Passo 4 consome $O\left(m^{2} n^{2}\right)$. Os Passos 5 e 6 consomem $O\left(m n^{2}\right)$ cada um e o Passo 7 consome $O\left(m n^{2} \log n\right)$. O Passo 8 consome $O\left(m n^{2}\right)$. 


\section{Capítulo 6}

\section{Conclusão}

Com relação aos objetivos do trabalho, avaliamos termos obtido êxito. No tocante ao objetivo básico, que foi estudar e conhecer o problema de Predição de Estrutura Secundária do RNA, acreditamos que tivemos possibilidade de apreender os vários aspectos relacionados à sua caracterização, bem como conhecer os vários métodos e modelos desenvolvidos para resolução do problema. Em particular, o desenvolvimento do código possibilitou um entendimento bastante detalhado de alguns dos algoritmos baseados em cálculo de energia livre mínima.

A precisão dos resultados fornecidos pelos algoritmos baseados em minimização de energia tendem a melhorar na medida em que os parâmetros termodinâmicos se tornam mais precisos. Neste contexto, os parâmetros de energia tendem a incorporar cada vez mais casos especiais que surgem à medida em que avança o conhecimento sobre as propriedades físico-químicas dos ácidos nucléicos.

Em relação às soluções fornecidas pelos algoritmos baseados em cálculo de energia livre mínima, podemos dizer que essas soluções podem não descrever adequadamente a situação real. Em outras palavras, o modelo adotado para descrever as interações termodinâmicas pode não capturar a totalidade das situações que efetivamente ocorrem na natureza. Isto ocorre por dois motivos.

Primeiro, os parâmetros de energia com os quais os algoritmos trabalham são inevitavelmente imprecisos. Logo, a estrutura de energia livre mínima pode ser sub-ótima em relação aos parâmetros usados. O mesmo pode ocorrer em função do não conhecimento (ou não tratamento) de alguma restrição biológica que pode alterar as energias relativas, tornando/levando a uma outra estrutura subótima entre as mais favoráveis. Estes fatos justificam o desenvolvimento de algoritmos que forneçam várias soluções.

Os algoritmos de Eppstein e Larmore representam importantes avanços no campo estrito da computação para o problema. No entanto, eles não representam um avanço importante do ponto de vista da contribuição biológica, pois na natureza as funções de desestabilização de laços não são convexas nem côncavas. Além disto a suposição de não existência de multilaços não é razoável.

Como a suposição de linearidade é ainda mais restritiva do que a convexidade e a concavidade, não acreditamos que algoritmos baseados nesta suposição representem contribuições significativas para o 
problema.

Talvez o leitor espere por considerações que apontem para uma relação superioridade/inferioridade entre as duas estratégias estudadas aqui. Concluímos não ser possível fazer afirmações categóricas neste sentido, tendo em vista a grande diferença de princípios que caracterizam uma e outra estratégia. No entanto, é possível estabelecer vantagens/desvantagens entre elas.

Algoritmos baseados em minimização energética conseguem operar sobre uma única sequiência e, em relação à qual, não é necessário conhecer qualquer informação filogenética. Isto representa uma vantagem desta estratégia em relação àquela baseada em análise comparativa, já esta última exige que se disponha de um conjunto de moléculas homólogas como entrada, o que, nem sempre é possível.

No entanto, parece razoável supor que, com o tempo, o acúmulo de informação nas bases de dados de bioseqüências pode levar a um estado onde raramente, para um dada seqüência, não se disponha de um conjunto de homólogos.

Os métodos baseados em análise comparativa conseguem detectar interações terciárias (pseudo-nós) na estrutura. Isto representa uma vantagem desta estratégia em relação àquela baseada no cálculo de energia livre mínima. Esses métodos, geralmente, são insensíveis a pequenas variações na seqüência de nucleotídeos, enquanto nos métodos baseados em cálculo de energia livre mínima, pode-se chegar a estruturas muito diferentes a partir de seqüências que variam em poucas bases. Isto representa uma vantagem da análise comparativa, pois, segundo os biólogos, esta "insensibilidade" está mais próxima do que ocorre no mundo biológico.

Os biólogos, desde que disponham de um conjunto de seqüências homólogas, é claro, parecem preferir os métodos baseados em análise comparativa aos baseados em cálculo de energia livre mínima. Isto porque, quando a estrutura é extraída de um conjunto de homólogos, ela (a estrutura) pode carregar um significado biológico que, geralmente, é de interesse do pesquisador biólogo.

Do ponto de vista de trabalhos futuros, acreditamos existir alguns caminhos que podem ser seguidos com razoáveis perspectivas de resultado. Estes caminhos podem levar, basicamente, a três direções: a) melhoria dos modelos, algoritmos e técnicas baseados em cálculo de energia livre mínima, b) melhoria dos modelos e técnicas baseados na análise comparativa entre moléculas homólogas e c) melhoria nos modelos e métodos que misturam características dos dois itens anteriores.

Em relação à primeira direção, como já dissemos, acreditamos que a precisão dos resultados tende a melhorar significativamente, por conta do aperfeiçoamento dos parâmetros termodinâmicos. No entanto, isto não representa avanço no que diz respeito à necessidade de computação para o problema. Uma opção possível é tentar identificar propriedades no modelo, que permitam melhorar os algoritmos de programação dinâmica.

Existem versões paralelas para alguns dos algoritmos propostos. No entanto, nem tudo está paralelizado (algoritmos de Eppstein e Larmore, por exemplo). Uma outra opção, é tentar paralelizar estes algoritmos e construir um método que se utilize deles para fornecer soluções locais - aceitáveis em relação às restrições que eles impõem - que podem ser combinadas para construir uma solução global. Isto, é claro, representa a construção de uma heurística. Esta idéia de construir soluções globais a 
partir de soluções parciais fornecidas por algoritmos rápidos — porém, restritivos - também pode ser usada para construir um método sequencial similar.

Com relação à segunda direção, percebemos ser possível a utilização das propriedades presentes na comparação entre homólogos através de abordagens bastante diferentes. Um caminho possivel é tentar elaborar e/ou adaptar estruturas de dados específicas que, se utilizadas, possam melhorar o desempenho destes métodos.

Tendo em vista a terceira direção, ou seja, tentando combinar características de cálculo de energia com análise comparativa entre homólogos, acreditamos que algoritmos rápidos - porém restritivos baseados em programação dinâmica e cálculo de energia livre mínima podem ser utilizados para fornecer hélices potenciais. Estas hélices potenciais, que equivalem a soluções locais, podem ser combinadas com hélices potenciais extraídas do dobramento comum entre os homólogos para construir uma solução global.

Um método baseado nesta idéia poderia também se utilizar de versões paralelas para alguns de seus passos. Por exemplo, versões paralelas dos algoritmos de Eppstein e Larmore poderiam ser utilizadas para fornecer as hélices potenciais geradas a partir do cálculo de energia livre mínima. Também se poderia utilizar uma versão paralela no passo correspondente ao cálculo da matriz de covariância.

Então, para concluir, acreditamos ser viável a continuidade do estudo e aprofundamento do problema e de suas soluções, em uma das linhas acima. Isto certamente não levará a resultados definitivos, haja vista a atual "inexpressividade" dos modelos até então desenvolvidos; porém, melhorias que, eventualmente, se conquistem podem ser de grande valor para o pesquisador biólogo. 


\section{Apêndice A}

\section{Implementação}

\section{Uma visão geral}

Apresentamos agora uma visão geral de como o código não incluso nos capítulos anteriores está organizado. O programa está dividido em seis módulos principais e três auxiliares, como segue.

No primeiro estão apenas os nomes dos blocos que implementam o Algoritmo Básico.

No segundo (o módulo mais importante) estão definidas as funções que executam todos os cálculos e operações que resolvem o problema com a contabilização das energias associadas aos laços.

No terceiro e quarto estão os nomes dos blocos que implementam as otimizações em laços internos.

No quinto estão as definições das funções comuns aos algoritmos implementados.

No sexto estão as definições das funções utilizadas para:

a) alocar e inicializar estruturas de dados;

b) ler de e escrever em arquivos;

c) contar o tempo de processamento.

No sétimo estão as definições das funções auxiliares utilizadas para depuração e visualização de resultados parciais.

No oitavo estão:

a) a definição das estruturas e constantes simbólicas;

b) a declaração das variáveis globais e protótipos das funções;

c) a identificação dos arquivos de inclusão para pré-processamento do compilador.

No nono está a definição da função principal do código. 


\section{Instruções de como executar}

A partir do prompt: $>$ fold1 arq_de_entrada op

onde op é um inteiro com o seguinte significado:

(1) Dobrar sem contabilizar a energia dos laços dos laços (complexidade $O\left(n^{3}\right)$ );

(2) Dobrar contabizando a energia dos laços (complexidade $O\left(n^{4}\right)$ );

(3) Dobrar considerando a energia dos laços e otimizando os cálculos para os laços internos segundo algoritmo de Waterman e Smith (complexidade $O\left(n^{3}\right)$ );

(4) Dobrar considerando a energia dos laços e otimizando os cálculos para os laços internos segundo algoritmo de Lyngsø e Zuker (complexidade $O\left(n^{3}\right)$ ).

\section{A.1 Algoritmo Básico}

As funções que implementam o Algoritmo Básico conforme descrito na seção 3.1 já estão descritas nesta mesma seção. O nomes dos blocos que correspondem a estes códigos são:

$36\langle$ Algoritmo Básico 36〉 三

〈Cálculo matriz de energia (pares de bases independentes) 7〉

(Identificação de pares do dobramento (Algoritmo traceback) 8)

Este código é citado no bloco 3 .

Este código é usado no bloco 2.

\section{A.2 Incorporação de Laços}

Nos blocos listados abaixo estão definidas as funções que realizam as operações essenciais no cálculo da estrutura secundária que considera a energia associada aos laços.

$37\langle$ Incorporação de Laços 37〉 $\equiv$

〈Cálculo da matriz de energia (dependente de laços) 10

〈Cálculo do laço de menor energia 40

〈Cálculo da energia de um laço arco 41 〉

〈Cálculo da energia de um empilhamento de pares de bases adjacente 42 〉

〈Cálculo da energia de um laço barriga em i 43〉

〈Cálculo da energia de um laço barriga em j 44

〈Cálculo da energia de um laço interno 45〉 
〈Cálculo da energia de um multilaço 47

〈Cálculo, conforme Waterman e Smith, da energia de um laço interno 19〉

〈Cálculo, conforme Lyngsø e Zuker, de energia de um laço interno 20

〈traceback em E 12〉

$\langle$ traceback em L 13〉

$\langle$ traceback em G 14〉

Este código é citado no bloco 3 .

Este código é usado no bloco 2.

$\langle$ matrizes que guardam parâmetros de energia 38$\rangle \equiv$

double $l o o p_{-} d g[30][3] ; \quad / *$ matriz para onde é lido o arq. loop.dg*/

double stack_dg[256]; /* matriz para onde é lido o arq. tstack.dg */

double tstackh_dg[256]; /* matriz para onde é lido o arq. ttstackh.dg*/

double tstacki_dg[256]; $/ *$ matriz para onde é lido o arq. ttstacki.dg*/

struct energiatetra tetraloop_dg[78]; /* matriz para onde é lido o arq. tetraloop.dg*/

double dangle5_dg[64]; /* matriz para onde é lido o arq. dangle5.dg*/

double dangle3_dg[64]; /*matriz para onde é lido o arq. dangle3.dg*/

double sim2x2_dg[6][6][16][16]; $\quad / *$ matriz para onde é lido o arq. sint4.dg*/

double asint1x2_dg[6][4][4][6][4]; $\quad / *$ matriz para onde é lido o arq. asint1x2.dg*/

Este código é usado no bloco 10.

$39\langle$ variáveis de calc_matriz_energia_dep_laços 39$\rangle \equiv$

int $i, j, k, h$, diag;

double menor_energ;

double $b=0.40$

double $c=0.10$;

Este código é usado no bloco 10 .

\section{A.2.1 Cálculo do Laço de Menor Energia}

Esta função preenche a matriz $L[i][j], 1 \leq i<j \leq n$, com os valores do laços de energia mínima fechados pelas bases $i$ e $j$, segundo a expressão

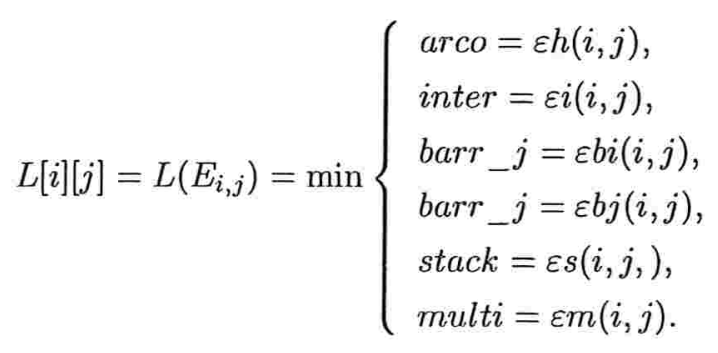


Nomeada como laço_menor_energia(), esta função recebe três inteiros nas variáveis $i, j$ e otimiza, os quais representam, respectivamente, os pares de fechamento do laço e um sinalizador que indica se o cálculo referente ao laço interno deve ser otimizado ou não. Ela faz a chamada de outras funções que calculam as energias de cada um dos laços indicados na expressão acima e decide pela menor delas, a qual retorna à função chamadora (calc_matriz_energia_dep_laços (), descrita em 〈Cálculo da matriz de energia (dependente de laços) 10) / Seção 3.2) através da variável menor_energ.

$40\langle$ Cálculo do laço de menor energia 40$\rangle \equiv$

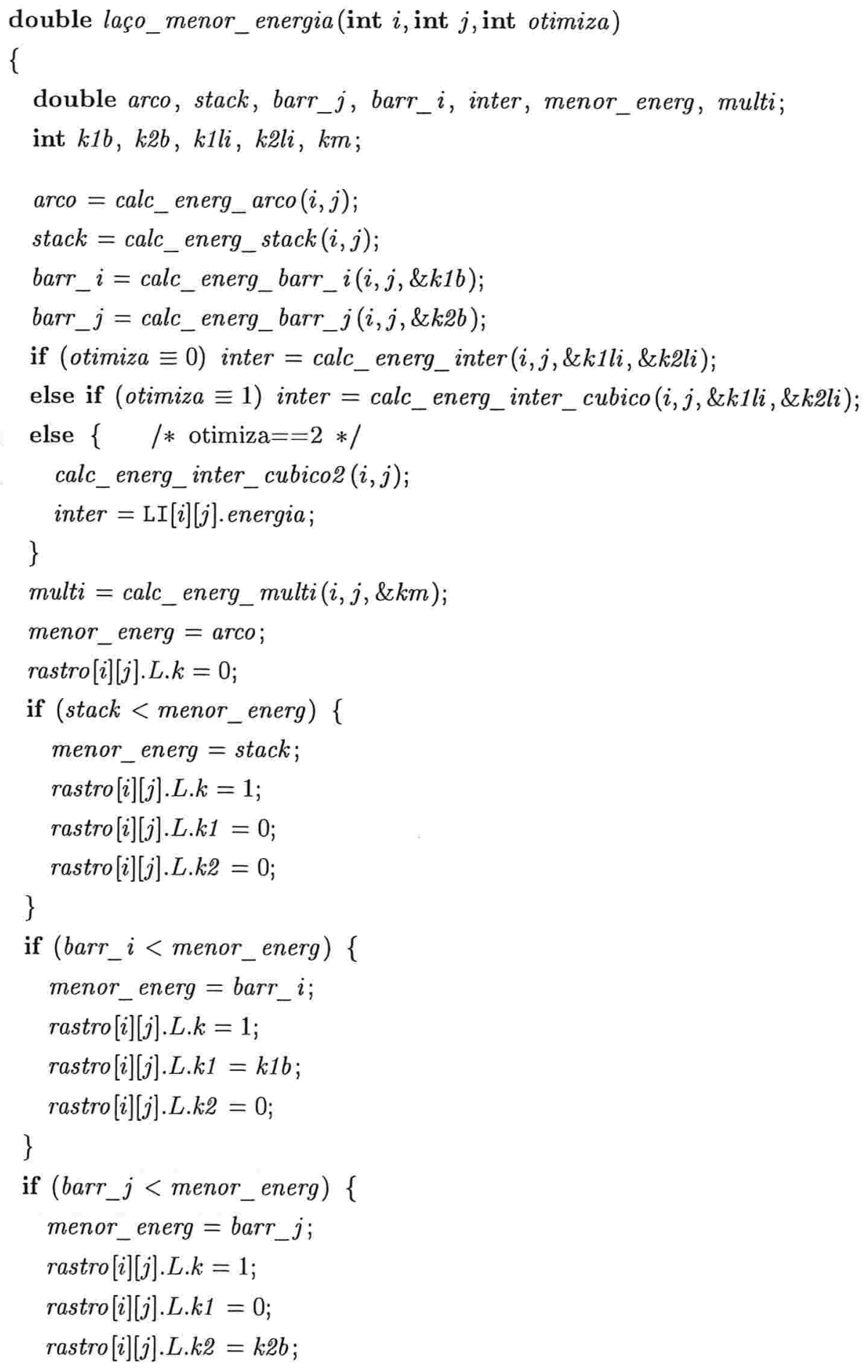




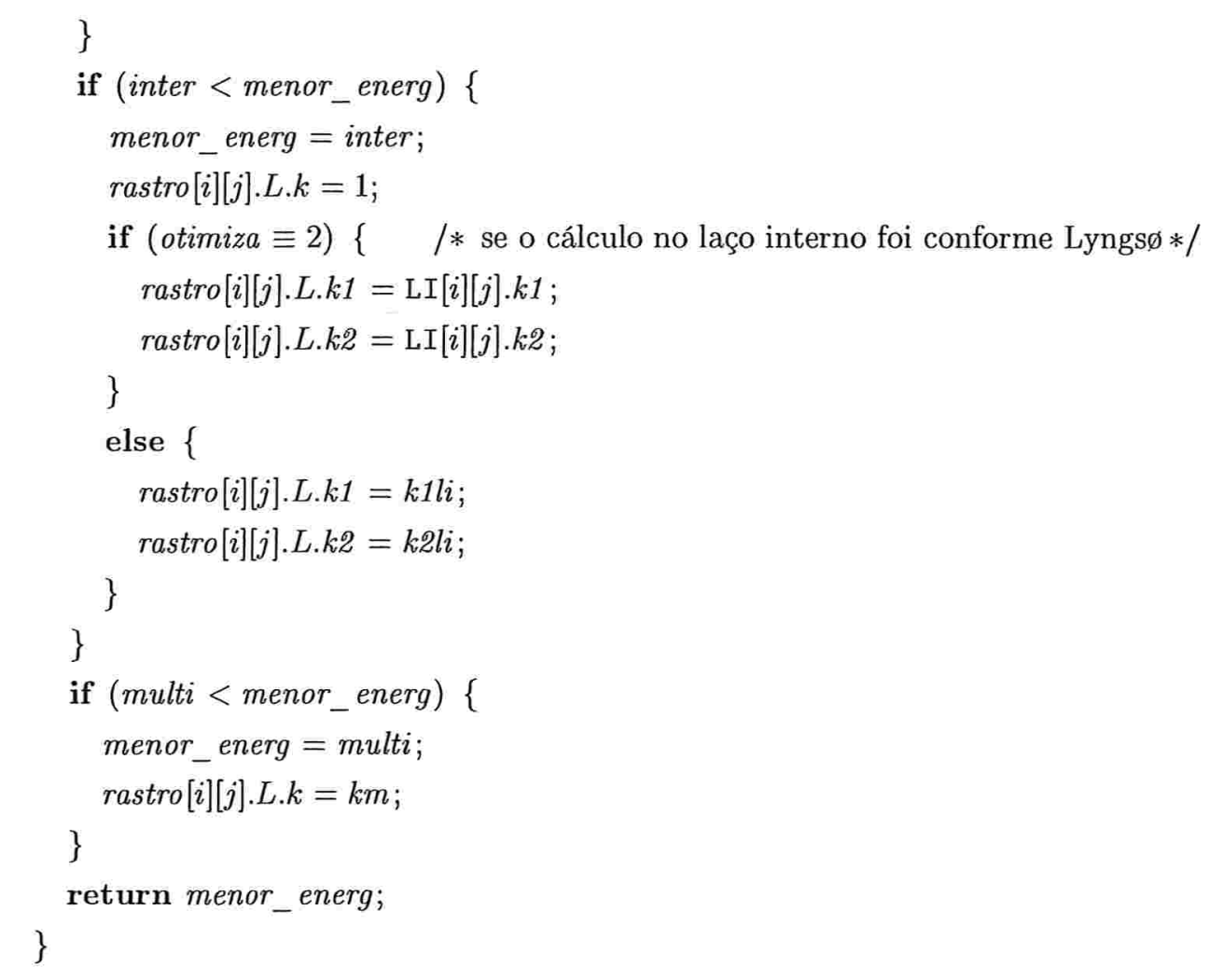

Este código é citado nos blocos 10, 19 e 41.

Este código é usado no bloco 37 .

\section{A.2.2 Cálculo da Energia de um Laço Arco}

O valor da energia do laço arco é armazenado na variável arco e é calculado conforme a expressão

$$
\operatorname{arco}=\varepsilon h(i, j)=\zeta(j-i-1)
$$

onde as bases $i$ e $j$ estão pareadas fechando o laço.

Temos $\zeta(j-i-1)$ definido da seguinte maneira:

$$
\zeta(j-i-1)=E h 1+E h 2+E h 3+E h 4, \text { onde }:
$$

- $E h 1=1.75 * R * T * \ln (j-i-1)$, se $j-i-1<=30$ (lido no arquivo loop.dg), ou $E h 1=1.75 * R * T * \ln (30)+1.75 * R * T * \ln ((j-i-1) / 30)$, se $j-i-1>30$.

Eh1 armazena a contribuição energética puramente entrópica, que depende do tamanho do laço. Para tamanho até 30 usamos a expressão $1.75 * R * T * \ln (j-i-1)$. Para tamanhos maiores do que 30 um termo extra $1.75 * R * T * \ln ((j-i-1) / 30)$ é adicionado, onde $R$ é a constante universal dos gases e $T$ é a temperatura absoluta.

- Eh2 = contribuição energética dos pares terminais não pareados mismatched (lido no arquivo tstackh.dg). 
- Eh3 = bonus energético de triloops ou tetraloops (lido no arquivo tetraloop.dg).

- Eh4 = bonus ou penalidades energéticas para casos especiais (lido no arquivo miscloop.dg).

Nomeada como calc_energ_arco(), esta função recebe dois inteiros nas variáveis $i$ e $j$, os quais, representam os pares de fechamento do laço. Ela então retorna à função chamadora (laço_menor_energia ( ), descrita em (Cálculo do laço de menor energia 40) / Item A.2.1) o valor do laço arco através da variável arco.

41 〈Cálculo da energia de um laço arco 41) $\equiv$ double calc_energ_arco(int $i$,int $j)$

\{

double $E h 1=0, E h 2=0, E h 3=0, E h 4=0 ;$

double zeta;

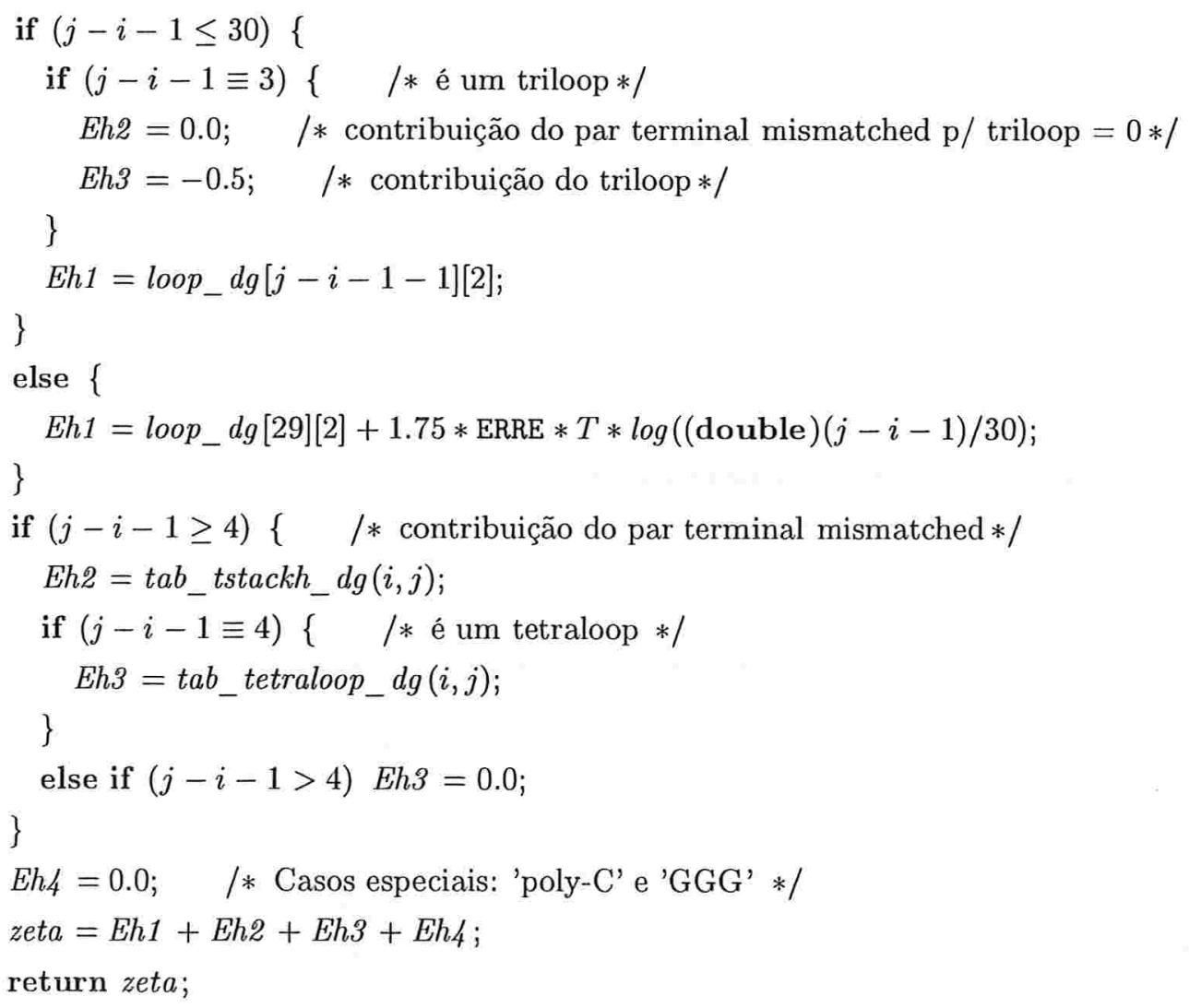

Este código é citado nos blocos 11 e 15 .

Este código é usado no bloco 37 . 


\section{A.2.3 Cálculo da Energia de um Empilhamento de Pares de Bases Adjacentes}

O valor da energia de empilhamento de um par de bases adjacentes é calculado e armazenado na variável emplh, conforme a expressão:

$$
\text { emplh }=\varepsilon s(i, j)=\eta+L\left(R_{i+1, j-1}\right)
$$

onde o par de bases $\left(r_{i}, r_{j}\right)$ está empilhado sobre o par imediamente adjacente $\left(r_{i+1}, r_{j-1}\right)$.

O valor $\eta$ é lido do arquivo stack.dg e é obtido experimentalmente.

Nomeada como calc_energ_stack(), esta função recebe dois inteiros nas variáveis $i \mathrm{e} j$, os quais, representam o par de fechamento do laço. Ela retorna à função chamadora (laço_menor_energia () ) o valor (contribuição energética) do empilhamento dos pares adjacentes $(i, j)$ e $(i+1, j-1)$ através da variável emplh.

〈Cálculo da energia de um empilhamento de pares de bases adjacente 42$\rangle \equiv$

double $c a l c \_e n e r g \_s t a c k($ int $i$,int $j$ )

\{

double emplh, eta;

eta $=t a b \_s t a c k \_d g(i, i+1, j-1, j)$;

emplh $=$ eta $+L[i+1][j-1]$;

return emplh;

\}

Este código é citado nos blocos 11 e 15 .

Este código é usado no bloco 37 .

\section{A.2.4 Cálculo da Energia de um Laço Barriga em $i$}

O valor da energia de uma laço barriga em i é calculado e armazenado na variável barr_ $i$, conforme a expressão:

$$
\text { barr_ } i=\varepsilon b i(i, j)=\min _{k \geq 1}\{\beta(k)+L(R i+k+1, j-1)\}
$$

onde as bases $i$ e $j$ estão pareadas fechando o laço e $k$ é o número de bases não pareadas da barriga.

Temos $\beta(k)$ definido de uma das seguintes maneiras:

- $\beta(k)=$ valor obtido experimentalmente, se $k<=30$ (lido no arquivo loop.dg). Se a barriga tem tamanho 1, então a energia de empilhamento para os pares $\left(r_{i}, r_{j}\right)$ e $\left(r_{i+2}, r_{j-1}\right)$ é adicionada (lido do arquivo stack.dg).

- $\beta(k)=($ valor experimental para $k=30)+1.75 * R * T * \ln (k / 30)$, se $k>30$.

Nomeada como calc_energ_barr_i(), esta função recebe dois inteiros nas variáveis $i$ e $j$, os quais, representam o par de fechamento do laço. Recebe também o endereço de uma posição de memória 
(kb1) na qual é armazenado o tamanho da barriga $(k)$ para o qual se obtém $\varepsilon b i(i, j)$ de valor mínimo. Ela retorna à função chamadora (laço_menor_energia () ) o valor do laço barriga em $i$ através da variável barr_ $i$.

$43\langle$ Cálculo da energia de um laço barriga em i 43 〉 $\equiv$

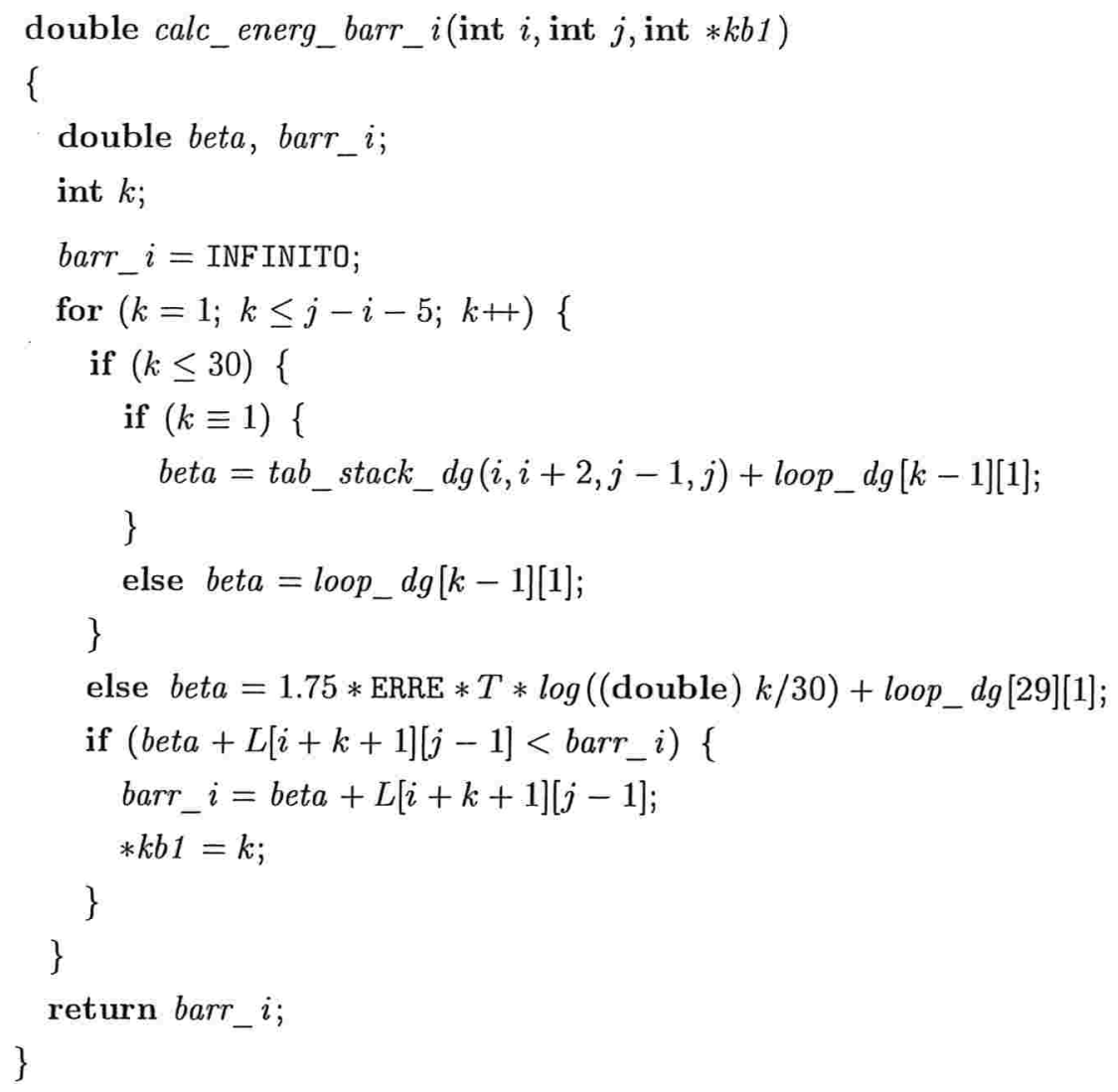

Este código é citado nos blocos 11 e 15.

Este código é usado no bloco 37.

\section{A.2.5 Cálculo da Energia de um Laço Barriga em $j$}

$\mathrm{O}$ valor da energia de uma laço barriga em j é calculado e armazenado na variável $b a r r \_j$, conforme a expressão:

$$
\text { barr_j } j=\varepsilon b j(i, j)=\min _{k \geq 1}\left\{\beta(k)+L\left(R_{i+1, j-k-1}\right)\right\}
$$

onde as bases $i$ e $j$ estão pareadas fechando o laço e $k$ é o número de bases não pareadas da barriga.

Aqui $\beta$ é definido exatamente como para barriga em i (logo acima).

Nomeada como calc_energ_barr_ $j$ (), esta função recebe dois inteiros nas variáveis $i$ e $j$, os quais, representam o par de fechamento do laço. Recebe também o endereço de uma posição de memória (kb2) na qual é armazenado o tamanho da barriga ( $k$ ) para o qual se obtém $\varepsilon b j(i, j)$ de valor mínimo. Ela retorna à função chamadora (laço_menor_energia () ) o valor do laço barriga em $j$ através da variável barr_j. 
$44\langle$ Cálculo da energia de um laço barriga em j 44$\rangle \equiv$

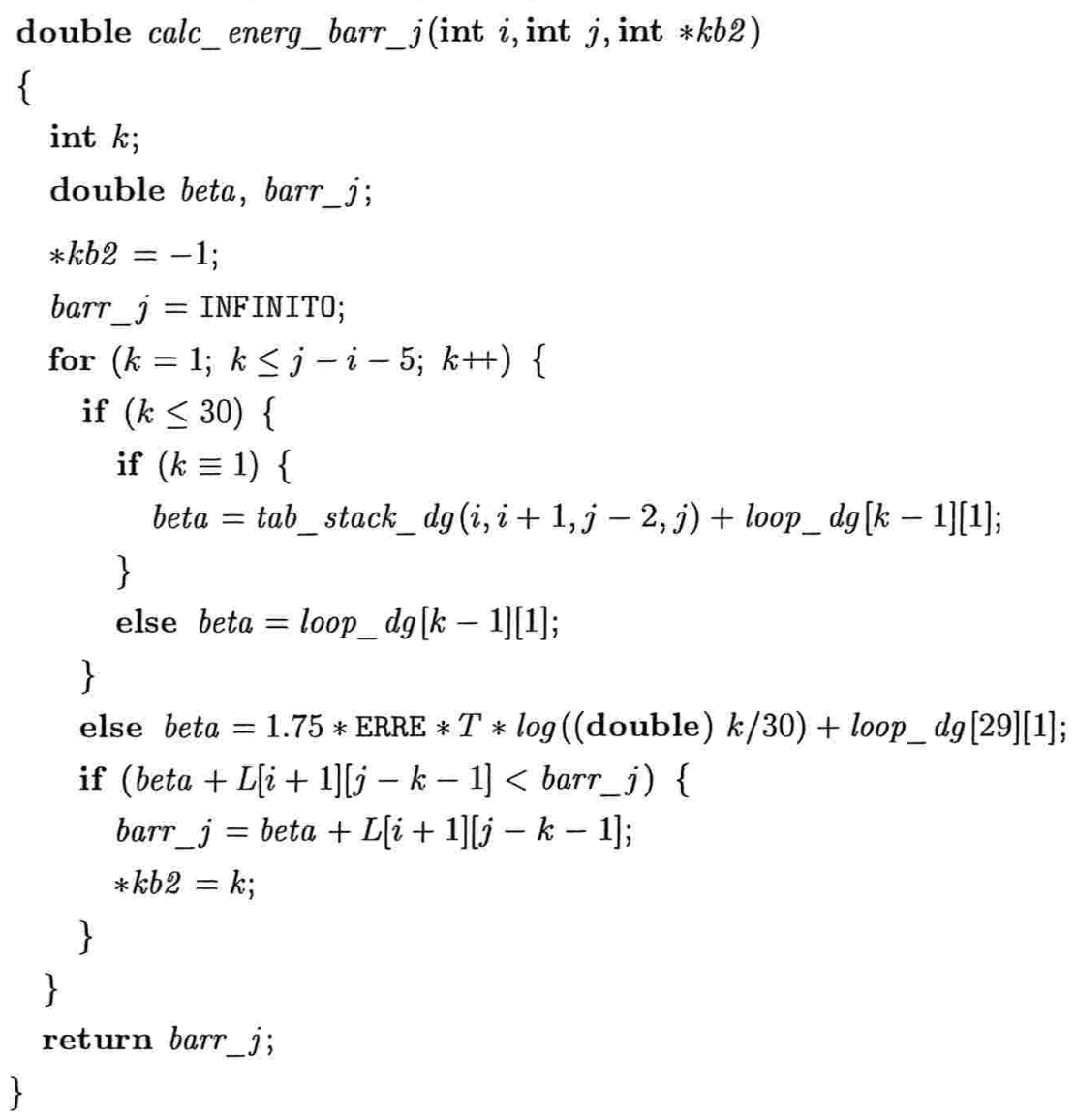

Este código é citado nos blocos 11 e 15 .

Este código é usado no bloco 37 .

\section{A.2.6 Cálculo da Energia de um Laço Interno}

O valor da energia do laço interior é calculado e armazenado na variável inter, conforme a expressão:

$$
\text { inter }=\varepsilon i(i, j)=\min _{k_{1}, k_{2} \geq 1}\left\{\gamma\left(k_{1}+k_{2}\right)+L\left(R_{i+1+k_{1}, j-1-k_{2}}\right)\right\}
$$

onde as bases $i$ e $j$ estão pareadas fechando o laço e $\left(k_{1}+k_{2}\right)$ é o número de bases não pareadas do laço.

Temos $\gamma\left(k_{1}+k_{2}\right)$ definido da seguinte maneira:

$$
\gamma\left(k_{1}+k_{2}\right)=E i 1+E i 2+E i 3+E i 4 \text {, onde }:
$$

- Ei1 = valor experimental, se $k 1+k 2<=30$ (lido no arquivo loop.dg), ou $E i 1=$ (valor experimental para $k 1+k 2=30)+1.75 * R * T * \ln ((k 1+k 2) / 30)$, se $k 1+k 2>30$.

- Ei2 = contribuição energética do par terminal mismatched $\left(r_{i+1}, r_{j-1}\right)$ (lido no arquivo tstacki.dg) 
- Ei3 = contribuição energética do par terminal mismatched $\left(r_{i^{\prime}-1}, r_{j^{\prime}+1}\right)$ (lido no arquivo tstacki.dg)

- Ei4 = penalidade energética para o caso do laço ser assimétrico. Esta penalidade é 0 se o laço for simétrico. (lido no arquivo miscloop.dg)

Nomeada como calc_energ_inter(), esta função recebe dois inteiros nas variáveis $i$ e $j$, os quais, representam o par de fechamento do laço. Recebe também os endereços de duas posições de memória ( $k 1 l i$ e $k 2 l i)$ nas quais é armazenado o tamanho da laço interno $\left(k_{1}+k_{2}\right)$ para o qual se obtém $\varepsilon i(i, j)$ de valor mínimo. Ela então retorna à função chamadora (laço_menor_energia ()$)$ o valor (contribuição energética) do laço interno fechado por $i$ e $j$ através da variável inter.

$45\langle$ Cálculo da energia de um laço interno 45$\rangle \equiv$

double $c a l c \_e n e r g \_i n t e r($ int $i$, int $j$, int $* k 1 l i$, int $* k 2 l i)$

\{

double gama $=0$, inter, Ei1 $=0, E i 2=0, E i 3=0, E i 4=0$;

int $k 1, k 2$, modulo;

inter $=$ INFINITO;

$* k 1 l i=-1$

$* k 2 l i=-1$;

for $(k 1=1 ; k 1 \leq j-i-3 ; k 1+)\{$

for $(k 2=1 ; k 2 \leq j-i-3-k 1 ; k 2++)\{$

if $(k 1+k 2 \leq 30)\{\quad / *$ se o tamanho do laço é menor ou igual a $30 * /$

if $(k 1+k 2 \leq 4)\{\langle$ Casos especiais no laço interno 46$\rangle$

\}

else $E i 1=l o o p \_d g[k 1+k 2-1][0]$;

\}

else $E i 1=1.75 * \operatorname{ERRE} * T * \log (($ double $)(k 1+k 2) / 30)+l_{0 o p} d g[29][0] ;$

$E i 2=t a b_{\text {_tstacki_d }} d g(i, i+1, j-1, j)$;

/* par terminal mismatched $(\mathrm{i}+1, \mathrm{j}-1)($ tstacki.dg $) * /$

$E i 3=t a b b_{-} t a c k i d g(i+k 1+1, i+k 1, j-k 2-1+1, j-k 2-1)$;

/* par terminal mismatched (i'-1,j'+1)(tstacki.dg) $* /$

if $(k 1>k 2)$ modulo $=k 1-k 2$;

else modulo $=k 2-k 1$;

if $($ modulo $\equiv 0)\{$

$E i_{4}=0 ; \quad / *$ simétrico de tamanho maior que 4 tem penalidade igual a zero $* /$ \}

else \{

$E i_{4}=\operatorname{assimetria}(k 1, k 2) ; \quad / *$ penalidade de Ninio: miscloop.dg $* /$

\}

$g a m a=E i 1+E i 2+E i 3+E i 4 ;$

if $($ gama $+L[i+k 1+1][j-k 2-1]<$ inter $)\{$

inter $=$ gama $+L[i+k 1+1][j-k 2-1] ;$ 


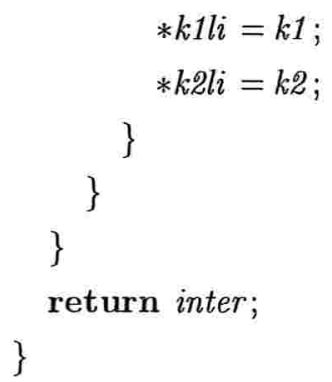

Este código é citado nos blocos 11 e 15 .

Este código é usado no bloco 37 .

\section{Casos especiais no laço interno}

Existem regras especiais para laços internos do tipo $1 \times 1,1 \times 2$ e $2 \times 2$. Os valores, obtidos experimentalmente, que expressam estas especificidades podem ser vistos nos arquivos sint2.dg, asint1x2.dg e sint4.dg no Apêndice B.

$46\langle$ Casos especiais no laço interno 46$\rangle \equiv$

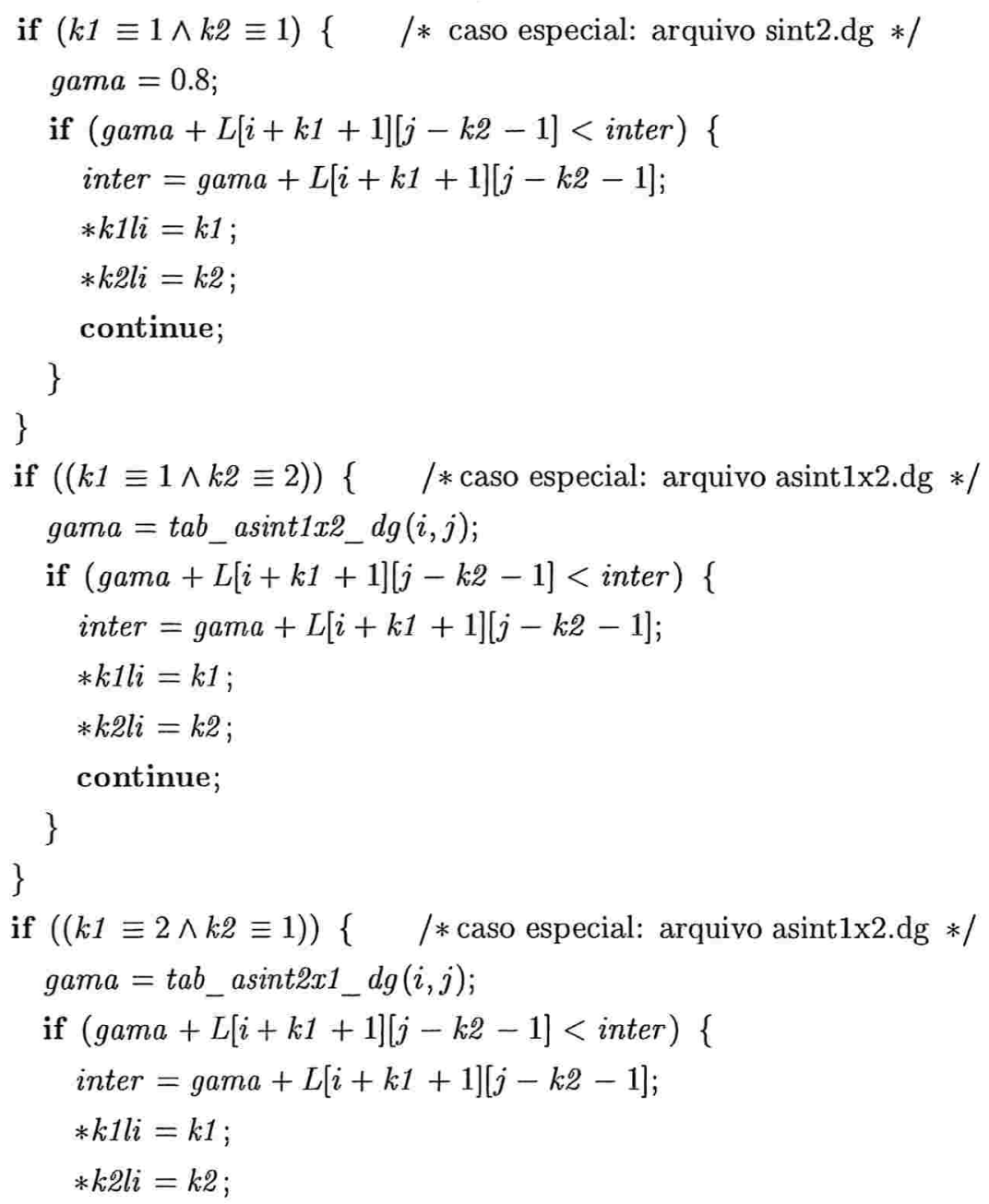




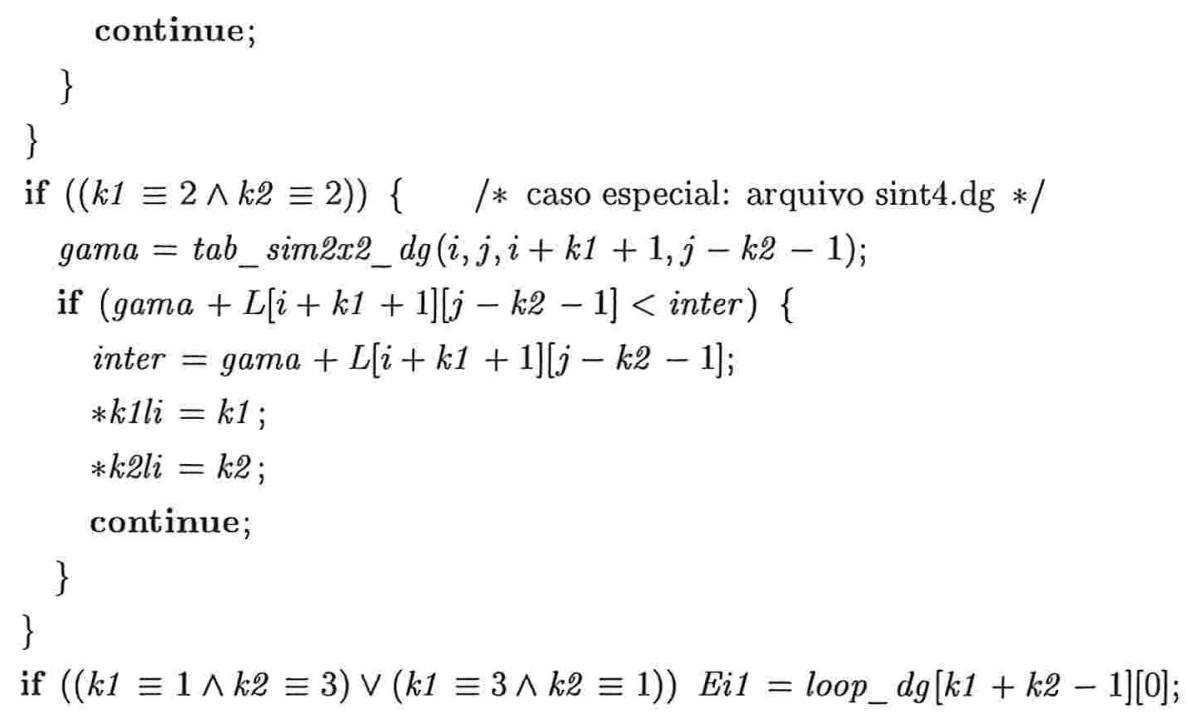

Este código é usado no bloco 45.

\section{A.2.7 Cálculo da Energia de um Multilaço}

O valor da energia de um multilaço é calculado e armazenado na variável multi, conforme a expressão:

$$
\text { multi }=\varepsilon m(i, j)=\min _{i<k<j-1}\{G[i+1, k]+G[k+1, j-1]+a\} .
$$

onde

$$
G[i, j]=\min \left\{\begin{array}{l}
V[i, j]+b \\
\min _{i<h<j} \min \left\{\begin{array}{l}
G[i, h]+(j-h) \times c \\
G[i, h]+G[h+1, j] \\
(h-i+1) \times c+G[h+1, j]
\end{array}\right.
\end{array}\right.
$$

sendo que a representa a contribuição do par de fechamento $(i, j)$ do multi-laço, $b$ a contribuição de cada par acessível a $(i, j)$ e $c$ a contribuição de cada base não pareada acessivel a $(i, j)$.

Nomeada como calc_energ_multi(), esta função recebe dois inteiros nas variáveis $i$ e $j$, os quais, representam o par de fechamento do laço. Recebe também o endereço de uma posição de memória $(\mathrm{km})$ na qual é armazenado o valor de $k$ para o qual se obtém $\varepsilon m(i, j)$ de valor mínimo. Ela então retorna à função chamadora (laco_menor_energia()) o valor (contribuição energética) do multi-laço fechado por $i$ e $j$ através da variável multi.

$47\langle$ Cálculo da energia de um multilaço 47 〉

double calc_energ_multi(int $i$, int $j$, int $* k m$ )

\{

int $k$;

double $a=3.5$;

double $m u l t i=$ INFINITO;

for $(k=i+1 ; k<j-1 ; k++)\{\quad / *$ calc. multi $=\min \mathrm{G}(\mathrm{i}+1, \mathrm{k})+\mathrm{G}(\mathrm{k}+1, \mathrm{j}-1) * /$ if $(G[i+1][k]+G[k+1][j-1]+a<$ multi $)$ 


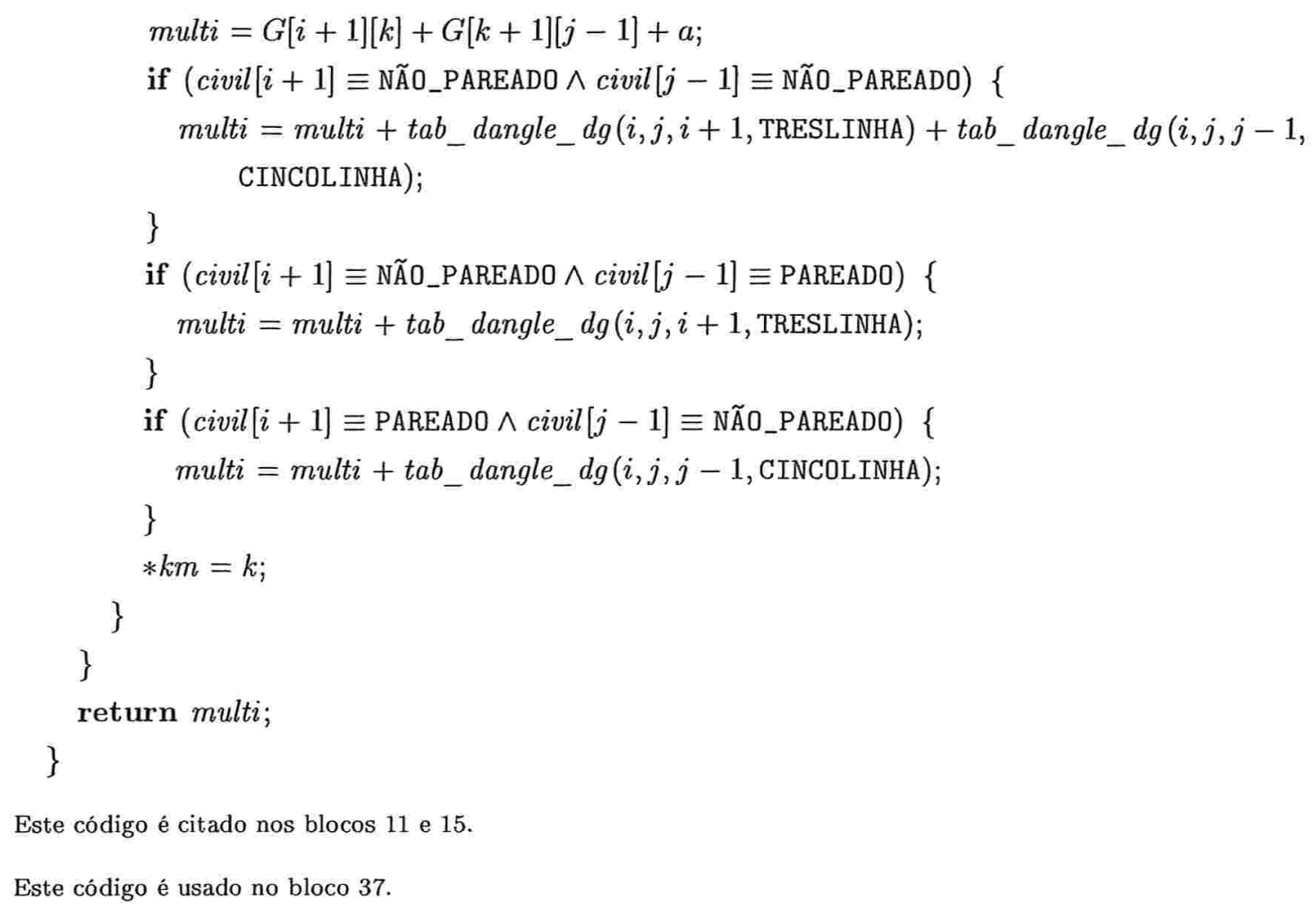

\section{A.2.8 Algoritmo traceback em $E$}

A função que implementa o Algoritmo traceback em $E$ já está descrita na Seção 3.2 .

\section{A.2.9 Algoritmo traceback em $L$}

A função que implementa o Algoritmo traceback em $L$ já está descrita na Seção 3.2.

\section{A.2.10 Algoritmo traceback em $G$}

A função que implementa o Algoritmo traceback em $G$ já está descrita na Seção 3.2 .

\section{A.3 Otimização de Waterman e Smith para Laços Internos $\left(O\left(n^{3}\right)\right)$.}

A função que implemeta o olgoritmo de Waterman e Smith conforme descrito na seção 3.3.1 já está descrita nesta mesma seção no bloco 〈Cálculo, conforme Waterman e Smith, da energia de um laço interno 19). Porém, neste mesmo bloco, é invocado um trecho de código que trata dos casos especiais, que é assim descrito: 
51 Casos especiais no cálculo do laço interno em Waterman e Smith 51$\rangle \equiv$

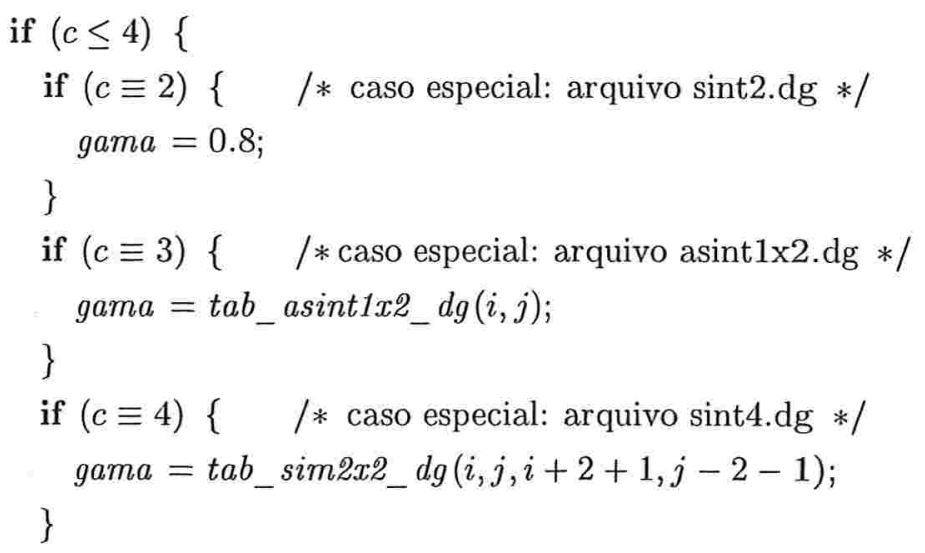

Este código é usado no bloco 19.

\section{A.4 Otimização de Lyngsø e Zuker para Laços Internos $\left(O\left(n^{3}\right)\right)$.}

As funções que implemetam o olgoritmo de conforme Lyngsøe Zuker descrito na seção 3.3.2 já estão descritas nesta mesma seção. No entanto, a parte do código que trata dos casos especiais, que é invocado neste bloco, é como segue:

$52\langle$ Casos especiais no cálculo do laço interno em Lyngsø 52$\rangle \equiv$

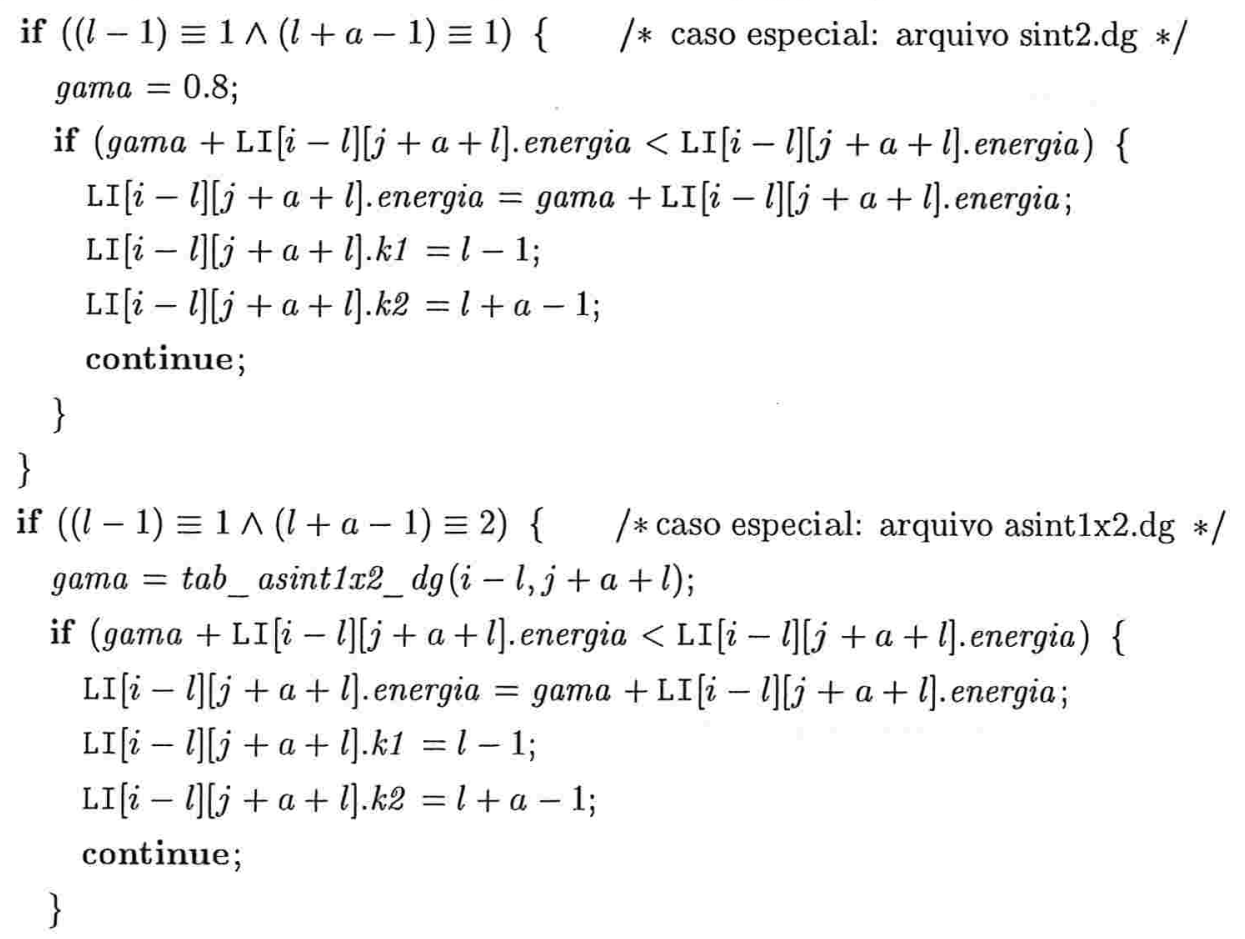




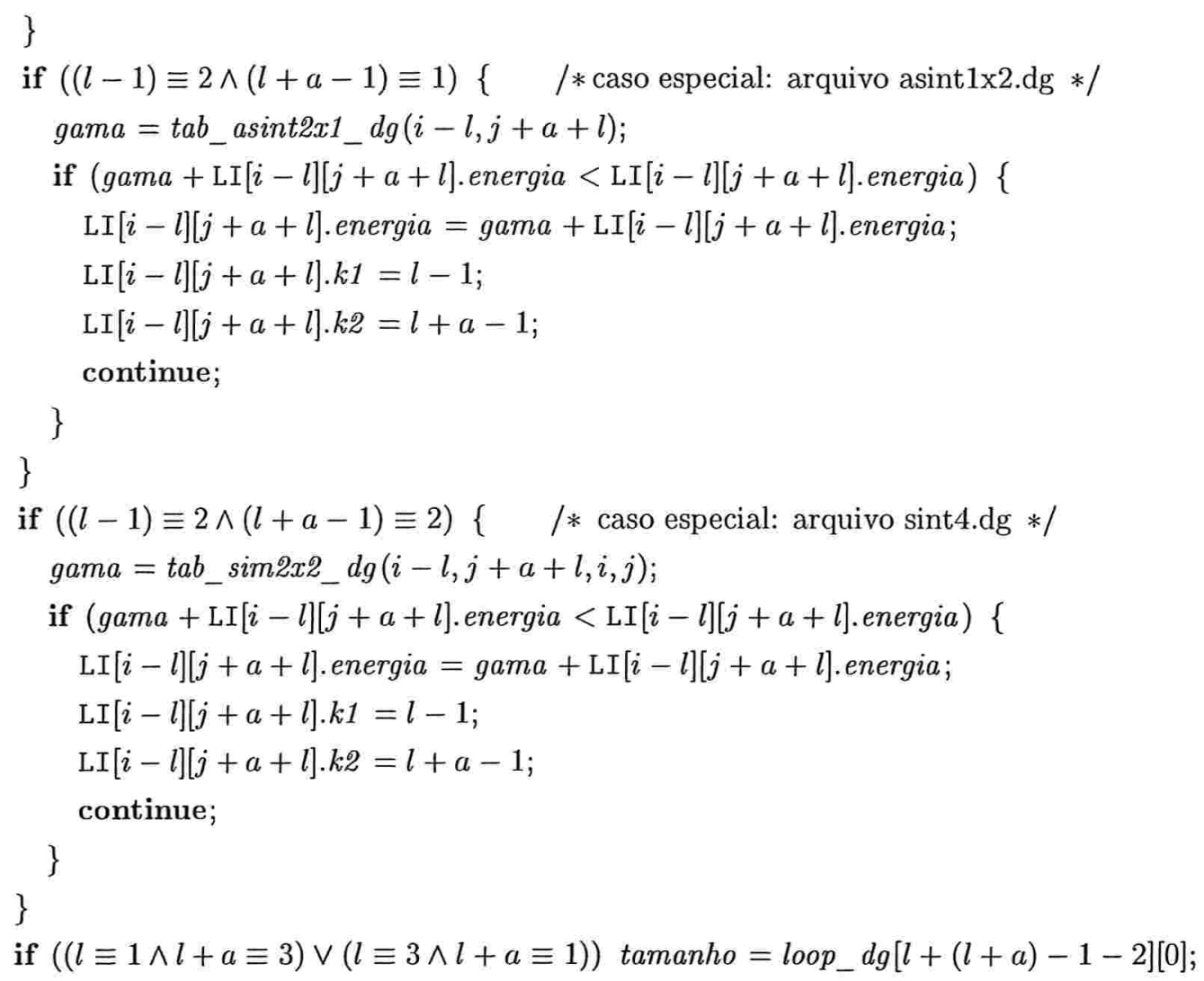

Este código é usado no bloco 20.

\section{A.5 Funções Comuns}

Nos blocos listados abaixo estão definidas funções comuns aos algoritmos implementados.

〈Funções comuns 53 〉 $\equiv$

$\langle$ Guarda o conjunto de pares 57 〉

$\langle$ Cálculo energia de um par de bases 56$\rangle$

〈Calcula o mínimo entre dois ou três valores 55)

$\langle$ Calcula penalidade de assimetria segundo Ninio 54〉

Este código é usado no bloco 2.

Calculo da penalidade de assimetria segundo Ninio

A assimetria no laço interno é calculada conforme a expressão

$$
\operatorname{assimetria}(n 1, n 2)=\min \{K, n \times f(m)\}
$$


onde $n=|n 1-n 2|$ e $m=\min \{n 1, n 2, c\}$. As constantes $K, c$ e a função $f$ são assim definidas:

- $c=5$, segundo Papanicolaou [PGN84] e Ninio e $c=1$, segundo Peritz;

- $k=6$, segundo Papanicolaou e Ninio;

- $f(1)=0.7 ; f(2)=0.6 ; f(3)=0.4 ; f(4)=0.2$ e $f(5)=0.1$, segundo Papanicolaou e Ninio.

$54\langle$ Calcula penalidade de assimetria segundo Ninio 54$\rangle \equiv$

double assimetria(int $n 1$, int $n 2$ )

\{

double $f m=0.1, K=6 ; \quad / * K=6$ segundo Papanicolaou e Ninio $* /$

int $c=1 ; \quad / * c=5$ segundo Papanicolaou e Ninio $\mathrm{c}=1$ segundo Peritz $* /$

int $m, n$;

if $(n 1>n 2) n=n 1$

else $n=n 2$;

$m=$ min_de_3_valores $(n 1, n 2, c)$;

switch $(m)\{\quad / * f(m)$ segundo Papanicolau/Ninio $* /$

case 1: $f m=0.7$;

break;

case $2: f m=0.6$;

break;

case 3: $f m=0.4$;

break;

case $4: f m=0.2$;

break

case $5: f m=0.1$;

break;

\}

return min_de_2_valores $(K, n * f m)$;

\}

Este código é citado no bloco 20 .

Este código é usado no bloco 53.

Calcula o mínimo entre dois ou três valores

$55\langle$ Calcula o mínimo entre dois ou três valores 55 〉 三

double min_de_2_valores (double $a$, double $b$ )

\{

return $(a<b ? a: b)$;

\} 
double min_de_3_valores (double $a$, double $b$, double $c$ )

\{

double $d$;

$d=(a<b ? a: b)$;

return $(c<d ? c: d)$;

\}

Este código é usado no bloco 53 .

Cálculo da energia de um par de bases

Calcula a energia $\alpha\left(r_{i}, r_{j}\right)$ do par formado pelas bases $i$ e $j$.

$56\langle$ Cálculo energia de um par de bases 56$\rangle \equiv$

double alfa(char base1, char base2)

\{

if $\left(\left(\right.\right.$ base1 $\equiv{ }^{\prime} \mathrm{G} ' \wedge$ base $\left.2 \equiv{ }^{\prime} \mathrm{C} '\right) \vee\left(\right.$ base1 $\equiv{ }^{\prime} \mathrm{C} ' \wedge$ base2 $\left.\left.\equiv{ }^{\prime} \mathrm{G}^{\prime}\right)\right)$ return $(-3)$;

else if $\left(\left(\right.\right.$ base1 $\equiv{ }^{\prime} A^{\prime} \wedge$ base $\left.2 \equiv ' U^{\prime}\right) \vee\left(\right.$ base1 $\equiv{ }^{\prime} U^{\prime} \wedge$ base2 $\left.\left.\equiv{ }^{\prime} A '\right)\right)$ return $(-2)$;

else if $\left(\left(\right.\right.$ base1 $\equiv ' G{ }^{\prime} \wedge$ base $\left.2 \equiv{ }^{\prime} U^{\prime}\right) \vee\left(\right.$ base1 $\equiv{ }^{\prime} U^{\prime} \wedge$ base $\left.\left.2 \equiv ' G '\right)\right)$ return $(-1)$;

else return (INFINITO);

\}

Este código é usado no bloco 53.

Guarda o conjunto de pares

$57\langle$ Guarda o conjunto de pares 57$\rangle \equiv$

struct par $* S ; \quad / *$ estrutura de dados que armazena os pares do dobramento $* /$

void guarda_S(int base1, int base2)

\{

$S[$ num_pares $]$. base1 $=$ base1;

$S[$ num_pares $]$. base2 $=$ base2 $;$

num_pares ++;

\}

Este código é usado no bloco 53. 


\section{A.6 Funções de Inicialização e Leitura}

Nesta seção estão descritas as funções que realizam as inicializações necessárias às execuções (alocação de memória e inicialização de variáveis, por exemplo), bem como a leitura dos parâmetros de energia a partir dos arquivos de dados (.dg).

58 〈Funções de Inicialização e Finalização 58 〉 $\equiv$

〈Carrega energia de empilhamento da memória (stack_dg) 60〉

〈Carrega energia de pares terminais mismatched(tstackh_dg) 61)

〈Carrega energia de pares terminais mismatched(tstacki_dg) 62

〈Carrega energia de bases dangle's) 63〉

〈Carrega energia de tetraloops da memória (tetraloop_dg) 64)

〈Carrega energia da memória sim2x2_dg 65

〈Carrega energia de laços internos (1x2) 66)

〈Carrega energia de laços internos (2x1) 67〉

〈Leitura da seqüência (molécula) de entrada 69)

〈Leitura dos arquivos de parâmetros de energia 70〉

〈Alocação de matrizes 80 >

〈Alocação da sequência 83

〈Alocação do vetor auxiliar D[] 84

〈Alocação da matriz auxiliar de rastreamento 81)

〈Alocação da matriz para laços internos em Lyngsø 82 )

〈Alocação do conjunto de conjunto de pares 85)

〈Inicialização do conjunto de pares 86 〉

Este código é usado no bloco 2 .

\section{Funções que carregam da memória}

As funções deste grupo fornecem os valores dos parâmetros de energia. Elas retornam estes valores a partir de consultas realizadas em tabelas presentes na memória principal, que já foram preenchidas a partir de valores lidos em arquivos.

Carrega energia de empilhamento da memória (tabela obtida experimentalmente)

Esta função recebe quatro inteiros $\left(i, k, l\right.$ e $j$ ) que indicam as posições das bases $R_{i}, R_{k}, R_{l}$ e $R_{j}$ na seqüência $R_{1, n}$. Retorna a energia corresponde ao empilhamento das bases $R_{k}$ e $R_{l}$ sobre as bases $R_{i}$ e $R_{j}$. 
$60\langle$ Carrega energia de empilhamento da memória (stack_dg) 60$\rangle \equiv$

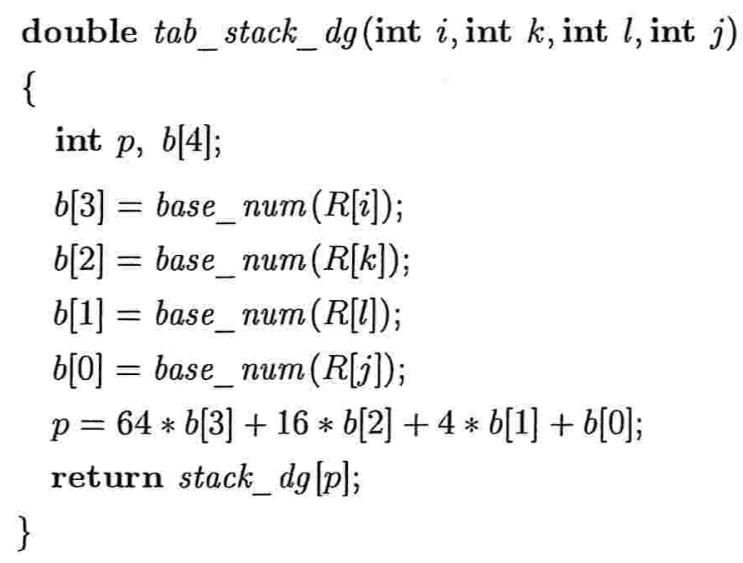

Este código é usado no bloco 58 .

Carrega da memória energia de pares terminais mismatched em arcos (tabela obtida experimentalmente)

$61\langle$ Carrega energia de pares terminais mismatched(tstackh_dg) 61$\rangle \equiv$

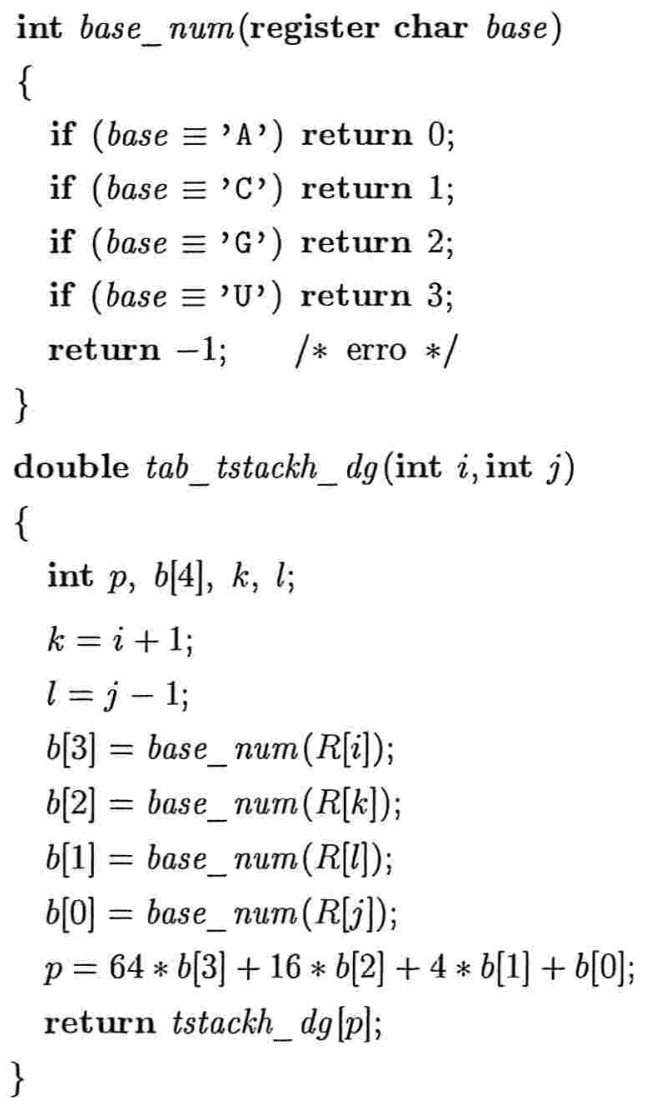

Este código é usado no bloco 58. 
Carrega da memória energia de pares terminais mismatched em laços interiores (tabela obtida experimentalmente)

$62\langle$ Carrega energia de pares terminais mismatched(tstacki_dg) 62$\rangle \equiv$

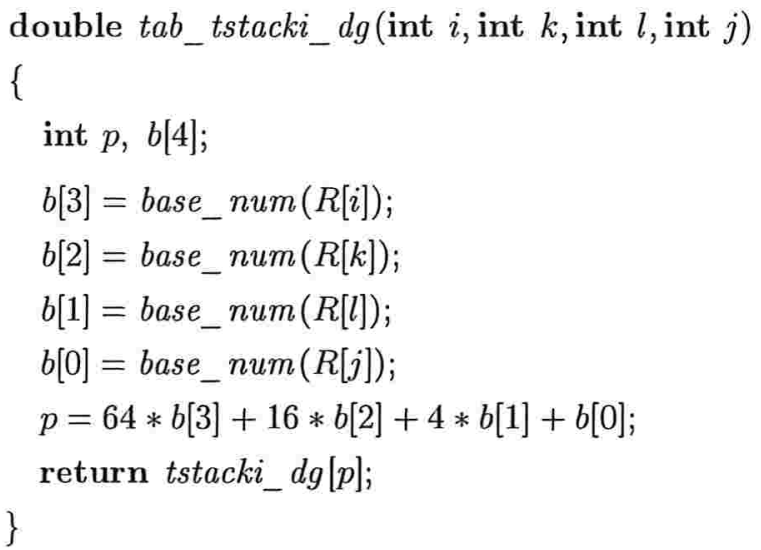

Este código é usado no bloco 58 .

Carrega da memória energia das pares não pareadas adjacentes aos pares de bases pertencentes ao multilaço

$63\langle$ Carrega energia de bases dangle's) 63〉 $\equiv$

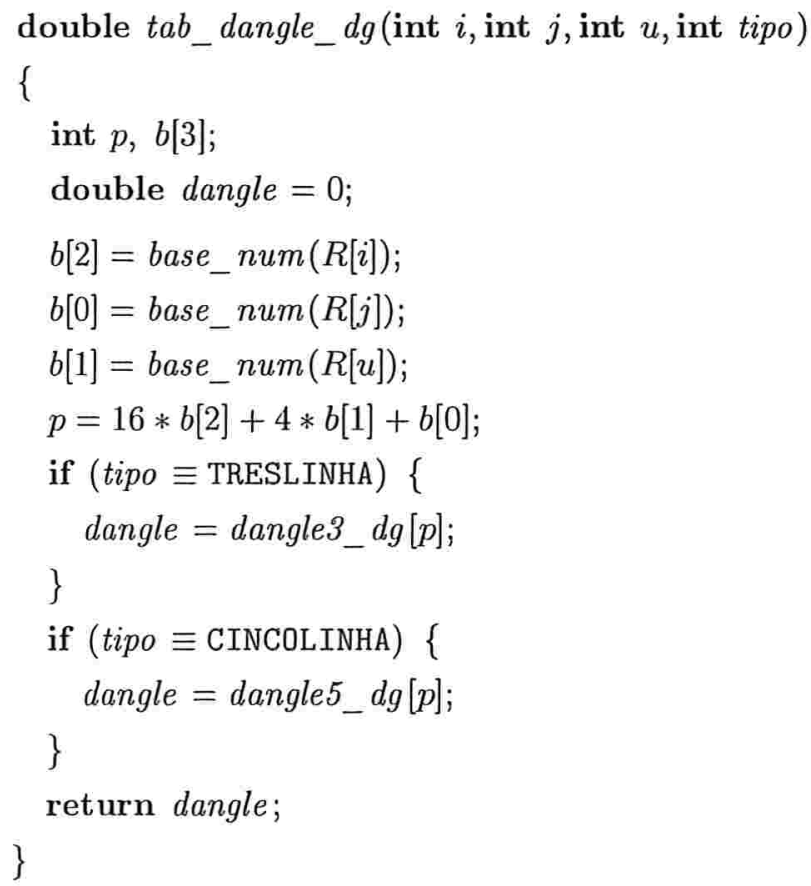


Este código é usado no bloco 58.

Carrega energia de tetraloops da memória (tabela obtida experimentalmente)

$64\langle$ Carrega energia de tetraloops da memória (tetraloop_dg) 64$\rangle \equiv$

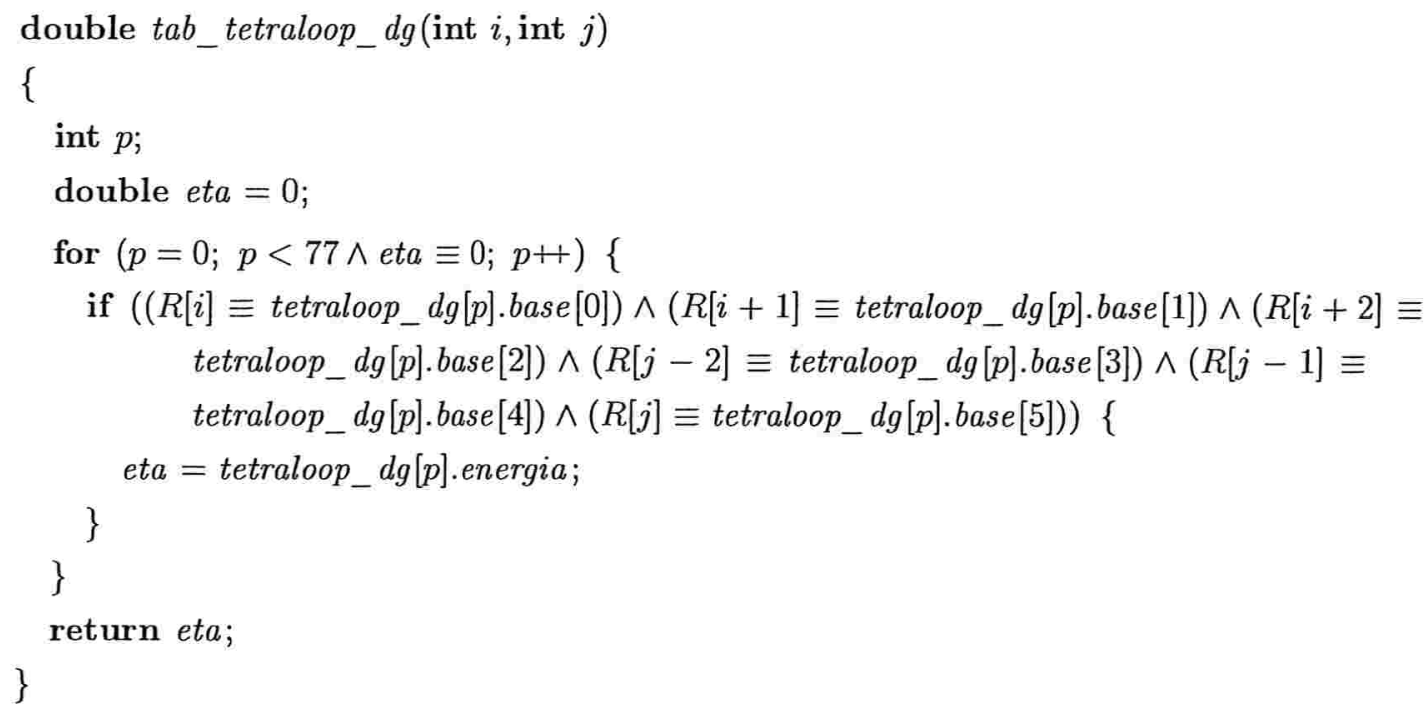

Este código é usado no bloco 58 .

Carrega energia de laços internos simétricos de tamanho 4 (tabela obtida experimentalmente)

Esta função recebe quatro inteiros $(i, j, k$ e $l)$ que indicam as posições das bases $R_{i}, R_{j}, R_{k}$ e $R_{l}$ na seqüência $R_{i, n}$. Retorna a energia corresponde à formação de um laço interno fechado externamente pelas bases $R_{i}$ e $R_{j}$ e fechado internamente pelas bases $R_{k}$ e $R_{l}$.

$65\langle$ Carrega energia da memória sim2x2_dg 65 〉 $\equiv$

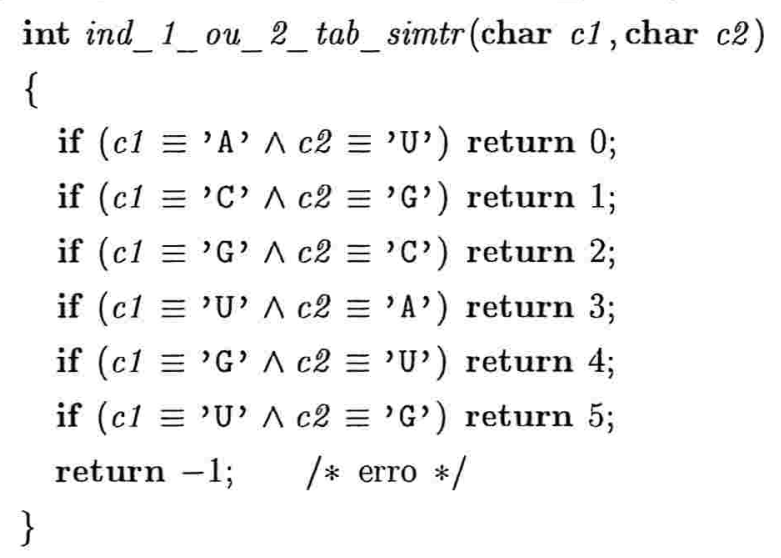




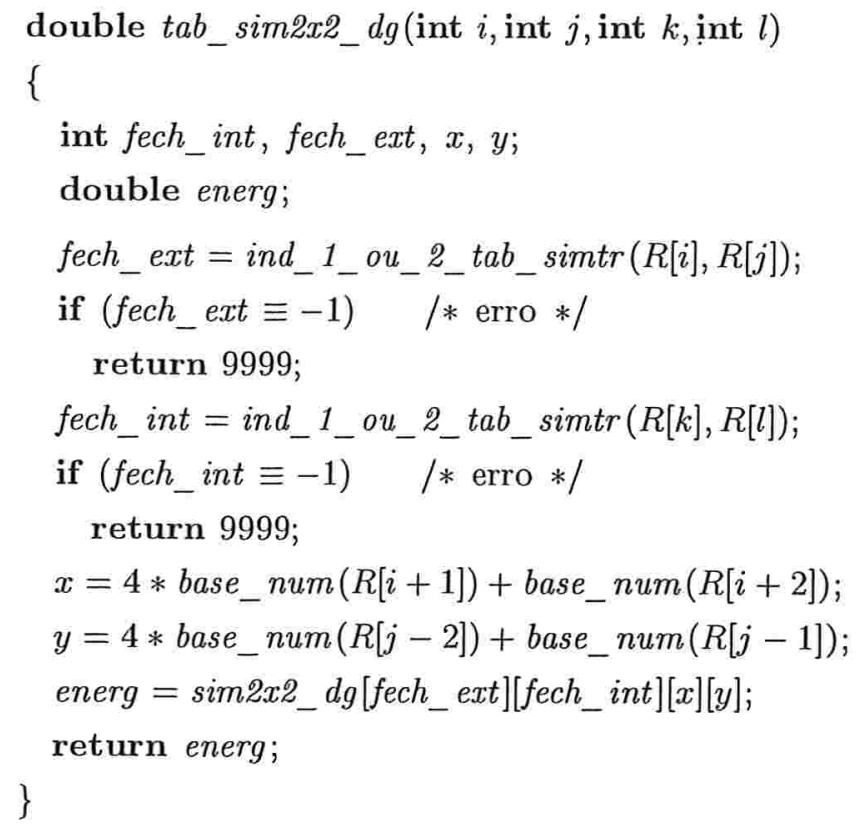

Este código é usado no bloco 58.

Carrega da memória energia de laços internos assimétricos do tipo (1×2)

Esta função recebe dois inteiros ( $i$ e $j$ ) que indicam as posições das bases $R_{i}$ e $R_{j}$ na seqüência $R_{i, n}$. Retorna a energia corresponde à formação de um laço interno fechado externamente pelas bases $\left(r_{i}, r_{j}\right)$ e fechado internamente pelas bases $R_{i+2}$ e $R_{j-3}$.

$66\langle$ Carrega energia de laços internos (1x2) 66 〉 $\equiv$

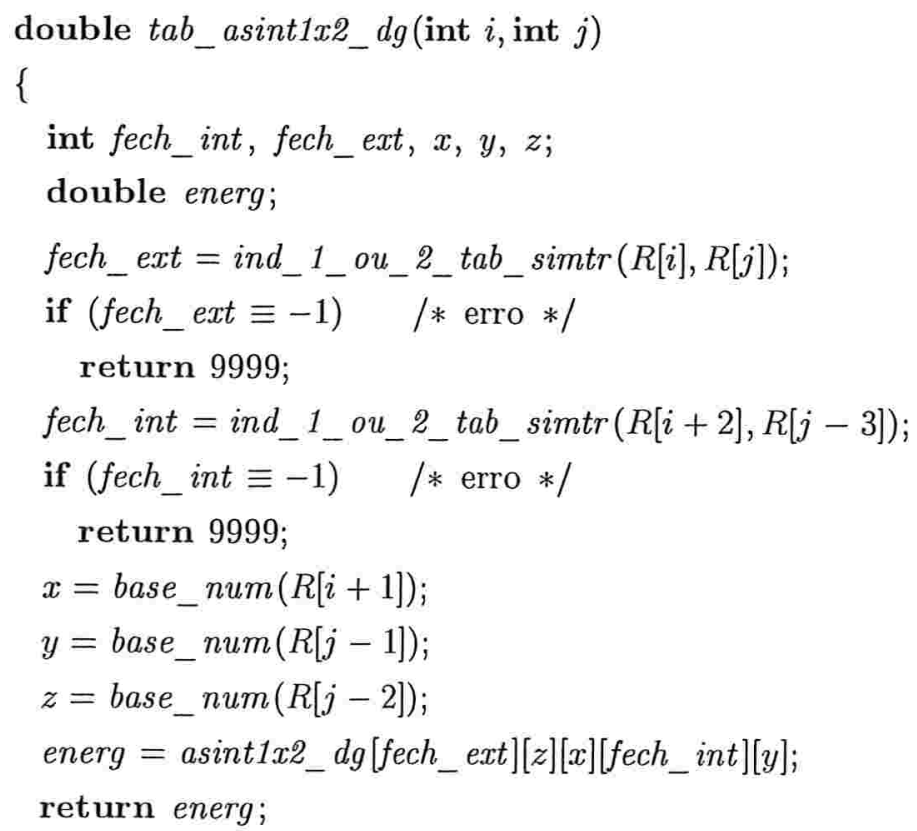




\section{\}}

Este código é usado no bloco 58.

Carrega da memória energia de laços internos assimétricos do tipo $(2 \times 1)$

Esta função recebe dois inteiros ( $i$ e $j$ ) que indicam as posições das bases $R_{i}$ e $R_{j}$ na sequiência $R_{i, n}$. Retorna a energia corresponde à formação de um laço interno fechado externamente pelas bases $\left(r_{i}, r_{j}\right)$ e fechado internamente pelas bases $R_{i+3}$ e $R_{j-2}$.

$67\langle$ Carrega energia de laços internos (2x1) 67$\rangle \equiv$

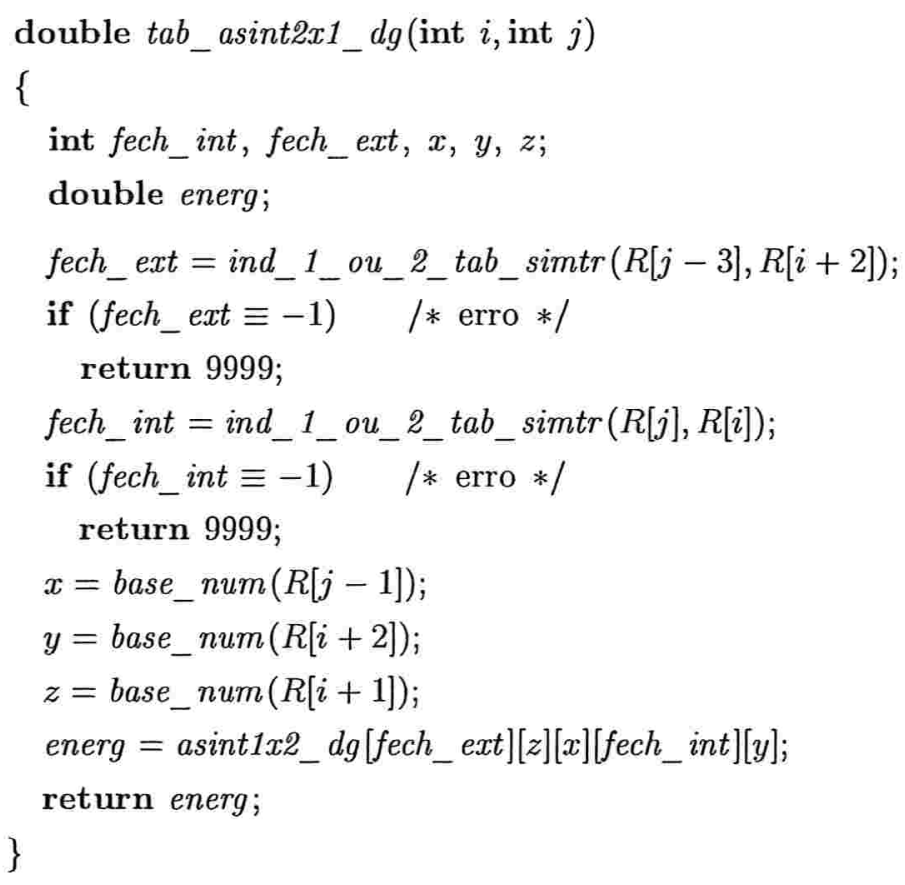

Este código é usado no bloco 58.

\section{Leitura de arquivos para memória}

As funções deste grupo carregam para a memória principal os valores dos parâmetros energéticos e a seqüência de entrada que representa a molécula a ser dobrada.

Leitura da seqüência (molécula) de entrada 
$69\langle$ Leitura da seqüência (molécula) de entrada 69 〉 $\equiv$

void le_seqüência $($ char *nome_do_prog, char *nome_do_arq)

\{

int $i$, formato;

char car;

arquivo $=$ fopen $($ nome_do_arq, READ_ONLY);

if (arquivo $\equiv \Lambda)\{$

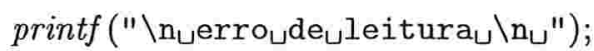

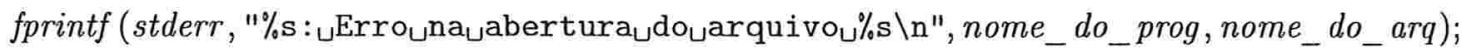
exit(erro_na_leitura_de_arquivo);

\}

car $=$ fgetc $($ arquivo $)$;

while (car $\equiv$ '\#' $\wedge \neg f e o f($ arquivo ) $)\{$

car $=$ fgetc $($ arquivo $) ;$

while $\left(\right.$ car $\neq{ }^{\prime} \backslash \mathrm{n}^{\prime} \wedge \neg$ feof (arquivo) $)\{$

car $=$ fgetc $($ arquivo $)$;

\}

car $=$ fgetc $($ arquivo $) ;$

\}

ungetc (car, arquivo);

fscanf (arquivo, "\% $\mathrm{d}_{\sqcup} \% \mathrm{~d} \backslash \mathrm{n}^{\prime}$, \& tam_R, \&formato);

aloca_seqüência();

if (formato $\equiv 1)\{$

for $\left(i=0 ; i<t a m_{-} R ; i++\right)\{$

car $=$ toupper $(\operatorname{getc}($ arquivo $))$;

if ( $c a r \equiv ' \mathrm{~T}$ ') $R[i]=$ ' $\mathrm{U}$ ';

else $R[i]=c a r ;$

\}

\}

else \{

car $=$ toupper $($ getc $($ arquivo $)) ;$

$i=0$;

while ( $\neg$ feof (arquivo)) \{

if $\left(c a r \equiv ' A{ }^{\prime} \vee c a r \equiv ' C ' \vee c a r \equiv ' G ' \vee c a r \equiv{ }^{\prime} T ' \vee c a r \equiv ' U '\right)\{$

if $\left(c a r \equiv{ }^{\prime} \mathrm{T}^{\prime}\right)\{$

$R[i]=$ 'U';

$i++$;

\}

else \{

$R[i]=\operatorname{car} ;$

$i++$; 


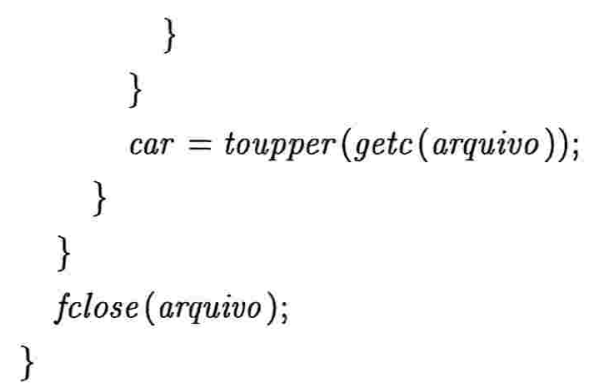

Este código é usado no bloco 58 .

\section{Leitura dos arquivos de parâmetros de energia}

Esta função faz a leitura, de arquivo para a memória principal, dos arquivos que contêm os parâmetros de energia dos laços. Todos os dados contidos nestes arquivos são obtidos laboratorialmente e geralmente sofrem modificações/atualizações à medida que novos experimentos são realizados. As energias neles indicadas estão expressas em $\mathrm{kcal} / \mathrm{mol}$.

$70\langle$ Leitura dos arquivos de parâmetros de energia 70$\rangle \equiv$

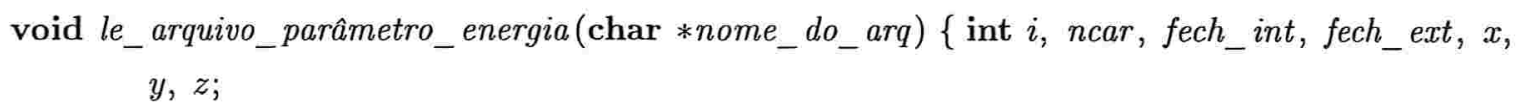




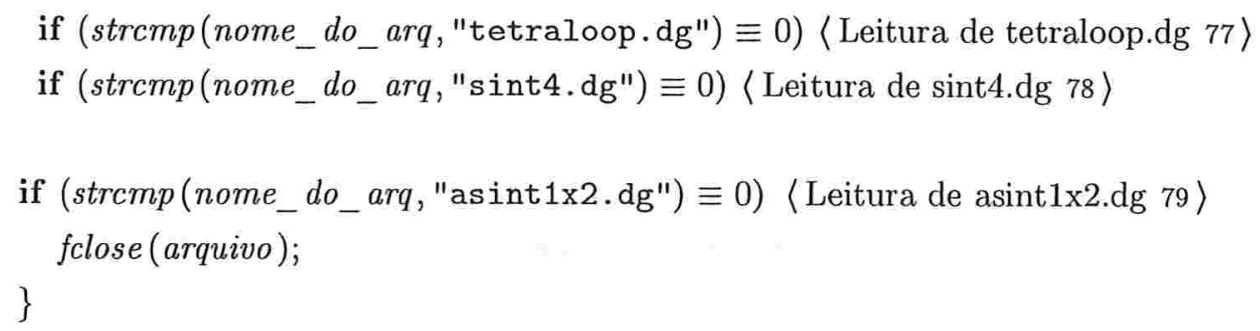

Este código é usado no bloco 58.

\section{Carrega para a memória o arquivo loop.dg}

$\mathrm{O}$ arquivo loop.dg contém as contribuições energéticas, associadas ao tamanho, para os seguintes laços: interno, barriga e arco. Neste arquivo há valores para estes laços até o tamanho 30. Ele consiste de uma tabela da forma

$\begin{array}{cccc}\text { SIZE } & \text { INTERNAL } & \text { BULGE } & \text { ARCO } \\ 1 & 9999 & 3.90 & 9999 \\ \ldots & & & \\ 15 & 6.70 & 6.00 & 5.80 \\ \ldots & & & \\ 30 & 7.40 & 6.70 & 6.50\end{array}$

onde a primeira coluna indica o tamanho do laço, a segunda a energia referente ao um laço interno, a terceira a energia associada à barriga e, por útimo, a quarta coluna representa a energia relativa ao arco. Parte deste arquivo está no Item B.1 do Apêndice B.

$71\langle$ Leitura de loop.dg 71$\rangle \equiv$

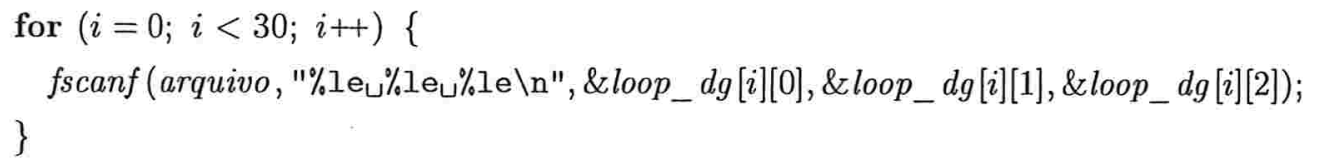

Este código é citado no bloco 15 .

Este código é usado no bloco 70 . 
Carrega para a memória o arquivo stack.dg

Este arquivo contém os parâmetros de energia referente ao empilhamento de pares de bases e é da forma

$$
\begin{array}{ccccc}
A & A & A & A & 9999 \\
\cdots & & & & \\
A & A & U & U & -0.90 \\
\cdots & & & & \\
U & U & U & U & 9999
\end{array}
$$

onde a quinta coluna corresponde a energia de empilhamento do par representado pelas bases da segunda e terceira colunas sobre o par representado pelas primeira e quarta colunas. O arquivo está ordenado pelas colunas e o valor da quinta coluna é atribuído ao vetor stack_dg[]. Parte deste arquivo está no Item B.2 do Apêndice B.

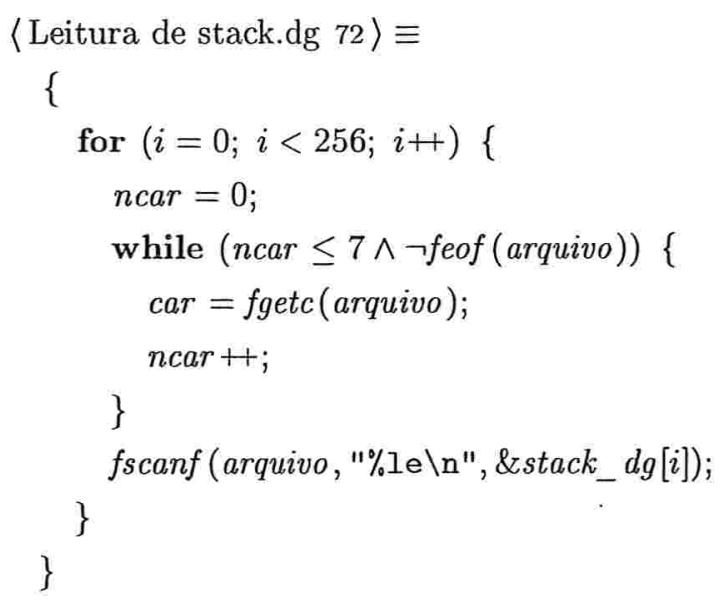

Este código é usado no bloco 70 .

\section{Carrega para a memória o arquivo tstackh.dg}

Este arquivo contém os parâmetros de energia referente ao empilhamento, em laços arcos, de bases terminais adjacentes não pareadas é da forma

$$
\begin{array}{ccccc}
A & A & A & A & 9999 \\
\cdots & & & & \\
A & A & A & U & -0.80 \\
\cdots & & & & \\
U & U & U & U & 9999
\end{array}
$$

onde a quinta coluna corresponde a energia de empilhamento das bases terminais adjacentes não pareadas, representadas pelas segunda e terceira colunas, sobre o par representado pelas primeira e 
quarta colunas. Este par corresponde somente ao par de fechamento do laço arco. O arquivo está ordenado pelas colunas e o valor da quinta coluna é atribuído ao vetor tstackh_dg/l. Parte deste arquivo está no Item B.3 do Apêndice B.

$73\langle$ Leitura de tstackh.dg 73$\rangle \equiv$

\{

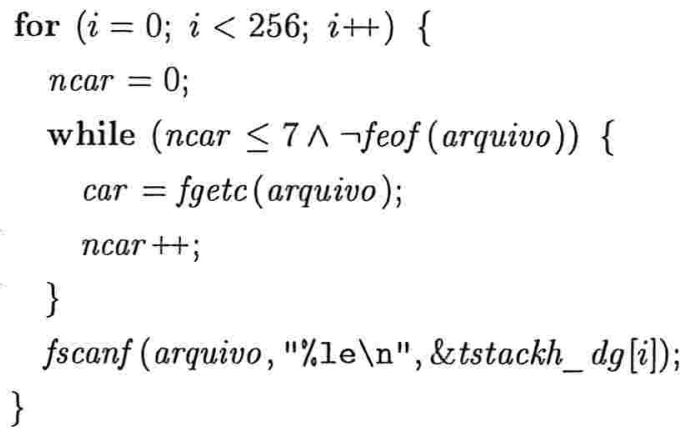

Este código é citado no bloco 15 .

Este código é usado no bloco 70 .

\section{Carrega para a memória o arquivo tstacki.dg}

Este arquivo contém os parâmetros de energia referente ao empilhamento, em laços internos, de bases terminais adjacentes não pareadas é da forma

$$
\begin{array}{ccccc}
A & A & A & A & 9999 \\
\cdots & & & & \\
A & A & A & U & -1.00 \\
\cdots & & & & \\
U & U & U & U & 9999
\end{array}
$$

onde a quinta coluna corresponde a energia de empilhamento das bases terminais adjacentes não pareadas, representadas pelas segunda e terceira colunas, sobre o par representado pelas primeira e quarta colunas. Este par corresponde ao par de fechamento do laço ou ao par interno do laço. O arquivo está ordenado pelas colunas e o valor da quinta coluna é atribuído ao vetor tstacki_dg[]. Parte deste arquivo está no Item B.4 do Apêndice B.

$74\langle$ Leitura de tstacki.dg 74$\rangle \equiv$

\{

$$
\begin{aligned}
& \text { for }(i=0 ; i<256 ; i++)\{ \\
& \quad n c a r=0 ; \\
& \text { while }(\text { ncar } \leq 7 \wedge \neg f e o f(\text { arquivo }))\{ \\
& \quad \text { car }=\text { fgetc (arquivo); }
\end{aligned}
$$




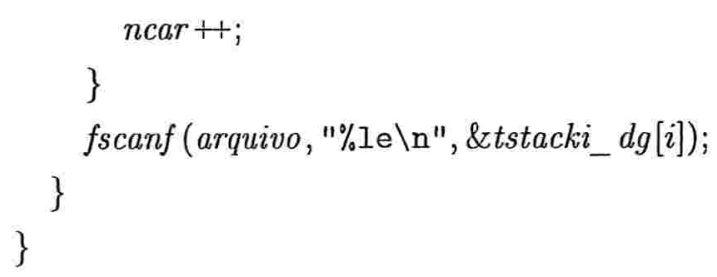

Este código é citado no bloco 15.

Este código é usado no bloco 70 .

Carrega para a memória o arquivo dangle5.dg

Este arquivo contém os parâmetros de energia referente ao efeito dangling, em laços multilaços e no laço externo, de bases terminais adjacentes não pareadas é da forma

$$
\begin{array}{cccc}
A & A & A & 9999 \\
\cdots & & & \\
A & A & U & -0.80 \\
\cdots & & & \\
U & U & U & 9999
\end{array}
$$

onde a quarta coluna corresponde a energia do efeito dangling da base terminal adjacente não pareada, representada pela segunda coluna, sobre o par representado pelas primeira e terceira colunas. Esta base não pareada é adjacente à base representa pela primeira coluna, ou seja, está mais próxima à extremidade 5' da molécula. Este par corresponde ao par de fechamento de um multilaço ou a um branch de um multilaço, ou ainda a um branch do laço externo. O arquivo está ordenado pelas colunas e o valor da quarta coluna é atribuído ao vetor dangles_dg[]. Parte deste arquivo está no Item B.6 do Apêndice B.

$75\langle$ Leitura de dangle5.dg 75$\rangle \equiv$

$$
\{
$$

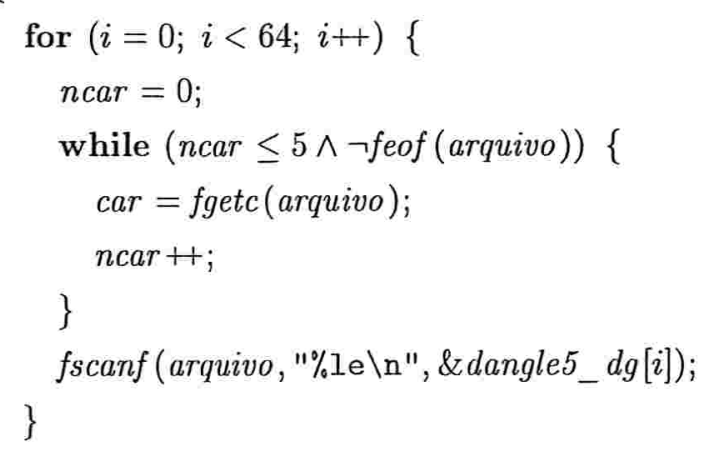

Este código é usado no bloco 70 . 


\section{Carrega para a memória o arquivo dangle3.dg}

Este arquivo contém os parâmetros de energia referente ao efeito dangling, em multilaços e no laço externo, de bases terminais adjacentes não pareadas é da forma

$$
\begin{array}{cccc}
A & A & A & 0.0 \\
\cdots & & & \\
A & A & U & -0.30 \\
\cdots & & & \\
U & U & U & 9999
\end{array}
$$

onde a quarta coluna corresponde a energia do efeito dangling da base terminal adjacente não pareada, representada pela segunda coluna, sobre o par representado pelas primeira e terceira colunas. Esta base não pareada é adjacente à base representa pela terceira coluna, ou seja, está mais próxima à extremidade 3' da molécula. Este par corresponde ao par de fechamento de um multilaço ou a um branch de um multilaço, ou ainda a um branch do laço externo. O arquivo está ordenado pelas colunas e o valor da quarta coluna é atribuído ao vetor dangle3_dg[]. Parte deste arquivo está no Item B.7 do Apêndice B.

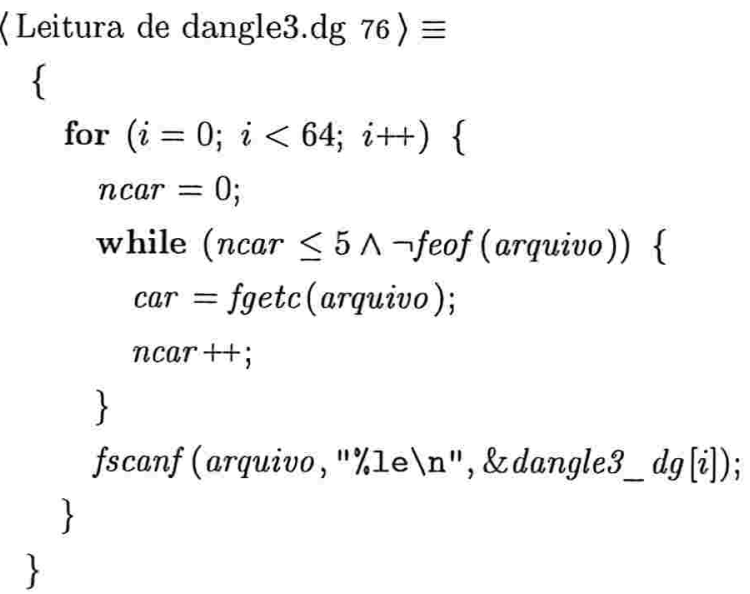


Carrega para a memória o arquivo tetraloop.dg

Este arquivo contém os parâmetros de energia referente à situação onde temos um laço tipo arco de tamanho 4, ou seja, com quatro bases acessíveis, e é da forma

$$
\begin{array}{ccccccc}
A & G & A & A & A & U & -2.00 \\
\cdots & & & & & & \\
C & U & U & U & A & G & -2.00 \\
\cdots & & & & & & \\
U & U & U & U & A & G & -2.00
\end{array}
$$

onde a sétima coluna corresponde a energia do tetraloop fechado pelo par representado pela primeira e sexta colunas. Cada uma das linhas do arquivo corresponde a um tetraloop específico para o qual se determinou, experimentalmente, a energia associada. Este arquivo conta com 78 destes tetraloops. Os casos não listados neste arquivo recebem bônus energético igual a zero. $\mathrm{O}$ valor da sétima coluna é atribuído ao vetor tetraloop_dg[].energia. Parte deste arquivo está no Item B.5 do Apêndice B.

$77\langle$ Leitura de tetraloop.dg 77$\rangle \equiv$

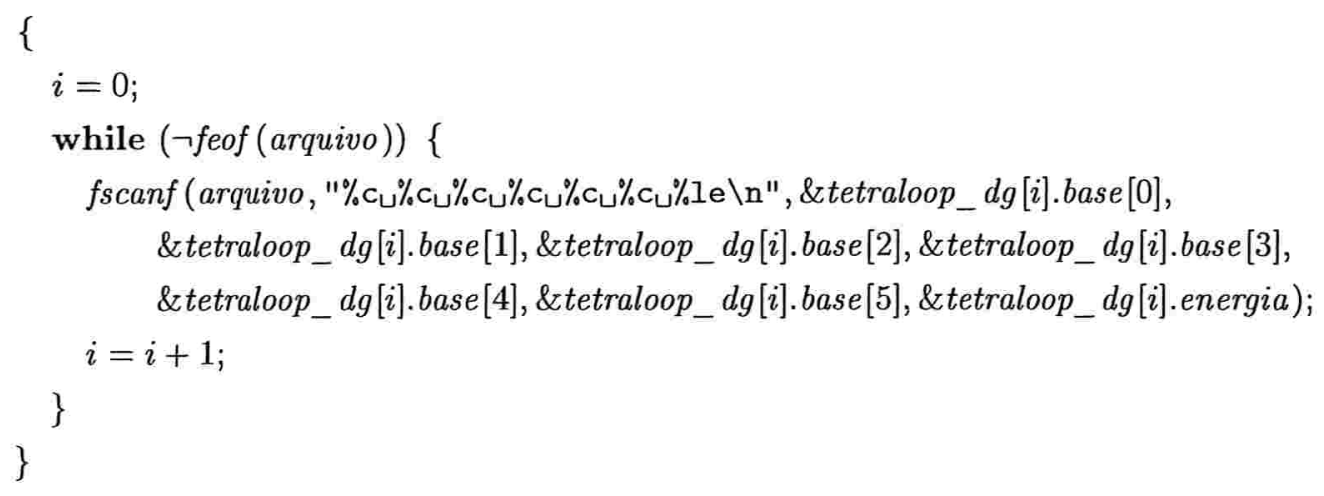

Este código é citado no bloco 15.

Este código é usado no bloco 70 .

\section{Carrega para a memória o arquivo sint $4 . \mathrm{dg}$}

Este arquivo contém os parâmetros de energia referente à situação onde temos um laço tipo interno simétrico de tamanho 4, ou seja, com quatro bases acessíveis, duas de cada lado. Este arquivo contem 36 tabelas $16 \times 16$ que são cada uma da forma

$$
\begin{array}{ccccccccccccccccc} 
& A & A & A & A & C & C & C & C & G & G & G & G & U & U & U & U \\
& A & C & G & U & A & C & G & U & A & C & G & U & A & C & G & U \\
A A & 2.9 & 2.9 & 1.7 & 4.1 & 2.9 & 2.9 & 3.5 & 2.9 & 1.7 & 4.1 & 2.9 & 4.1 & 3.5 & 2.9 & 3.5 & 1.9 \\
\ldots & & & & & & & & & & & & & & & & \\
U U & 1.9 & 1.9 & 0.7 & 3.1 & 1.9 & 1.9 & 2.5 & 1.9 & 0.7 & 3.1 & 1.9 & 3.1 & 2.5 & 1.9 & 2.5 & 0.9
\end{array}
$$


Cada uma destas tabelas representa uma das 36 possíveis situações para o par de fechamento e par acessível do laço. Em uma tabela 16x16, cada célula representa o valor de energia para uma das 256 possiveis composições de bases não pareadas acessiveis para esta tabela. Parte deste arquivo está no Item B.8 do Apêndice B.

$78\langle$ Leitura de sint4.dg 78$\rangle \equiv$

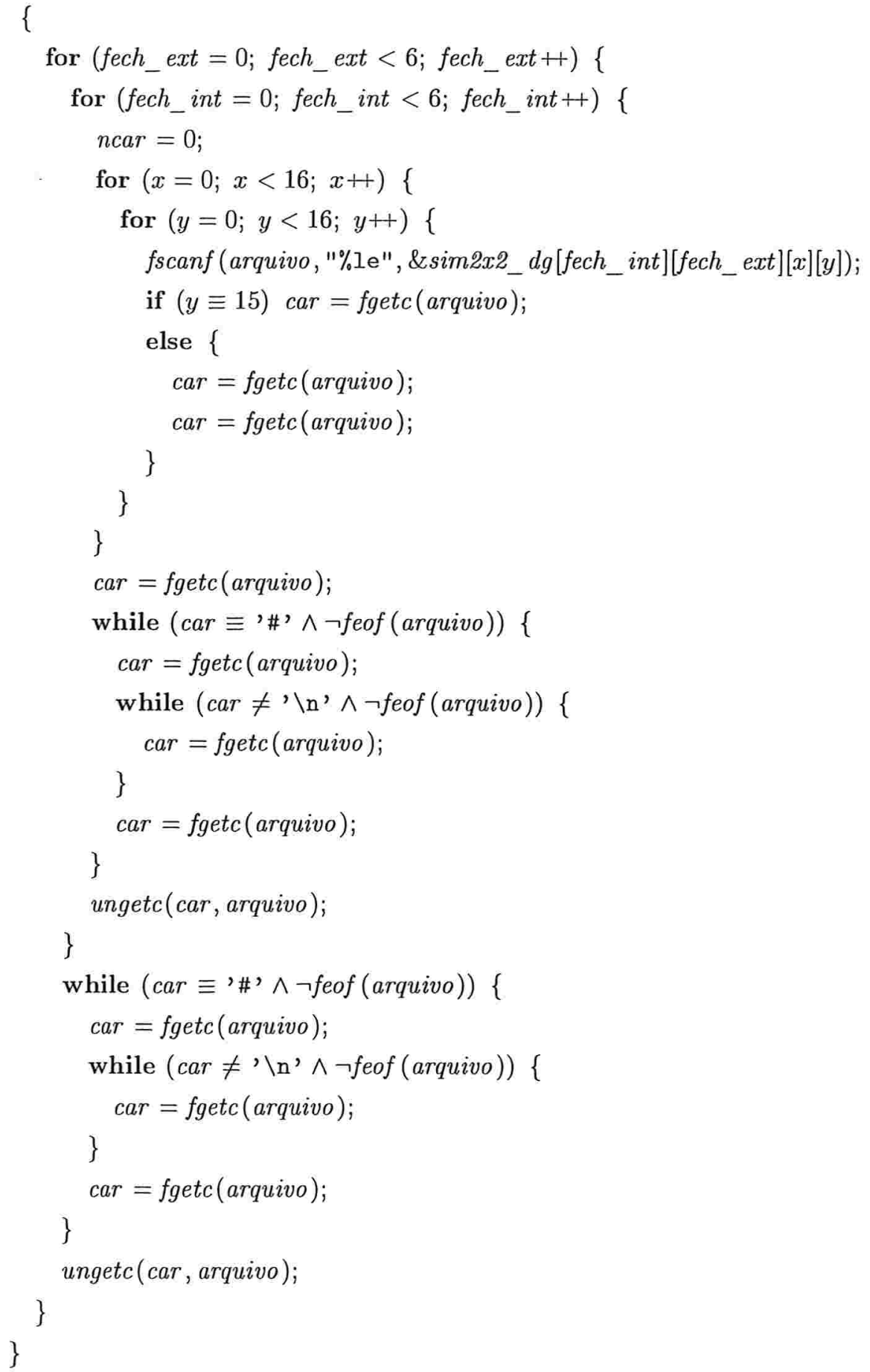




\section{Carrega para a memória o arquivo asint1x2.dg}

Este arquivo contém os parâmetros de energia referente à situação onde temos um laço tipo interno assimétrico de tamanho 3, ou seja, com três bases acessíveis. Este arquivo contem 144 tabelas $4 \times 4$ que são cada uma da forma

$\begin{array}{ccccc} & & & Y & \\ (X) & A & C & G & U \\ & 5^{\prime} & -> & 3^{\prime} & \\ & & X & & \\ & & & & \\ & A & & & \\ & U & & U & \\ & & Y A & & \\ & & & & \\ & 3^{\prime} & < & 5^{\prime} & \\ & & & & \\ (A) & 3.4 & 3.4 & 2.2 & 3.9 \\ (C) & 3.4 & 3.4 & 4.2 & 3.4 \\ (G) & 1.0 & 2.7 & 2.2 & 2.7 \\ (U) & 4.7 & 4.0 & 4.7 & 3.0\end{array}$

Parte deste arquivo está no Item B.10 do Apêndice B.

$79\langle$ Leitura de asint1x2.dg 79$\rangle \equiv$

\{

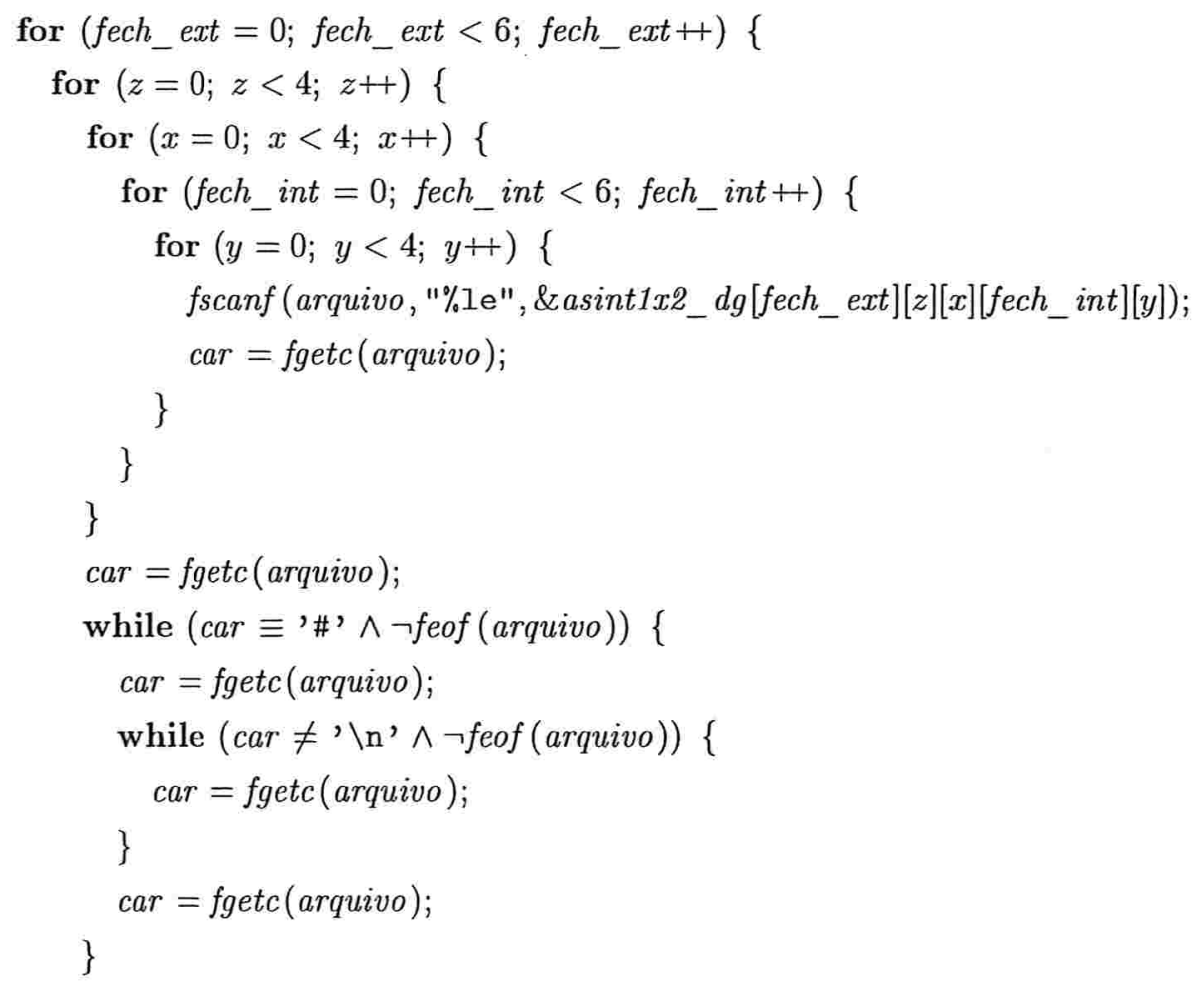




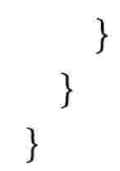

Este código é usado no bloco 70 .

\section{Alocação de matrizes}

$80\langle$ Alocação de matrizes 80$\rangle \equiv$

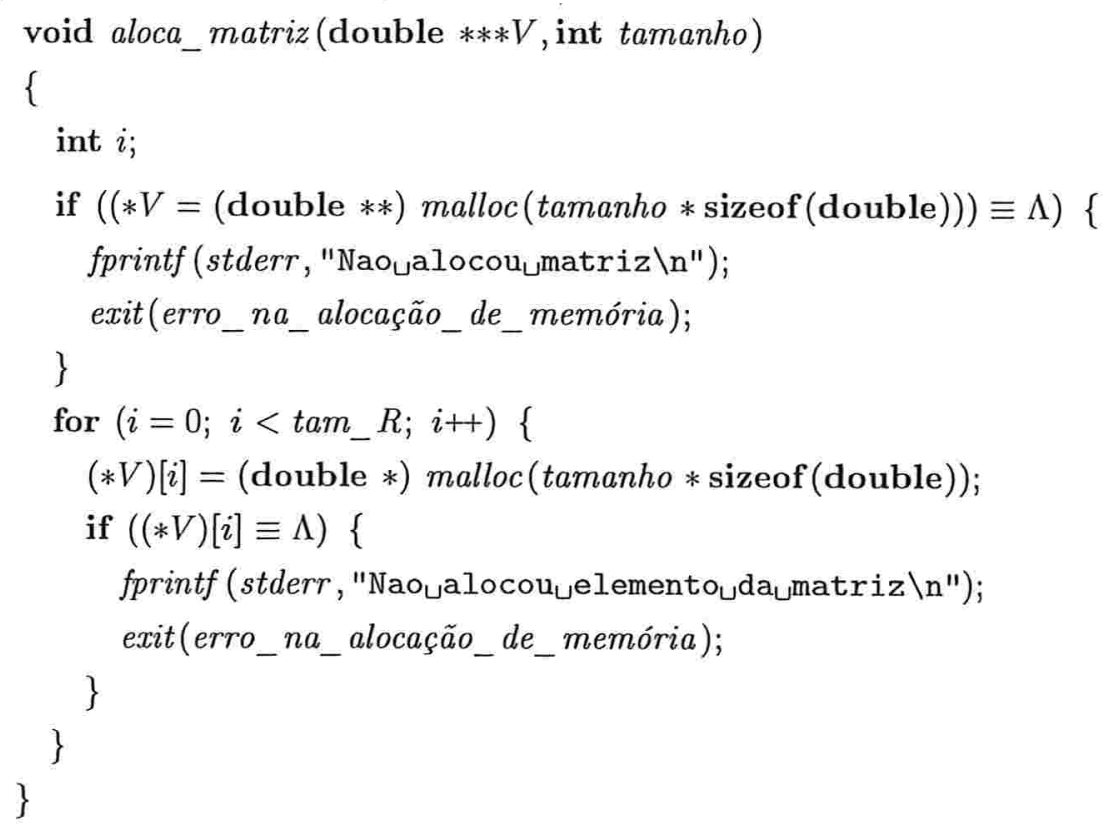

Este código é usado no bloco 58 .

Alocação da matriz auxiliar de rastreamento

81 〈Alocação da matriz auxiliar de rastreamento 81 〉 $\equiv$ void aloca_matriz_rastreamento()

\{

int $i$;

if $(($ rastro $=($ struct pista $* *)$ malloc $($ tam_ $R * \operatorname{sizeof}($ struct pista $))) \equiv \Lambda)\{$ fprintf (stderr, "Naoualocou $r a s t r o[i][j] \backslash n ")$; exit(erro_na_alocação_de_memória); 


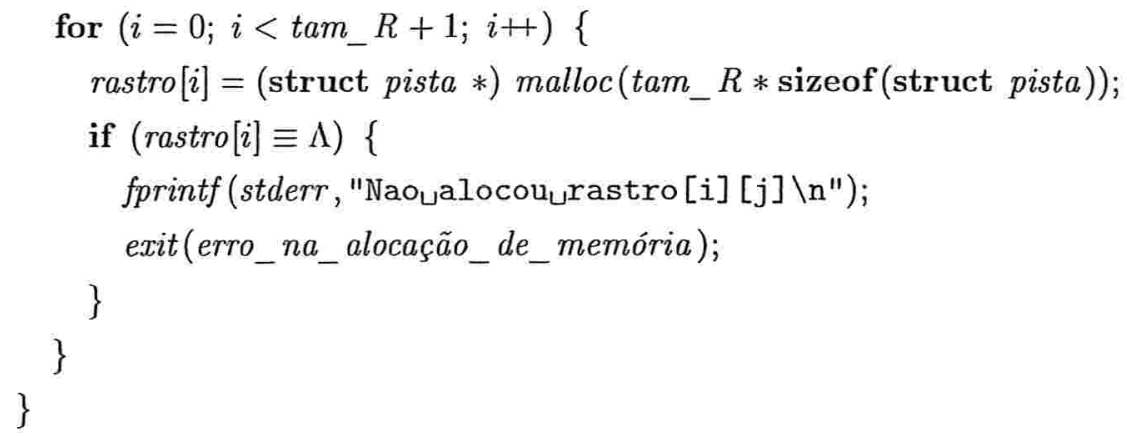

Este código é usado no bloco 58 .

Alocação da matriz para laços internos em Lyngs $\emptyset$

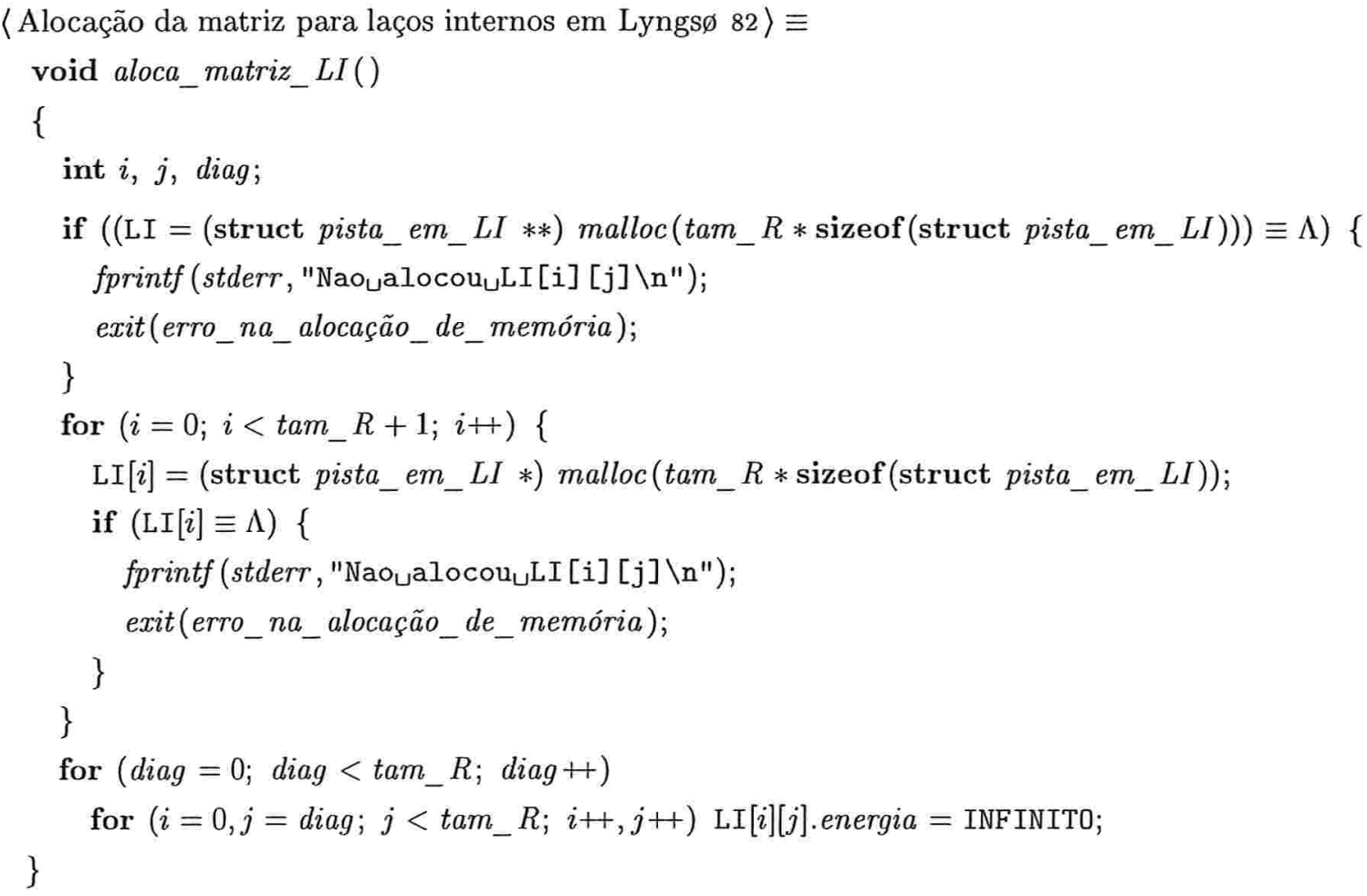

Este código é usado no bloco 58 .

Alocação da sequência 
$83\langle$ Alocação da sequência 83 〉 $\equiv$ void aloca_seqüência()

\{

int $i$;

$R=(\operatorname{char} *)$ malloc $($ tam_ $R * \operatorname{sizeof}($ int $))$;

if $(R \equiv \Lambda)$ fprintf (stderr, "Nãoualocou $R \backslash n$ ");

civil $=(\operatorname{char} *)$ malloc $($ tam_ $R * \operatorname{sizeof}(\operatorname{char}))$;

for $(i=0 ; i<$ tam_ $R ; i++)$ civil $[i]=$ NÃO_PAREADO;

\}

Este código é usado no bloco 58 .

Alocação do vetor auxiliar D[] para cálculo de laço interior

$84\langle$ Alocação do vetor auxiliar D[ 84 〉 三

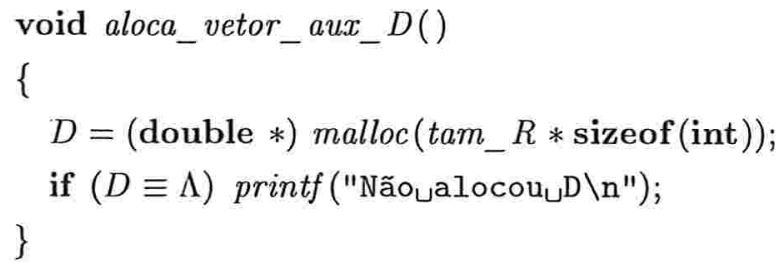

Este código é usado no bloco 58.

Alocação do conjunto de conjunto de pares

85 〈Alocação do conjunto de conjunto de pares 85 ) 三

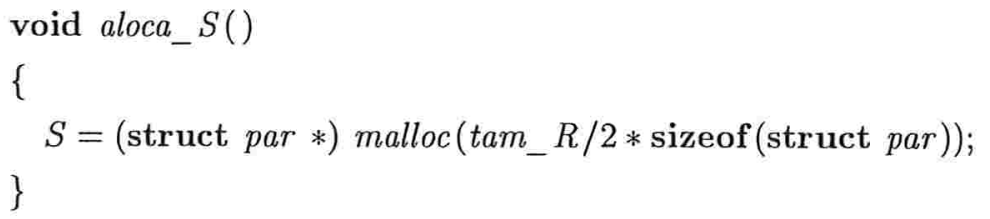

Este código é usado no bloco 58 . 
Inicialização do conjunto de pares

$86\langle$ Inicialização do conjunto de pares 86 ) 三 void $z e r a_{-} S()$

\{

int $i$;

for $\left(i=0 ; i<t a m_{-} R / 2 ; i++\right)\{$

$S[i]$.base1 $=0$;

$S[i]$.base $2=0$;

\}

\}

Este código é usado no bloco 58 . 


\section{A.7 Funções Auxiliares}

Nesta seção são descritas funções que auxiliam na visualização de alguns arquivos e matrizes de energia.

87 〈Funções Auxiliares 87) 三

〈Imprime a matriz de energia 88 〉

〈Imprime a matriz auxiliar de energia para laços (L[i][j]) 89

〈Imprime a matriz para multilaços (G[i][j]) 90

$\langle$ Imprime a molécula (seqüência) 91〉

〈Imprime o conjunto de pares 92〉

〈Imprime o arquivo loop.dg 93〉

Este código é usado no bloco 2.

Imprime a matriz de energia

$88\langle$ Imprime a matriz de energia 88$\rangle \equiv$

void print_matriz_energia()

\{

int $a, b$;

printf ("Matriz $\mathrm{E}: \backslash \mathrm{n} ")$;

for $\left(a=0 ; a<t a m_{-} R ; a++\right)\{$

for $\left(b=0 ; b<t a m_{-} R ; b++\right)$

if $(E[a][b] \equiv \operatorname{INFINITO)}$ printf ("UபபINF");

else printf $\left(" \% 5.2 \mathrm{f}_{\cup} ", E[a][b]\right)$;

printf ("\n");

\}

\}

Este código é usado no bloco 87.

Imprime a matriz auxiliar de energia para laços $(\mathrm{L}[\mathrm{i}][\mathrm{j}])$

$89\langle$ Imprime a matriz auxiliar de energia para laços (L[i][j]) 89$\rangle \equiv$ void print_matriz_energia_aux_L()

\{

int $a, b$; 


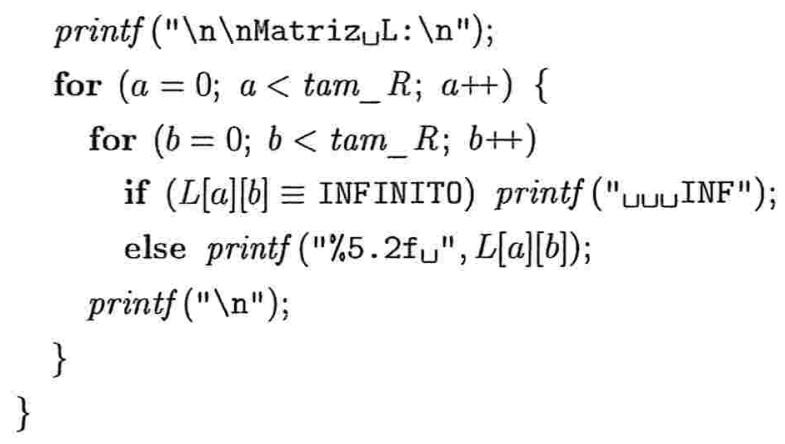

Este código é usado no bloco 87.

Imprime a matriz para multilaços $(\mathrm{G}[\mathrm{i}][\mathrm{j}])$

$90\langle$ Imprime a matriz para multilaços $(\mathrm{G}[\mathrm{i}][\mathrm{j}]) 90\rangle \equiv$ void print_matriz_multi()

\{

int $i, j$;

for $\left(i=0 ; i<t a m_{-} R ; i++\right)\{$

for $\left(j=1 ; j<t a m_{-} R ; j++\right)\{$ printf (" [\%-3.1f] ", G[i] $[j])$;

\}

printf ("\n");

\}

\}

Este código é usado no bloco 87.

\section{Imprime a molécula (seqüência)}

$91\langle$ Imprime a molécula (seqüência) 91$\rangle \equiv$

void print_seqüência()

\{

long int $i$;

printf ("\n");

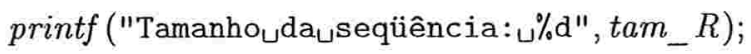

printf ("\n");

printf ("R $\left.\mathrm{R}_{\mathrm{U}}=\mathrm{u}\right)$; 


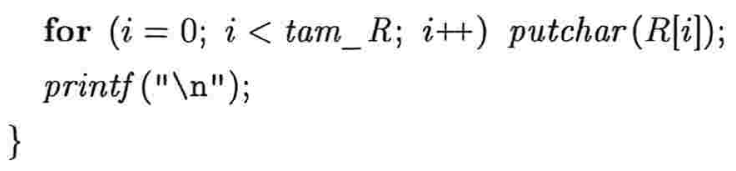

Este código é usado no bloco 87.

Imprime o conjunto de pares

$92\langle$ Imprime o conjunto de pares 92$\rangle \equiv$

void print_S(int caso)

\{

char $*$ letras;

int $i$;

letras $=(\operatorname{char} *)$ malloc $($ tam_ $R * \operatorname{sizeof}(\operatorname{char}))$;

for $(i=0 ; i<$ tam_ $R ; i++)$ letras $[i]=$ '. ';

printf (" $\backslash \mathrm{n}_{\sqcup}$ CONJUNTO $\mathrm{DE}_{\sqcup}$ PARES $_{\sqcup} \mathrm{DO} \mathrm{O}_{\sqcup}$ DOBRAMENTO $\backslash \mathrm{n}$ ");

for $\left(i=0 ; i<n u m \_p a r e s ; i+1\right)\{$

letras $[S[i]$.base1 $]=$ ' (';

letras $[S[i]$.base2 $\left.]={ }^{\prime}\right) '$;

\}

printf ("Número total $_{\sqcup}$ de $_{\cup}$ pares $\left._{\sqcup}=\sqcup \% \mathrm{~d} \backslash \mathrm{n} ", i\right)$;

printf ("Energia total do $_{\sqcup}$ dobramento $o_{\sqcup}=4.2 \mathrm{f}_{\cup \mathrm{kcal}} / \mathrm{mol} \backslash \mathrm{n}$ ", $E[0]\left[\operatorname{tam}_{-} R-1\right]$ );

for $\left(i=0 ; i<\right.$ tam_ $\left._{-} ; i++\right)$ printf $(" \% \mathrm{c} ", R[i])$;

printf ("\n");

for $(i=0 ; i<$ tam_R; $i++)$ printf $(" \% \mathrm{c} "$, letras $[i])$;

printf ("\n");

\}

Este código é usado no bloco 87 .

Imprime o arquivo loop.dg

$93\langle$ Imprime o arquivo loop.dg 93〉 $三$

void print_loop_dg()

\{

int $i$; 


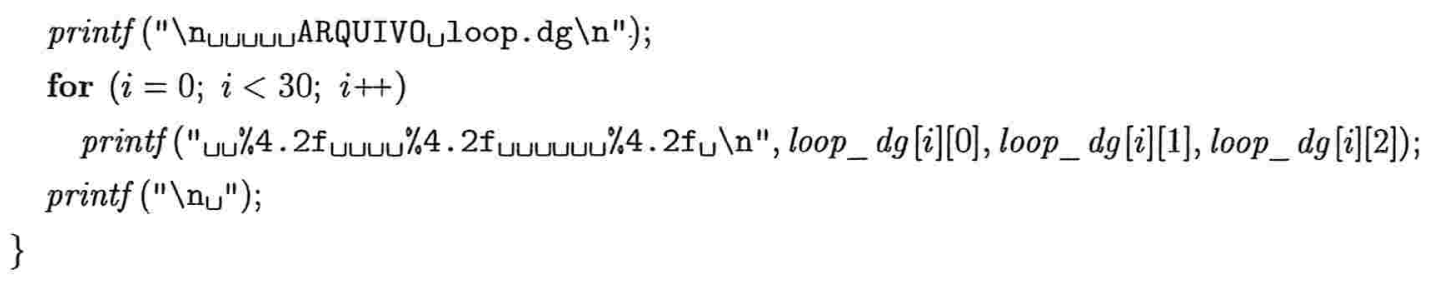

Veja também bloco 94 .

Este código é usado no bloco 87 .

Imprime o arquivo stack.dg

$94\langle$ Imprime o arquivo loop.dg 93$\rangle+\equiv$

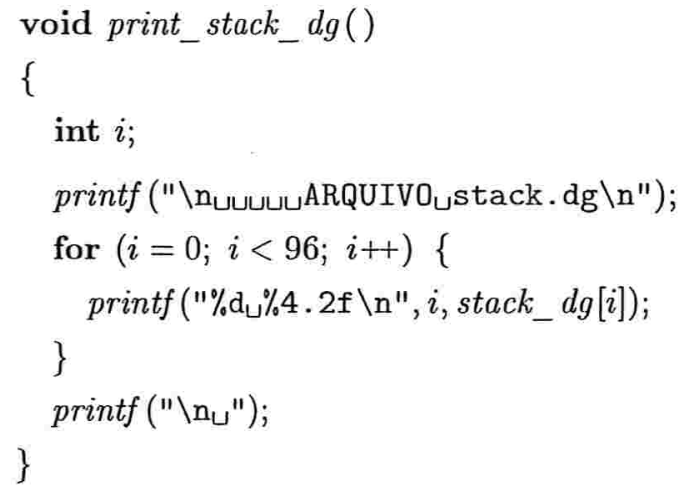




\section{A.8 Definições, Declarações e Arquivos de Inclusão}

Neste bloco foram agrupadas os seguintes items, nesta ordem:

- arquivos de inclusão ("include's");

- definição de constantes ("define's");

- definição das estruturas ("struct's");

- declaração das variáveis globais do código;

- protótipos das funções.

$95\langle$ Definições, Declarações e Arquivos de Inclusão 95〉 $\equiv$ \#include <stdio.h>

\#include <stdlib.h>

\#include <ctype.h>

\#include <time.h>

\#include <limits.h>

\#include <string.h>

\#include <math.h>

\#define OK 0

\#define erro_nos_dados 1

\#define erro_na_leitura_de_arquivo 2

\#define erro_na_alocação_de_memória 3

\#define erro_de_uso 4

\#define READ_ONLY " $r$ "

\#define WRITE "w"

\#define _REENTRANT_

\#define TRUE 1

\#define FALSE 0

\#define MAXLIN 1000

\#define ERRE 0.0019872

\#define $T 310$

\#define $t 2$

\#define TRESLINHA 0

\#define CINCOLINHA 1

\#define DANGLE3J 1

\#define DANGLE5I 2

\#define DANGLE_AMBOS 3

\#define PAREADO 1

\#define NÃO_PAREADO 0

\#define DANGLEADO 2 


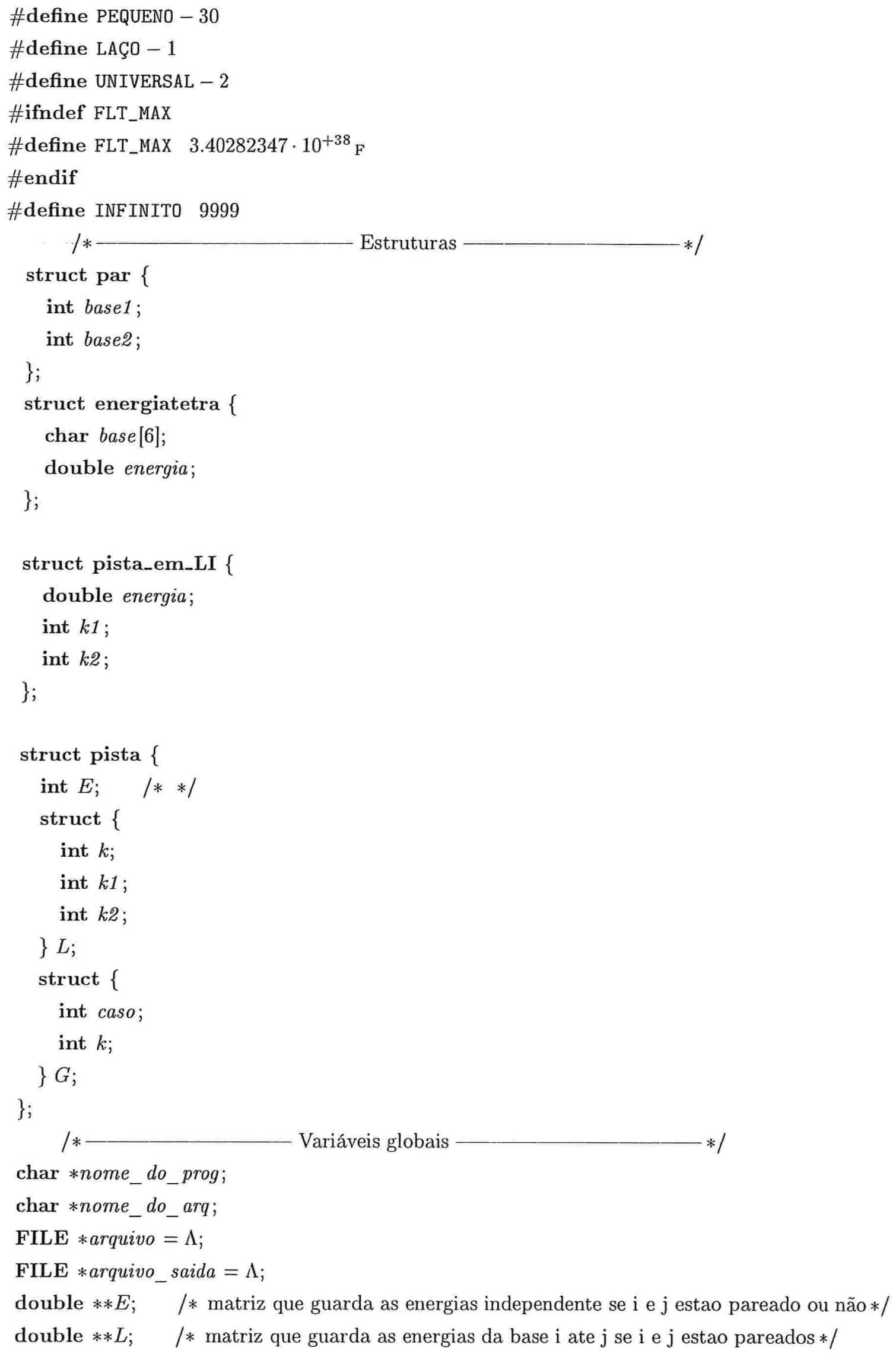


double $* * G ; \quad / *$ matriz que guarda as energias para o cálculo do multilaço $* /$ struct pista_em_LI $* *$ LI; $\quad / *$ matriz que guarda as energias dos laços internos (Lyngsø) $* /$ struct pista $* *$ rastro;

$\operatorname{char} * R$;

double $* D$;

int $t a m_{-} R$;

int num_pares $=0$;

char *civil;

I*—_- Protótipo das funções_—_ $* 1$

double diff_time(time_t time1, time_t time2);

void aloca_matriz(double $* * *$, int);

void aloca_matriz_rastreamento();

void aloca_matriz_LI ();

void aloca_seqüência();

void aloca_S();

void aloca_vetor_aux_D();

int base_num(char base);

int ind_1_ou_2_tab_simtr (char $c 1$, char $c 2)$;

void inicializa_matriz_rastro();

void zera_S();

void le_seqüência $\left(\right.$ char $* n o m e \_d o \_p r o g$, char $\left.* n o m e \_d o \_a r q\right)$;

void le_arquivo_parâmetro_energia $\left(\mathbf{c h a r} * n o m e \_d o \_a r q\right)$;

double $t a b \_s t a c k \_d g($ int $i$,int $k$, int $l$,int $j)$;

double tab_tstackh_dg(int,int);

double $t a b \_t s t a c k i \_d g$ (int $i$, int $k$, int $l$,int $j$ );

double $t a b \_d a n g l e \_d g($ int $i$, int $j$, int $u$, int tipo);

double $t a b \_t e t r a l o o p \_d g$ (int $i$,int $j$ );

double $t a b \_s i m 2 x 2 \_d g($ int $i$,int $j$, int $k$,int $l)$;

double $t a b_{-} a \operatorname{sint1} 1 x 2_{-} d g$ (int $i$, int $j$ );

double $t a b_{-} a \operatorname{sint} 2 x 1_{-} d g($ int $i$, int $j)$;

void calc_matriz_energia();

double alfa (char, char);

void identifica_pares (int $i$, int $j$ );

void guarda_S(int base1, int base2);

void traceback_E(int $i$, int $j$ );

void traceback_L(int $i$, int $j)$;

void traceback_G(int $i$, int $j)$;

void guarda_S(int base1, int base2);

void calc_matriz_energia_dep_laços(int otimiza);

double laço_menor_energia(int $i$, int $j$, int otimiza);

double calc_energ_arco (int $i$, int $j$ );

double calc_energ_stack(int $i$,int $j$ ); 
double $c a l c \_e n e r g \_b a r r \_i(\operatorname{int} i$, int $j$, int $*)$;

double $c a l c \_e n e r g \_b a r r \_j($ int $i$, int $j$, int $*$ );

double calc_energ_inter (int $i$, int $j$, int $*$,int $*$ );

double calc_energ_inter_cubico(int $i$, int $j$, int $*$, int $*$ );

double calc_energ_multi(int $i$, int $j$, int $*$ );

void calc_energ_inter_cubico2(int $i$, int $j$ );

double min_de_2_valores(double aux1, double aux2);

double min_de_3_valores (double E, double aux1, double aux2);

double assimetria (int $n 1$, int $n 2)$;

void print_matriz_energia();

void print_matriz_energia_aux_L( );

void print_matriz_multi();

void print_seqüência();

void print_S(int caso);

void print_loop_dg();

void print_stack_dg();

void print_tab_experimental();

Este código é usado no bloco 2. 


\section{A.9 Programa Principal}

Nesta função faz-se apenas quatro tarefas básicas, nesta ordem:

- Leitura do arquivo de entrada que contém a molécula a ser dobrada e alocação de estruturas de dados comuns a qualquer método (matriz de energias $(W)$ e conjunto de pares);

- Leitura do tipo de método que o usuário deseja executar, conforme as seguintes opções:

- (1) Energia de pares independentes (não contabilizando laços)

- (2) Considerando laços (contabilizando energia dos laços)

- (3) Otimizando laços internos para $O\left(n^{3}\right)$ segundo algoritmo de Waterman

- (4) Otimizando laços internos para $O\left(n^{3}\right)$ segundo algoritmo de Lyngø

- Chamada das funções que executam o método conforme escolha acima.

- Para finalizar, imprime-se a estrutura secundária (conjunto de pares) e faz-se a medida do tempo gasto na execução do programa.

97 〈Programa Principal 97〉 $\equiv$

int $\operatorname{main}(\operatorname{argc}, \arg v)$

int $\operatorname{argc}$;

char **argv;

\{

〈variáveis da função main 98

/* Inicializacao */

nome_do_prog $=\operatorname{argv}[0]$;

if $(\operatorname{argc} \equiv 3)\{$

nome_do_arq $=\operatorname{argv}[1]$;

tipo $=\arg v[2] ;$

if $\left(\right.$ tipo $[0] \equiv{ }^{\prime} 1$ ' $\vee$ tipo $[0] \equiv{ }^{\prime}{ }^{\prime}$ ' $\vee$ tipo $[0] \equiv{ }^{\prime} 3^{\prime} \vee$ tipo $\left.[0] \equiv{ }^{\prime} 4^{\prime}\right)\{$

le_seqüência(nome_do_prog,nome_do_arq);

aloca_matriz $\left(\& E, t a m_{-} R\right)$;

aloca_S();

\}

else \{

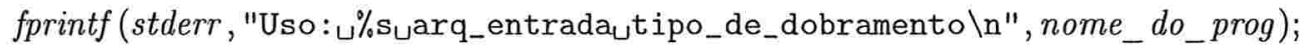

〈menu de opções na função main 104)

exit(erro_de_uso);

\}

\}

else \{

fprintf (stderr, "Uso: $\%$ suarq_entrada_tipo_de_dobramento $\backslash n "$ ", nome_do_prog);

〈menu de opções na função main 104〉 


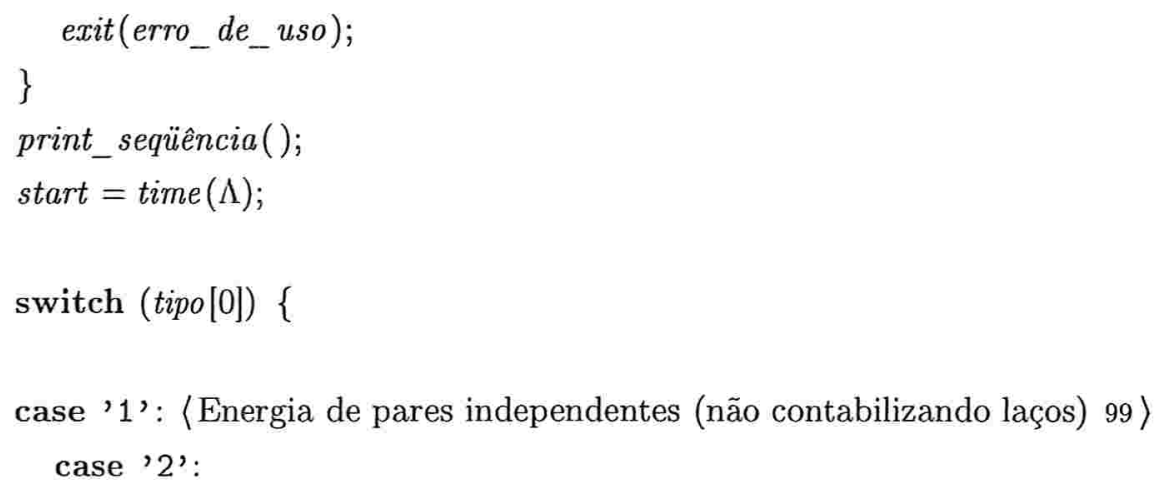

〈Chamada das funções para opção que considera laços (contabilizando energia dos laços) 100〉 case ' 3 ': 〈Otimizando laços interiores para $O\left(n^{3}\right)$ 101〉

Este código é usado no bloco 2.

98 〈variáveis da função main 98〉 三

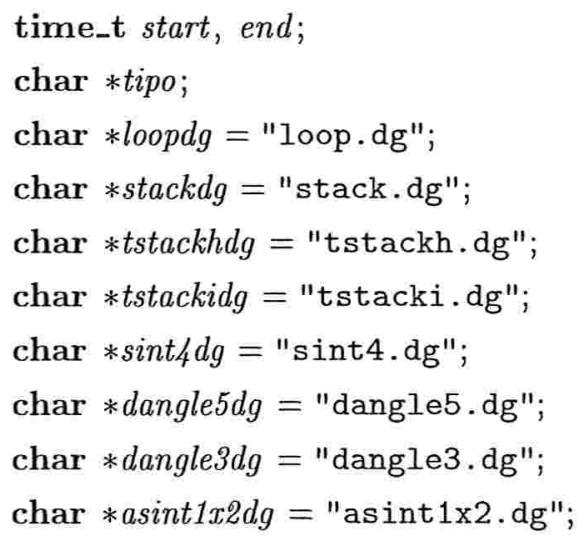

Este código é usado no bloco 97 .

99 〈Energia de pares independentes (não contabilizando laços) 99〉 $\equiv$ calc_matriz_energia (); identifica_pares $\left(0\right.$, tam_$\left._{-} R-1\right)$;

break;

Este código é usado no bloco 97 . 
100 〈Chamada das funções para opção que considera laços (contabilizando energia dos laços) 100 〉 $\equiv$

$$
\begin{aligned}
& \text { le_arquivo_parâmetro_energia(loopdg); } \\
& \text { le_arquivo_parâmetro_energia (stackdg); } \\
& \text { le_arquivo_parâmetro_energia (tstackhdg); } \\
& \text { le_arquivo_parâmetro_energia(tstackidg); } \\
& \text { le_arquivo_parâmetro_energia(sint4dg); } \\
& \text { le_arquivo_parâmetro_energia(dangle5dg); } \\
& \text { le_arquivo_parâmetro_energia(dangle3dg); } \\
& \text { le_arquivo_parâmetro_energia(asint1x2dg); } \\
& \text { aloca_matriz }\left(\& L, t a m \_R\right) \text {; } \\
& \text { aloca_matriz }(\& G, \text { tam_R); } \\
& \text { aloca_matriz_rastreamento(); } \\
& \text { calc_matriz_energia_dep_laços (0); } \\
& \text { traceback_E(0,tam_R-1); } \\
& \text { break; }
\end{aligned}
$$

Este código é usado no bloco 97.

$101\left\langle\right.$ Otimizando laços interiores para $\left.O\left(n^{3}\right) 101\right\rangle \equiv$

$$
\begin{aligned}
& \text { le_arquivo_parâmetro_energia }(\text { loopdg }) ; \\
& \text { le_arquivo_parâmetro_energia }(\text { stackdg }) ; \\
& \text { le_arquivo_parâmetro_energia }(\text { tstackhdg }) \text {; } \\
& \text { le_arquivo_parâmetro_energia }(\text { tstackidg }) ; \\
& \text { aloca_matriz }\left(\& L, t a m_{-} R\right) ; \\
& \text { aloca_matriz }\left(\& G, t a m_{-} R\right) ; \\
& \text { aloca_matriz_rastreamento }() ; \\
& \text { aloca_vetor_aux_D }() ; \\
& \text { calc_matriz_energia_dep_laços }(1) ; \\
& \text { traceback_E(0,tam_R-1); } \\
& \text { break; }
\end{aligned}
$$

Este código é usado no bloco 97 .

$102\langle$ Laços interiores otimizados segundo Lyngs $\emptyset 102\rangle \equiv$

$$
\begin{aligned}
& \text { le_arquivo_parâmetro_energia(loopdg); } \\
& \text { le_arquivo_parâmetro_energia(stackdg); } \\
& \text { le_arquivo_parâmetro_energia (tstackhdg); } \\
& \text { le_arquivo_parâmetro_energia(tstackidg); } \\
& \text { aloca_matriz (\&L, tam_R); } \\
& \text { aloca_matriz }\left(\& G, t a m \_R\right) \text {; } \\
& \text { aloca_matriz_LI(); } \\
& \text { aloca_matriz_rastreamento(); }
\end{aligned}
$$


calc_matriz_energia_dep_laços (2);

traceback_E $\left(0\right.$, tam_ $\left._{-} R-1\right)$;

break;

Este código é usado no bloco 97.

$104\langle$ menu de opções na função main 104〉 $\equiv$

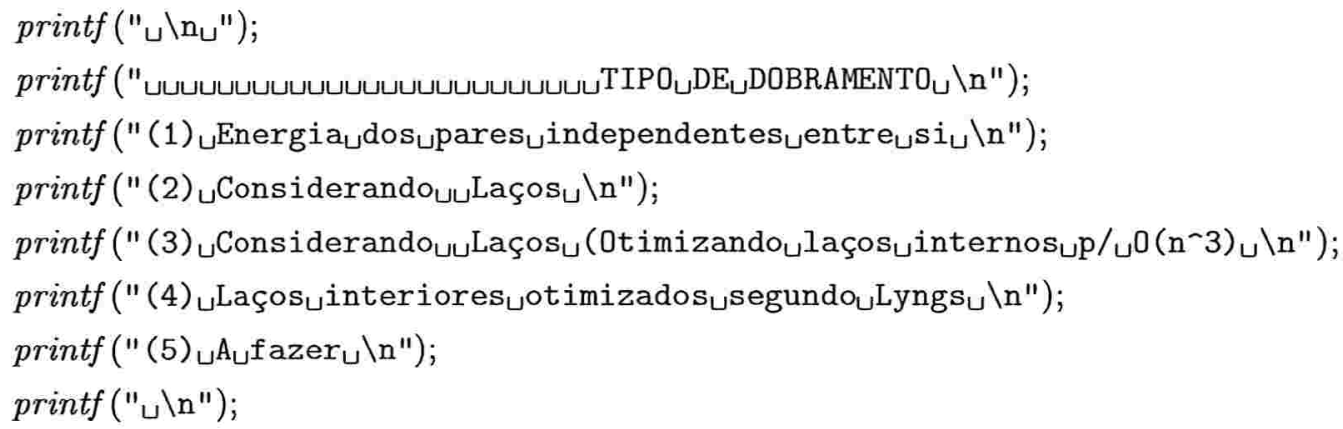

Este código é usado no bloco 97 . 



\section{Apêndice B}

\section{Tabelas}

\section{B.1 loop.dg}

Fonte: <http://bioinfo.math.rpi.edu/ zukerm/rna/energy $>$ Obtida em: 01/07/2000

$\begin{array}{cccc}\text { SIZE } & \text { INTERNAL } & \text { BULGE } & \text { ARCO } \\ 1 & 9999 & 3.90 & 9999 \\ 2 & 4.10 & 3.10 & 9999 \\ 3 & 5.10 & 3.50 & 4.10 \\ 4 & 4.90 & 4.20 & 4.90 \\ 5 & 5.30 & 4.80 & 4.40 \\ 6 & 5.70 & 5.00 & 4.70 \\ 7 & 5.90 & 5.20 & 5.00 \\ 8 & 6.00 & 5.30 & 5.10 \\ 9 & 6.10 & 5.40 & 5.20 \\ 10 & 6.30 & 5.50 & 5.30 \\ 11 & 6.40 & 5.70 & 5.40 \\ 12 & 6.40 & 5.70 & 5.50 \\ 13 & 6.50 & 5.80 & 5.60 \\ 14 & 6.60 & 5.90 & 5.70 \\ 15 & 6.70 & 6.00 & 5.80 \\ 16 & 6.80 & 6.10 & 5.80 \\ 17 & 6.80 & 6.10 & 5.90 \\ 18 & 6.90 & 6.20 & 5.90 \\ 19 & 6.90 & 6.20 & 6.00 \\ 20 & 7.00 & 6.30 & 6.10 \\ 21 & 7.10 & 6.30 & 6.10 \\ 22 & 7.10 & 6.40 & 6.20 \\ 23 & 7.10 & 6.40 & 6.20 \\ 24 & 7.20 & 6.50 & 6.30 \\ 25 & 7.20 & 6.50 & 6.30 \\ 26 & 7.30 & 6.50 & 6.30 \\ 27 & 7.30 & 6.60 & 6.40 \\ 28 & 7.40 & 6.70 & 6.40 \\ 29 & 7.40 & 6.70 & 6.50 \\ 30 & 7.40 & 6.70 & 6.50\end{array}$




\section{B.2 stack.dg}

Fonte: <http://bioinfo.math.rpi.edu/ zukerm/rna/energy > Obtida em: 01/07/2000

\begin{tabular}{|c|c|c|c|c|c|}
\hline A A A A 9999 & A G G U 9999 & C C C G 9999 & G A A C 9999 & G G U A 9999 & U C C U 9999 \\
\hline A A A C 9999 & A G U A 9999 & C C C U 9999 & G A A G 9999 & G G U C -1.40 & U C G A -2.30 \\
\hline A A A G 9999 & A G U C 9999 & C C G A 9999 & G A A U 9999 & G G U G 9999 & U C G C 9999 \\
\hline A A A U 9999 & A G U G 9999 & C C G C 9999 & G A C A 9999 & G G U U -0.40 & U C G G -1.40 \\
\hline A A C A 9999 & A G U U -0.50 & C C G G -2.90 & G A C C 9999 & G U A A 9999 & U C G U 9999 \\
\hline A A C C 9999 & A U A A 9999 & C C G U 9999 & G A C G 9999 & G U A C -2.10 & U C U A 9999 \\
\hline A A C G 9999 & A U A C 9999 & C C U A 9999 & G A C U 9999 & G U A G 9999 & U C U C 9999 \\
\hline A A C U 9999 & A U A G 9999 & C C U C 9999 & G A G A 9999 & G U A U -1.00 & U C U G 9999 \\
\hline A A G A 9999 & A U A U -0.90 & C C U G 9999 & G A G C 9999 & G U C A 9999 & U C U G 9999 \\
\hline A A G C 9999 & A U C A 9999 & C C U U 9999 & G A G G 9999 & G U C C 9999 & U G A A 9999 \\
\hline A A G G 9999 & A U C C 9999 & C G A A 9999 & G A G U 9999 & G U C G 9999 & U G A C 9999 \\
\hline A A G U 9999 & A U C G 9999 & C G A C 9999 & G A U A 9999 & G U C U 9999 & U G A G 9999 \\
\hline A A U A 9999 & A U C U 9999 & C G A G 9999 & G A U C -2.30 & G U G A 9999 & U G A U 9999 \\
\hline A A U C 9999 & A U G A 9999 & C G A U 9999 & G A U G 9999 & G U G C -2.10 & U G C A -1.80 \\
\hline A A U G 9999 & A U G C 9999 & C G C A 9999 & G A U U -1.10 & G U G G 9999 & U G C C 9999 \\
\hline A A U U -0.90 & A U G G 9999 & C G C C 9999 & G C A A 9999 & G U G U -1.50 & U G C G -1.20 \\
\hline A C A A 9999 & A U G U -1.00 & C G C G -2.00 & G C A C 9999 & G U U A 9999 & U G C U 9999 \\
\hline A C A C 9999 & A U U A 9999 & C G C U 9999 & G C A G 9999 & G U U C 9999 & U G G A 9999 \\
\hline A C A G 9999 & A U U C 9999 & C G G A 9999 & G C A U 9999 & G U U G 9999 & U G G C 9999 \\
\hline A C A U 9999 & A U U G 9999 & C G G C 9999 & G C C A 9999 & G U U U 9999 & U G G G 9999 \\
\hline A C C A 9999 & A U U U 9999 & C G G G 9999 & G C C C 9999 & U A A A 9999 & U G G U 9999 \\
\hline A C C C 9999 & C A A A 9999 & C G G U 9999 & G C C G 9999 & U A A C 9999 & U G U A -0.80 \\
\hline A C C G 9999 & C A A C 9999 & C G U A 9999 & G C C U 9999 & U A A G 9999 & U G U C 9999 \\
\hline A C C U 9999 & C A A G 9999 & C G U C 9999 & G C G A 9999 & U A A U 9999 & U G U G -0.20 \\
\hline A C G A 9999 & C A A U 9999 & C G U G -1.20 & G C G C -3.40 & U A C A 9999 & U G U U 9999 \\
\hline A C G A 9999 & C A C A 9999 & C G U U 9999 & G C G G 9999 & U A C C 9999 & U U A A -0.90 \\
\hline A C G A 9999 & C A C C 9999 & C U A A 9999 & G C G U -2.10 & U A C G 9999 & U U A C 9999 \\
\hline A C G U -2.10 & C A C G 9999 & C U A C 9999 & G C U A 9999 & U A C U 9999 & U U A G -0.50 \\
\hline A C U A 9999 & C A C U 9999 & C U A G -1.70 & G C U C 9999 & U A G A 9999 & U U A U 9999 \\
\hline A C U C 9999 & C A G A 9999 & C U A U 9999 & G C U G 9999 & U A G C 9999 & U U C A 9999 \\
\hline A C U G 9999 & C A G C 9999 & C U C A 9999 & G C U U 9999 & U A G G 9999 & U U C C 9999 \\
\hline A C U U 9999 & C A G G 9999 & C U C C 9999 & G G A A 9999 & U A G U 9999 & U U C G 9999 \\
\hline A G A A 9999 & C A G U 9999 & C U C G 9999 & G G A C 9999 & U A U A - -1.10 & U U C U 9999 \\
\hline A G A C 9999 & C A U A 9999 & C U C U 9999 & G G A G 9999 & U A U C 9999 & U U G A -1.10 \\
\hline A G A G 9999 & C A U C 9999 & C U G A 9999 & G G A U 9999 & U A U G -0.80 & U U G C 9999 \\
\hline A G A U 9999 & C A U G -1.80 & C U G C 9999 & G G C A 9999 & U A U U 9999 & U U G G -0.40 \\
\hline A G C A 9999 & C A U U 9999 & C U G G -1.90 & G G C C -2.90 & U C A A 9999 & U U G U 9999 \\
\hline A G C C 9999 & C C A A 9999 & C U G U 9999 & G G C G 9999 & U C A C 9999 & U U U A 9999 \\
\hline A G C G 9999 & C C A C 9999 & C U U A 9999 & G G C U -1.90 & U C A G 9999 & U U U C 9999 \\
\hline A G C U -1.70 & C C A G 9999 & C U U C 9999 & G G G A 9999 & U C A U 9999 & U U U G 9999 \\
\hline A G G A 9999 & C C A U 9999 & C U U G 9999 & G G G C 9999 & U C C A 9999 & U U U U 9999 \\
\hline A G G C 9999 & C C C A 9999 & C U U U 9999 & G G G G 9999 & U C C C 9999 & \\
\hline A G G G 9999 & C C C C 9999 & G A A A 9999 & G G G U 9999 & U C C G 9999 & \\
\hline
\end{tabular}




\section{B.3 tstackh.dg}

Fonte: <http://bioinfo.math.rpi.edu/ zukerm/rna/energy> Obtida em: $01 / 07 / 2000$

\begin{tabular}{|c|c|c|c|c|c|}
\hline A A A A 9999 & A G G U -1.00 & C C C G -1.10 & G A A C -1.10 & G G U A -2.00 & U C C U 9999 \\
\hline A A A C 9999 & $\mathrm{~A} G \mathrm{U} \mathrm{A}-1.20$ & C C C U 9999 & G A A G 9999 & G G U C -1.50 & $\mathrm{UC} \mathrm{G} \mathrm{A}-0.30$ \\
\hline A A A G 9999 & A G U C -0.90 & C C G A -1.30 & G A A U -0.80 & G G U G -1.30 & U C G C -0.50 \\
\hline A A A U -0.80 & A G U G -2.00 & C C G C -0.60 & G A C A 9999 & $G G \cup U-1.00$ & U C G G -0.70 \\
\hline A A C A 9999 & A G U U -1.00 & C C G G -1.00 & G A C C -1.30 & G U A A -1.70 & $\mathrm{UC} \mathrm{G} \mathrm{U}-0.70$ \\
\hline A A C C 9999 & A U A A -0.80 & C C G U -0.80 & G A C G 9999 & G U A C -0.80 & U C U A -0.50 \\
\hline A A C G 9999 & A U A C -0.70 & C C U A 9999 & G A C U -1.00 & G U A G -1.00 & U C U C 9999 \\
\hline A A C U -1.00 & A U A G -1.50 & C C U C 9999 & G A G A 9999 & G U A U -0.80 & U C U G -0.70 \\
\hline A A G A 9999 & $\mathrm{~A} U \mathrm{~A} \mathrm{U}-0.80$ & $\mathrm{C} C \mathrm{C} G-0.80$ & G A G C -2.00 & G U C A 9999 & U C U U 9999 \\
\hline A A G C 9999 & A U C A 9999 & C C U U 9999 & G A G G 9999 & G U C C -0.80 & U G A A -1.80 \\
\hline A A G G 9999 & A U C C 9999 & C G A A 9999 & G A G U -1.70 & G U C G 9999 & U G A C 9999 \\
\hline A A G U -1.70 & A U C G 9999 & C G A C 9999 & G A U A -1.80 & $\mathrm{G} U \mathrm{C} \cup-0.80$ & U G A G -2.00 \\
\hline A A U A -1.00 & $\mathrm{~A} \cup \mathrm{C} \cup-0.80$ & C G A G -2.10 & G A U C -1.30 & G U G A -1.70 & U G A U 9999 \\
\hline A A U C -0.70 & $\mathrm{~A} U \mathrm{G} \mathrm{A}-0.80$ & C G A U 9999 & G A U G -1.20 & G U G C -0.80 & U G C A -0.90 \\
\hline A A U G -1.80 & $\mathrm{~A} U \mathrm{G} \mathrm{C}-0.70$ & C G C A -2.00 & G A U U -1.00 & G U G G -1.00 & U G C C -0.80 \\
\hline A A U U -1.00 & A U G G -1.50 & C G C C -1.10 & G C A A 9999 & G U G U -0.80 & U G C G -1.40 \\
\hline A C A A 9999 & A U G U -0.80 & C G C G -1.90 & G C A C -1.10 & G U U A 9999 & U G C U -1.20 \\
\hline A C A C 9999 & A U U A 9999 & C G C U -1.50 & G C A G 9999 & G U U C -0.70 & U G G A -1.20 \\
\hline A C A G 9999 & A U U C 9999 & C G G A 9999 & G C A U -0.70 & G U U G 9999 & U G G C 9999 \\
\hline A C A U -0.70 & A U U G 9999 & C G G C 9999 & G C C A 9999 & G U U U -0.80 & U G G G -1.30 \\
\hline A C C A 9999 & $\mathrm{~A} \cup \cup \mathrm{U}-0.80$ & C G G G -1.40 & G C C C -0.60 & U A A A -1.00 & U G G U 9999 \\
\hline A C C C 9999 & C A A A 9999 & C G G U 9999 & G C C G 9999 & U A A C 9999 & $\mathrm{U} G \mathrm{U} A-0.90$ \\
\hline A C C G 9999 & C A A C 9999 & C G U A -1.40 & G C C U -0.70 & U A A G -1.20 & U G U C -0.70 \\
\hline A C C U -0.70 & C A A G -1.40 & C G U C -0.90 & G C G A -2.00 & U A A U 9999 & U G U G -1.40 \\
\hline A C G A -1.10 & C A A U 9999 & C G U G -1.90 & G C G C -0.60 & U A C A -0.80 & U G U U -0.90 \\
\hline A C G C -1.10 & C A C A 9999 & $\mathrm{C} \mathrm{G} \mathrm{U} \mathrm{U}-1.10$ & G C G G -1.40 & U A C C 9999 & U U A A -0.30 \\
\hline A C G G -2.30 & C A C C 9999 & C U A A -1.00 & G C G U -0.70 & U A C G -1.40 & U U A C -0.70 \\
\hline A C G U -0.70 & C A C G -2.00 & C U A C -0.70 & G C U A 9999 & U A C U 9999 & U U A G -0.90 \\
\hline A C U A 9999 & C A C U 9999 & $\mathrm{C}$ U A G -1.40 & $\mathrm{G} \mathrm{C} \mathrm{U} \mathrm{C}-0.50$ & U A G A -1.80 & U U A U -0.80 \\
\hline A C U C 9999 & C A G A 9999 & C U A U -0.80 & G C U G 9999 & U A G C 9999 & U U C A -0.60 \\
\hline A C U G 9999 & C A G C 9999 & C U C A 9999 & G C U U -0.70 & U A G G -2.00 & U U C C 9999 \\
\hline A C U U -0.70 & C A G G -2.10 & C U C C 9999 & G G A A 9999 & U A G U 9999 & $\mathrm{U} U \mathrm{C} \mathrm{G}-1.10$ \\
\hline A G A A 9999 & C A G U 9999 & C U C G -1.50 & G G A C -2.30 & U A U A -0.90 & U U C U 9999 \\
\hline A G A C 9999 & C A U A -0.80 & C U C U 9999 & G G A G 9999 & U A U C -0.50 & U U G A -0.30 \\
\hline A G A G 9999 & C A U C -0.60 & C U G A -1.00 & G G A U -1.50 & U A U G -1.40 & U U G C -0.70 \\
\hline A G A U -1.50 & C A U G -1.90 & C U G C -0.70 & G G C A -2.10 & $\mathrm{U} A \mathrm{U} U-0.50$ & U U G G -0.90 \\
\hline A G C A -1.40 & $\mathrm{C} A \mathrm{~A} U-0.60$ & C U G G -1.40 & G G C C -1.50 & U C A A -0.70 & U U G U -0.80 \\
\hline A G C C -1.00 & C C A A 9999 & $\mathrm{C} U \mathrm{G} \mathrm{U}-0.80$ & G G C G -1.40 & U C A C 9999 & $\mathrm{U} U \mathrm{U} A-0.50$ \\
\hline A G C G -2.10 & C C A C 9999 & C U U A 9999 & G G C U -1.00 & U C A G -0.90 & U U U C 9999 \\
\hline A G C U -1.00 & C C A G -1.00 & C U U C 9999 & G G G A 9999 & U C A U 9999 & $\mathrm{U} U \mathrm{U} \mathrm{G}-0.90$ \\
\hline A G G A 9999 & C C A U 9999 & $\mathrm{C} \cup \mathrm{U} \mathrm{G}-1.20$ & G G G C -1.40 & $\mathrm{UCCA}-0.60$ & U U U U 9999 \\
\hline A G G C 9999 & C C C A 9999 & C U U U 9999 & G G G G 9999 & U C C C 9999 & \\
\hline A G G G 9999 & C C C C 9999 & G A A A 9999 & G G G U -1.00 & U C C G -0.90 & \\
\hline
\end{tabular}




\section{B.4 tstacki.dg}

Fonte: <http://bioinfo.math.rpi.edu/ zukerm/rna/energy>

Obtida em: 01/07/2000

\begin{tabular}{|c|c|c|c|c|c|}
\hline A A A A 9999 & A G G U -1.00 & C C C G -1.50 & G A A C -1.50 & G G U A -2.20 & U C C U 9999 \\
\hline A A A C 9999 & A G U A -1.00 & C C C U 9999 & G A A G 9999 & G G U C -1.50 & U C G A -0.20 \\
\hline A A A G 9999 & A G U C -1.00 & C C G A -1.50 & G A A U -1.50 & G G U G -1.00 & U C G C -1.50 \\
\hline A A A U -1.00 & A G U G -2.20 & C C G C -1.50 & G A C A 9999 & G G U U -1.50 & $\mathrm{U} \mathrm{C} \mathrm{G} \mathrm{G}-0.20$ \\
\hline A A C A 9999 & $\mathrm{~A} G \cup U-0.50$ & C C G G -1.00 & $\mathrm{G} \mathrm{A} \mathrm{C} \mathrm{C}-1.50$ & G U A A -2.20 & U C G U -2.50 \\
\hline A A C C 9999 & A U A A -1.00 & C C G U -1.50 & G A C G 9999 & G U A C -0.80 & U C U A -1.00 \\
\hline A A C G 9999 & A U A C -1.00 & C C U A 9999 & G A C U -1.50 & G U A G -1.00 & U C U C 9999 \\
\hline A A C U -1.00 & $\mathrm{~A}$ U A G -2.20 & C C U C 9999 & G A G A 9999 & G U A U -0.80 & U C U G -1.00 \\
\hline A A G A 9999 & A U A U -0.30 & C C U G -1.50 & G A G C -2.70 & G U C A 9999 & U C U U 9999 \\
\hline A A G C 9999 & A U C A 9999 & C C U U 9999 & G A G G 9999 & G U C C -1.50 & U G A A -2.20 \\
\hline A A G G 9999 & A U C C 9999 & C G A A 9999 & G A G U -2.70 & G U C G 9999 & U G A C 9999 \\
\hline A A G U -2.20 & A U C G 9999 & C G A C 9999 & G A U A -2.20 & G U C U -1.50 & $\mathrm{U}$ G A G -2.20 \\
\hline A A U A -1.00 & A U C U -1.00 & C G A G -2.70 & G A U C -1.30 & G U G A -2.70 & U G A U 9999 \\
\hline A A U C -1.10 & A U G A -1.50 & C G A U 9999 & G A U G -1.00 & $G \cup G C-0.80$ & U G C A -0.40 \\
\hline A A U G -2.20 & A U G C -1.50 & C G C A -1.50 & G A U U -1.30 & G U G G -1.50 & U G C C -1.50 \\
\hline A A U U -0.50 & A U G G -2.70 & C G C C -1.50 & G C A A 9999 & $\mathrm{G} \cup \mathrm{G} U-0.80$ & U G C G -0.40 \\
\hline A C A A 9999 & A U G U -0.30 & C G C G -1.90 & G C A C -1.50 & G U U A 9999 & $\mathrm{U} G \mathrm{C} \mathrm{U}-2.50$ \\
\hline A C A C 9999 & A U U A 9999 & C G C U -1.50 & G C A G 9999 & $\mathrm{G} \cup \cup \mathrm{C}-2.50$ & U G G A -1.00 \\
\hline A C A G 9999 & A U U C 9999 & C G G A 9999 & G C A U -1.50 & G U U G 9999 & U G G C 9999 \\
\hline A C A U -1.00 & A U U G 9999 & C G G C 9999 & G C C A 9999 & $G \cup \cup U-2.50$ & U G G G -1.00 \\
\hline A C C A 9999 & A U U U -2.00 & C G G G -1.50 & G C C C -1.50 & U A A A -1.00 & U G G U 9999 \\
\hline A C C C 9999 & C A A A 9999 & C G G U 9999 & G C C G 9999 & U A A C 9999 & U G U A -0.40 \\
\hline A C C G 9999 & C A A C 9999 & C G U A -1.00 & G C C U -1.50 & U A A G -1.00 & U G U C -1.00 \\
\hline $\mathrm{AC} \mathrm{C} \mathrm{U}-1.00$ & C A A G -1.50 & C G U C -1.00 & G C G A -2.70 & U A A U 9999 & U G U G -0.40 \\
\hline A C G A -1.50 & C A A U 9999 & C G U G -1.90 & G C G C -0.60 & U A C A -1.00 & $U G U U-2.00$ \\
\hline A C G C -1.50 & C A C A 9999 & $C G U U-1.00$ & G C G G -1.50 & U A C C 9999 & U U A A -0.20 \\
\hline A C G G -2.70 & C A C C 9999 & C U A A -1.00 & G C G U -0.60 & U A C G -1.00 & U U A C -1.00 \\
\hline A C G U -0.20 & C A C G -1.50 & C U A C -1.00 & G C U A 9999 & U A C U 9999 & U U A G -0.20 \\
\hline A C U A 9999 & C A C U 9999 & C U A G -1.40 & G C U C -1.50 & U A G A -2.20 & U U A U -2.00 \\
\hline A C U C 9999 & C A G A 9999 & C U A U -1.00 & G C U G 9999 & U A G C 9999 & U U C A -1.00 \\
\hline A C U G 9999 & C A G C 9999 & C U C A 9999 & G C U U -1.50 & $\mathrm{U} A \mathrm{~A} G-2.20$ & U U C C 9999 \\
\hline A C U U -1.00 & C A G G -2.70 & C U C C 9999 & G G A A 9999 & U A G U 9999 & U U C G -1.00 \\
\hline A G A A 9999 & C A G U 9999 & C U C G -1.50 & G G A C -2.70 & U A U A -0.40 & U U C U 9999 \\
\hline A G A C 9999 & C A U A -1.00 & C U C U 9999 & G G A G 9999 & U A U C -1.00 & $\mathrm{U} U \mathrm{G} A-0.20$ \\
\hline A G A G 9999 & C A U C -1.00 & C U G A - -1.50 & G G A U -2.70 & $\mathrm{U} A \mathrm{~A} \mathrm{G}-0.40$ & U U G C -1.70 \\
\hline A G A U -2.20 & C A U G -1.90 & C U G C -1.50 & G G C A -2.70 & $U A \cup U-2.00$ & U U G G -0.20 \\
\hline A G C A -1.50 & C A U U -1.00 & C U G G -1.40 & G G C C -1.50 & U C A A -1.00 & $\mathrm{U} U \mathrm{G} \mathrm{U}-2.50$ \\
\hline A G C C -1.50 & C C A A 9999 & C U G U -1.50 & G G C G -1.50 & U C A C 9999 & U U U A -2.00 \\
\hline A G C G -2.70 & C C A C 9999 & C U U A 9999 & $G G C U-1.50$ & U C A G -1.00 & U U U C 9999 \\
\hline A G C U -0.50 & C C A G -1.50 & C U U C 9999 & G G G A 9999 & U C A U 9999 & $\mathrm{U} U \mathrm{U} G-2.00$ \\
\hline A G G A 9999 & C C A U 9999 & $\mathrm{C} U \mathrm{U} \mathrm{G}-2.50$ & G G G C -1.50 & U C C A -1.00 & U U U U 9999 \\
\hline A G G C 9999 & C C C A 9999 & C U U U 9999 & G G G G 9999 & U C C C 9999 & \\
\hline A G G G 9999 & C C C C 9999 & G A A A 9999 & G G G U -1.50 & $\mathrm{U} C \mathrm{C} \mathrm{G}-1.00$ & \\
\hline
\end{tabular}




\section{B.5 tetraloop.dg}

Fonte: <http://bioinfo.math.rpi.edu/ zukerm/rna/energy $>$ Obtida em: 01/07/2000

$\begin{array}{ll}\text { AGAAAU }-2.00 & \text { CGAAAG }-2.00 \\ \text { AGCAAU }-2.00 & \text { CGCAAG }-2.00 \\ \text { AGAGAU -2.00 } & \text { CGAGAG }-2.00 \\ \text { AGUGAU -2.00 } & \text { CGUGAG }-2.00 \\ \text { AGGAAU -2.00 } & \text { CGGAAG }-2.00 \\ \text { AUUCGU }-2.00 & \text { CUUCGG }-2.00 \\ \text { AUACGU }-2.00 & \text { CUACGG }-2.00 \\ \text { AGCGAU -2.00 } & \text { CGCGAG }-2.00 \\ \text { AUCCGU -2.00 } & \text { CUCCGG }-2.00 \\ \text { AGUAAU -2.00 } & \text { CGUAAG }-2.00 \\ \text { ACUUGU -2.00 } & \text { CCUUGG }-2.00 \\ \text { AAUUUU -2.00 } & \text { CAUUUG }-2.00 \\ \text { AUUUAU }-2.00 & \text { CUUUAG }-2.00\end{array}$

AGAAAU -2.00

AGCAAU -2.00

AGGAAU -2.00

AUUCGU -2.00

AGCGAU -2.00

AUCCGU -2.00

AGUAAU -2.00

AAUUUU - 2.00
GGAAAC -2.00 GGCAAC -2.00 GGAGAC -2.00 GGUGAC -2.00 GGGAAC -2.00 GUUCGC - 2.00 GUACGC - 2.00 GGCGAC - 2.00 GUCCGC -2.00 GGUAAC -2.00 GCUUGC -2.00 GAUUUC -2.00 GUUUAC -2.00
UGAAAA -2.00 UGCAAA -2.00 UGAGAA -2.00 UGUGAA -2.00 UGGAAA -2.00 UUUCGA -2.00 UUACGA -2.00 UGCGAA -2.00 UUCCGA -2.00 UGUAAA -2.00 UCUUGA -2.00 UAUUUA -2.00 UUUUAA -2.00
GGAAAU -2.00 GGCAAU -2.00 GGAGAU -2.00 GGUGAU -2.00 GGGAAU -2.00 GUUCGU -2.00 GUACGU -2.00 GGCGAU -2.00 GUCCGU -2.00 GGUAAU -2.00 GCUUGU -2.00 GAUUUU -2.00 GUUUAU -2.00
UGAAAG -2.00 UGCAAG -2.00 UGAGAG -2.00 UGUGAG -2.00 UGGAAG -2.00 UUUCGG -2.00 UUACGG -2.00 UGCGAG -2.00 UUCCGG -2.00 UGUAAG -2.00 UCUUGG -2.00 UAUUUG - 2.00 UUUUAG -2.00

\section{B.6 dangle5.dg}

Fonte: <http://bioinfo.math.rpi.edu/ zukerm/rna/energy > Obtida em: 01/07/2000

\begin{tabular}{|c|c|c|c|c|c|}
\hline A A A 0.0 & A G U -0.80 & C C G -0.80 & G A C -1.1 & G U A 0.0 & U C U 0.0 \\
\hline A A C 0.0 & A U A 0.0 & C C U 0.0 & G A G 0.0 & G U C - 0.6 & U G A -0.70 \\
\hline A A G 0.0 & A U C 0.0 & C G A 0.0 & G A U -0.8 & G U G 0.0 & U G C 0.0 \\
\hline A A U -0.80 & A U G 0.0 & C G C 0.0 & G C A 0.0 & G U U - 0.6 & U G G -1.20 \\
\hline A C A 0.0 & $\mathrm{~A} U \mathrm{U}-0.60$ & C G G -1.70 & G C C -0.4 & U A A -0.70 & U G U 0.0 \\
\hline A C C 0.0 & C A A 0.0 & C G U 0.0 & G C G 0.0 & U A C 0.0 & U U A -0.10 \\
\hline A C G 0.0 & C A C 0.0 & C U A 0.0 & G C U -0.5 & U A G -1.20 & U U C 0.0 \\
\hline A C U -0.50 & C A G -1.70 & C U C 0.0 & G G A 0.0 & U A U 0.0 & U U G -0.70 \\
\hline A G A 0.0 & C A U 0.0 & C U G -1.20 & G G C -1.3 & U C A -0.10 & U U U 0.0 \\
\hline A G C 0.0 & C C A 0.0 & C U U 0.0 & G G G 0.0 & U C C 0.0 & \\
\hline A G G 0.0 & C C C 0.0 & G A A 0.0 & G G U -0.8 & U C G -0.50 & \\
\hline
\end{tabular}

\section{B.7 dangle3.dg}

Fonte: <http://bioinfo.math.rpi.edu/ zukerm/rna/energy > Obtida em: $01 / 07 / 2000$

$\begin{array}{llll}\text { A A A } 0.0 & \text { A G A } 0.0 & \text { C A A } 0.0 & \text { C G A } 0.0 \\ \text { A A } 0.0 & \text { A G C } 0.0 & \text { C A C } 0.0 & \text { C G C } 0.0 \\ \text { A A } 0.0 & \text { A G } 0.0 & \text { C A G }-0.20 & \text { C G G }-0.00 \\ \text { A A U }-0.30 & \text { A G U }-0.20 & \text { C A U } 0.0 & \text { C G U } 0.0 \\ \text { A C A } 0.0 & \text { A U A } 0.0 & \text { C C A } 0.0 & \text { C U A } 0.0 \\ \text { A C C } 0.0 & \text { A U C } 0.0 & \text { C C C } 0.0 & \text { C U C } 0.0 \\ \text { A C G } 0.0 & \text { A U G } 0.0 & \text { C C G }-0.30 & \text { C U G }-0.00 \\ \text { A C U }-0.10 & \text { A U U }-0.20 & \text { C C U } 0.0 & \text { C U U } 0.0\end{array}$

$\begin{array}{ll}\text { G A A } 0.0 & \text { G G A } 0.0 \\ \text { G A C }-0.50 & \text { G G C }-0.20 \\ \text { G A G } 0.0 & \text { G G G } 0.0 \\ \text { G A U }-0.20 & \text { G G U }-0.20 \\ \text { G C A } 0.0 & \text { G U A } 0.0 \\ \text { G C C }-0.30 & \text { G U C }-0.10 \\ \text { G C G } 0.0 & \text { G U G } 0.0 \\ \text { G C U }-0.20 & \text { G U U }-0.20\end{array}$




\begin{tabular}{|c|c|c|c|c|c|}
\hline U A A -0.30 & U A U 0.0 & U C G -0.20 & U G C 0.0 & U U A -0.20 & $\mathrm{U} \cup \mathrm{U} 0.0$ \\
\hline U A C 0.0 & U C A -0.30 & U C U 0.0 & U G G -0.20 & $\mathrm{U} U \mathrm{C} 0.0$ & \\
\hline A G -0.20 & U C C 0.0 & U G A -0.40 & U G U 0.0 & U U G -0.20 & \\
\hline
\end{tabular}

\section{B. 8 sint $4 . d g$}

Fonte: <http://bioinfo.math.rpi.edu/ zukerm/rna/energy >

Obtida em: $01 / 07 / 2000$

$$
\begin{gathered}
5^{\prime} \rightarrow 3^{\prime} \\
\text { A x A } \\
\text { U y U } \\
3^{\prime} \leftarrow 5^{\prime} \\
\text { y }
\end{gathered}
$$

$\begin{array}{ccccccccccccccccc} & A & A & A & A & C & C & C & C & G & G & G & G & U & U & U & U \\ & A & C & G & U & A & C & G & U & A & C & G & U & A & C & G & U \\ (A A) & 2.9 & 2.9 & 1.7 & 4.1 & 2.9 & 2.9 & 3.5 & 2.9 & 1.7 & 4.1 & 2.9 & 4.1 & 3.5 & 2.9 & 3.5 & 1.9 \\ (A C) & 2.9 & 2.9 & 1.7 & 4.1 & 2.9 & 2.9 & 3.5 & 2.9 & 1.7 & 4.1 & 2.9 & 4.1 & 3.5 & 2.9 & 3.5 & 1.9 \\ (A G) & 1.7 & 1.7 & 0.5 & 2.9 & 1.7 & 1.7 & 2.3 & 1.7 & 0.5 & 2.9 & 1.7 & 2.9 & 2.3 & 1.7 & 2.3 & 0.7 \\ (A U) & 3.4 & 3.4 & 2.2 & 4.6 & 3.4 & 3.4 & 4.0 & 3.4 & 2.2 & 4.6 & 3.4 & 4.6 & 4.0 & 3.4 & 4.0 & 2.4 \\ (C A) & 2.9 & 2.9 & 1.7 & 4.1 & 2.9 & 2.9 & 3.5 & 2.9 & 1.7 & 4.1 & 2.9 & 4.1 & 3.5 & 2.9 & 3.5 & 1.9 \\ (C C) & 2.9 & 2.9 & 1.7 & 4.1 & 2.9 & 2.9 & 3.5 & 2.9 & 1.7 & 4.1 & 2.9 & 4.1 & 3.5 & 2.9 & 3.5 & 1.9 \\ (C G) & 3.7 & 3.7 & 2.5 & 4.9 & 3.7 & 3.7 & 4.3 & 3.7 & 2.5 & 4.9 & 3.7 & 4.9 & 4.3 & 3.7 & 4.3 & 2.7 \\ (C U) & 2.9 & 2.9 & 1.7 & 4.1 & 2.9 & 2.9 & 3.5 & 2.9 & 1.7 & 4.1 & 2.9 & 4.1 & 3.5 & 2.9 & 3.5 & 1.9 \\ (G A) & 1.7 & 1.7 & 0.5 & 2.9 & 1.7 & 1.7 & 2.3 & 1.7 & 0.5 & 2.9 & 1.7 & 2.9 & 2.3 & 1.7 & 2.3 & 0.7 \\ (G C) & 3.4 & 3.4 & 2.2 & 4.6 & 3.4 & 3.4 & 4.0 & 3.4 & 2.2 & 4.6 & 3.4 & 4.6 & 4.0 & 3.4 & 4.0 & 2.4 \\ (G G) & 2.9 & 2.9 & 1.7 & 4.1 & 2.9 & 2.9 & 3.5 & 2.9 & 1.7 & 4.1 & 2.9 & 4.1 & 3.5 & 2.9 & 3.5 & 1.9 \\ (G U) & 3.4 & 3.4 & 2.2 & 4.6 & 3.4 & 3.4 & 4.0 & 3.4 & 2.2 & 4.6 & 3.4 & 4.6 & 4.0 & 3.4 & 4.0 & 2.4 \\ (U A) & 3.6 & 3.6 & 2.4 & 4.8 & 3.6 & 3.6 & 4.2 & 3.6 & 2.4 & 4.8 & 3.6 & 4.8 & 4.2 & 3.6 & 4.2 & 2.6 \\ (U C) & 2.9 & 2.9 & 1.7 & 4.1 & 2.9 & 2.9 & 3.5 & 2.9 & 1.7 & 4.1 & 2.9 & 4.1 & 3.5 & 2.9 & 3.5 & 1.9 \\ (U G) & 3.6 & 3.6 & 2.4 & 4.8 & 3.6 & 3.6 & 4.2 & 3.6 & 2.4 & 4.8 & 3.6 & 4.8 & 4.2 & 3.6 & 4.2 & 2.6 \\ (U U) & 1.9 & 1.9 & 0.7 & 3.1 & 1.9 & 1.9 & 2.5 & 1.9 & 0.7 & 3.1 & 1.9 & 3.1 & 2.5 & 1.9 & 2.5 & 0.9\end{array}$

$$
\begin{aligned}
& 5^{\prime} \rightarrow 3^{\prime} \\
& A \times C \\
& \text { U y G } \\
& 3^{\prime} \leftarrow 5^{\prime}
\end{aligned}
$$




\begin{tabular}{|c|c|c|c|c|c|c|c|c|c|c|c|c|c|c|c|c|}
\hline & $A$ & $A$ & $A$ & $A$ & $C$ & $C$ & $C$ & $C$ & $G$ & $G$ & $G$ & $G$ & $U$ & $U$ & $U$ & $U$ \\
\hline & $A$ & $C$ & $G$ & $U$ & $A$ & $C$ & $G$ & $U$ & $A$ & $C$ & $G$ & $U$ & $A$ & $C$ & $G$ & $U$ \\
\hline$(A A)$ & 2.4 & 2.4 & 1.2 & 3.1 & 2.4 & 2.4 & 2.4 & 2.4 & 1.2 & 3.3 & 2.4 & 3.1 & 2.6 & 2.4 & 2.4 & 1.4 \\
\hline$(A C)$ & 2.4 & 2.4 & 1.2 & 3.1 & 2.4 & 2.4 & 2.4 & 2.4 & 1.2 & 3.3 & 2.4 & 3.1 & 2.6 & 2.4 & 2.4 & 1.4 \\
\hline$(A G)$ & 1.2 & 1.2 & 0.0 & 1.9 & 1.2 & 1.2 & 1.2 & 1.2 & 0.0 & 2.1 & 1.2 & 1.9 & 1.4 & 1.2 & 1.2 & 0.2 \\
\hline$(A U)$ & 2.9 & 2.9 & 1.7 & 3.6 & 2.9 & 2.9 & 2.9 & 2.9 & 1.7 & 3.8 & 2.9 & 3.6 & 3.1 & 2.9 & 2.9 & 1.9 \\
\hline$(C A)$ & 2.4 & 2.4 & 1.2 & 3.1 & 2.4 & 2.4 & 2.4 & 2.4 & 1.2 & 3.3 & 2.4 & 3.1 & 2.6 & 2.4 & 2.4 & 1.4 \\
\hline$(C C)$ & 2.4 & 2.4 & 1.2 & 3.1 & 2.4 & 2.4 & 2.4 & 2.4 & 1.2 & 3.3 & 2.4 & 3.1 & 2.6 & 2.4 & 2.4 & 1.4 \\
\hline$(C G)$ & 3.2 & 3.2 & 2.0 & 3.9 & 3.2 & 3.2 & 3.2 & 3.2 & 2.0 & 4.1 & 3.2 & 3.9 & 3.4 & 3.2 & 3.2 & 2.2 \\
\hline$(C U)$ & 2.4 & 2.4 & 1.2 & 3.1 & 2.4 & 2.4 & 2.4 & 2.4 & 1.2 & 3.3 & 2.4 & 3.1 & 2.6 & 2.4 & 2.4 & 1.4 \\
\hline$(G A)$ & 1.2 & 1.2 & 0.0 & 1.9 & 1.2 & 1.2 & 1.2 & 1.2 & 0.0 & 2.1 & 1.2 & 1.9 & 1.4 & 1.2 & 1.2 & 0.2 \\
\hline$(G C)$ & 2.9 & 2.9 & 1.7 & 3.6 & 2.9 & 2.9 & 2.9 & 2.9 & 1.7 & 3.8 & 2.9 & 3.6 & 3.1 & 2.9 & 2.9 & 1.9 \\
\hline$(G G)$ & 2.4 & 2.4 & 1.2 & 3.1 & 2.4 & 2.4 & 2.4 & 2.4 & 1.2 & 3.3 & 2.4 & 3.1 & 2.6 & 2.4 & 2.4 & 1.4 \\
\hline$(G U)$ & 2.9 & 2.9 & 1.7 & 3.6 & 2.9 & 2.9 & 2.9 & 2.9 & 1.7 & 3.8 & 2.9 & 3.6 & 3.1 & 2.9 & 2.9 & 1.9 \\
\hline$(U A)$ & 3.1 & 3.1 & 1.9 & 3.8 & 3.1 & 3.1 & 3.1 & 3.1 & 1.9 & 4.0 & 3.1 & 3.8 & 3.3 & 3.1 & 3.1 & 2.1 \\
\hline$(U C)$ & 2.4 & 2.4 & 1.2 & 3.1 & 2.4 & 2.4 & 2.4 & 2.4 & 1.2 & 3.3 & 2.4 & 3.1 & 2.6 & 2.4 & 2.4 & 1.4 \\
\hline$(U G)$ & 3.1 & 3.1 & 1.9 & 3.8 & 3.1 & 3.1 & 3.1 & 3.1 & 1.9 & 4.0 & 3.1 & 3.8 & 3.3 & 3.1 & 3.1 & 2.1 \\
\hline$(U U)$ & 1.4 & 1.4 & 0.2 & 2.1 & 1.4 & 1.4 & 1.4 & 1.4 & 0.2 & 2.3 & 1.4 & 2.1 & 1.6 & 1.4 & 1.4 & 0.4 \\
\hline \multicolumn{17}{|c|}{$5^{\prime} \rightarrow 3^{\prime}$} \\
\hline \multicolumn{17}{|c|}{$A \times G$} \\
\hline \multicolumn{17}{|c|}{ U y C } \\
\hline \multicolumn{17}{|c|}{$3^{\prime} \leftarrow 5^{\prime}$} \\
\hline & & & & & & & & & & & & & & & & \\
\hline
\end{tabular}

$\begin{array}{llllllllllllllll}A & A & A & A & C & C & C & C & G & G & G & G & U & U & U & U\end{array}$ $\begin{array}{llllllllllllllll}A & C & G & U & A & C & G & U & A & C & G & U & A & C & G & U\end{array}$ $\begin{array}{lllllllllllllllll}(A A) & 2.4 & 2.4 & 1.2 & 2.5 & 2.4 & 2.4 & 2.0 & 2.4 & 1.2 & 2.9 & 2.4 & 2.5 & 2.0 & 2.4 & 2.0 & 1.4\end{array}$ $\begin{array}{lllllllllllllllll}(A C) & 2.4 & 2.4 & 1.2 & 2.5 & 2.4 & 2.4 & 2.0 & 2.4 & 1.2 & 2.9 & 2.4 & 2.5 & 2.0 & 2.4 & 2.0 & 1.4\end{array}$ $\begin{array}{lllllllllllllllll}(A G) & 1.2 & 1.2 & 0.0 & 1.3 & 1.2 & 1.2 & 0.8 & 1.2 & 0.0 & 1.7 & 1.2 & 1.3 & 0.8 & 1.2 & 0.8 & 0.2\end{array}$ $\begin{array}{lllllllllllllllll}(A U) & 2.9 & 2.9 & 1.7 & 3.0 & 2.9 & 2.9 & 2.5 & 2.9 & 1.7 & 3.4 & 2.9 & 3.0 & 2.5 & 2.9 & 2.5 & 1.9\end{array}$ $\begin{array}{lllllllllllllllll}(C A) & 2.4 & 2.4 & 1.2 & 2.5 & 2.4 & 2.4 & 2.0 & 2.4 & 1.2 & 2.9 & 2.4 & 2.5 & 2.0 & 2.4 & 2.0 & 1.4\end{array}$ $\begin{array}{lllllllllllllllll}(C C) & 2.4 & 2.4 & 1.2 & 2.5 & 2.4 & 2.4 & 2.0 & 2.4 & 1.2 & 2.9 & 2.4 & 2.5 & 2.0 & 2.4 & 2.0 & 1.4\end{array}$ $\begin{array}{lllllllllllllllll}(C G) & 3.2 & 3.2 & 2.0 & 3.3 & 3.2 & 3.2 & 2.8 & 3.2 & 2.0 & 3.7 & 3.2 & 3.3 & 2.8 & 3.2 & 2.8 & 2.2\end{array}$ $\begin{array}{lllllllllllllllll}(C U) & 2.4 & 2.4 & 1.2 & 2.5 & 2.4 & 2.4 & 2.0 & 2.4 & 1.2 & 2.9 & 2.4 & 2.5 & 2.0 & 2.4 & 2.0 & 1.4\end{array}$ $\begin{array}{lllllllllllllllll}(G A) & 1.2 & 1.2 & 0.0 & 1.3 & 1.2 & 1.2 & 0.8 & 1.2 & 0.0 & 1.7 & 1.2 & 1.3 & 0.8 & 1.2 & 0.8 & 0.2\end{array}$ $\begin{array}{lllllllllllllllll}(G C) & 2.9 & 2.9 & 1.7 & 3.0 & 2.9 & 2.9 & 2.5 & 2.9 & 1.7 & 3.4 & 2.9 & 3.0 & 2.5 & 2.9 & 2.5 & 1.9\end{array}$ $\begin{array}{lllllllllllllllll}(G G) & 2.4 & 2.4 & 1.2 & 2.5 & 2.4 & 2.4 & 2.0 & 2.4 & 1.2 & 2.9 & 2.4 & 2.5 & 2.0 & 2.4 & 2.0 & 1.4\end{array}$

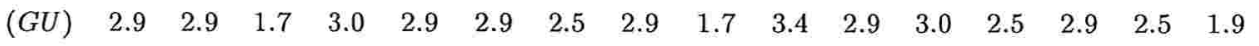
$\begin{array}{lllllllllllllllll}(U A) & 3.1 & 3.1 & 1.9 & 3.2 & 3.1 & 3.1 & 2.7 & 3.1 & 1.9 & 3.6 & 3.1 & 3.2 & 2.7 & 3.1 & 2.7 & 2.1\end{array}$ $\begin{array}{lllllllllllllllll}(U C) & 2.4 & 2.4 & 1.2 & 2.5 & 2.4 & 2.4 & 2.0 & 2.4 & 1.2 & 2.9 & 2.4 & 2.5 & 2.0 & 2.4 & 2.0 & 1.4\end{array}$ $\begin{array}{lllllllllllllllll}(U G) & 3.1 & 3.1 & 1.9 & 3.2 & 3.1 & 3.1 & 2.7 & 3.1 & 1.9 & 3.6 & 3.1 & 3.2 & 2.7 & 3.1 & 2.7 & 2.1\end{array}$

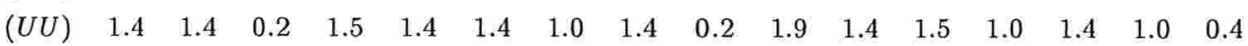




\section{B.9 sint2.dg}

Fonte: <http://bioinfo.math.rpi.edu/ zukerm/rna/energy $>$ Obtida em: 01/07/2000

\begin{tabular}{|c|c|c|c|c|c|}
\hline $\mathrm{Y}$ & $\mathrm{x}$ & & + & & \\
\hline & $\mathrm{U} A$ & $\begin{array}{llll}0.8 & 0.8 & 0.8 & 0.8\end{array}$ & $\mathrm{AC} \mathrm{GU}$ & $\mathrm{G} \mathrm{C}$ & $\begin{array}{llll}0.8 & 0.8 & 0.8 & 0.8\end{array}$ \\
\hline A C G U & $A U$ & $\begin{array}{llll}0.8 & 0.8 & 0.8 & 0.8\end{array}$ & - & Y & $\begin{array}{llll}0.8 & 0.8 & 0.8 & 0.8\end{array}$ \\
\hline & $\mathrm{Y}$ & $\begin{array}{lllll}0.8 & 0.8 & 0.8 & 0.8\end{array}$ & $5^{\prime}->3^{\prime}$ & $3^{\prime}<-5^{\prime}$ & Y \\
\hline $5^{\prime} \rightarrow 3^{\prime}$ & $3^{\prime}<-5^{\prime}$ & $\mathrm{Y}$ & X & $\begin{array}{llll}0.8 & 0.8 & 0.8 & 0.8\end{array}$ & - \\
\hline X & $\begin{array}{lllll}0.8 & 0.8 & 0.8 & 0.8\end{array}$ & $\longrightarrow$ & $\mathrm{G} \mathrm{C}$ & $\begin{array}{lllll}0.8 & 0.8 & 0.8 & 0.8\end{array}$ & $\mathrm{AC} \mathrm{G} \mathrm{U}$ \\
\hline $\mathrm{AA}$ & $\begin{array}{llll}0.8 & 0.8 & 0.8 & 0.8\end{array}$ & A C G U & U G & $\begin{array}{llll}0.8 & 0.8 & 0.8 & 0.8\end{array}$ & \\
\hline U U & $\begin{array}{llll}0.8 & 0.8 & 0.8 & 0.8\end{array}$ & $\longrightarrow$ & $\mathrm{Y}$ & $\begin{array}{llll}0.8 & 0.8 & 0.8 & 0.8\end{array}$ & $5^{\prime} \rightarrow 3^{\prime}$ \\
\hline $\mathrm{Y}$ & $\begin{array}{llll}0.8 & 0.8 & 0.8 & 0.8\end{array}$ & $5^{\prime}->3^{\prime}$ & $3^{\prime}<-5^{\prime}$ & $\mathrm{Y}$ & $\mathrm{X}$ \\
\hline $3^{\prime}<-5^{\prime}$ & $\mathrm{Y}$ & $\mathrm{X}$ & $\begin{array}{llll}0.8 & 0.8 & 0.8 & 0.8\end{array}$ & - & $\mathrm{U} \mathrm{G}$ \\
\hline $\begin{array}{llll}0.8 & 0.8 & 0.8 & 0.8\end{array}$ & $\longrightarrow$ & $\mathrm{C} \mathrm{C}$ & $\begin{array}{llll}0.8 & 0.8 & 0.8 & 0.8\end{array}$ & A C G U & $\mathrm{G} \mathrm{C}$ \\
\hline $\begin{array}{lllll}0.8 & 0.8 & 0.8 & 0.8\end{array}$ & A C G U & G G & $\begin{array}{llll}0.8 & 0.8 & 0.8 & 0.8\end{array}$ & - - - & $\mathrm{Y}$ \\
\hline $\begin{array}{llll}0.8 & 0.8 & 0.8 & 0.8\end{array}$ & - & Y & $\begin{array}{llll}0.8 & 0.8 & 0.8 & 0.8\end{array}$ & $5^{\prime} \rightarrow>3^{\prime}$ & $3^{\prime}<-5^{\prime}$ \\
\hline $\begin{array}{llll}0.8 & 0.8 & 0.8 & 0.8\end{array}$ & $5^{\prime} \rightarrow 3^{\prime}$ & $3^{\prime}<-5^{\prime}$ & $\mathrm{Y}$ & $\mathrm{X}$ & $\begin{array}{lllll}0.8 & 0.8 & 0.8 & 0.8\end{array}$ \\
\hline $\mathrm{Y}$ & $\mathrm{X}$ & $\begin{array}{llll}0.8 & 0.8 & 0.8 & 0.8\end{array}$ & - & G G & $\begin{array}{llll}0.8 & 0.8 & 0.8 & 0.8\end{array}$ \\
\hline & G A & $\begin{array}{llll}0.8 & 0.8 & 0.8 & 0.8\end{array}$ & A C G U & $\mathrm{C} \mathrm{C}$ & $\begin{array}{lllll}0.8 & 0.8 & 0.8 & 0.8\end{array}$ \\
\hline A C G U & $\mathrm{U} \mathrm{U}$ & $\begin{array}{lllll}0.8 & 0.8 & 0.8 & 0.8\end{array}$ & - - - - - & $\mathrm{Y}$ & $\begin{array}{llll}0.8 & 0.8 & 0.8 & 0.8\end{array}$ \\
\hline & $\mathrm{Y}$ & $\begin{array}{llll}0.8 & 0.8 & 0.8 & 0.8\end{array}$ & $5^{\prime}->3^{\prime}$ & $3^{\prime}<-5^{\prime}$ & $\mathrm{Y}$ \\
\hline $5^{\prime} \rightarrow 3^{\prime}$ & $3^{\prime}<-5^{\prime}$ & $\mathrm{Y}$ & $\mathrm{X}$ & $\begin{array}{llll}0.8 & 0.8 & 0.8 & 0.8\end{array}$ & - \\
\hline $\mathrm{x}$ & $\begin{array}{lllll}0.8 & 0.8 & 0.8 & 0.8\end{array}$ & - & $\mathrm{U} \mathrm{C}$ & $\begin{array}{llll}0.8 & 0.8 & 0.8 & 0.8\end{array}$ & A C G U \\
\hline C A & $\begin{array}{llll}0.8 & 0.8 & 0.8 & 0.8\end{array}$ & A C G U & G G & $\begin{array}{llll}0.8 & 0.8 & 0.8 & 0.8\end{array}$ & - \\
\hline G U & $\begin{array}{lllll}0.8 & 0.8 & 0.8 & 0.8\end{array}$ & - & $\mathrm{Y}$ & $\begin{array}{llll}0.8 & 0.8 & 0.8 & 0.8\end{array}$ & $5^{\prime}->3^{\prime}$ \\
\hline $\mathrm{Y}$ & $\begin{array}{llll}0.8 & 0.8 & 0.8 & 0.8\end{array}$ & $5^{\prime} \rightarrow 3^{\prime}$ & $3^{\prime}<-5^{\prime}$ & $\mathrm{Y}$ & $\mathrm{x}$ \\
\hline $3^{\prime}<-5^{\prime}$ & $\mathrm{Y}$ & $\mathrm{X}$ & $\begin{array}{llll}0.8 & 0.8 & 0.8 & 0.8\end{array}$ & - - & $\mathrm{AU}$ \\
\hline $\begin{array}{lllll}0.8 & 0.8 & 0.8 & 0.8\end{array}$ & - - - - & G C & $\begin{array}{llll}0.8 & 0.8 & 0.8 & 0.8\end{array}$ & A C G U & U A \\
\hline $\begin{array}{llll}0.8 & 0.8 & 0.8 & 0.8\end{array}$ & A C G U & C G & $\begin{array}{llll}0.8 & 0.8 & 0.8 & 0.8\end{array}$ & - & $\mathrm{Y}$ \\
\hline $\begin{array}{llll}0.8 & 0.8 & 0.8 & 0.8\end{array}$ & - & Y & $\begin{array}{llll}0.8 & 0.8 & 0.8 & 0.8\end{array}$ & $5^{\prime}->3^{\prime}$ & $3^{\prime}<-5^{\prime}$ \\
\hline $\begin{array}{lllll}0.8 & 0.8 & 0.8 & 0.8\end{array}$ & $5^{\prime}->3^{\prime}$ & $3^{\prime}<-5^{\prime}$ & $\mathrm{Y}$ & X & $\begin{array}{llll}0.8 & 0.8 & 0.8 & 0.8\end{array}$ \\
\hline $\mathrm{Y}$ & $\mathrm{X}$ & $\begin{array}{lllll}0.8 & 0.8 & 0.8 & 0.8\end{array}$ & - & U G & $\begin{array}{llll}0.8 & 0.8 & 0.8 & 0.8\end{array}$ \\
\hline & U A & $\begin{array}{llll}0.8 & 0.8 & 0.8 & 0.8\end{array}$ & A C G U & A C & $\begin{array}{llll}0.8 & 0.8 & 0.8 & 0.8\end{array}$ \\
\hline A C G U & $\mathrm{G} \mathrm{U}$ & $\begin{array}{llll}0.8 & 0.8 & 0.8 & 0.8\end{array}$ & - & Y & $\begin{array}{llll}0.8 & 0.8 & 0.8 & 0.8\end{array}$ \\
\hline & $\mathrm{Y}$ & $\begin{array}{llll}0.8 & 0.8 & 0.8 & 0.8\end{array}$ & $5^{\prime} \rightarrow 3^{\prime}$ & $3^{\prime}<-5^{\prime}$ & $\mathrm{Y}$ \\
\hline $5^{\prime} \rightarrow 3^{\prime}$ & $3^{\prime}<-5^{\prime}$ & $\mathrm{Y}$ & X & $\begin{array}{llll}0.8 & 0.8 & 0.8 & 0.8\end{array}$ & - \\
\hline $\mathrm{X}$ & $\begin{array}{llll}0.8 & 0.8 & 0.8 & 0.8\end{array}$ & $\longrightarrow$ & A G & $\begin{array}{lllll}0.8 & 0.8 & 0.8 & 0.8\end{array}$ & A C G U \\
\hline $\mathrm{G} \mathrm{A}$ & $\begin{array}{llll}0.8 & 0.8 & 0.8 & 0.8\end{array}$ & A C G U & $\mathrm{U} \mathrm{C}$ & $\begin{array}{llll}0.8 & 0.8 & 0.8 & 0.8\end{array}$ & - \\
\hline $\mathrm{C} \mathrm{U}$ & $\begin{array}{lllll}0.8 & 0.8 & 0.8 & 0.8\end{array}$ & 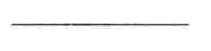 & Y & $\begin{array}{llll}0.8 & 0.8 & 0.8 & 0.8\end{array}$ & $5^{\prime}->3^{\prime}$ \\
\hline $\mathrm{Y}$ & $\begin{array}{llll}0.8 & 0.8 & 0.8 & 0.8\end{array}$ & $5^{\prime} \rightarrow>3^{\prime}$ & $3^{\prime}<-5^{\prime}$ & $\mathrm{Y}$ & $\mathrm{X}$ \\
\hline $3^{\prime}<-5^{\prime}$ & $\mathrm{Y}$ & $\mathrm{X}$ & $\begin{array}{llll}0.8 & 0.8 & 0.8 & 0.8\end{array}$ & - - & $\mathrm{C} \mathrm{U}$ \\
\hline $\begin{array}{lllll}0.8 & 0.8 & 0.8 & 0.8\end{array}$ & $-1-$ & $\mathrm{U} \mathrm{C}$ & $\begin{array}{llll}0.8 & 0.8 & 0.8 & 0.8\end{array}$ & A C G U & G A \\
\hline $\begin{array}{llll}0.8 & 0.8 & 0.8 & 0.8\end{array}$ & $\mathrm{AC} \mathrm{G} \mathrm{U}$ & A G & $\begin{array}{lllll}0.8 & 0.8 & 0.8 & 0.8\end{array}$ & - & Y \\
\hline $\begin{array}{llll}0.8 & 0.8 & 0.8 & 0.8\end{array}$ & - & $\mathrm{Y}$ & $\begin{array}{llll}0.8 & 0.8 & 0.8 & 0.8\end{array}$ & $5^{\prime} \rightarrow 3^{\prime}$ & $3^{\prime}<-5^{\prime}$ \\
\hline $\begin{array}{lllll}0.8 & 0.8 & 0.8 & 0.8\end{array}$ & $5^{\prime} \rightarrow>3^{\prime}$ & $3^{\prime}<-5^{\prime}$ & $\mathrm{Y}$ & X & $\begin{array}{llll}0.8 & 0.8 & 0.8 & 0.8\end{array}$ \\
\hline Y & $\mathrm{X}$ & $\begin{array}{llll}0.8 & 0.8 & 0.8 & 0.8\end{array}$ & - & G G & $\begin{array}{lllll}0.8 & 0.8 & 0.8 & 0.8\end{array}$ \\
\hline & $\mathrm{AC}$ & $\begin{array}{llll}0.8 & 0.8 & 0.8 & 0.8\end{array}$ & A C G U & $\mathrm{U} \mathrm{C}$ & $\begin{array}{llll}0.8 & 0.8 & 0.8 & 0.8\end{array}$ \\
\hline A C G U & U G & $\begin{array}{llll}0.8 & 0.8 & 0.8 & 0.8\end{array}$ & - & Y & $\begin{array}{llll}0.8 & 0.8 & 0.8 & 0.8\end{array}$ \\
\hline & Y & $\begin{array}{llll}0.8 & 0.8 & 0.8 & 0.8\end{array}$ & $5^{\prime} \rightarrow 3^{\prime}$ & $3^{\prime}<-5^{\prime}$ & \\
\hline $5^{\prime} \rightarrow 3^{\prime}$ & $3^{\prime}<-5^{\prime}$ & $\mathrm{Y}$ & X & $\begin{array}{llll}0.8 & 0.8 & 0.8 & 0.8\end{array}$ & \\
\hline
\end{tabular}




\section{B.10 asint1x2.dg}

Fonte: <http://bioinfo.math.rpi.edu/ zukerm/rna/energy $>$ Obtida em: $01 / 07 / 2000$

\begin{tabular}{|c|c|c|c|c|c|}
\hline & & & \multirow[b]{2}{*}{ - } & & \\
\hline \multirow[t]{2}{*}{$\mathrm{Y}$} & $\mathrm{X}$ & $\begin{array}{llll}1.7 & 1.7 & 0.5 & 1.3\end{array}$ & & U A & $\begin{array}{llll}2.9 & 2.9 & 3.8 & 2.9\end{array}$ \\
\hline & A A & 3.53 .54 .03 .5 & A C G U & $\mathrm{AU}$ & $\begin{array}{llll}0.5 & 1.7 & 1.7 & 1.7\end{array}$ \\
\hline A C G U & U U & 1.72 .52 .92 .5 & - & YC & 4.23 .54 .22 .5 \\
\hline & YU & 3.63 .53 .62 .5 & $5^{\prime}->3^{\prime}$ & $3^{\prime}<-5^{\prime}$ & $\mathrm{Y}$ \\
\hline $5^{\prime}->3^{\prime}$ & $3^{\prime}<-5^{\prime}$ & $\mathrm{Y}$ & X & 3.43 .42 .24 .0 & 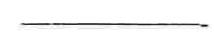 \\
\hline $\mathrm{X}$ & 4.64 .63 .45 .1 & - & G A & 3.43 .44 .63 .4 & A C G U \\
\hline $\mathrm{A} A$ & 3.43 .44 .23 .4 & A C G U & $\mathrm{C} \mathrm{U}$ & 3.45 .24 .65 .2 & \\
\hline U U & 3.45 .14 .65 .1 & - & YG & 4.63 .44 .62 .4 & $5^{\prime}->3^{\prime}$ \\
\hline YA & 3.12 .43 .11 .4 & $5^{\prime}->3^{\prime}$ & $3^{\prime}<-5^{\prime}$ & $\mathrm{Y}$ & $\mathrm{X}$ \\
\hline $3^{\prime}<-5^{\prime}$ & $\mathrm{Y}$ & $\mathrm{X}$ & $\begin{array}{llll}1.7 & 1.7 & 0.5 & 1.9\end{array}$ & $\longrightarrow$ & G A \\
\hline 3.43 .42 .23 .9 & - & $\mathrm{C} \mathrm{A}$ & 3.53 .54 .43 .5 & A C G U & $\mathrm{UU}$ \\
\hline 3.43 .44 .23 .4 & A C G U & G U & 1.72 .92 .92 .9 & - - & YC \\
\hline $\begin{array}{llll}1.0 & 2.7 & 2.2 & 2.7\end{array}$ & - & YU & 4.23 .54 .22 .5 & $5^{\prime}->3^{\prime}$ & $3^{\prime}<-5^{\prime}$ \\
\hline 4.74 .04 .73 .0 & $5^{\prime}->3^{\prime}$ & $3^{\prime}<-5^{\prime}$ & $\mathrm{Y}$ & $\mathrm{X}$ & 2.92 .91 .73 .1 \\
\hline $\mathrm{Y}$ & $\mathrm{X}$ & 4.14 .12 .93 .7 & $\longrightarrow$ & $\mathrm{U} A$ & 2.92 .93 .82 .9 \\
\hline - & C A & 2.92 .93 .42 .9 & A C G U & $\mathrm{AU}$ & 2.94 .14 .14 .1 \\
\hline A C G U & G U & 2.93 .74 .13 .7 & 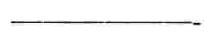 & YG & 3.62 .93 .61 .9 \\
\hline & YA & $\begin{array}{llll}2.0 & 1.9 & 2.0 & 0.9\end{array}$ & $5^{\prime}->3^{\prime}$ & $3^{\prime}<-5^{\prime}$ & $\mathrm{Y}$ \\
\hline $5^{\prime}->3^{\prime}$ & $3^{\prime}<-5^{\prime}$ & $\mathrm{Y}$ & $\mathrm{X}$ & $\begin{array}{llll}2.2 & 2.2 & 1.0 & 2.8\end{array}$ & - \\
\hline $\mathrm{X}$ & 2.92 .91 .72 .5 & - & G A & 4.04 .05 .24 .0 & A C G U \\
\hline A A & 2.92 .93 .42 .9 & A C G U & $\mathrm{C} \mathrm{U}$ & 2.24 .03 .44 .0 & - \\
\hline U U & $\begin{array}{lllll}0.5 & 1.3 & 1.7 & 1.3\end{array}$ & - & YU & 5.24 .05 .23 .0 & $5^{\prime} \rightarrow 3^{\prime}$ \\
\hline YC & 3.63 .53 .62 .5 & $5^{\prime}->3^{\prime}$ & $3^{\prime}<-5^{\prime}$ & $\mathrm{Y}$ & $\mathrm{X}$ \\
\hline $3^{\prime}<-5^{\prime}$ & $\mathrm{Y}$ & $\mathrm{X}$ & 4.14 .12 .94 .3 & $\longrightarrow$ & G A \\
\hline 3.43 .42 .23 .9 & - & G A & 2.92 .93 .82 .9 & $\mathrm{~A} \mathrm{C} \mathrm{G} \mathrm{U}$ & $\mathrm{U} U$ \\
\hline 3.43 .44 .23 .4 & A C G U & $\mathrm{C} \mathrm{U}$ & 2.94 .14 .14 .1 & - & YG \\
\hline 3.45 .14 .65 .1 & - - & YA & $2.6 \quad 1.92 .60 .9$ & $5^{\prime}->3^{\prime}$ & $3^{\prime}<-5^{\prime}$ \\
\hline 4.13 .44 .12 .4 & $5^{\prime} \rightarrow>3^{\prime}$ & $3^{\prime}<-5^{\prime}$ & $\mathrm{Y}$ & $\mathrm{X}$ & $\begin{array}{llll}1.7 & 1.7 & 0.5 & 1.9\end{array}$ \\
\hline $\mathrm{Y}$ & $\mathrm{X}$ & $\begin{array}{llll}2.9 & 2.9 & 1.7 & 3.1\end{array}$ & - & $\mathrm{U} A$ & 3.53 .54 .43 .5 \\
\hline 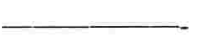 & $\mathrm{C} \mathrm{A}$ & 2.92 .93 .82 .9 & $\mathrm{AC} \mathrm{G} \mathrm{U}$ & $\mathrm{A} U$ & 1.72 .92 .92 .9 \\
\hline A C G U & G U & $\begin{array}{lllll}0.5 & 1.7 & 1.7 & 1.7\end{array}$ & $\longrightarrow$ & YU & 4.23 .54 .22 .5 \\
\hline & YC & 4.23 .54 .22 .5 & $5^{\prime}->3^{\prime}$ & $3^{\prime}<-5^{\prime}$ & $\mathrm{Y}$ \\
\hline $5^{\prime}->3^{\prime}$ & $3^{\prime}<-5^{\prime}$ & $\mathrm{Y}$ & $\mathrm{X}$ & 4.64 .63 .45 .2 & - \\
\hline $\mathrm{X}$ & 2.92 .91 .72 .5 & $\longrightarrow$ & $\mathrm{U} A$ & 3.43 .44 .63 .4 & A C G U \\
\hline A A & 2.92 .93 .42 .9 & A C G U & $\mathrm{AU}$ & 3.45 .24 .65 .2 & 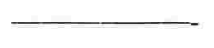 \\
\hline $\mathrm{U} \mathrm{U}$ & 2.93 .74 .13 .7 & $\longrightarrow$ & YA & $3.62 .43 .6 \quad 1.4$ & $5^{\prime} \rightarrow>3^{\prime}$ \\
\hline YG & $\begin{array}{llll}3.0 & 2.9 & 3.0 & 1.9\end{array}$ & $5^{\prime}->3^{\prime}$ & $3^{\prime}<-5^{\prime}$ & $\mathrm{Y}$ & $\mathrm{X}$ \\
\hline $3^{\prime}<-5^{\prime}$ & $\mathrm{Y}$ & $\mathrm{X}$ & 3.43 .42 .24 .0 & - - & G A \\
\hline 2.22 .21 .02 .7 & - & $\mathrm{G} \mathrm{A}$ & 3.43 .44 .63 .4 & A C G U & U U \\
\hline 4.04 .04 .84 .0 & A C G U & $\mathrm{C} \mathrm{U}$ & $\begin{array}{llll}1.0 & 2.82 .2 & 2.8\end{array}$ & - & YU \\
\hline 2.23 .93 .43 .9 & - & YC & 5.24 .05 .23 .0 & $5^{\prime}->3^{\prime}$ & $3^{\prime}<-5^{\prime}$ \\
\hline 4.74 .04 .73 .0 & $5^{\prime}->3^{\prime}$ & $3^{\prime}<-5^{\prime}$ & $\mathrm{Y}$ & $\mathrm{X}$ & 4.14 .12 .94 .3 \\
\hline $\mathrm{Y}$ & $\mathrm{X}$ & $2.92 .9 \quad 1.73 .1$ & 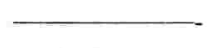 & G A & 2.92 .93 .82 .9 \\
\hline & $\mathrm{CA}$ & 2.92 .93 .82 .9 & A C G U & $\mathrm{UU}$ & 2.94 .14 .14 .1 \\
\hline A C G U & G U & 2.94 .14 .14 .1 & 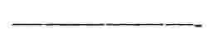 & YA & 2.61 .92 .60 .9 \\
\hline & YG & 3.62 .93 .61 .9 & $5^{\prime}->3^{\prime}$ & $3^{\prime}<-5^{\prime}$ & \\
\hline $5^{\prime} \rightarrow 3^{\prime}$ & $3^{\prime}<-5^{\prime}$ & $\mathrm{Y}$ & $\mathrm{X}$ & 2.92 .91 .73 .1 & \\
\hline
\end{tabular}




\section{B.11 miscloop.dg}

Fonte: <http://bioinfo.math.rpi.edu/ zukerm/rna/energy $>$

Obtida em: 01/07/2000

Miscellaneous energies

FREE ENERGY BY SIZE OF LOOP

misc. loop functions

$\rightarrow$ internal, bulge or hairpin loops $>30: \mathrm{dS}(\mathrm{T})=\mathrm{dS}(30)+$ param $* \ln (\mathrm{n} / 30)$

1.079

asymmetric internal loops: the ninio equation

$\rightarrow$ the maximum correction

3.00

$\rightarrow$ the $\mathrm{f}(\mathrm{m})$ array (see ninio for details)

$\begin{array}{llll}0.30 & 0.30 & 0.30 & 0.30\end{array}$

multibranched loops

$\rightarrow$ offset, free base penalty, helix penalty

4.600 .400 .10

efn2 multibranched loops

offset, free base penalty, helix penalty

$\rightarrow$

$10.10-0.30-0.30$

terminal AU penalty

$\rightarrow$

0.00

bonus for GGG hairpin

$\rightarrow$

0.00

c hairpin slope

$\rightarrow$

0.00

c hairpin intercept

$\rightarrow$

0.00

c hairpin of 3

$\rightarrow$

0.00

Intermolecular initiation free energy

$\rightarrow$

4.10

GAIL Rule (Grossly Asymmetric Interior Loop Rule) (on/off $<->1 / 0$ ) $\rightarrow$

0 


\section{Referências Bibliográficas}

[ABBP98] J. P. Abrahams, M. Berg, E. Batenburg, and C. W. Pleij, Prediction of RNA secondary structure, including pseudoknotting, by computer simulation, Nucleic Acids Res. (1998), no. 18, 3035-3044.

[BGP95] F. H. Batenburg, A. P. Gultyaev, and C. W. Pleij, An APL-programmed genetic algorithm for prediction of RNA secondary structure, Journal Theor.. Biol. (1995), no. 174, 269-280.

[BS99] D. Bouthinon and H. Soldano, A new method to predict the consensus secondary structure of a set of unaligned RNA sequences, Biolnformatics 15 (1999), no. 10, 72-80.

[BV01] P. Bonizzoni and G. Della Vedova, The complexity of multiple alignment with sp-score that is a metric, Theoretical Computer Science 259 (2001), no. 1-2, 63-79.

[CK91] D. K. Y. Chiu and T. Kolodziejczak, Inferring consensus structure from nucleic acid sequences, Computer Applications in the Biosciences (1991), no. 7, 347-352.

[CL88] H. Carrilo and D Lipman, The multiple sequence alignment problem in biology, SIAM Journal on Applied Math. 48 (1988), no. 5, 1073-1082.

[CLSM98] J. Chen, S. Le, B. Shapiro, and J. Maizel, Optimization of an RNA folding algorithm for parallel architectures, Parallel Computing (1998), no. 24, 1617-1634.

[CS95] R. B. Cary and G. D. Stormo, Graph-theoretic approach to RNA modeling using comparative data, In ISMB-95 (C. Rawling, et al, eds), vol. AAAI Pres, 1995, pp. 75-80.

[CZJ90] L. Chan, M. Zuker, and A. B. Jacobson, A computer method for finding common base paired helices in aligned sequences: application to the analysis of random sequences, Nucleic Acids Research 19 (1990), no. 2, 353-358.

[DEKM98] R. Durbin, S. Eddy, A. Krogh, and G. Mitchison, Biological sequence analysis / probabilistic models of proteins and nucleic acids, Cambridge University Press, 1998.

[DPD92] E. Dam, K. Pleij, and D. Draper, Structural and functional aspects of RNA pseudoknots, Biochemistry (1992), no. 31, 11665-11676.

[ED94] S. R. Eddy and R. Durbin, RNA sequence analysis using covariance models, Nucleic Acids Research 22 (1994), no. 11, 2079-2088.

[Edm65] J. Edmonds, Maximum matching and polyhedron with 0, 1-vertices, J. Nat. Bur. Stand. (1965), no. 69B, 125-130.

[EGG88] D. Eppstein, Z. Galil, and R. Giancarlo, Speeding up dynamic programming, 28th Symposium on the Foundations of Computer Science, 1988, pp. 488-495.

[FAD60] J. R. Fresco, B. M. Alberts, and P. Doty, Some molecular details of the secondary structure of ribonucleic acid, Nature (1960), no. 188, 98-101.

[FH88] S. Feng and E. C. Holland, HIV-1 tat trans-activation requeries the loop sequence within tar, Nature (1988), no. $334,165-167$.

[Gab76] H. N. Gabow, An efficient implementation of Edmonds' algorithm for maximum matching on graphs, J. Asc. Com. Mach (1976), no. 23, 221-234. 
[GBP95] A. P. Gultyaev, F. H. Batenburg, and C. W. Pleij, The computer simulation of RNA folding pathways using a genetic algorithm, Journal Mol. Biol. (1995), no. 250, 37-51.

[GH96] B. Gulko and D. Haussler, Using multiple alignments and phylogenetic trees to detect rna secondary structure, Pacific Symposium on Biocomputing, World Scientific, L. Hunter and T. Klein, eds, January 1996, pp. $350-367$.

[Got82] O. Gotoh, An improved algorithm for matching biological sequences, J. of Molecular Biology (1982), no. 162, 705-708.

[GPH ${ }^{+92}$ R. R. Gutell, A. Power, G. Z. Hertz, E. J. Putz, and G. D. Stormo, Identifying constraints on the higherorder structure of RNA: continued development and applications of comparative sequence analysis methods, Nucleic Acids Research (1992), no. 20, 5785-5795.

[Gra95] L. Grate, Automatic RNA secondary structure determination with stochastic context-free grammars, Intelligent Systems for Molecular Biology, 136-144, 1995.

[Gus93] D. Gusfield, Efficient methods for multiple sequence alignment with guaranteed error bounds, Bulletin of Mathematical Biology 55 (1993), no. 1, 141-154.

[HFS+94] I. L. Hofacker, W. Fontana, P. F. Stadler, L. S. Bonhoeffer, M. Tacker, and P. Schuster, Fast folding and comparison of RNA secondary structures, Monatshefte für Chemie (1994), no. 125, 1167-188.

[HK93] K. Han and H. J. Kim, Prediction of common folding structures of homologous RNAs, Nucleic Acids Res. (1993), no. 21, 1251-1257.

[HS88] D. G. Higgins and P. M. Sharp, CLUSTAL: a package for performing multiple sequence alignment on a microcomputer, Gene (1988), no. 73, 237-244.

[HSS98] I. L. Hofacker, P. Schuster, and P. F. Stadler, Combinatorics of RNA secondary structures, Discrete Applied Mathematics (1998), no. 88, 207-237.

[JW99] V. Juan and C. Wilson, RNA secondary structure prediction based on free energy and phylogenetic analysis, J. Mol. Biol. (1999), no. 289, 953-947.

[KGW+98] M. H. Kolk, M. Graff, S. Wijmenga, C. W. Pleij, H. Heus, and C. W. Hilbers, NMR structure of a classical pseudoknot: interplay of single-and double-stranded RNA, Science (1998), no. 280, 434-438.

[KK88] M. M. Klawe and D. J. Kleitman, An almost linear time algorithm for generalized matrix searching, Technical Report RJ 6275, IBM - Research Division, Almaden Research Center, 1988.

[KL93] D. E. Knuth and S. Levy, The CWEB system of structured documentation, Reading, Massachusetts: Addison-Wesley, 1993.

[Knu73] D. E. Knuth, The art of computer programming, vol. 3: Sorting and Searching, Addison-Wesley, 1973.

[Lef95] F. Lefebvre, An optimized parsing algorithm well-suited to RNA folding, Proc. of the Third International Conference on Intelligent Systems for Molecular Biology, AAAI Press, 1995, pp. 222-230.

[Lef96] _ _ A grammar-based unification of several alignment and folding algorithms, Proc. of the Fourth International Conference on Intelligent Systems for Molecular Biology, AAAI Press, 1996, pp. 143-154.

[LP00] R. B. Lyngsøand C. N. S. Pedersen, Pseudoknots in RNA secondary structure, Proc. 4rd Int. Conf. Computational Molecular Biology (RECOMB'00), ACM, Apr 2000.

[LS90] L. Lamore and B. Schieber, On-line dynamic programming with applications to the prediction of RNA secondary structure, First ACM-SIAM Symposium on Discrete Algorithms, 1990, pp. 503-512.

[LSR96] R. Lück, G. Steger, and D. Riesner, Thermodynamic prediction of conserved secondary structure: Application to the RRE element of HIV, the tRNA-like element of CMV and the mRNA of prion protein, J. Mol. Biol. (1996), no. 258, 813-826.

[LZP99] R. B. Lyngsø, M. Zuker, and C. N. S. Pedersen, Internal loops in RNA secondary structure prediction, Proc. 3rd Int. Conf. Computational Molecular Biology (RECOMB'99), ACM, Apr 1999.

[Mac90] P. M. MacDonald, Bicoid mRNA localization signal, phylogenetic conservation of function and RNA secondary structure, Development (1990), no. 110, 161-171. 
[McC90] J.S. McCaskill, The equilibrium partition function and base pair binding probabilities for RNA secondary structure, Biopolymers (1990), no. 29, 1105.

[NC00] David L. Nelson and Michael M. Cox, Principles of biochemistry, Worth, 2000.

[NPGK78] R. Nussinov, G. Pieczenik, J. R. Griggs, and D. J. Kleitman, Algoritms for loop matchings, SIAM J. appl. Math. (1978), no. 35, 68-82.

[NYY96] A. Nakaya, A. Yonezawa, and K. Yamamoto, Classification fo RNA secondary structure using the techniques of cluster analysis, Journal Theor. Biol. (1996), no. 183, 105-117.

[PGN84] C. Papanicolaou, M. Gouy, and J. Ninio, An energy model that predicts the correct folding of both the tRNAs and the 5S RNA molecules, Nucleic Acids Res. (1984), no. 21, 31-44.

[PKST91] A. E. Peritz, R. Kierzek, N. Sugimoto, and D. Turner, Thermodynamic study of internal loops in oligoribonucleotides: symmetric loops are more stable than asymmetric loops, Biochemistry (1991), no. 30, 6428-6436.

[Pol88] B. Polisky, ColE1 replication control circuitry: Sense from antisense, Cell (1988), 929-932.

[PRB92] C. W. Pleij, K. Rietveld, and L. Bosch, A new principle of RNA folding basead on pseudoknotting, Nucleic Acids Res. (1992), no. 13, 1717-1731.

[RE99] E. Rivas and S. Eddy, A dynamic programming algorithm for RNA structure prediction including pseudoknots, Journal of Molecular Biology (1999), no. 285, 2053-2068.

[RE00] The language of RNA: A formal grammar that includes pseudoknots, Bioinformatics (2000), no. 16, $334-340$.

[San85] D. Sankoff, Simultaneous solution of the mRNA folding, alignment and protosequense problems, SIAM J. Appl. Math. (1985), no. 5, 1-35.

$\left[\mathrm{SBH}^{+}{ }^{94}\right] \quad$ Y. Sakakibara, M. Brown, R. Hughey, I. S. Mian, K. Sjölander, R. C. Underwood, and D. Haussler, Stochastic context-free grammars for tRNA modeling, Nucleic Acids Res. (1994), no. 22, 5112-5120.

[SD90] M. H. Smit and J. Duin, Control of prokaryotic translation initiation by mRNA secondary structure, Progress in Nucleic Acid Research in Molecular Biology (1990), no. 38, 1-35.

[SHF $\left.{ }^{+} 84\right] \quad$ G. Steger, H. Hofmann, J. Förtsch, H. J. Gross, J. W. Randles, L. H. Sänger, and D. Riesner, Conformational transitions in viroids and virusoids: comparison of results energy minimization algorithm and from experimental data, J. Biomol. Struct. Dynam. (1984), no. 2, 543-571.

[SM97] J. C. Setubal and J. Meidanis, Introduction to computational molecular biology, IC-UNICAMP/PWS, 1997.

[SW96] B. A. Shapiro and J. C. Wu, An annealing mutation operator in the genetic algoritms for RNA folding, Computer Applications in the Biosciences (1996), no. 12, 309-318.

[TCGS98] J. E. Tabaska, R. B. Cary, H. N. Gabow, and G. D. Stormo, An RNA folding method capable of identifying pseudoknots and base triples, Bioinformatics (1998), no. 8, 691-699.

[THG94] J. D. Thompson, D. G. Higgins, and T. J. Gibson, CLUSTAL W: improving the sensitivity of progressive multiple sequence alignment through sequence weighting, position specific gap penalties and weight matrix choice, Nucleic Acids Research 22 (1994), no. 22, 4673-4680.

[VA90] M. Vingron and P. Argos, Determination of reliable regions in protein sequence aligments, Protein Eng. (1990), no. 3, 565-569.

[WFHS99] S. Wuchty, W. Fontana, I. L. Hofacker, and P. Schuster, Complete suboptimal folding of RNA and the stability of secondary structures, Biopolymers (1999), no. 49, 145-165.

[WJ94] L. Wang and T. Jiang, On the complexity of multiple sequence alignment, Journal of Computational Biology (1994), 337-348.

[WOW ${ }^{+90}$ ] S. Winker, R. Overbeek, C. R. Woese, G. J. Olsen, and N. Pfluger, Structure detection through automated covariance search, Comput. Appl. Biosci. (1990), no. 6, 365-371.

[WS78] M. S. Waterman and T. F. Smith, RNA secondary structure: A complete mathematical analysis, Math. Biosci. (1978), no. 42, 257-266. 
[WS86] _ _ Rapid dynamic programming algorithms for RNA secondary structure, Advances in Applied Mathematics (1986), no. 7, 455-464.

[ZJT91] M. Zuker, J. A. Jaeger, and D. H. Turner, A comparison of optimal and suboptimal RNA secondary structures predicted by free energy minimization with structures determined by phylogenetic comparison, Nucleic Acids Res. 19 (1991), no. 10, 2707-2714.

[ZS84] M. Zuker and D. Sankoff, RNA secondary structures and their prediction, Bull. Math. Biol. (1984), no. 46, $591-621$.

[ZT99] M. Zuker and C. D. H. Turner, Algorithms and thermodynamics for RNA secondary structure prediction: A practical guide, no. 333, 333-344.

[Zuk89] M. Zuker, On finding all suboptimal foldings of an RNA molecule, Science (1989), no. 244, 48-52.

[Zuk91] _ Suboptimal sequence alignment in molecular biology: Alignment with error analysis, J. Mol. Biol. (1991), no. 221, 403-420. 


\section{Índice Remissivo de Definições e}

\section{Conceitos}

área, 55

indice de informação, 67

indice de informação mútua, 67, 68

acessivel, 15

alcance, 79

alteração compensatória, 65

análise comparativa filogenética, 69

arco, 16

assimétrico, 34

barriga em i, 16

barriga em $j, 16$

base externa, 16

bloco, 5

\section{côncava, 55}

canônicos, 10

candidatos, 55

centro do pareamento, 78

convexa, 55

densidade, 52

distancia, 66

distância, 49

distribuição de estrutura, 73

dobra, 21

dobrada, 21

dominio, 56

dot plot, 12

efeito oscilatório, 35

energia de empilhamento terminal, 33

energia livre, 15

energia livre não pareada terminal, 33

entropia, 67

entropia relativa, 68

esqueleto, 72

estrutura completa, 50

estrutura parcial, 50

estrutura secundária, 10, 12 fim do pareamento, 78

fragmento excluso, 46

fragmento incluso, 46

grampo, 16

hélice, 16

homólogas, 15, 65

instável, 10

interno, 16

janela, 78

k-laço, 16

laço, 15

laço externo, 16

limite inferior, 56

limite superior, 56

matriz de covariância, 69

matriz de probabilidade de pares de base, 76

matriz de probabilidade pares de base consensual, 74

matrizes de probabilidade de homólogos, 73

multi-laço, 16

não-par, 70, 72

normal, 11

oscilante, 10

P-otimal, 47

par externo, 16,76

par inexato, 70

par invariante exato, 69

par variante exato, 70

pareadas, 13

pareamento potencial, 79

Partição, 75

probabilidade dos pares de base, 76

pseudo-nó, 13 
região exclusa, 48

região inclusa, 48

retângulo, 55

SP-pontuação, 66

suporte, 72

Svedberg, 9

tetraloops, 33

triloops, 33

vencedor, 56

wobble, 10,70 


\section{Índice Remissivo dos Programas}

Aqui vai uma lista de identificadores usados na implementação e onde eles aparecem. Entradas grifadas indicam os lugares de definiçōes. Mensagens de erros também são mostradas.

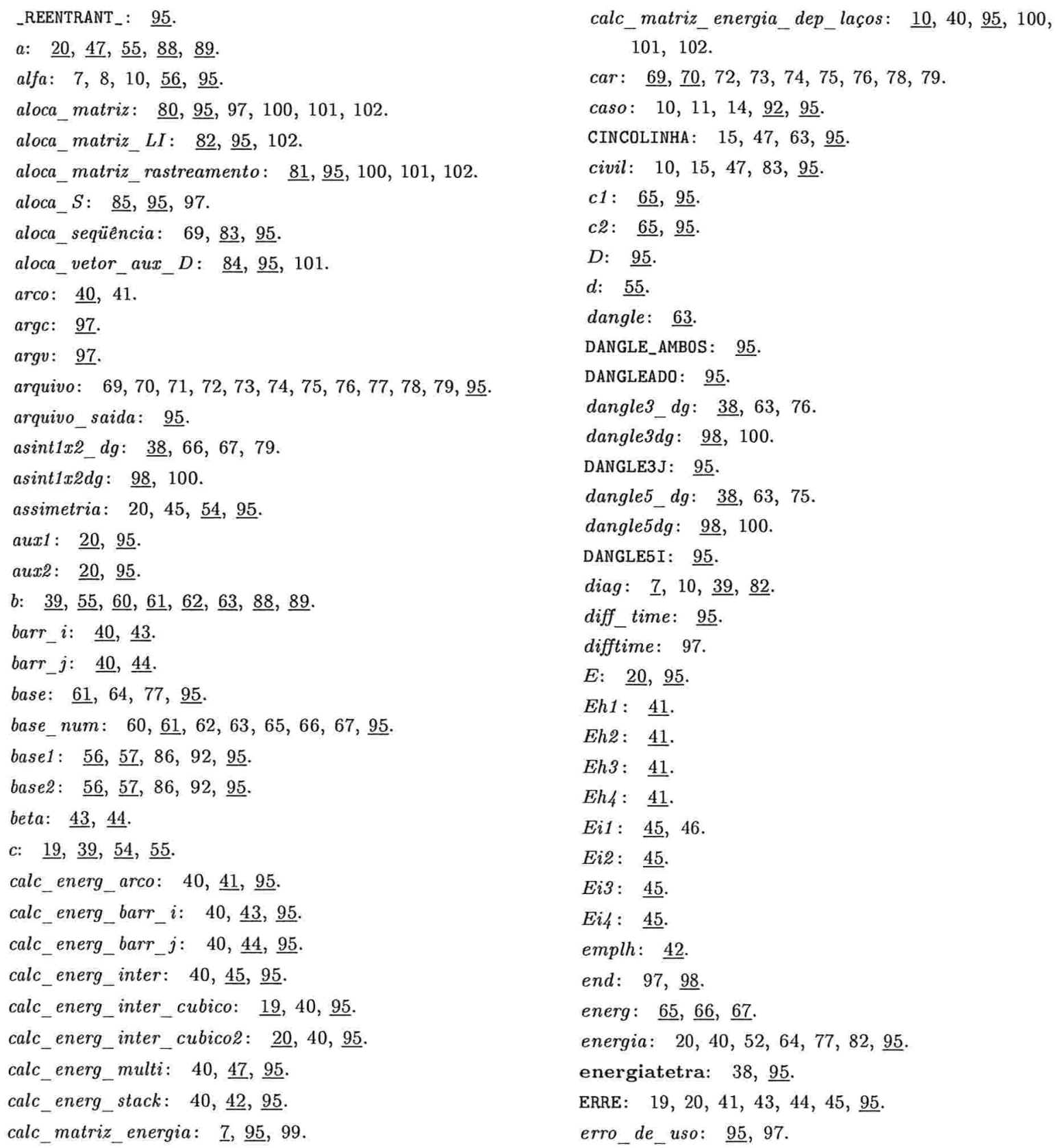




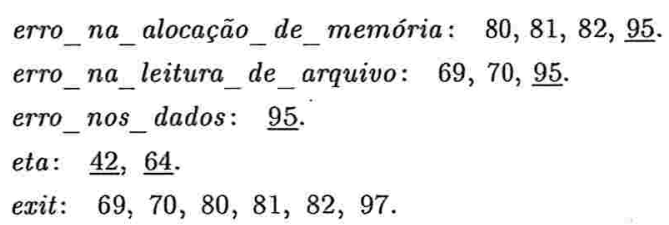

letras: 92 .

LI: $20,40,52,82, \underline{95}$.

log: 19, 20,41, 43, 44, 45 .

loop_dg: 19, 20, $\underline{38}, 41,43,44,45,46,52,71,93$.

loopdg: $\quad \underline{98}, 100,101,102$.

$m: \underline{54}$.

main: 97 .

malloc: 80, 81, 82, 83, 84, 85, 92.

MAXLIN : $\underline{95}$.

menor_energ: $\underline{7}, 10,15, \underline{39}, \underline{40}$.

min_de_2_valores: $20,54, \underline{55}, \underline{95}$.

min_de_3_valores: $20,54, \underline{55}, \underline{95}$.

modulo: $\underline{45}$.

multi: $\underline{40}, \underline{47}$.

minimo: 19 .

$n: \underline{54}$.

ncar: $\underline{70}, 72,73,74,75,76,78$.

nome_do_arq: $\underline{69}, \underline{70}, \underline{95}, 97$.

nome_do_prog: $\underline{69}, 70, \underline{95}, 97$.

num_pares: $57,92, \underline{95}$.

$n 1: \quad \underline{54}, \underline{95}$.

n2: $\underline{54}, \underline{95}$.

NÃO_PAREADO: $15,47,83, \underline{95}$.

OK: $\underline{95}$.

otimiza: $\underline{10}, \underline{40}, \underline{95}$.

$p: \underline{60}, \underline{61}, \underline{62}, \underline{63}, \underline{64}$.

par: $57,85, \underline{95}$.

PAREADO: $10,47, \underline{95}$.

PEQUENO: $10,12, \underline{95}$.

pista: $81, \underline{95}$.

pista_em_LI: $82, \underline{95}$.

print_loop_dg: $\underline{93}, \underline{95}$.

print_matriz_energia: $\underline{88}, \underline{95}$.

print_matriz_energia_aux_L: $\underline{89}, \underline{95}$.

print_matriz_multi: $\underline{90}, \underline{95}$.

print $S: \underline{92}, \underline{95}, 97$.

print_seqüência: $\underline{91}, \underline{95}, 97$.

print_stack_dg: $\underline{94}, \underline{95}$.

print_tab_experimental: $\underline{95}$.

printf: $13,69,84,88,89,90,91,92,93,94,97,104$.

putchar: 91.

$R:$ $\underline{95}$.

rastro: $10,11,12,13,14,15,40,81, \underline{95}$.

READ_ONLY: $69,70, \underline{95}$.

$S: \underline{57}$.

sim2x2_dg: $\underline{38}, 65,78$.

sint4dg: $\underline{98}, 100$.

stack: $\underline{40}$.

stack_dg: $\underline{38}, 60,72,94$.

stackdg: $\underline{98}, 100,101,102$.

start: $97, \underline{98}$.

stderr: $8,13,14,69,70,80,81,82,83,97$. 
strcmp: 70.

string: 10.

T: $\underline{95}$.

$t: \underline{95}$.

$t a b \_a s i n t 1 x 2_{-} d g: \quad 46,51,52, \underline{66}, \underline{95}$.

tab_asint2x1_dg: $46,52, \underline{67}, \underline{95}$.

tab_dangle_dg: $15,47, \underline{63}, \underline{95}$.

$t a b+s i m 2 x 2 \_d g: \quad 46,51,52, \underline{65}, \underline{95}$.

tab_stack_dg: $20,42,43,44, \underline{60}, \underline{95}$.

tab_tetraloop_dg: 41, $\underline{64}, \underline{95}$.

tab_tstackh_dg: 41, $\underline{61}, \underline{95}$.

tab_tstacki_dg: 45, $\underline{62}, \underline{95}$.

tam_R: $7,10,20,69,80,81,82,83,84,85,86,88$,

$89,90,91,92, \underline{95}, 97,99,100,101,102$.

tamanho: $\underline{20}, 52, \underline{80}$.

tetraloop_dg: $\underline{38}, 64,77$.

time: 97.

time1: $\underline{95}$.

time2: $\underline{95}$.

tipo: $\underline{63}, \underline{95}, 97, \underline{98}$.

toupper: 69 .

traceback_E: $\underline{12}, \underline{95}, 100,101,102$.

traceback_G: 13, 14, $\underline{95}$.

traceback_L: $12, \underline{13}, 14, \underline{95}$.

TRESLINHA: $15,47,63, \underline{95}$.

TRUE: $\underline{95}$.

tstackh_dg: $\underline{38}, 61,73$.

tstackhdg: $\underline{98}, 100,101,102$.

tstacki_dg: $\underline{38}, 62,74$.

tstackidg: 98, 100, 101, 102.

$u: \underline{63}, \underline{95}$.

ungetc: $69,70,78$.

UNIVERSAL: $\underline{95}$.

$V: \underline{80}$.

WRITE: $\underline{95}$.

$x: \underline{65}, \underline{66}, \underline{67}, \underline{70}$.

$y: \underline{65}, \underline{66}, \underline{67}, \underline{70}$.

$z: \quad \underline{66}, \underline{67}, \underline{70}$.

zera_S: $\underline{86}, \underline{95}$.

zeta: $\underline{41}$. 


\title{
Lista de Refinamentos
}

\author{
〈Algoritmo Básico 36〉 Citado no bloco $3 . \quad$ Usado no bloco 2.
}

〈Alocação da matriz auxiliar de rastreamento 81) Usado no bloco 58.

〈Alocação da matriz para laços internos em Lyngsø 82) Usado no bloco 58.

〈Alocação da sequência 83〉 Usado no bloco 58.

〈Alocação de matrizes 80 Usado no bloco 58.

〈Alocação do conjunto de conjunto de pares 85 ) Usado no bloco 58.

〈Alocação do vetor auxiliar D[] 84) Usado no bloco 58.

〈Cálculo da energia de um empilhamento de pares de bases adjacente 42〉 Citado nos blocos 11 e 15 . Usado no bloco 37 .

〈Cálculo da energia de um laço arco 41) Citado nos blocos 11 e 15 . Usado no bloco 37.

〈Cálculo da energia de um laço barriga em i 43〉 Citado nos blocos 11 e 15 . Usado no bloco 37.

〈Cálculo da energia de um laço barriga em j 44〉 Citado nos blocos 11 e 15 . Usado no bloco 37.

〈Cálculo da energia de um laço interno 45) Citado nos blocos 11 e 15 . Usado no bloco 37.

〈Cálculo da energia de um multilaço 47) Citado nos blocos 11 e 15 . Usado no bloco 37.

〈Cálculo da matriz de energia (dependente de laços) 10〉 Citado nos blocos 10, 11, 15 e 40 . Usado no bloco 37.

$\langle$ Cálculo do laço de menor energia 40〉 Citado nos blocos 10, 19 e 41 . Usado no bloco 37.

〈Cálculo energia de um par de bases 56〉 Usado no bloco 53.

〈Cálculo matriz de energia (pares de bases independentes) 7) Citado no bloco 3 . Usado no bloco 36.

〈Cálculo, conforme Lyngsø e Zuker, de energia de um laço interno 20) Usado no bloco 37.

〈Cálculo, conforme Waterman e Smith, da energia de um laço interno 19) Citado no bloco 51 . Usado no bloco 37.

〈Calcula o mínimo entre doís ou três valores 55 〉 Usado no bloco 53.

$\langle$ Calcula penalidade de assimetria segundo Ninio 54〉 Citado no bloco 20 . Usado no bloco 53.

〈Carrega energia da memória sim2x2_dg 65) Usado no bloco 58.

〈Carrega energia de tetraloops da memória (tetraloop_dg) 64) Usado no bloco 58.

〈Carrega energia de bases dangle's) 63〉 Usado no bloco 58.

〈Carrega energia de empilhamento da memória (stack_dg) 60〉 Usado no bloco 58.

〈Carrega energia de laços internos (1x2) 66) Usado no bloco 58.

〈Carrega energia de laços internos (2x1) 67) Usado no bloco 58.

〈Carrega energia de pares terminais mismatched(tstackh_dg) 61) Usado no bloco 58.

〈Carrega energia de pares terminais mismatched(tstacki_dg) 62〉 Usado no bloco 58.

(Casos especiais no cálculo do laço interno em Lyngsø 52) Usado no bloco 20.

〈Casos especiais no cálculo do laço interno em Waterman e Smith 51) Usado no bloco 19.

〈Casos especiais no laço interno 46) Usado no bloco 45.

〈Chamada das funçōes para opção que considera laços (contabilizando energia dos laços) 100) Usado no bloco 97.

〈Definiçōes, Declaraçōes e Arquivos de Inclusão 95) Usado no bloco 2.

〈Energia de pares independentes (não contabilizando laços) 99) Usado no bloco 97.

〈Funções Auxiliares 87) Usado no bloco 2.

〈Funçōes comuns 53) Usado no bloco 2.

〈Funçōes de Inicializaçāo e Finalizaçāo 58) Usado no bloco 2.

〈Guarda o conjunto de pares 57) Usado no bloco 53.

〈Identificação de pares do dobramento (Algoritmo traceback) 8) Citado no bloco 3 . Usado no bloco 36. 
〈Imprime a matriz auxiliar de energia para laços (L[i][j]) 89) Usado no bloco 87.

〈Imprime a matriz de energia 88) Usado no bloco 87.

〈Imprime a matriz para multilaços (G[i][j]) 90) Usado no bloco 87.

〈Imprime a molécula (seqüência) 91) Usado no bloco 87.

〈Imprime o arquivo loop.dg 93, 94〉 Usado no bloco 87.

〈Imprime o conjunto de pares 92) Usado no bloco 87.

〈Incorporação de Laços 37) Citado no bloco $3 . \quad$ Usado no bloco 2.

〈Inicialização do conjunto de pares 86) Usado no bloco 58.

〈Laços interiores otimizados segundo Lyngsø 102〉 Usado no bloco 97.

$\langle$ Leitura da sequiência (molécula) de entrada 69〉 Usado no bloco 58.

〈Leitura de asint1x2.dg 79〉 Usado no bloco 70.

〈Leitura de dangle3.dg 76) Usado no bloco 70.

〈Leitura de dangle5.dg 75〉 Usado no bloco 70.

〈Leitura de loop.dg 71) Citado no bloco 15. Usado no bloco 70.

(Leitura de sint4.dg 78) Usado no bloco 70.

〈Leitura de stack.dg 72〉 Usado no bloco 70.

〈Leitura de tetraloop.dg 77) Citado no bloco 15 . Usado no bloco 70.

〈Leitura de tstackh.dg 73〉 Citado no bloco 15. Usado no bloco 70.

〈Leitura de tstacki.dg 74) Citado no bloco 15 . Usado no bloco 70.

$\langle$ Leitura dos arquivos de parâmetros de energia 70〉 Usado no bloco 58.

〈Otimizando laços interiores para $O\left(n^{3}\right)$ 101) Usado no bloco 97.

〈Programa Principal 97) Usado no bloco 2.

(traceback em E 12) Usado no bloco 37.

〈traceback em G 14〉 Citado no bloco $13 . \quad$ Usado no bloco 37.

〈traceback em L 13〉 Citado no bloco 12 . Usado no bloco 37.

〈efeito dangling no laço externo 15〉 Usado no bloco 10.

〈matrizes que guardam parâmetros de energia 38〉 Usado no bloco 10.

〈menu de opções na função main 104〉 Usado no bloco 97.

〈preenche G 11) Usado no bloco 10.

〈variáveis da função main 98〉 Usado no bloco 97.

〈variáveis de calc_matriz_energia_dep_laços 39) Usado no bloco 10. 